
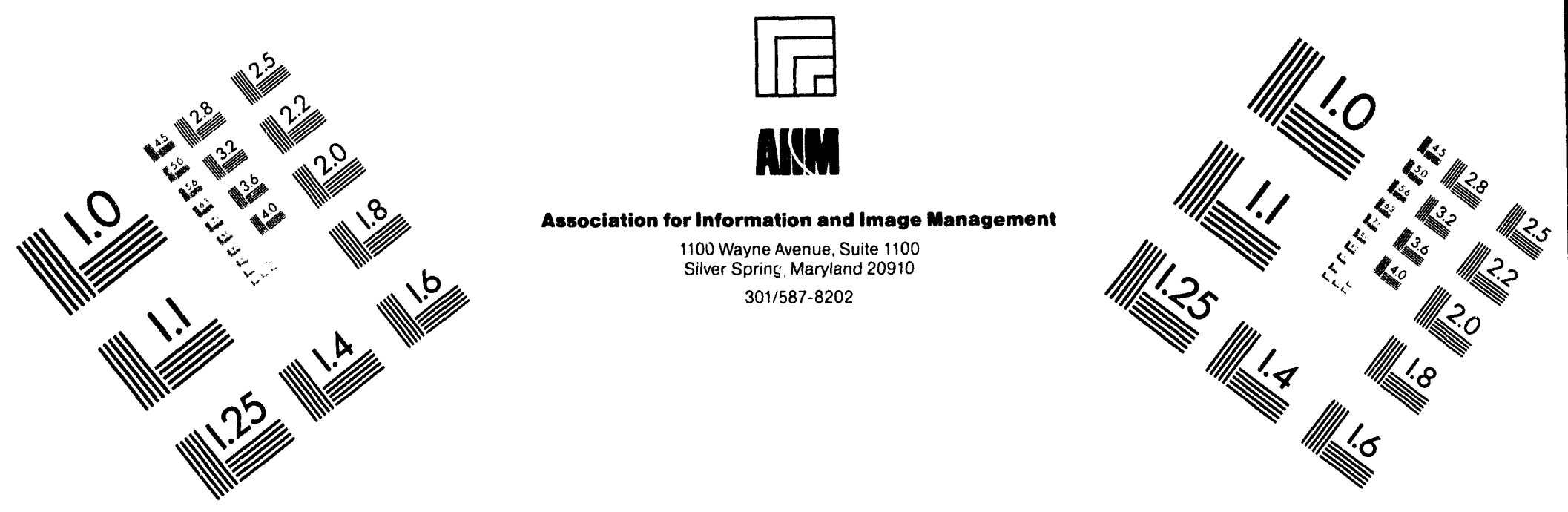

Centimeter

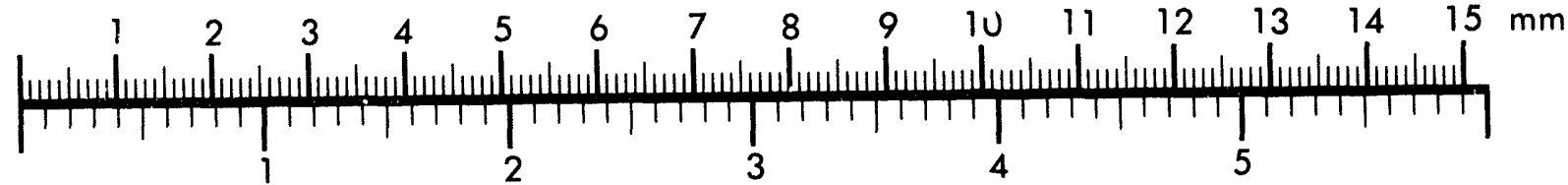
Inches
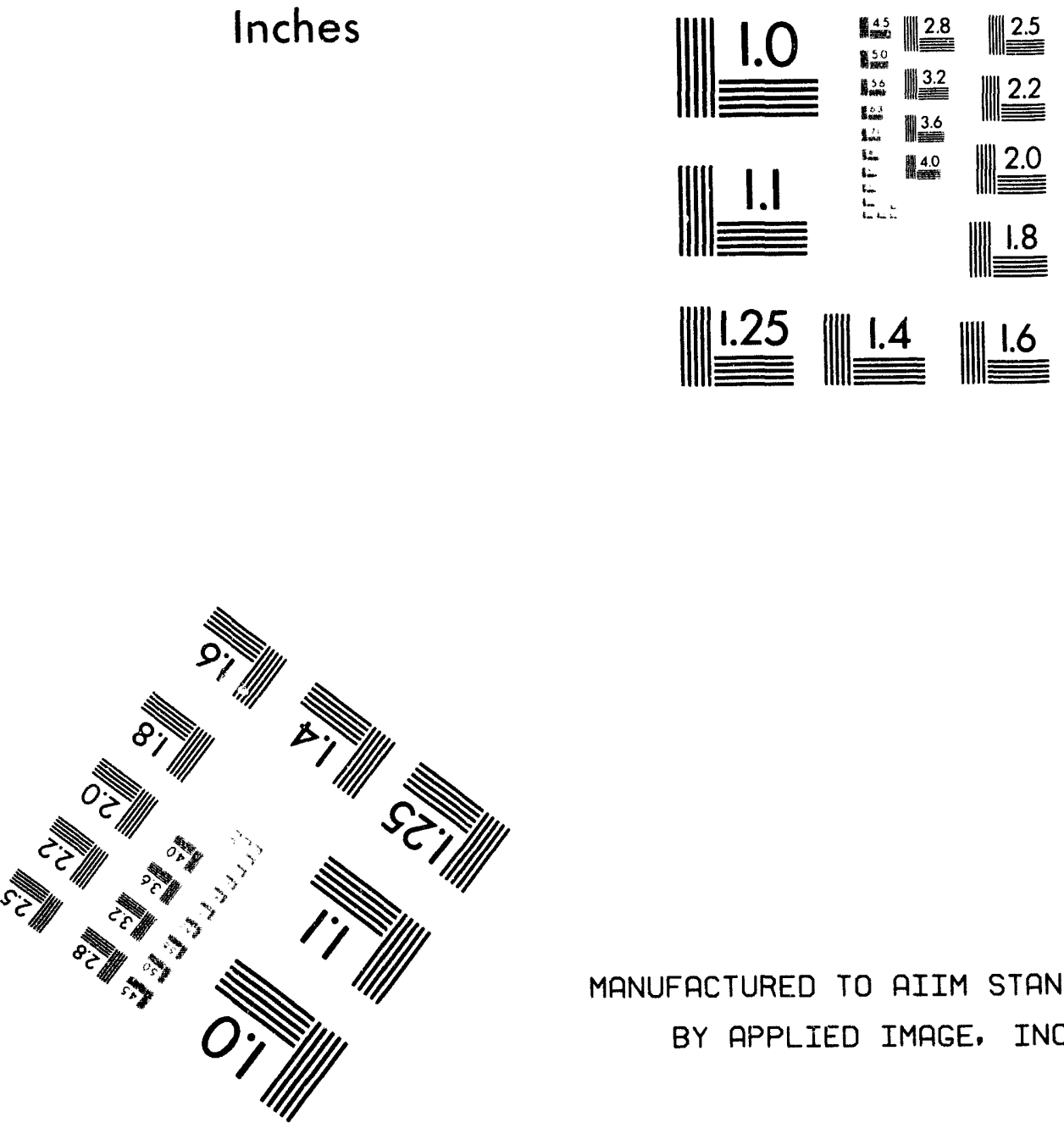

MANUFACTURED TO AIIM STANDARDS

BY APPLIED IMAGE. INC.

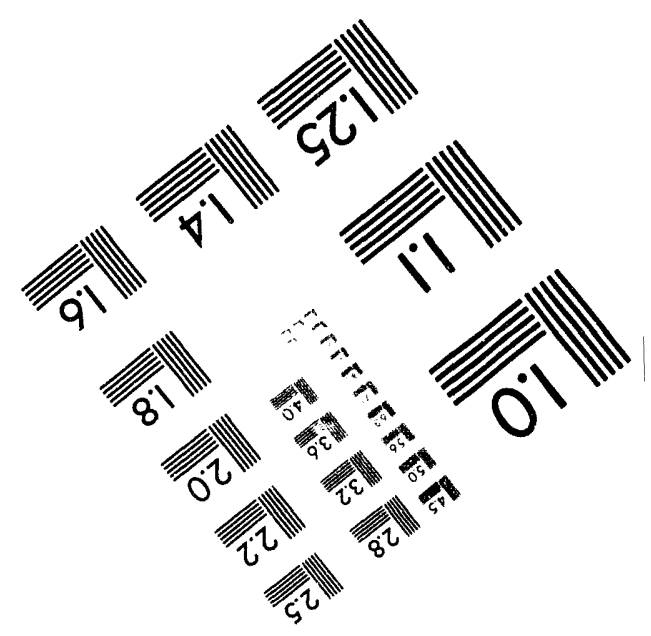



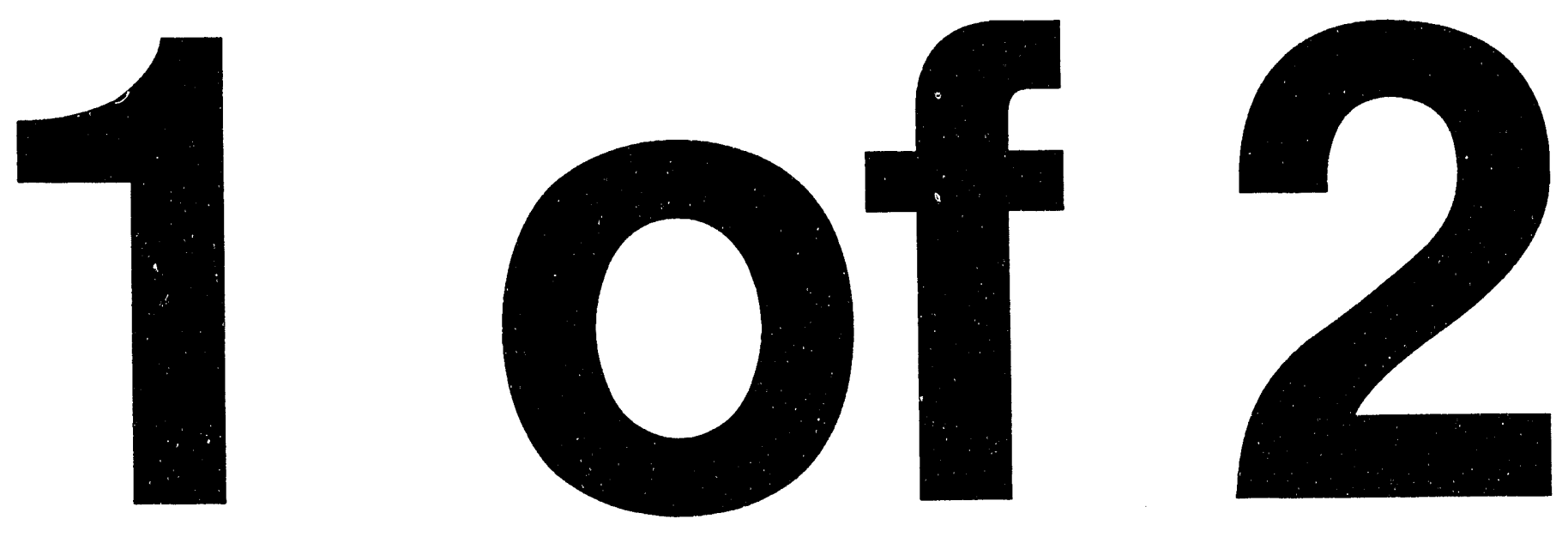


\section{DEVELOPMENT PROGRAM}

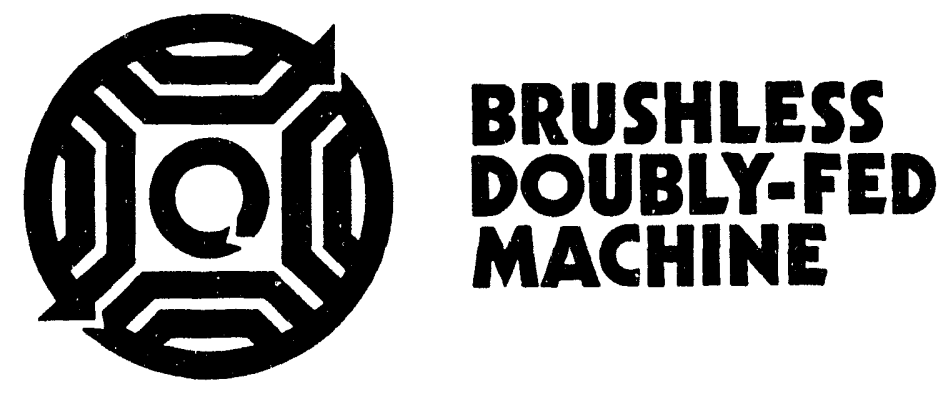

Gerald C. Alexander

René Spée

Alan K. Wallace

Prepared for

Bonneville Power Administration

Electric Power Research Institute

Puget Sound Power and Light 


\section{ACKNOWLEDGEMENTS}

The investigators thank the sponsor organizations for their support of the BDFM program at Oregon State University and for their confidence in the research team. Representatives devoted much of their valuable time to the projects and their efforts, encouragements and suggestions are greatly appreciated: Mr. Nick Butler of BPA, Mr. Ben Banerjee of EPRI and Mr. Brian Thomas of PSPL.

The authors would also like to thank other individuals whose contributions helped make the projeci a success: Mr. William Hostetler of OSU's Technology Transfer Office who has been instrumental in setting up the contracts and in securing patent protection; Mr. Mike Rugh of Rugh Electric who constructed most of the BDFM prototypes and offered valuable suggestions with regard to practical machine design; and Mssrs. Charles Meitle and Manfred Dittrich, who designed and constructed much of the mechanical laboratory hardware.

Last, but not least the investigators acknowledge the contributions of the graduate assistants, whose thesis research forms the basis for much of the research described in this report: Mr. A. Ramchandran, whose thesis concerns parameter estimation; Merrs. W. Brassfield and D. Zhou, who contribute towards control theory and hardware development for the BDFM; Mr. C. Brune, who developed the wind generation system; Mr. Brian Wiley, who developed the digital control for the car alternator; Mr. S. Bhowmik, who investigated optimized stator designs; and Mr. M. Salim, who investigated the BDFM magnetic characteristics using finite elements. Also appreciated are the efforts by other students who joined towards the end of Phase 1, namely Ms. B. Thompson and Mssrs. M. Boger, B. Gorti, and A. Alajmi. 


\section{TABLE OF CONTENTS}

page

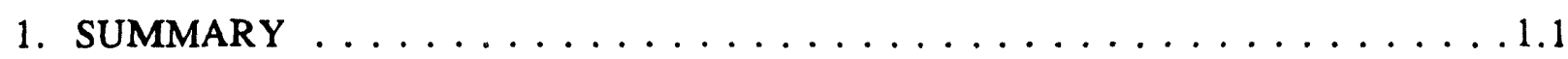

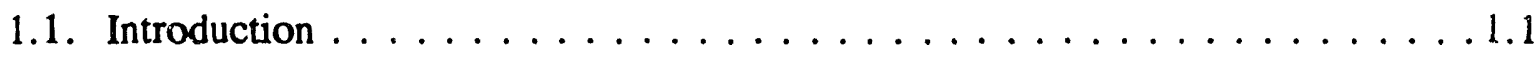

1.2. Adjustable Speed Pump and Wind Power Applications . . . . . . . . 1.1

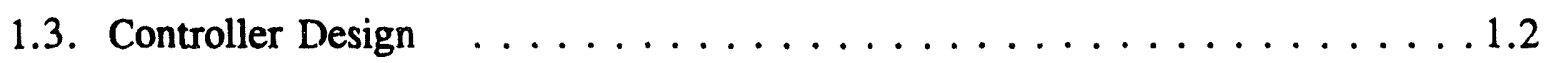

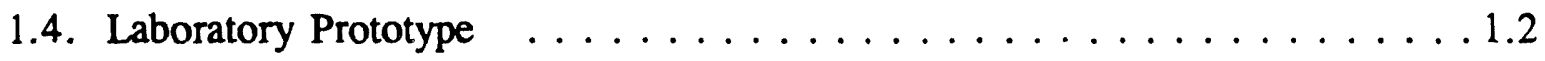

1.5. Laboratory Improvement . . . . . . . . . . . . . 1.3

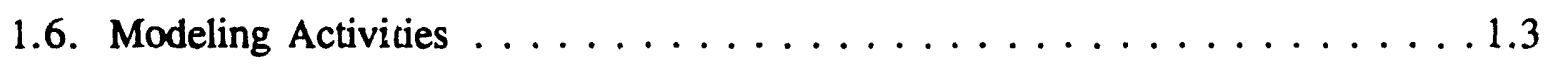

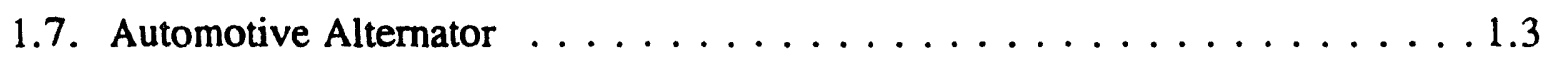

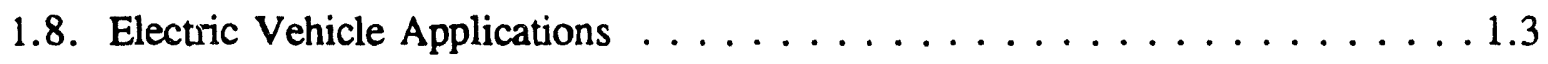

2. ADJUSTABLE SPEED PUMP AND WIND POWER APPLICATIONS $\ldots \ldots .1$

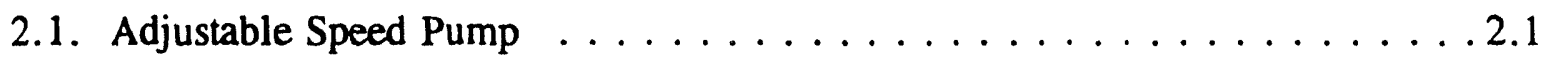

2.2. Wind Power Generation System $\ldots \ldots \ldots \ldots \ldots$

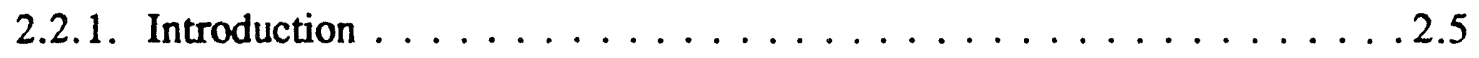

2.2.2. Proof-of-Concept BDFM System . . . . . . . . . . . 2.5

2.2.3. Experimental Evaluation . . . . . . . . . . . . . 2.9

2.2.4. Conclusions and Recommendations . . . . . . . . . . . 2.10

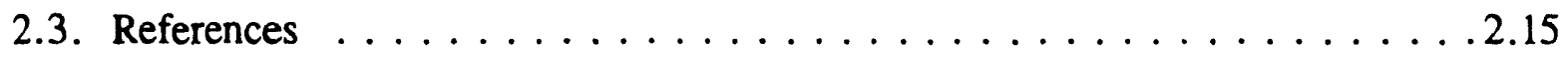

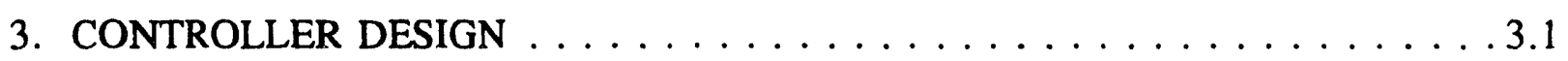

3.1. Direct Torque Control . . . . . . . . . . . . . . 3.1

3.1.1. Determination of Motor Quantities . . . . . . . . . . . 3.2

3.1.1.1. Flux Linkages . . . . . . . . . . . . . . . 3.4

3.1.1.2. Currents . . . . . . . . . . . . . . . . 3.4

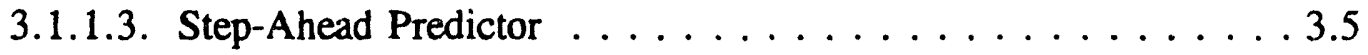

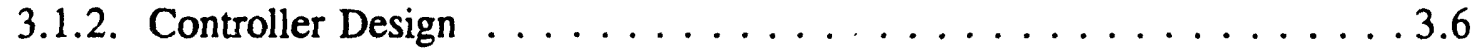

3.1.3. Simulation Results . . . . . . . . . . . . . . . 3.7

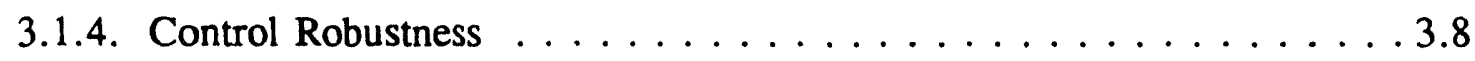

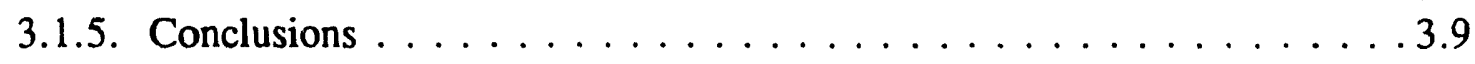

3.2. Model Reference Control . . . . . . . . . . . . . . . . 3.14

3.2.1. Model Reference Adaptive Control Development . . . . . . . . . . 3.14

3.2.2. Simulation Results . . . . . . . . . . . . . . . . 3.16

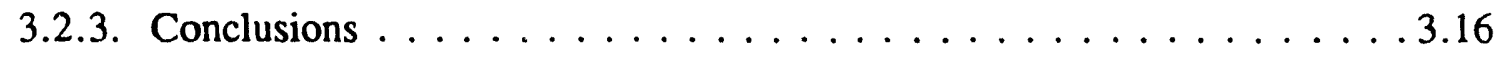


(Table of Contents, continued)

3.3. Laboratory Control Implementation $\ldots \ldots \ldots \ldots \ldots \ldots \ldots \ldots . . \ldots \ldots$

3.3.1. Laboratory Hardware Implementation . . . . . . . . . . . . 3.21

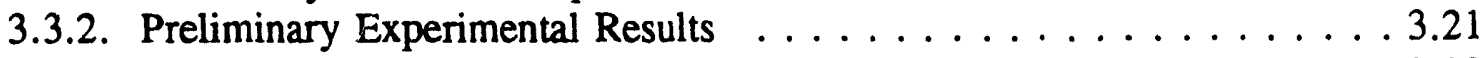

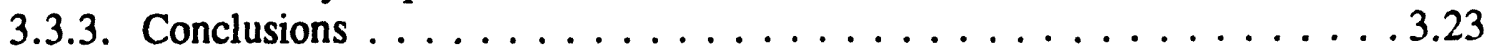

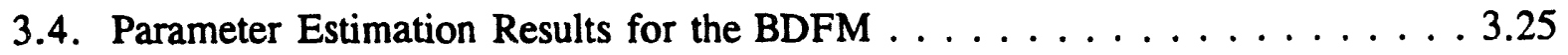

3.4.1. Introduction $\ldots \ldots \ldots \ldots \ldots \ldots \ldots \ldots \ldots \ldots \ldots \ldots \ldots \ldots \ldots \ldots \ldots \ldots \ldots .25$

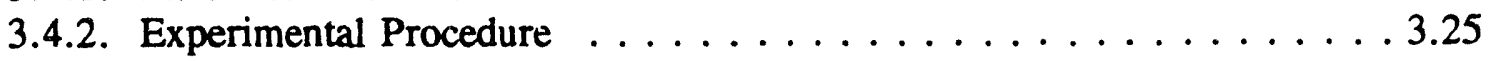

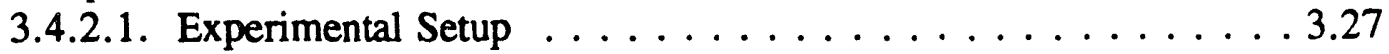

3.4.2.2. Signal Processing $\ldots \ldots \ldots \ldots \ldots \ldots \ldots \ldots \ldots \ldots .27$

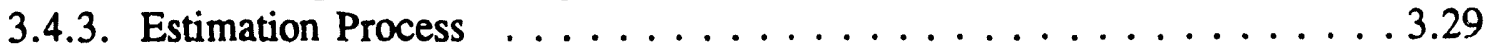

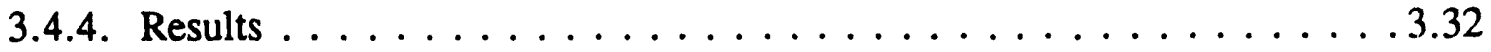

3.4.5. Conclusions $\ldots \ldots \ldots \ldots \ldots \ldots \ldots \ldots \ldots \ldots \ldots \ldots \ldots \ldots \ldots$

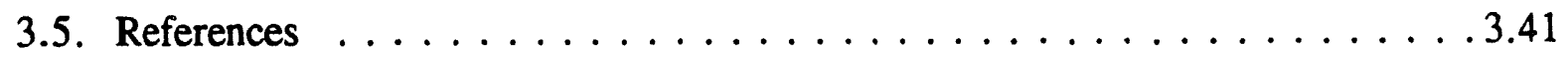

4. LABORATORY PROTOTYPE $\ldots \ldots \ldots \ldots \ldots \ldots \ldots \ldots \ldots \ldots \ldots \ldots \ldots \ldots$

4.1. BDFM Design $\ldots \ldots \ldots \ldots \ldots \ldots \ldots \ldots \ldots \ldots \ldots \ldots \ldots \ldots \ldots \ldots$

4.2. Induction Machine Performance $\ldots \ldots \ldots \ldots \ldots \ldots \ldots .9$

4.2.1. 15 hp Induction Machine Performance $\ldots \ldots \ldots \ldots \ldots \ldots . . \ldots$

4.2.2. 5 hp Induction Machine Performance . . . . . . . . . . 4.10

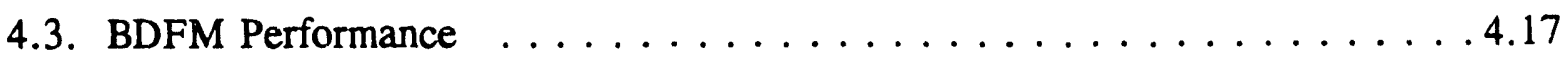

5. LABORATORY IMPROVEMENT $\ldots \ldots \ldots \ldots \ldots \ldots \ldots \ldots \ldots \ldots \ldots \ldots \ldots \ldots \ldots$

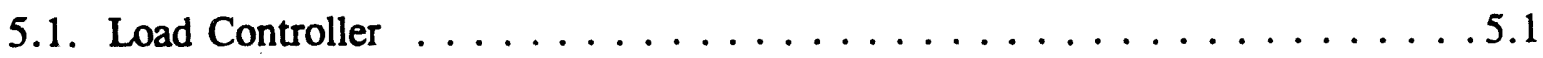

5.2. BDFM Laboratory Test Stand and Instrumentation $\ldots \ldots \ldots \ldots \ldots .8$

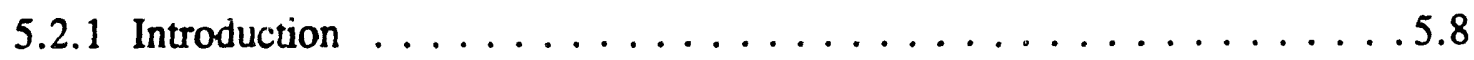

5.2.2. Overview of the Test Stand $\ldots \ldots \ldots \ldots \ldots \ldots \ldots \ldots . . \ldots \ldots$

5.2.3. Catalog of Instruments and Test-Stand Equipment $\ldots \ldots \ldots \ldots .10$

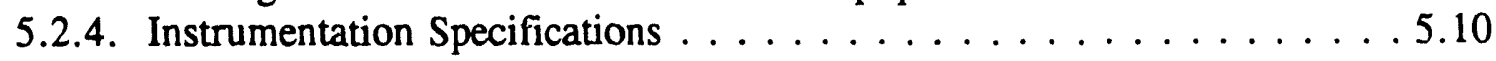

6. BDFM MODELING ACTIVITIES $\ldots \ldots \ldots \ldots \ldots \ldots \ldots \ldots \ldots \ldots \ldots \ldots \ldots$

6.1. Steady-State Model and Simulator $\ldots \ldots \ldots \ldots \ldots \ldots . \ldots \ldots$

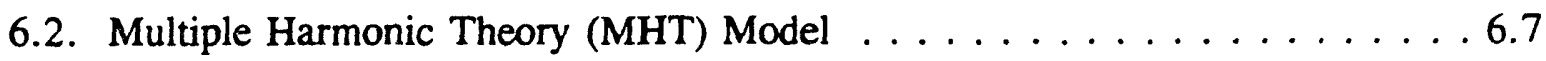

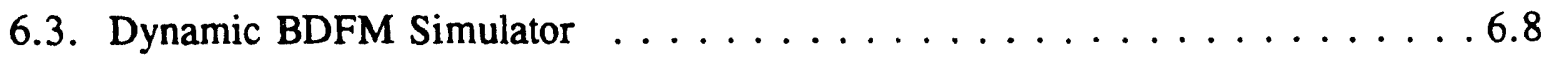

6.4. Finite Element Modeling $\ldots \ldots \ldots \ldots \ldots \ldots \ldots \ldots \ldots \ldots \ldots \ldots$

6.4.1. Finite Element Assisted Analysis of the BDFM . . . . . . . 6.13

6.4.2. Finite Element Analysis Using Superposition . . . . . . . . . . 6.14

6.4.3. Three-Dimensional Finite Element Analysis . . . . . . . . . 6.15 
(Table of Contents, continued)

6.5. Detailed Machine Model . . . . . . . . . . . . . . . . . . . 6.19

6.6. Current Forced Model . . . . . . . . . . . . . . . . .6.20

6.6.1. Model Development . . . . . . . . . . . . . . . . 6.20

6.6.2. Simulation Results in the Induction Mode of Operation . . . . . 6.21

6.6.3. Converter Topologies for Current-Forced Operation . . . . . . . 6.22

6.7. Stator Design Optimization $\ldots \ldots \ldots \ldots \ldots \ldots \ldots . .27$

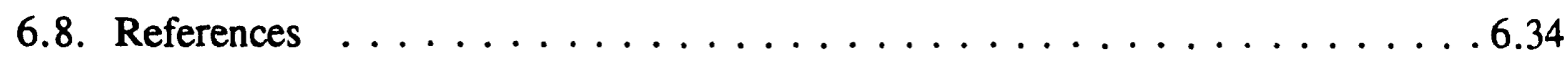

7. BDFM AUTOMOTIVE ALTERNATOR $\ldots \ldots \ldots \ldots \ldots \ldots \ldots \ldots \ldots$

7.1. Digital Control $\ldots \ldots \ldots \ldots \ldots \ldots \ldots \ldots \ldots \ldots \ldots \ldots \ldots \ldots$

7.2. 48V System Design $\ldots \ldots \ldots \ldots \ldots \ldots \ldots \ldots \ldots . \ldots \ldots$

7.3. Test Stand Upgrade $\ldots \ldots \ldots \ldots \ldots \ldots \ldots \ldots \ldots \ldots \ldots \ldots \ldots$

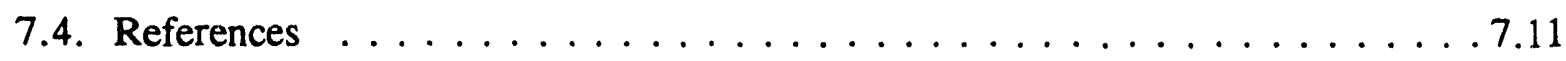

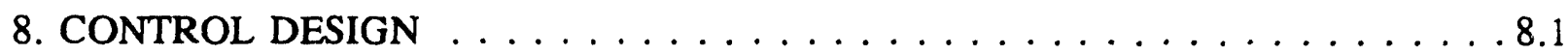

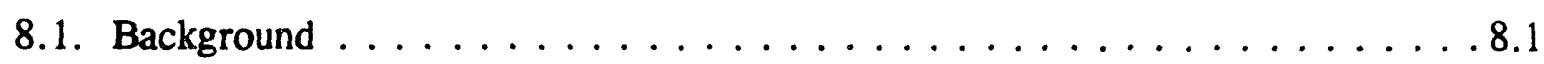

8.2. Potential BDFM Applications $\ldots \ldots \ldots \ldots \ldots \ldots \ldots \ldots$

8.2.1. Single-Motor; Pure Electric Vehicle $\ldots \ldots \ldots \ldots \ldots \ldots . \ldots .6$

8.2.2. Dual-Motor; Pure Electric Vehicle $\ldots \ldots \ldots \ldots \ldots \ldots .6 .6$

8.2.3. Hybrid or Extended-Range Vehicle $\ldots \ldots \ldots \ldots \ldots \ldots .6 \ldots$

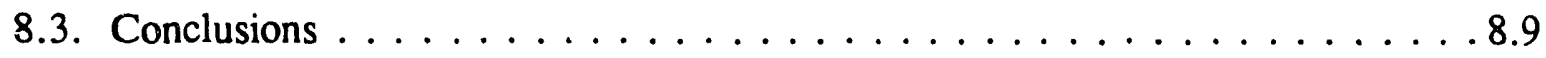

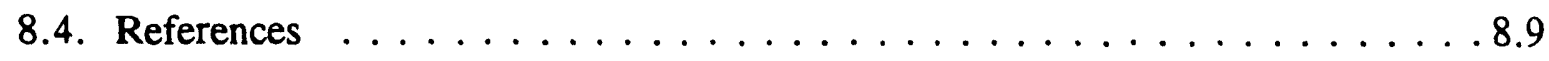




\section{LIST OF FIGURES}

page

Fig. 2.1.1. Schematic of Existing Wastewater Pump Drives . . . . . . . . . . . 2.3

Fig. 2.1.2. Comparison of Estimated Performance of Existing $45 \mathrm{~kW}$ Drive and Measured Performance of $5 \mathrm{~kW}$ BDFM Drive . . . . . . . . . 2.4

Fig. 2.1.3. Required Drive Performance . . . . . . . . . . . . . . . 2.4

Fig. 2.2.1. BDFM Wind Power Generation System . . . . . . . . . . . . 2.11

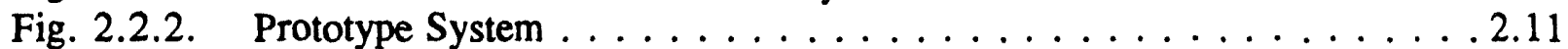

Fig. 2.2.3. Prototype Turbine Coefficient of Power . . . . . . . . . . . . . . 2.12

Fig. 2.2.4. Fixed vs. Variable-Speed Power Generation . . . . . . . . . . . . . 2.12

Fig. 2.2.5. Measured Power and Efficiency Characteristics . . . . . . . . . . 2.12

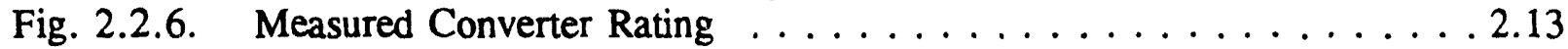

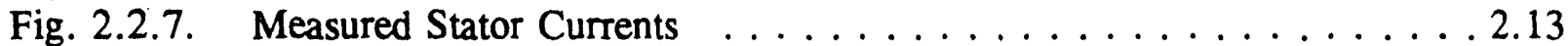

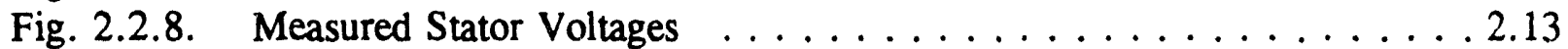

Fig. 2.2.9. Control Voltage Magnitude and System Performance . . . . . . . . . . 2.14

Fig. 2.2.10. Measured Current Waveforms $\left(\omega_{r}=1300 \mathrm{r} / \mathrm{min}\right)$.

Upper Trace: Control Winding (two-pole) Current, $5 \mathrm{~A} /$ div.

Lower Trace: Power Winding (six-pole) Current, 5 A/div. . . . . . . . . 2.14

Fig. 3.1.1. BDFM Two-Axis Equivalent Circuit . . . . . . . . . . . . 3.10

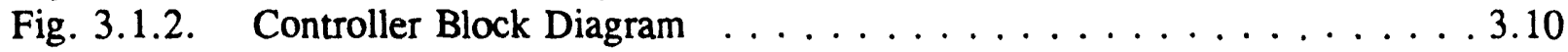

Fig. 3.1.3. Open-Loop Response to Load Torque Disturbance (1 Nm step decrease).

Fig. 3.1.4. Closed-Loop Response to Load Torque Disturbance (1 Nm step decrease).

(a) shaft speed; (b) two-pole flux; (c) electrical torque . . . . . . . . . 3.12

Fig. 3.1.5. Open-Loop Response to Step Change in Speed Command ( $100 \mathrm{r} / \mathrm{min}$ ).

(a) shaft speed; (b) two-pole flux level . . . . . . . . . . . . . . . 3.13

Fig. 3.1.6. Closed-Loop Response to Step Change in Speed Command (+ $100 \mathrm{r} / \mathrm{min})$.

(a) shaft speed; (b) two-pole flux level . . . . . . . . . . . . . . . 3.13

Fig. 3.2.1. MRAC Block Diagram ... . . . . . . . . . . . . . . 3.17

Fig. 3.2.2. System Response to Step Change in Speed Command.

Top: PI-Controller; Bottom: MRAC . . . . . . . . . . . . . . . 3.18

Fig. 3.2.3. System Response to Step Change in Inertia and Speed Command.

Top: PI-Controller (inertia doubled at $t=0.275 \mathrm{~s}$ );

Bottom: MRAC (inertia doubled at $t=0.525 \mathrm{~s}$ ) $\ldots \ldots . \ldots 3.19$

Fig. 3.2.4. MRAC Response to Step in Speed Command with 20\% Rotor

Resistance Error in the Direct Torque Controller . . . . . . . . . . . . 3.20

Fig. 3.3.1. DSP Control Outputs for Converter Current Frequency (top trace)

and Magnitude (bottom trace) . . . . . . . . . . . . . . 3.23

Fig. 3.3.2. Measured Shaft Speed (top trace) and Torque (bottom trace);

Open Loop Data . . . . . . . . . . . . . . . . . . . . . . . . . 3.24

Fig. 3.3.3. Converter Current Waveforms under DSP Control

Top trace: at $6001 / \mathrm{min}$; bottom trace: at $7001 / \mathrm{min} \ldots \ldots . . . . .3 .24$

Fig. 3.4.1. Flow Chart of the Parameter Estimation Procedure . . . . . . . . . . 3.35

Fig. 3.4.2. Open-circuit Magnetization rurve for the Two-pole Winding . . . . . . 3.36

Fig. 3.4.3. Frequency Response of a Butterworth, Zero-phase Digital Filter . . . . 3.36 
Fig. 3.4.4. Sampled Current Input to the Six-pole Winding $\ldots \ldots \ldots \ldots .37$

Fig. 3.4.5. (a) Input Current After Filtering;

(b)Input Current After Filtering (Enlarged) $\ldots \ldots \ldots \ldots \ldots \ldots .3 .38$

Fig. 3.4.6. Input Current Showing Modulation . . . . . . . . . . . . . . . . 3.39

Fig. 3.4.7. Comparison of Measured and Estimated q-axis Frequency Response of Six-pole Winding, with Two-pole Open . . . . . . . . . . . . 3.39

Fig. 3.4.8. Comparison of Measured and Estimated d-axis Frequency Response of Six-pole Winding, with Two-pole Open . . . . . . . . . . 3.40

Fig. 3.4.9. Magnitude Spectrum of Input Modulation Current in the q-d Domain . 3.40

Fig. 4.1.1. Commercially Available Stator Laminations . . . . . . . . . . . . 4.3

Fig. 4.1.2. Custom Made Rotor Laminations . . . . . . . . . . . . . . . . . 4.4

Fig. 4.1.3. BDFM Rotor During Assembly;

(a) View of Common Endring; (b) View of Isolated Endrings . . . . . 4.5

Fig. 4.1.4. Details of Isolated Endring Construction . . . . . . . . . . . . 4.6

Fig. 4.1.5. Schematic of Winding Layout and Resulting MMF: Six-Pole System . 4.7

Fig. 4.1.6. Schematic of Winding Layout and Resulting MMF: Two-Pole System . 4.8

Fig. 4.2.1. Induction Machine Steady State Equivalent Circuit . . . . . . . 4.12

Fig. 4.2.2. Induction Machine Efficiency (four-pole, $15 \mathrm{hp}$ ) . . . . . . . 4.12

Fig. 4.2.3. Induction Machine Power Factor (four-pole, $15 \mathrm{hp}$ ) . . . . . . . 4.13

Fig. 4.2.4. Adjustable Speed Induction Machine Drive Performance for Constant Load Torque (37\% of Rating, 15 hp IM, SRC-fed) . . . . . . 4.13

Fig. 4.2.5. Adjustable Speed Induction Machine Drive Performance for Fan Load (75\% of Rating at Rated Speed, 15 hp IM, SRC-fed) . . . 4.14

Fig. 4.2.6. Induction Machine Efficiency (eight-pole, $5 \mathrm{hp)} \mathrm{\ldots \ldots \ldots} \mathrm{\ldots} \mathrm{\ldots} \mathrm{.} \mathrm{.} \mathrm{.} \mathrm{.} \mathrm{.} \mathrm{.} \mathrm{.}$

Fig. 4.2.7. Induction Machine Power Factor (eight-pole, $5 \mathrm{hp}$ ) . . . . . . . . . 4.15

Fig. 4.2.8. Adjustable Speed Induction Machine Drive Performance for Constant Load Torque (50\% of Rating, 5 hp IM, SRC-fed) . . . . . . 4.15

Fig. 4.2.9. Adjustable Speed Induction Machine Drive Performance for Constant Load Torque (80\% of Rating, 5 hp IM, SRC-fed) . . . . . . 4.16

Fig. 4.2.10. Adjustable Speed Induction Machine Drive Performance for Fan Load (80\% of Rating at Rated Speed, 5 hp IM, SRC-fed) . . . . . 4.16

Fig. 4.3.1. BDFM Output Power and Converter Rating for Constant Load Torque (50\% or Rating, 5 hp Nominal Rating, SRC-control) . . . . . . . . 4.19

ᄃig. 4.3.2. BDFM Efficiency for Constant Load Torque (50\% of Rating, 5 hp Nominal Rating, SRC-control) . . . . . . . . . 4.19

Fig. 4.3.3. BDFM Output Power and Converter Rating for Fan Load (80\% of Rating at Rated Speed, $5 \mathrm{hp} \mathrm{Nominal} \mathrm{rating,} \mathrm{SRC-control)} \mathrm{.} \mathrm{.} 4.20$

Fig. 4.3.4. BDFM Efficiency for Fan Load

(80\% of Rating at Rated Speed, $5 \mathrm{hp}$ Nominal rating, SRC-control) . . 4 4.20

Fig. 4.3.5. Comparison of Converter Ratings - BDFM vs. IM . . . . . . . . 4.21

Fig. 4.3.6. Comparison of Drive Efficiencies - BDFM vs. IM . . . . . . . 4.21

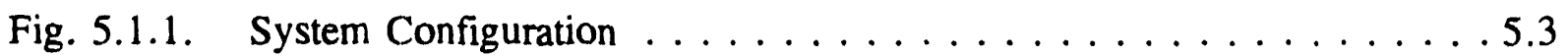

Fig. 5.1.2. Load Controller Schematic (Memory and Communication) . . . . . 5.4

Fig. 5.1.3. Load Controller Schematic (Input/Output) . . . . . . . . . . . . . 5.5 


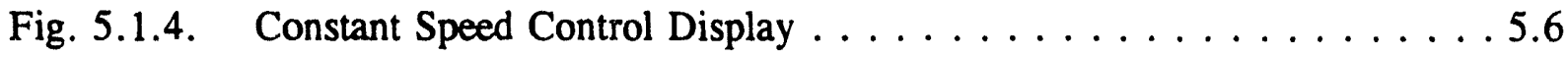

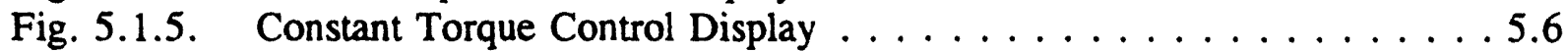

Fig. 5.1.6. Adjustable Torque Control Display . . . . . . . . . . . . . . . 5.7

Fig. 5.2.1. Fixed-Equipment Components of the BDFM Test Stand and Their Interconnection Links . . . . . . . . . . . . . . . . . 5.25

Fig. 5.2.2. The Interconnections of the Steady-State (rms) and Instantaneous Data Acquisition Systems . . . . . . . . . . 5.26

Fig. 6.1.1. Steady State Equivalent Circuit of BDFM . . . . . . . . . . . . 6.4

Fig. 6.1.2. User Screen of BDFM Simulator . . . . . . . . . . . . . . . 6.5

Fig. 6.1.3 Performance Prediction Obtained from Simulator for LBDFM . . . . 6.6

Fig. 6.3.1. Dynamic Simulator Display in Open-Loop Mode . . . . . . . . . 6.12

Fig. 6.4.1. 12-Pole Flux Plot - Eddy Current Solution (200 A total 12-pole current, $22 \mathrm{~Hz}$ rotor frequency) . . . . . . 6.16

Fig. 6.4.2. Four-Pole Flux Plot - Eddy Current Solution (200 A total Four-pole current, $22 \mathrm{~Hz}$ rotor frequency) . . . . . . 6.16

Fig. 6.4.3. Doubly-Fed Flux Plot - Superposition . . . . . . . . . . . . . . 6.17

Fig. 6.4.4. Three-Dimensional Rotor Structure . . . . . . . . . . . . 6.17

Fig. 6.4.5. Three-Dimensional Machine Structure . . . . . . . . . . . 6. 6.18

Fig. 6.6.1. Free acceleration speed response in mech. $\mathrm{rad} / \mathrm{sec} \ldots \ldots . . \ldots 6.24$

Fig. 6.6.2. (a) Q-axis current in the power winding;

(b) D-axis current in the power winding . . . . . . . . . . 6.25

Fig. 6.6.3. (a) Q-axis current in the rotor circuit;

(b) D-axis current in the rotor circuit $\ldots \ldots \ldots \ldots \ldots . \ldots \ldots 6.26$

Fig. 6.7.1. BDFM Steady State Circuit . . . . . . . . . . . . 6.32

Fig. 6.7.2. Simplified Flowchart for Stator Optimization Routine . . . . . . . 6.33

Fig. 7.1.1. Digital Controller for BDFM Automotive Alternator. . . . . . . . 7.3

Fig. 7.2.1. Advanced 48V dc Automobile Alternator Output

Performance Requirement . . . . . . . . . . . . . . . 7.6

Fig. 7.2.2. Stator Lamination $48 \mathrm{~V}$ dc Alternator . . . . . . . . . . . . . . . . . 7.7

Fig. 7.2.3. Rotor Lamination for 48V dc Alternator . . . . . . . . . . . . . 7.8

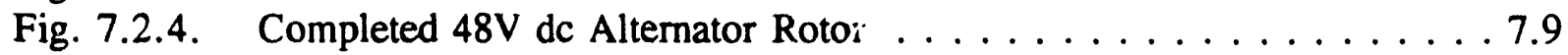

Fig. 7.2.5. Connection Diagram for $48 \mathrm{~V}$ dc Alternator . . . . . . . . . . 7.10

Fig. 8.1.1. Single and Double Motor Drive Systems for Pure Electric Vehicles . . 8 8.3

Fig. 8.1.2. Drive System for Hybrid or Extended-Range Electric Vehicles . . . . . 8.4

Fig. 8.1.3. Rated Efficiency; Power-to-Weight Ratio; Capital Cost of Induction Motors . . . . . . . . . . . . . . . . . . 8.5

Fig. 8.2.1. BDFM as a Drive for Single-Motor Electric Vehicle (with Mechanical Differential)and for a Dual-Motor Electric Vehicle ("Electric Differential" Configuration) . . . . . . . . . . . . . 8.7

Fig. 8.2.2. BDFM as an Adjustable Frequency Generator for Hybrid Electric Vehicles $\ldots \ldots \ldots \ldots \ldots \ldots . \ldots \ldots$ 


\section{LIST OF TABLES}

page

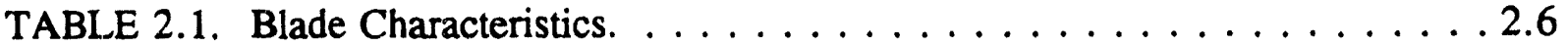

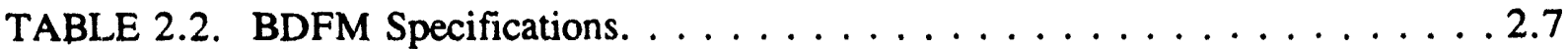

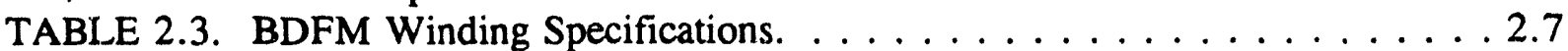

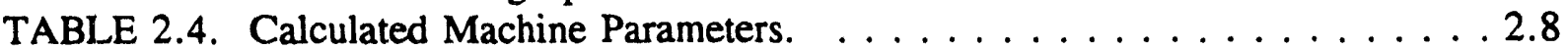

TABLE 3.1. Allowable Parameter Errors for Prediction. . . . . . . . . . . . . 3.9

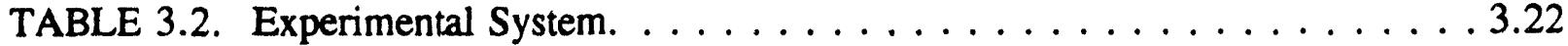

TABLE 3.3. Operating Conditions for Six-pole Winding Measurements. . . . . . . . 3.27

TABLE 3.4. Operating Conditions for Two-pole Winding Measurements. . . . . . . 3.27

TABLE 3.5. Parameter Estimation Results for the Six-pole Winding. . . . . . . . . . 3.33

TABLE 3.6. Parameter Estimation Results for the Two-pole Winding. . . . . . . . . 3.33

TABLE 4.1. Induction Motor Nameplate Data. . . . . . . . . . . . . . 4.9

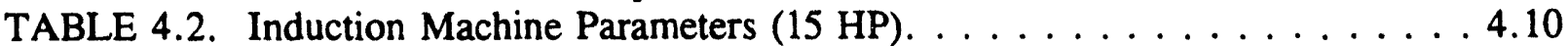

TABLE 4.3. Induction Machine Parameters $(5 \mathrm{hp}) . \ldots \ldots \ldots \ldots \ldots \ldots$

TABLE 5.1. BDFM Laboratory Test Equipment and Instrumentation. . . . . . . . 5.12

TABLE 5.2. BDFM $13 \mathrm{KVA} / 10 \mathrm{hp}$ Test Stand Instrumentation Specifications. . . . . 5.13

TABLE 5.3. BDFM Laboratory Undedicated Instrumentation Specifications. . . . . 5.19

TABLE 6.1. Dynamic Simulator Function Keys. . . . . . . . . . . . . 6.10

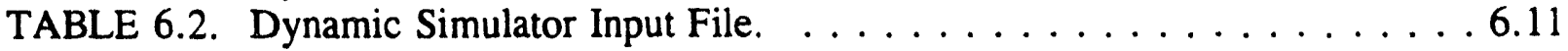

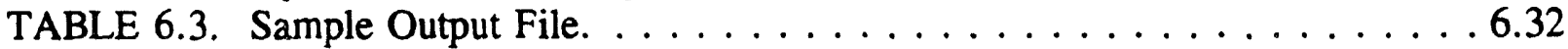

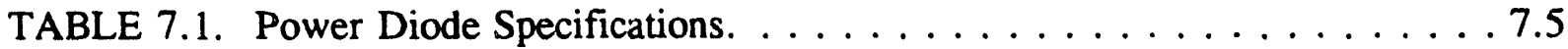

TABLE 7.2. Power Transistor Specifications. . . . . . . . . . . . 7.5 


\section{SUMMARY}

\subsection{Introduction}

Since the inception of the BDFM development program in 1989, the value of BDFM technology has become apparent. The BDFM provides for adjustable speed, synchronous operation while keeping costs associated with the required power conversion equipment lower than in competing technologies. This provides for an advantage in initial as well as maintenance expenses over conventional drive system. Thus, the BDFM enables energy efficient, adjustable speed process control for applications where established drive technology has not been able to deliver satisfactory returns on investment. At the samc time, the BDFM challenges conventional drive technologies in established markets by providing for improved performance at lower cost. BDFM converter rating is kept at a minimum, which significantly improves power quality at the utility interface over competing power conversion equipment. In summary, BDFM technology can be expected to provide significant benefits to utilities as well as their customers. This report discusses technical research and development activities related to Phase 3 of the Brushless DoublyFed Machine System Development Program, including work made possible by supplemental funds for laboratory improvement and prototype construction. Market research for the BDFM was provided by the College of Business at Oregon State University; market study results will be discussed in a separate report.

Phase 1 of the BDFM development program had addressed basic modeling and feasibility issues regarding stability and other operational aspects of the doubly-fed machine. The work in Phase 2 continued these activities with an emphasis on improving machine designs, speed range and control flexibility. Activities during Phase 3 applied the concepts developed to date to the construction of optimized laboratory systems, thus laying the groundwork for field prototype construction during Phase 4. Supporting activities related to control development and modeling continued throughout Phase 3.

The following summarizes the contents of the report, highlighting the important results presented in each chapter.

\subsection{Adjustable Speed Pump and Wind Power Applications}

Two applications are examined for which the BDFM is extremely suitable and very competitive with conventional induction motor drives: low speed pump drives and wind power 
generation.

Investigation of the pump drive application is a precursor to Phase 4 design activities. As expected, the BDFM shows tremendous cost and performance advantages over conventional induction motor drives as well as wound rotor, slip energy recovery systems.

The wind power application is examined with a $1.5 \mathrm{~kW}$ proof-of-concept prototype illustrating the reduced converter requirement as well as good harmonic performance. The results presented are very encouraging and support the investigation of high power designs suitable for field installation.

\subsection{Controller Design}

Research activities during Phase 3 continued to investigate parameter identification techniques for the BDFM. Information on parameters is needed in the design process as well as for closed loop control development. The two winding, cage rotor structure complicates the determination of machine parameters compared to conventional induction machines. The technique developed for the BDFM shows promising results.

Closed-loop controllers for high performance BDFM applications attempt to improve the dynamic response of BDFM drives. Initial designs are based on the concept of "direct torque control," where the converter control algorithm is based directly on torque and flux error. While showing good results, the technique is computationally intensive and requires a digital signal processor for implementation. Presently, efforts are underway to extend field oriented control methods known from induction machines to the BDFM.

\subsection{Laboratory Prototype}

In order to allow for a comparison of the BDFM with conventional induction machine drives, a commercial induction machine was acquired and tested thoroughly for a variety of loads. An optimized laboratory BDFM prototype was then constructed using the induction machine frame and stator in conjunction with a custom designed rotor. Extensive testing of the prototype shows that the BDFM performs superior to conventional 8-pole induction motor drives. The $5 \mathrm{hp}$ laboratory prototype was designed and evaluated with an emphasis on low speed pump loads to provide insight into the requirements of the field demonstration prototype for Phase 4 . Test results shown illustrate the superior cost and performance characteristics of the BDFM in this 
application.

\subsection{Laboratory Improvement}

Improvements to the BDFM laboratory test stand allow for better measurement capabilities and enhance the capacity for laboratory demi nstrations to interested parties. The chapter contains a comprehensive listing of the laboratory instrumentation. Also discussed is a digital controller, which has been developed for the dc drive providing load to the BDFM shaft. This system allows for convenient demonstration and evaluation of drive performance under a variety of load conditions.

\subsection{Modeling Activities}

During the prior phases of the BDFM development program, a number of models have been developed and utilized for the design and construction of prototype machines and controllers. Activities during Phase 3 addressed maintenance and enhancement of the modeling packages as required for the development of optimized prototypes. These efforts are necessary to provide good design tools to be used by the researchers at Oregon State University as well as manufacturers during the technology transfer process.

\subsection{Automotive Alternator}

The proof-of-concept automotive alternator described in the Phase 3 report has been updated with a much simplified digital controller. An upgrade of the alternator test stand allows for good high speed test capabilities and enhances the visual aspects for demonstration purposes. With regard to future automotive requirements, a $48 \mathrm{~V}$ alternator has been developed using custom stator and rotor lamination. The design goal is to generate $2.5 \mathrm{~kW}$ in a compact package at efficiencies of around $70 \%$, matching the requirements of the automotive industry. The alternator prototype has been constructed and the construction of the $48 \mathrm{~V}$ electronics is underway; test results will be reported in the Phase 4 report.

\subsection{Electric Vehicle Applications}

This chapter examines the potential of the BDFM for electric vehicle applications. The BDFM seems suitable for niche designs that bring out the inherent advantages of synchronous 
operation and reduced converter rating, when operating from a dc bus. Based on system studies performed, this requires a BDFM drive design from the ground up, including the concept of the "electric differential." At present, the automotive industry has a vested interest in conventional drive technologies due to past development activities; it is doubtful that the industry will discontinue their conventional designs to embrace an all new concept. 


\section{ADJUSTABLE SPEED PUMP DRIVE AND WIND POWER APPLICATIONS}

The BDFM shows great promise for low speed adjustable speed drive applications as well as variable speed generation systems. Thus, system designs are in progress for a low speed pump drive as well as a wind power generator. While these applications will be developed in detail

during Phase 4, initial progress has been made during Phase 3; preliminary design objectives and results are reported in the following.

\subsection{Adjustable Speed Pump}

The initial theoretical expectation of the reduced power converter rating of a BDFM, which prompted Phases 1, 2 and 3 of this project, was intended for a pump or fan adjustable speed drive. It is fitting, therefore, that a design study is now underway to convert the laboratory experience gained with the $5 \mathrm{~kW}$ BDFM into a $45 \mathrm{~kW}$ pump drive for wastewater treatment. This is an attempt to design a motor and converter for a specific purpose and rating based primarily on design rules and equations usually applied to induction machines.

The application under study is to replace one of four parallel pump drives in the City of Corvallis Wastewater Reclamation Plant as shown in the schematic of Fig. 2.1.1. The unit in question is noncritical to the overall pumping operation, thus helping relieve any potential liability problems, and has a speed range of $600 \mathrm{r} / \mathrm{min}$ to $850 \mathrm{r} / \mathrm{min}$, in which the existing six-pole/twopole BDFM operation is well documented and understood. The existing pump drive is provided by a wound rotor induction motor and speed control is produced by water rheostats cor aected in the rotor circuit. This system has poor efficiency at low speeds and poor power factor at the higher end of the speed range as shown in Fig. 2.1 .2 (which requires compensation by static capacitors. Whereas a BDFM has a p.f. that is adjustable by control winding excitiation.) Based on the nameplate data of the existing drive the required motor performance, according to an assumed load characteristic of torque proportional to the square of speed, is as shown in Fig. 2.1.3. The estimated performance of a scaled-up BDFM should be superior and require a power converter of no more than $25 \%$ of the motor rating (i.e. $\sim 10 \mathrm{~kW}$ ). In addition the BDFM drive will have a controllable power factor if required. Thus, the BDFM system should represent a considerable capital cost saving when compared to the alternative replacement system of a conventional squirrel cage induction motor drive (which required a $45 \mathrm{~kW}$ converter). 
Planned stages for the implementation of this application are as follows:

(i) evaluate actual performance of existing drive;

(ii) define interfaces (mechanical, input power, and controls) of existing system;

(iii) develop scaling of the laboratory $5 \mathrm{~kW}, 230 \mathrm{Vac}$ BDFM as described in Sections 4.1 and 4.3 to meet (or exceed) the performance recorded in (i), to produce a $45 \mathrm{~kW}, 460 \mathrm{Vac}$ BDFM;

(iv) liaise with manufacturers to design and construct the machine and converter defined in (iii);

(v) test the system produced in (iv) in the new Electric Motors and Drives Regional Resource Laboratory (EMDRRL) in OSU;

(vi) modify system as necessary to meet requirements of Corvallis Wastewater Reclamation Plant;

(vii) develop start-up system for BDFM drive;

(viii) install BDFM in pumping application and monitor performance.

At this time, items (i), (ii) and (iii) are underway and meetings with manufacturers are being scheduled. Advice on the installation and cautionary notes on potential pitfalls are being provided to OSU by Mr. R. Nichols, a senior engineer with the water treatment engineering company CH2M-Hill.

The scope of the project was presented in a recent paper [2.1] and progress will be reported at the end of Phase 4 of the BDFM program. 


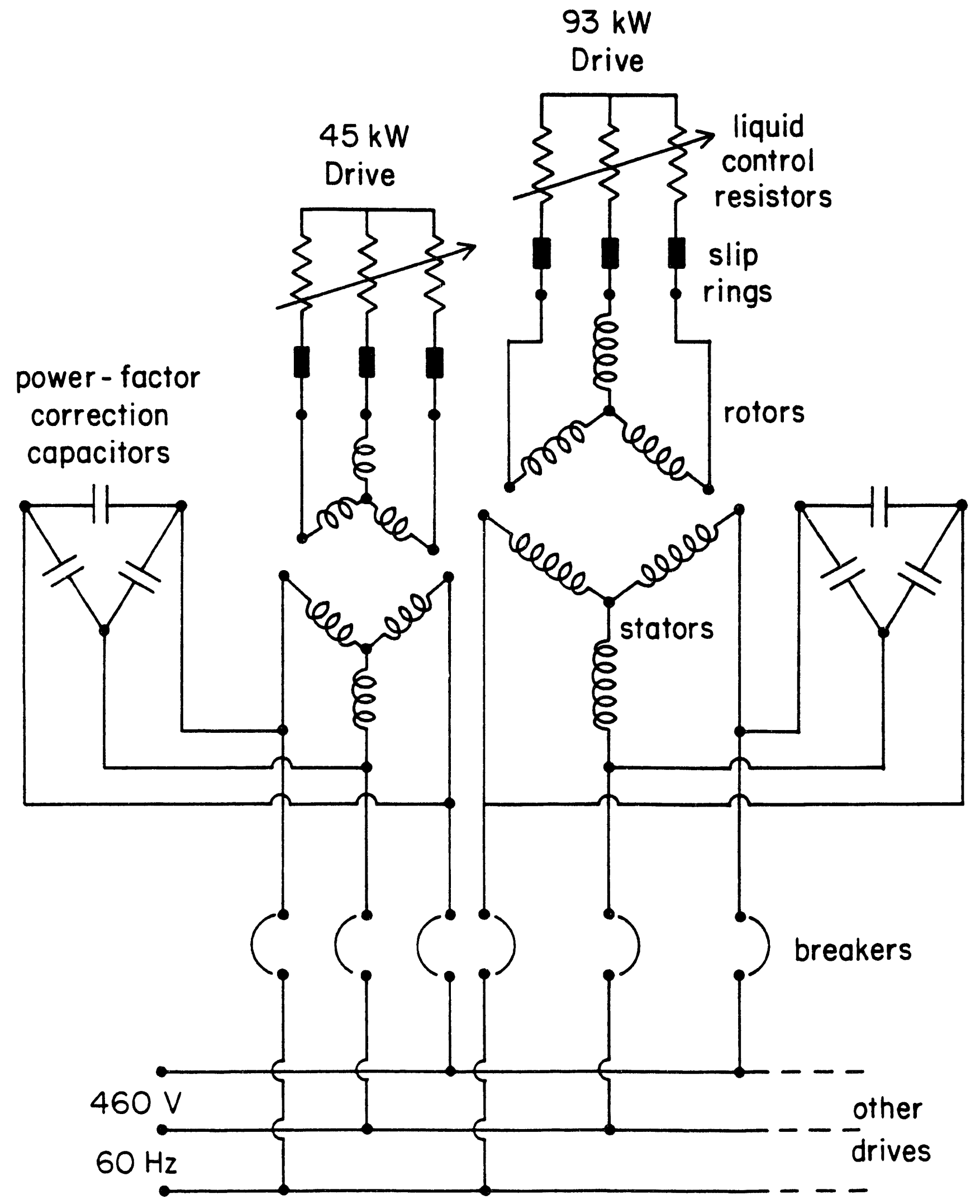

Fig. 2.1.1. Schematic of Existing Wastewater Pump Drives. 


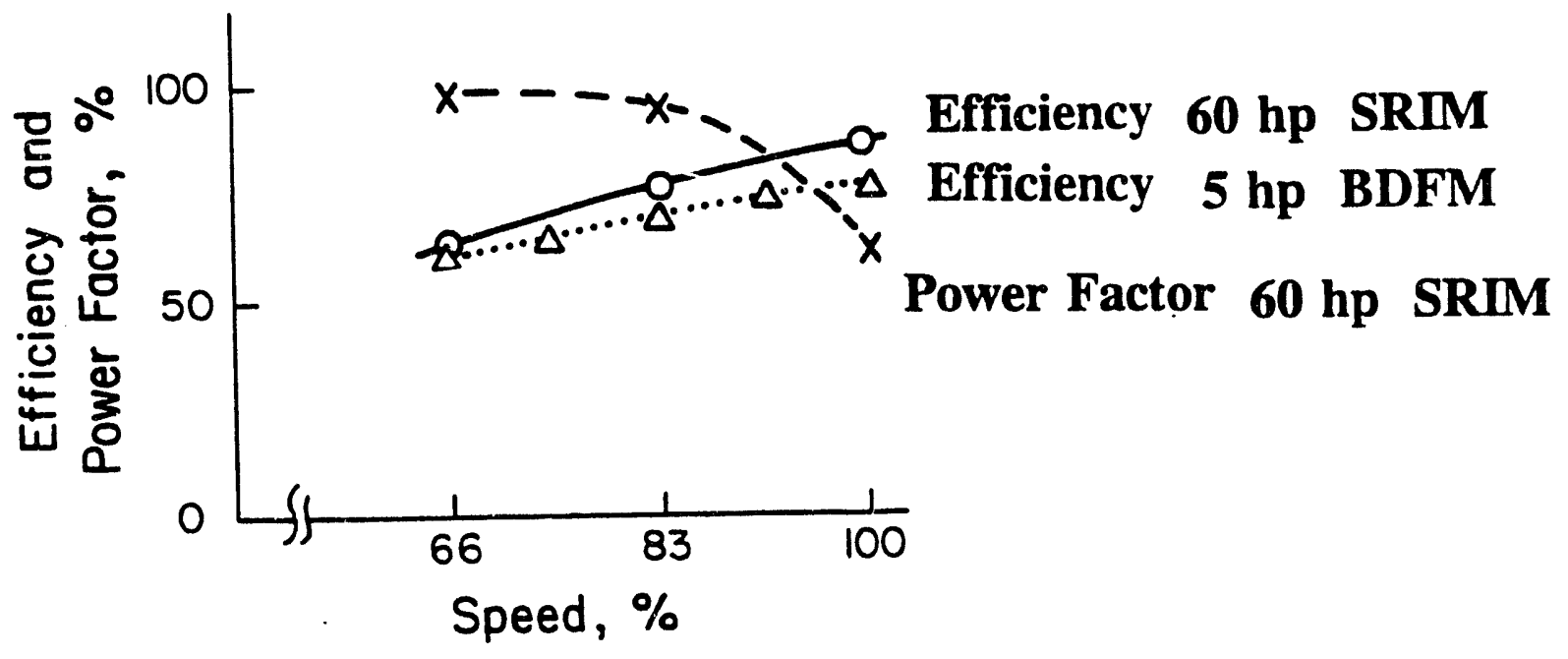

Fig. 2.1.2. Comparison of Estimated Performance of Existing $45 \mathrm{~kW}$ Drive and Measured Performance of $5 \mathrm{~kW}$ BDFM Drive.

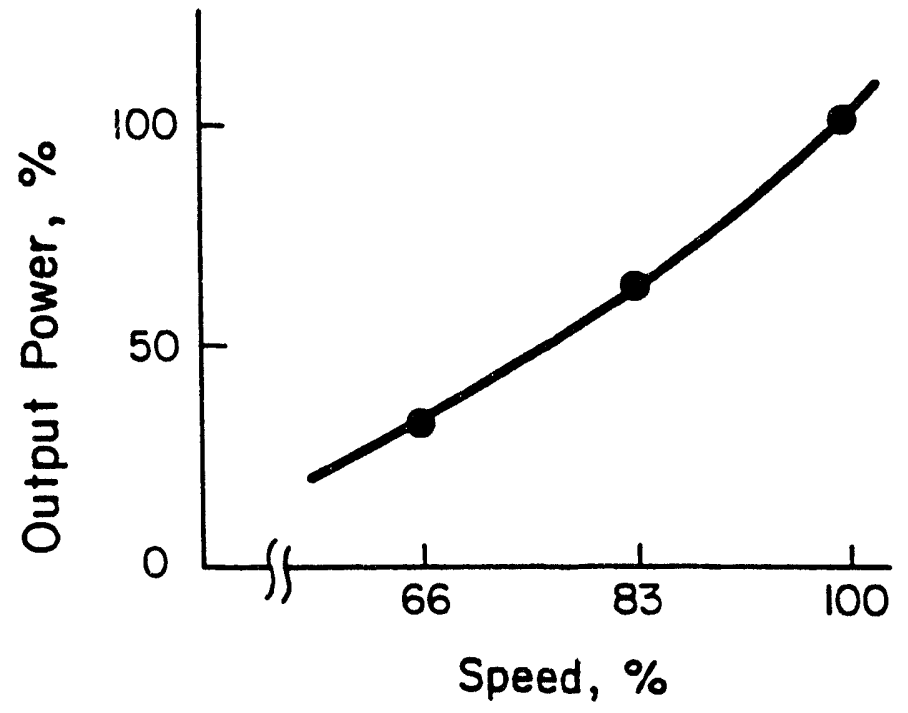

Fig. 2.1.3. Required Drive Performance. 


\subsection{Wind Power Generation System}

\subsubsection{Introduction}

In recent years, wind power has been gaining renewed interest due to an increased emphasis on environmentally sustainable technologies [2.2]. A consortium of utilities in the Pacific Northwest is investigating the area's potential for wind generation. Initial plans call for a total installed capacity of $50 \mathrm{MW}$ [2.3]. To establish feasibility, a $275 \mathrm{~kW}$ prototype is under development in a joint effort by the Bonneville Power Administration, Puget Sound Power and Light, Electronic Power Conditioning and R. Lynnette \& Associates. During Phase 4, it is planned to investigate the feasibility of the BDFM in a system of this rating. Preliminary work on a proof-of-concept prototype with a power rating of $1.5 \mathrm{~kW}$ has been completed during Phase 3.

Variabie-speed generation (VSG) systems can extract more energy from the wind by keeping the tip speed ratio (TSR) of the wind turbine at the optimum value during changes in wind speed. However, most variable-speed systems suffer from a cost disadvantage due to the required rating of the power electronic converter. This is true for all conventional synchronous, induction and reluctance systems. In some designs, multiple induction generators and converters are required on the same turbine shaft [2.4]. A reduction in power converter rating can be achieved by using a doubly-fed configuration with a slip ring induction machine. Full control over active and reactive power is possible, while minimizing the harmonic distortion of the generated waveforms $[2.5,2.6]$. Disadvantages of the slip-ring design irclude a slightly higher machine cost as well as added maintenance due to the use of slip rings and brushes.

The brushless doubly-fed topology offers the advantage of combining the benefits of the doubly-fed, slip-ring configuration with the robustness of the cage rotor induction machine. The advantages of the BDFM system are presently being evaluated on a low power prototype, using a commercially available, down wind blade. Steady state results are presented in this report, while dynamic performance will be evaluated during Phase 4 .

\subsubsection{Proof-of-Concept BDFM System}

The system block diagram is illustrated in Fig. 2.2.1. The maximum power controller shown in Fig. 2.2.1 tracks the characteristic wind power curve. While this procedure generally attempts to locate the maximum power point at a given wind speed, separate inputs for desired active and 
reactive power are provided to allow for external control overrides and to enable separate reactive power control. The power transducer is provided to allow for isedback of line quantities. In addition to optimizing steady-state performance, the controller also needs to ensure dynamic stability of the generator. This is achieved through a shaft speed feedback which allows appropriate control of converter output frequency and magnitude. The output of the wind speed transducer is used to determine when to start or shut down the system.

Figure 2.2.2 shows the resulting implementation of the variable-speed, doubly-fed generator. In the following, mechanical, electrical and control aspects of the prototype system are presented in more detail.

The prototype VSG system uses commercially available blades, manufactured by World Power Technologies. Blade characteristics are summarized in Table 2.1. A graph of power coefficient, $\mathrm{Cp}$, versus tip speed ratio for the turbine is shown in Fig. 2.2.3. It is evident that turbine efficiency drops rapidly as the tip speed ratio deviates from the optimum value of 8.5. Fig. 2.2.4 shows a comparison between the projected power output of the given turbine in fixed and variable-speed systems. The fixed-speed system is optimized at one wind speed $(6.7 \mathrm{~m} / \mathrm{s}$ for the prototype blades) and power output at all other wind speeds is less than in the variable-speed system. As illustrated, this effect is most pronounced at higher wind speeds, were the power output is more significant.

The wind turbine operating speed range needs to be matched to that of the generator via a gear box or, in case of the low power laboratory prototype, a belt and pulley arrangement. For the prototype system, a pulley ratio of 3.4 was selected, which offers a good compromise between the cut-in of the wind turbine and the optimum low-speed of the six-pole/two-pole BDFM generator constructed.

TABLE 2.1. Blade Characteristics.

\begin{tabular}{||l|l|}
\hline Diameter & $2.75 \mathrm{~m}$ \\
\hline Optimal TSR & 8.5 \\
\hline Optimal Cp & 0.41 \\
\hline Power output at $9 \mathrm{~m} / \mathrm{s}$ & $1000 \mathrm{~W}$ \\
\hline Cut-in wind speed & $4.5 \mathrm{~m} / \mathrm{s}$ \\
\hline
\end{tabular}

For the prototype system, a BDFM geometry with a six-pole $\left(\mathrm{P}_{\mathrm{p}}\right)$ "power" winding, a two- 
pole $\left(P_{c}\right)$ "control" winding and a four-pole rotor cage was selected. With this configuration, the desired speed range can be covered with converter output frequencies between approximately 25 $\mathrm{Hz}$ and $70 \mathrm{~Hz}$. For the pole numbers and speed range selected, the rating of the power converter can be expected to be less than or equal to $25 \%$ [i.e. $P_{c} /\left(P_{p}+P_{c}\right)$ ]. BDFM design, analysis and control procedures are covered elsewhere in this as well as previous BDFM reports and in references $[2.7,2.8]$. Machine and winding specifications for the prototype are listed in Tables 2.2 and 2.3. The parameters for the single-phase BDFM equivalent circuit [2.8] are listed in Table 2.4 .

TABLE 2.2. BDFM Specifications.

\begin{tabular}{||l|l|}
\hline Frame Size & 182 \\
\hline Rated Voltage & $115 \mathrm{~V}$ \\
\hline Rated Speed & $1800 \mathrm{r} / \mathrm{min}$ \\
\hline Rated Output Power & $1500 \mathrm{~W}$ \\
\hline Design Efficiency & $77 \%$ \\
\hline
\end{tabular}

TABLE 2.3. BDFM Winding Specifications.

\begin{tabular}{||l|l|}
\hline \hline Six-pole Winding & Double layer \\
& 15 turns/coil \\
& $\# 16$ AWG \\
\hline Two-pole Winding & Double layer \\
& 10 turns/coil \\
& $\# 19$ AWG \\
\hline "Four-pole" Rotor Cage & Round copper bars \\
& $\# 4$ AWG \\
\hline
\end{tabular}


TABLE 2.4. Calculated Machine Parameters.

\begin{tabular}{||l|l||}
\hline Six-pole resistance, $\mathrm{r}_{6}$ & $0.9 \Omega$ \\
\hline Six-pole inductance, $\mathrm{L}_{6}$ & $56 \mathrm{mH}$ \\
\hline Six-pole to rotor mutual coupling, $\mathrm{M}_{6}$ & $0.58 \mathrm{mH}$ \\
\hline Two-pole resistance, $\mathrm{r}_{2}$ & $1.8 \Omega$ \\
\hline Two-pole inductance, $\mathrm{L}_{2}$ & $210 \mathrm{mH}$ \\
\hline Two-pole to rotor mutual coupling, $\mathrm{M}_{2}$ & $2 \mathrm{mH}$ \\
\hline rotor resistance, $\mathrm{r}_{\mathrm{r}}$ & $0.24 \mathrm{m \Omega}$ \\
\hline rotor inductance, $\mathrm{L}_{\mathrm{r}}$ & $0.03 \mathrm{mH}$ \\
\hline
\end{tabular}

The converter for the BDFM as shown in Fig. 2.1.1 consists of a conventional, three phase, pulse-width-modulated (PWM) inverter and a synchronous rectifier. It should be noted that the Series Resonant Converter (SRC), as used with the higher power laboratory prototype (see chapter 4), is as applicable and in some ways preferable to the hard switched PWM implementation. However, the cost of an SRC ( $\$ 20,000$ for the 15 kVA laboratory unit), precluded the acquisition of a second converter for the wind system. Moreover, SRC design and control is quite complex and too involved as a subtopic for a Master's thesis project on BDFM wind power applications. Moreover, proving the performance of the BDFM with established PWM converter techniques may prove beneficial in the techrology transfer process.

The power converter design uses Insulated Gate Bipolar Transistors (IGBT); in order to provide for sufficient over capacity in the prototype system, IXYS IXGH20N60U1 IGBTs with ratings of $600 \mathrm{~V}$ and $20 \mathrm{~A}$ were selected. A separate microcontroller (Intel $80 \mathrm{C} 196 \mathrm{KC}$ ) is provided for each converter stage, allowing switching frequencies of $10 \mathrm{kHz}$ and hysteresis current control updates at a rate of $1 \mathrm{kHz}$. The microcontrollers also provide for fault protection and system performance feedback to a personal computer, allowing monitoring of system operation.

Power converter control implementation for in-wind operation (dynamic performance start-up, shut-down, power maximization) is currently underway and will be reported in the Phase 4 report. To date, the prototype BDFM wind turbine steady state performance has been determined under controlled laboratory conditions; this is discussed in the following section. 


\subsubsection{Experimental Evaluation}

In order to examine the steady state performance of the proof-of-concept system, laboratory testing is performed under controlled conditions. The generator system is operated with an induction motor drive providing the mechanical input power. As in the actual wind system, coupling to the generator is achieved via a belt/pulley arrangement. The variable-speed generation system can be operated and tested over the entire design speed and power ranges.

Figure 2.2.5 illustrates the resulting mechanical power profile and system efficiency. Note that the flattening of the power curve represents power limiting at the rated value via a reduction of speed; the experimental generator power characteristic compares favorably with the theoretical consideration shown in Fig. 2.2.4.

Note that system efficiency is maintained at a constant level throughout the speed/power range. As illustrated, system efficiency values around $60 \%$ are obtained. This represents a loss of approximately $3 \%$ with respect to the original induction motor drive system, which can be attributed to the rewind process. With new stator laminations, the doubly-fed generator is expected to be as efficient as a conventional squirrel cage induction machine system. Overall, considering the voltage and power levels in the proof-of-concept prototype, the laboratory system exhibits satisfactory efficiency performance.

Figure 2.2.6 shows the benefit of reduced converter rating for the brushless doubly-fed system. As illustrated, the electronically processed apparent power is kept below $25 \%$ of total apparent power. Figs. 2.2.7 and 2.2.8 illustrate currents and voltages measured for the Six-pole and two-pole systems. Again, it is evident that only a fraction of total current needs to be processed by the power converter, leading to a significant reduction in size, weight and cost of the power electronic hardware. For optimized machine/converter systems, this feature will also allow for improved efficiency, as power converter loss is minimized. As illustrated in Fig. 2.2.8, the controller does not utilize the full value of the available voltage. Thus, the control winding can be fitted with additional turns to decrease converter current levels even further.

Figure 2.2.9 depicts system quantities at a constant speed $\left(\omega_{\mathrm{r}}=1550 \mathrm{r} / \mathrm{min}, \mathrm{f}_{2}=43.3 \mathrm{~Hz}\right)$ with varying voltage excitation of the two-pole control winding. It is evident that two desirable operating conditions (maximum efficiency and minimum converter rating) coincide with appropriate control. For stability reasons [2.7], the control voltage cannot be lowered beyond a minimum value. An increase in control winding voltage increases machine magnetization through 
the converter. This can be used to generate reactive power from the six-pole power winding in response to a set point $Q^{*}$ (Fig. 2.2.1). However, this reduces system efficiency and leads to an increase in electronically processed apparent power. Thus, the reactive power generation capability of the system is limited and is more pronounced at low wind and shaft speeds, where excess converter capacity is available. The minimization of converter rating in practical systems may require the installation of capacitors to improve reactive power performance.

Sample current waveforms for the experimental system are illustrated in Fig. 2.2.10. The harmonics on the six-pole power winding are caused by the prototype rotor, which does not have skewed bars. Nevertheless, total harmonic distortion in the six-pole current is below $5 \%$. Appropriate rotor skew will improve waveform quality considerably. As expected, converter switching noise is present in the two-pole current waveform. The excellent frequency separation between the two stator winding systems is also evident.

\subsubsection{Conclusions and Recommendations}

The advantages of the BDFM generation system for wind power applications have been illustrated for a low-power prototype system. The BDFM concept allows for the realization of a low cost and robust system, with relatively simple and flexible control. Based on laboratory measurements, the steady state performance is summarized as follows:

(i) The rating of the power converter is approximately $25 \%$ of system kVA rating;

(ii) System efficiency is maximized over a wide speed and power range and is comparable to variable-speed induction generator topologies;

(iii) Waveform quality is excellent.

While the steady-state performance has been verified in the laboratory, dynamic operation under severe wind conditions needs to be investigated, including maintenance of stability and controlled start-up and shut-down. Long term data acquisition for a variety of wind conditions and speeds will be used to determine system reliability as well as investigate improved energy capture due to variable-speed operation.

The laboratory prototype is used to demonstrate the viability of the BDFM VSG concept. Next, a feasibility study for a large scale $(275 \mathrm{~kW})$ system is planned. With support from the BDFM sponsors and possible the National Renewable Energy Laboratory (NREL), it may be possible to design, construct and install a high power BDFM VSG system in the near future. 


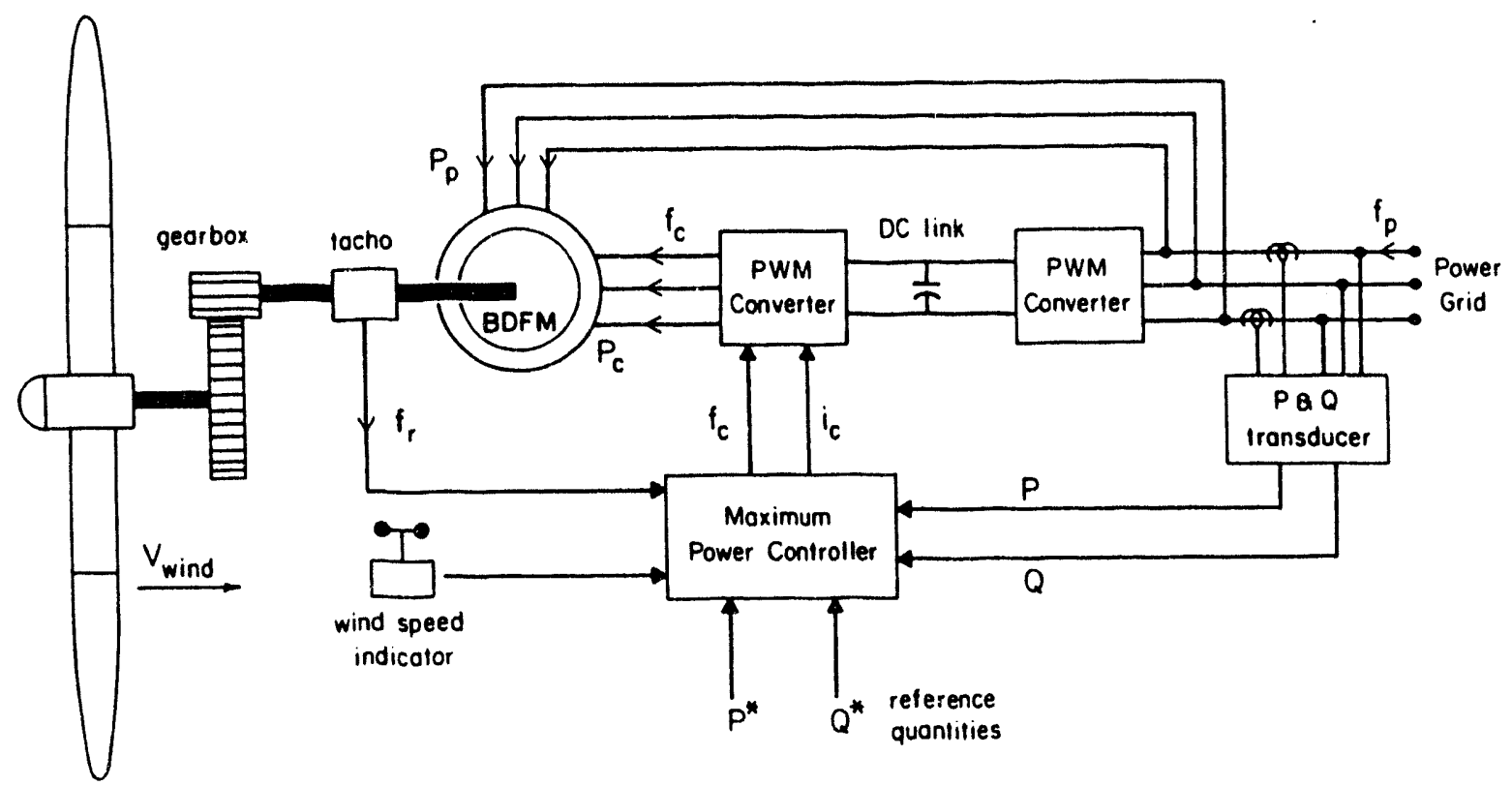

Fig. 2.2.1. BDFM Wind Power Generation System.

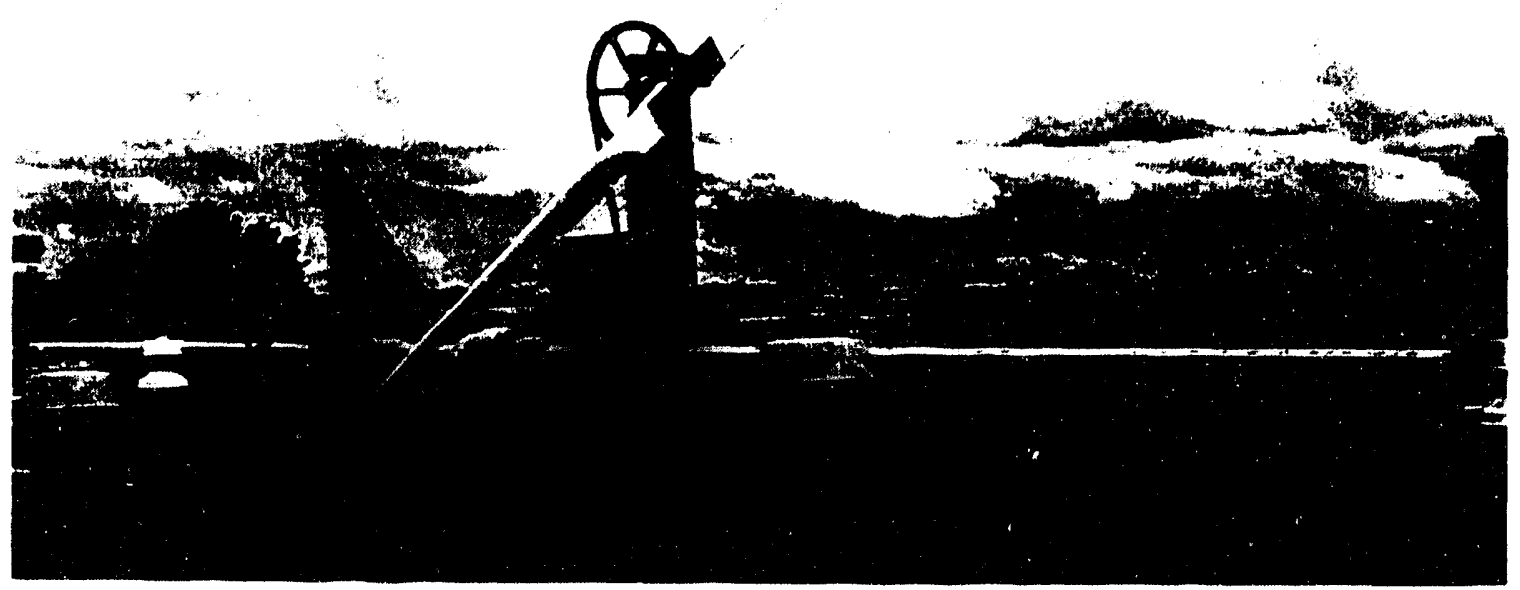

Fig. 2.2.2. Prototype System. 


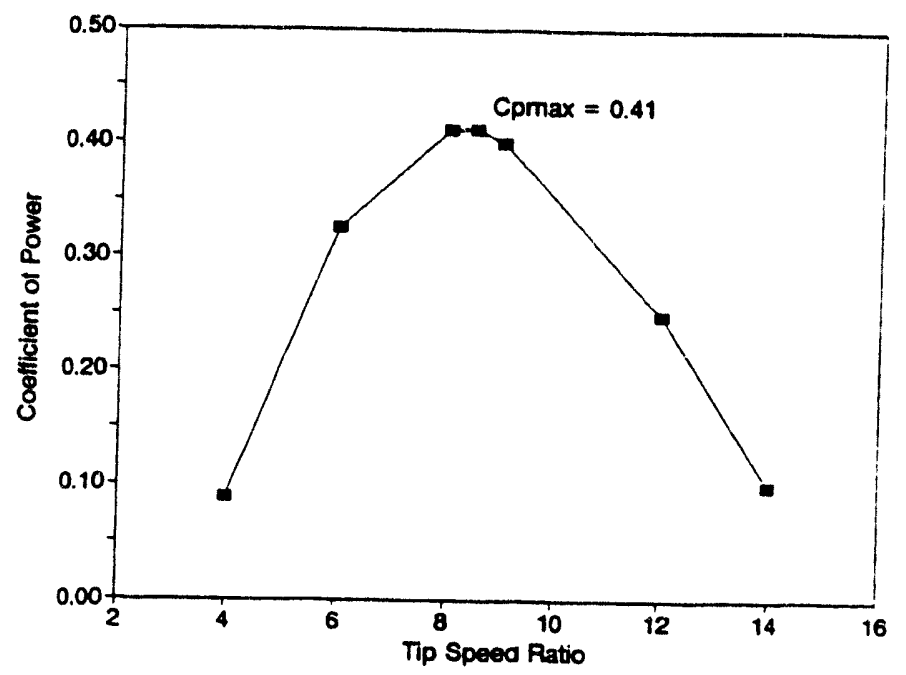

Fig. 2.2.3. Prototype Turbine Coefficient of Power.

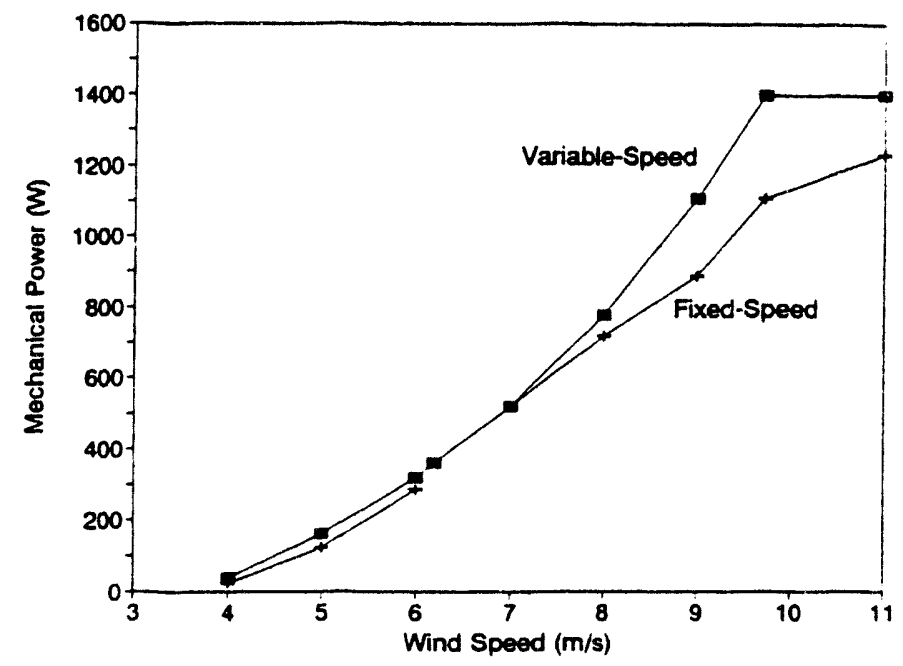

Fig. 2.2.4. Fixed vs. Variable-Speed Power Generation.

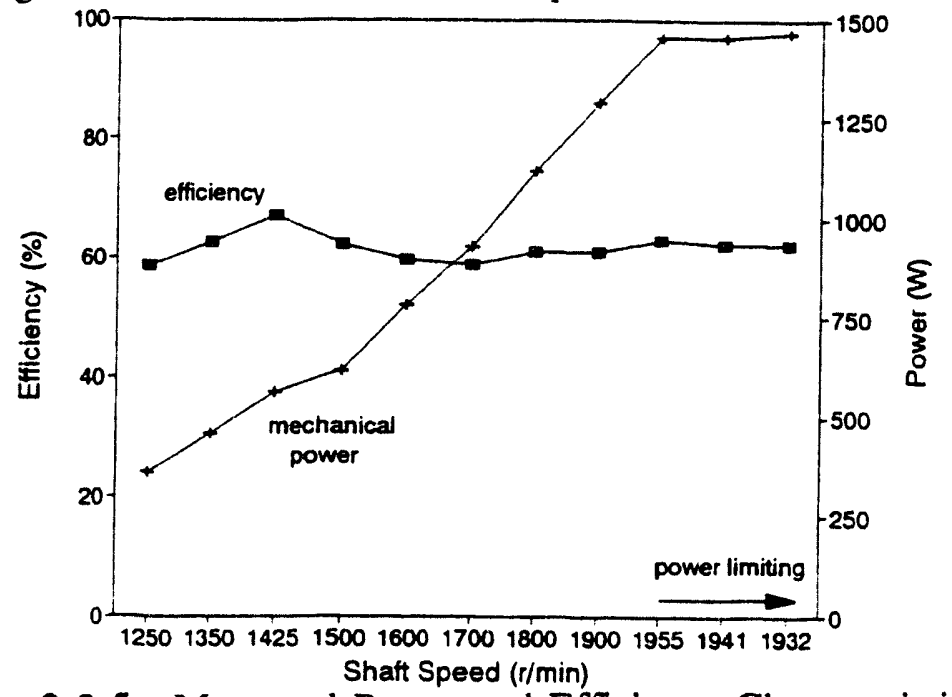

Fig. 2.2.5. Measured Power and Efficiency Characteristics. 


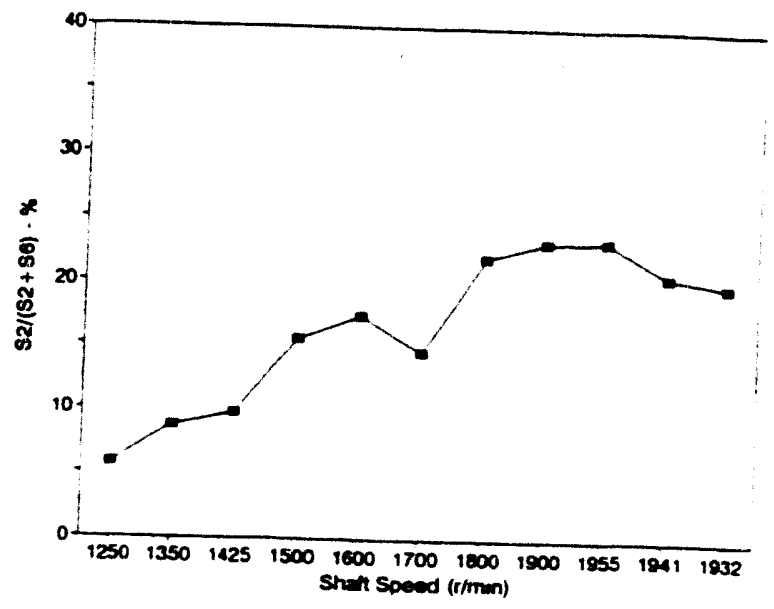

Fig. 2.2.6. Measured Converter Rating.

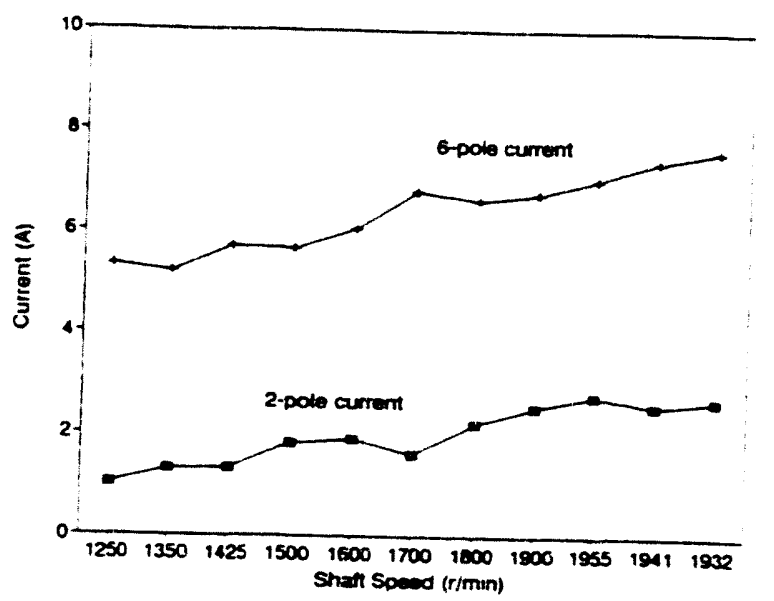

Fig. 2.2.7. Measured Stator Currents.

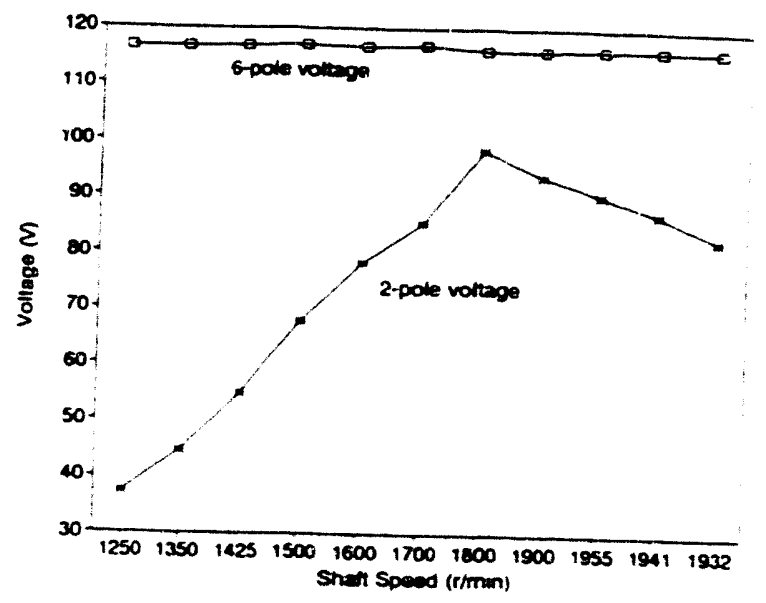

Fig. 2.2.8. Measured Stator Voltages. 


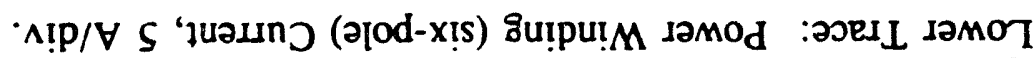

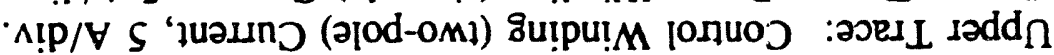

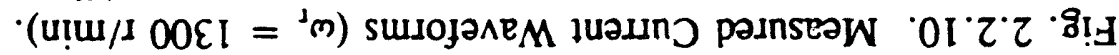

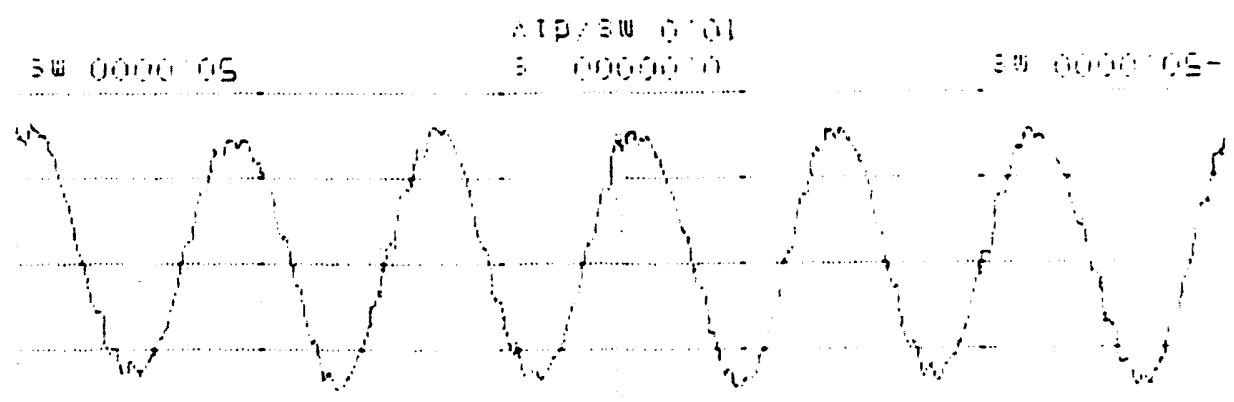

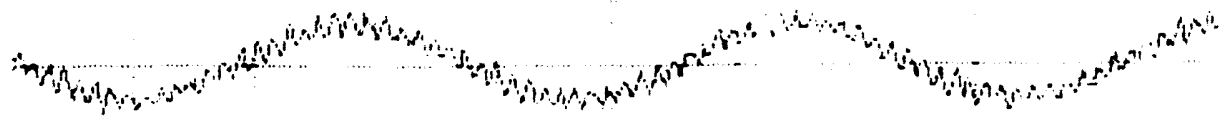

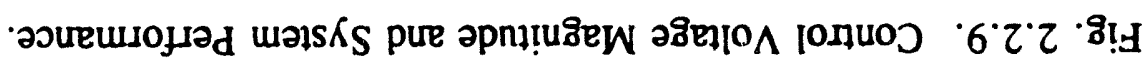

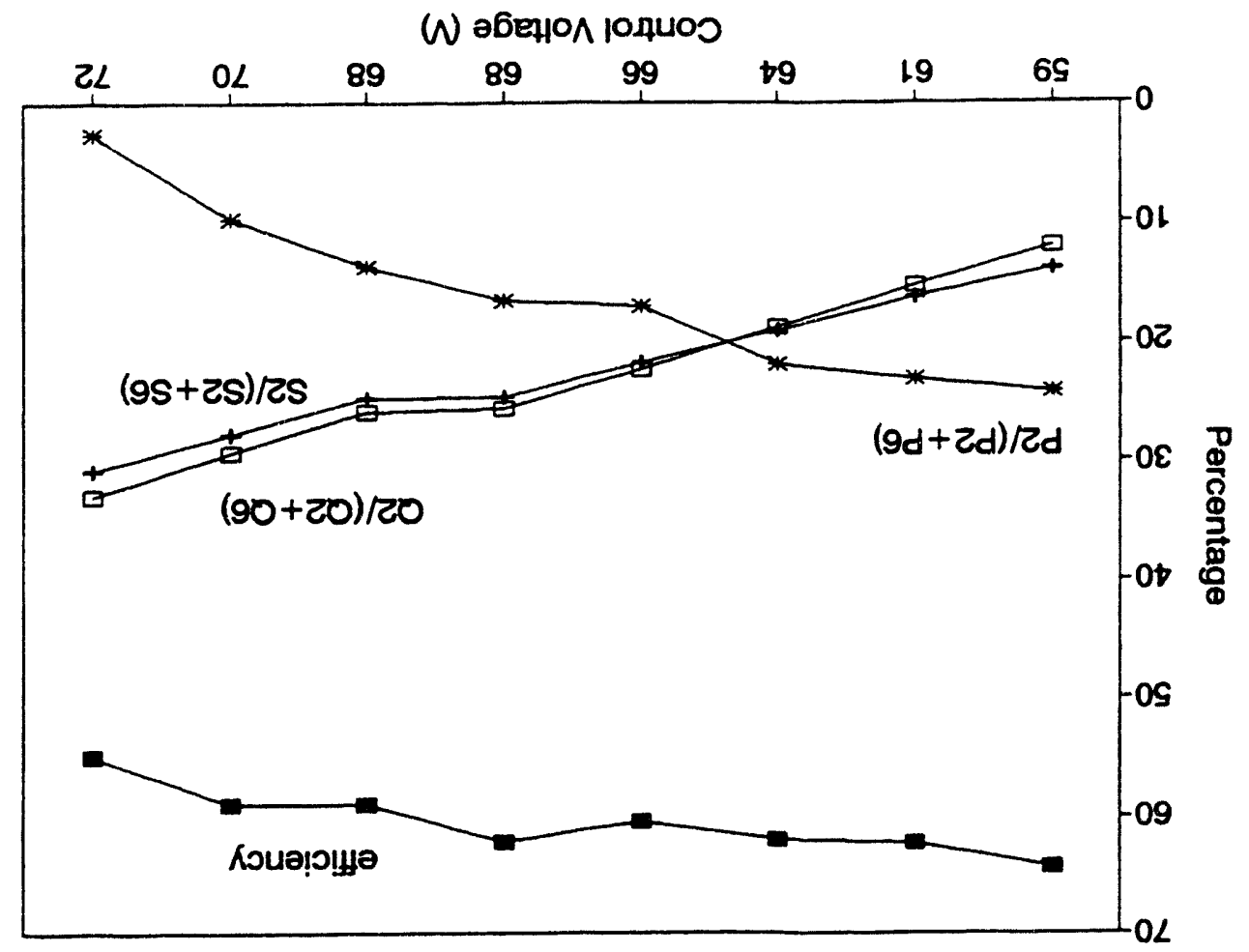




\subsection{References}

[2.1] A.K. Wallace, R. Spée and G.C. Alexander, "The Brushless Doubly-Fed Motor as a Limited-Speed-Range Pump Drive," IEEE International Symposium on Industrial Electronics, pp 33-37, 1993.

[2.2] J. Douglas, "Renewables on the Rise," EPRI Journal, June 1991.

[2.3] Brian Thomas, Puget Sound Power and Light, Private Communication, 1992.

[2.4] R.D. Richardson and W.L. Erdman, "Variable Speed Wind Turbine," U.S. Patent No. 5,083,039, Jan. 21, 1992.

[2.5] M. Yamamoto and O. Motoyoshi, "Active and Reactive Power Control for Doubly-Fed Wound Rotor Induction Generator," IEEE Transactions on Power Electronics, Vol. 6, No. 4, pp 624-629, Oct. 1991.

[2.6] H.K. Lauw, J.B. Klaassens, N.G. Butler and D.B. Seeley, "Variable-Speed Generation With the Series-Resonant Converter," IEEE Transactions on Energy Conversion, Vol. 3, pp 755-764, 1988.

[2.7] R. Li, A.K. Wallace and R. Spée, "Determination of Converter Control Algorithms for Stable Brushless Doubly-Fed Machines," IEEE PESC Conference Record, pp 571-577, 1991.

[2.8] R. Li, R. Spée, A.K. Wallace and G.C. Alexander, "Synchronous Drive Performance of Brushless Doubly-Fed Motors," IEEE LAS Annual Meeting Conference Record, pp 631-638, 1992. 


\section{CONTROLLER DESIGN}

The investigation of controller design and implementation for BDFM drive systems is continuing. This addresses parameter identification techniques as well as on-line control methods. This chapter gives an overview over progress made during Phase 3. The investigations are continuing and further results on control development will be reported in the Phase 4 report.

Since only one set of stator quantities in the BDFM is directly controllable, conventional induction motor drive control techniques are not directly transferable to the doubly-fed case. Thus, the emphasis during Phase 3 has been on the development of a direct torque control algorithm which controls the control winding voltage directly based on torque and flux error. While the resulting system, as shown here, promises to yield very good dynamic performance, the implementation is relatively complex. Presently, development efforts are underway attempting an extension of induction motor field-oriented control to the BDFM. This will be reported on in the Phase 4 report.

\subsection{Direct Torque Control}

Previous work, as discussed in the Phase 2 report and Ref. [3.1] has illustrated BDFM control algorithms based on constant $\mathrm{V} / \mathrm{Hz}$ schemes known from conventional induction motor drives. However, while this strategy assures open-loop stable operation of the doubly-fed drive, the dynamic response is poor and steady-state performance is at times far from optimum. This motivates the development of a closed-loop torque and flux control scheme in order to achieve competitive drive performance.

Traditional methods of torque control in induction machines (IM) utilize a controlled current source and field orientation principles to determine the appropriate stator current reference which achieves torque and flux control. This type of control may not be readily adaptable to the BDFM since the six-pole voltages and currents are not directly controllable. (However, efforts are currently underway to develop a field oriented control scheme for the BDFM.) Alternatively, sliding mode schemes such as Direct Self Control [3.2, 3.3] as well as those presented in [3.4] and [3.5], determine the inverter switching state directly from the torque and flux error; that is, without an inner current regulation loop. Existing sliding mode schemes are typically based on the fact that each of the inverter voltage vectors is known without calculation or knowledge of machine parameters to increase or decrease the torque and flux. Therefore, a hysteresis, or 
sliding mode control based on the torque and flux error can be easily formulated.

The direct formulation of a sliding surface to determine the inverter state, based only on the torque and flux error, is not available in the BDFM since the voltage vectors which drive the torque and flux in the correct direction are not explicitly known (nor can they be predicted) without calculating the actual torque and flux which results from a particular inverter voltage vector. This is due to the fact that the torque and flux depend on both controlled (two-pole) and uncontrolled (six-pole) quantities. Therefore, a predictive method which calculates an estimate of the change in flux and torque for a given set of inputs is appropriate. One such predictive, direct torque control scheme was presented in [3.6], for control of squirrel cage IM. In the steady-state, this scheme calculates the value of stator voltage which results in the desired change in torque and flux.

Here, a similar approach is used for the BDFM. With the doubly-fed machine, the two-pole voltage is calculated which results in the desired changes in torque and flux. The predictive calculations use measured terminal quantities, rotor speed and position, and machine parameters. Space vector PWM can be used to determine the inverter switching function, resulting in a constant switching frequency. Alternatively, a resonant converter in the voltage mode can be appropriately controlled. Control update or switching frequency needs to be kept at around $1 \mathrm{kHz}$ to ensure feasibility of real time implementation using a Digital Signal Processing (DSP) System.

\subsubsection{Determination of Motor Quantities}

Figure 3.1.1 shows the equivalent circuit of the six-pole/two-pole BDFM upon which the regulator design is based. The machine equations in the rotor reference frame have been derived in the previous reports and in Ref. [3.7] as (zero quantities neglected): 


$$
\left[\begin{array}{c}
v_{q 6}^{r} \\
v_{d 6}^{r} \\
v_{q 2}^{r} \\
v_{d 2}^{r} \\
v_{q r}^{r} \\
v_{d r}^{r}
\end{array}\right]=\left[\begin{array}{cccccc}
r_{6}+L_{s 6} p & 3 L_{s 6} \omega_{r} & 0 & 0 & M_{6} p & 3 M_{6} \omega_{r} \\
-3 L_{s 6} \omega_{r} & r_{6}+L_{s 6} p & 0 & 0 & -3 M_{6} \omega_{r} & M_{6} p \\
0 & 0 & r_{2}+L_{s 2} p & L_{s 2} \omega_{r} & -M_{2} p & M_{2} \omega_{r} \\
0 & 0 & -L_{s 2} \omega_{r} & r_{2}+L_{s 2} p & M_{2} \omega_{r} & M_{2} p \\
M_{6} p & 0 & -M_{2} p & 0 & r_{r}+L_{s} p & 0 \\
0 & M_{6} p & 0 & M_{2} p & 0 & r_{r}+L_{r} p
\end{array}\right]\left[\begin{array}{c}
i_{q 6}^{r} \\
i_{d 6}^{r} \\
i_{q 2}^{r} \\
i_{d 2}^{r} \\
i_{q r}^{r} \\
i_{d r}^{r}
\end{array}\right]
$$

with

$$
\left[\begin{array}{c}
\lambda_{q 6}^{r} \\
\lambda_{d 6}^{r} \\
\lambda_{q 2}^{r} \\
\lambda_{d 2}^{r}
\end{array}\right]=\left[\begin{array}{cccccc}
\mathrm{L}_{s 6} & 0 & 0 & 0 & \mathrm{M}_{6} & 0 \\
0 & \mathrm{~L}_{s 6} & 0 & 0 & 0 & \mathrm{M}_{6} \\
0 & 0 & \mathrm{~L}_{s 2} & 0 & -\mathrm{M}_{2} & 0 \\
0 & 0 & 0 & \mathrm{~L}_{s 2} & 0 & \mathrm{M}_{2}
\end{array}\right]\left[\begin{array}{c}
\mathrm{i}_{q 6}^{r} \\
\mathrm{i}_{d 6}^{r} \\
\mathrm{i}_{q 2}^{r} \\
\mathrm{i}_{d 2}^{r} \\
\mathrm{i}_{q r}^{r} \\
\mathrm{i}_{d r}^{r}
\end{array}\right]
$$

It can be shown that electromagnetic torque is expressed as:

$$
T_{c}=T_{c 6}+T_{e 2}=3\left(i_{q 6}^{r} \lambda_{d 6}^{r}-i_{d 6}^{r} \lambda_{q 6}^{r}\right)+\left(i_{q 2}^{r} \lambda_{d 2}^{r}-i_{d 2}^{r} \lambda_{q 2}^{r}\right)
$$

with a derivative of

$$
\begin{aligned}
\dot{\mathrm{T}}_{c} & =3\left(\mathrm{i}_{q 6}^{r} \dot{\lambda}_{d 6}^{r}+\mathrm{i}_{q 6}^{r} \lambda_{d 6}^{r}-\mathrm{i}_{d 6}^{r} \dot{\lambda}_{q 6}^{r}-\dot{i}_{d 6}^{r} \lambda_{q 6}^{r}\right) \\
& +\left(\dot{i}_{q 2}^{r} \dot{\lambda}_{d 2}^{r}+\dot{i}_{q 2}^{r} \lambda_{d 2}^{r}-i_{d 2}^{r} \dot{\lambda}_{q 2}^{r}-\dot{i}_{d 2}^{r} \lambda_{q 2}^{r}\right)
\end{aligned}
$$

If a dead-beat algorithm is to be implemented, the torque controller can be designed to establish an appropriate converter voltage reference to yield a desired torque derivative $\mathrm{dT}_{\mathrm{e}} / \mathrm{dt} \approx \Delta \mathrm{T}_{\mathrm{e}} / \mathrm{T}_{\mathrm{s}}$ within one controller update period, $T_{3}$. 
The determination of the appropriate machine quantities for the torque control algorithm relies on measurements of terminal currents and voltages as well as machine speed. In the controller implementation pursued, shaft speed is also used to generate the torque reference. Unlike a conventional IM, where stationary frame controllers are appropriate, the BDFM requires control development in the rotor reference. Thus, in addition to requiring more information than an equivalent IM controller, the BDFM torque control process involves reference frame transformations between stationary and rotor frames. Consequently, measurement procedures and signal processor software require careful implementation.

3.1.1.1. Flux Linkages. Before transformation to the rotor reference frame, flux linkage information is determined in the stationary frame using voltage measurements:

$$
\begin{gathered}
\bar{\lambda}_{s}=\int\left(\bar{V}_{s}-\bar{I}_{s} \bar{R}_{s}\right) d t \\
\text { where } \bar{R}_{s}=\operatorname{diag}\left(r_{6}, r_{6}, r_{2}, r_{2}\right) .
\end{gathered}
$$

The six-pole terminals are directly connected to the $60 \mathrm{~Hz}, 230 \mathrm{~V}$ utility grid. Consequently, stator $\mathrm{I}_{6} \mathrm{R}_{6}$ drop can be neglected and since six-pole voltage and flux are maintained at rated levels, measurement demands are greatly reduced. Above a few $\mathrm{Hz}$, stator $\mathrm{I}_{2} \mathrm{R}_{2}$ drop also becomes insignificant. However, a linear correction term is ultimately added to the final converter voltage signals.

3.1.1.2. Currents. Terminal currents are taken directly from the $A / D$ converters and transformed to the rotor reference frame. As in the direct controller for a conventional IM, current derivatives are difficult to determine.

It is possible to estimate change in current by using an equivalent voltage behind transient reactance representation for the six-pole and two-pole windings. In this case and neglecting IR drops,

$$
\Delta \overline{\mathrm{I}}_{\mathrm{s}}=\left[\mathrm{L}_{\mathrm{s}}\right]^{-1}(\overline{\mathrm{V}}-\overline{\mathrm{E}}) \mathrm{T},
$$

where $\left[L_{s}^{\prime}\right]=\operatorname{diag}\left(L_{s 6}^{\prime}, L_{s 6}^{\prime}, L_{s 2}^{\prime}, L_{s 2}^{\prime}\right)$ and assuming sinusoidal variations, is expressed as: 


$$
\begin{aligned}
& \bar{E}_{6}=j \omega_{\infty 6}\left(\bar{\lambda}_{6}-L_{26}^{\prime} \bar{I}_{6}\right) \\
& \bar{E}_{2}=j \omega_{e 2}\left(\bar{\lambda}_{2}-L_{s 2}^{\prime} \bar{I}_{2}\right)
\end{aligned}
$$

Transformation of Egns. (3-6) and (3-7) to the rotor reference frame will introduce speed voltage terms. While this method avoids the use of rotor parameters and potentially utilizes relatively few computational resources, it requires the solution of a quadratic Eqn. (3-6). It was also found for the case of the BDFM that this method leads to degraded transient performance for all but slow dynamic changes.

It is also possible to estimate current derivatives from the differential equations. Expressing rotor currents as

$$
\bar{I}_{r}^{r}=\frac{1}{M_{6}}\left(\bar{\lambda}_{6}^{r}-L_{36} \bar{I}_{6}^{r}\right)
$$

and substituting into Eqn. (3-1) yields an expression for stator current derivatives as a function of converter voltages. The expressions take on the form

$$
\begin{aligned}
& \mathrm{i}_{q 6}^{r}=\alpha_{1}-k_{1} V_{q 2}^{r} \\
& i_{d 6}^{r}=\alpha_{2}-k_{2} V_{d 2}^{r} \\
& i_{q 2}^{r}=\alpha_{3}-k_{3} V_{q 2}^{r} \\
& i_{d 2}^{r}=\alpha_{4}-k_{4} V_{d 2}^{r}
\end{aligned}
$$

where the $\alpha_{i}$ are functions of parameters and terminal quantities, while the $k_{i}$ are expressions relating machine parameters alone. However, this method requires knowledge of machine parameters and, as in conventional IM, rotor resistance and leakage are difficult to establish (see also section 3.4 on a discussion of parameter identification techniques.)

3.1.1.3. Step-Ahead Predictor. The control algorithm is based on measurements at time 4 and the new converter voltages are calculated during the ensuing controller update interval, $T_{3}$, to be applied at $t_{k+1}=t_{k}+T_{3}$. Since the controller is based on a $1 \mathrm{kHz}$ update frequency, the error introduced can be significant, especially for the $60 \mathrm{~Hz}$ quantities on the six-pole winding. The delay of one switching period can cause steady-state error in flux and torque. However, the outer speed loop serves to eliminate steady state error. 
Since parameters are already provided for current derivative estimation, a step-ahead predictor is also implemented. Thus, before estimated quantities are used in the controller algorithm, they are extrapolated using a one-step ahead predictor based on measured quantities and machine parameters.

\subsubsection{Controller Design}

Once the motor quantities are determined, torque and flux error can be used to establish desired rates of change which in turn determine the new converter voltage reference. Substituting into Eqn. (3-4) and simplifying yields a linear relationship between desired rate of change of electrical torque and two-pole converter voltages.

$$
T_{c}^{*}=\beta_{1} V_{q 2}^{\prime}+\beta_{2} V_{q 2}^{\prime}+\beta_{3}
$$

where the $\beta_{i}$ are functions of machine parameters and terminal quantities.

At this point it is necessary to define a second constraining condition in order to assure a unique solution for $V_{q 2}^{r}$ and $V_{d 2}^{r}$. The additional equation is based on the two-pole flux level rate of change. Nominally, at steady state the flux derivative is zero; a slow outer control loop uses this quantity to search for an appropriate excitation level maximizing a steady state performance quantity, such as efficiency.

The two pole flux level in the BDFM is expressed as:

$$
\lambda_{2}^{\prime}=\sqrt{\lambda_{q 2}^{\prime 2}+\lambda_{\alpha 2}^{2}}
$$

Squaring and differentiating yields

$$
\lambda_{q 2}^{r} \dot{\lambda}_{q 2}^{r}+\lambda_{d 2}^{r} \dot{\lambda}_{d 2}^{r}=\lambda_{2}^{r} \dot{\lambda}_{2}^{\prime}=\dot{\lambda}_{2}^{r} \sqrt{\lambda_{q 2}^{r}+\lambda_{d 2}^{r}}
$$

Including IR drop, the rotor frame two-pole flux expressions are

$$
\begin{aligned}
& \dot{\lambda}_{q 2}^{r}=V_{q 2}^{r}-\omega_{r} \lambda_{d 2}^{r}-i_{q 2}^{r} r_{2} \\
& \dot{\lambda}_{d 2}^{r}=V_{d 2}^{r}-\omega_{r} \lambda_{q 2}^{r}-i_{d 2}^{r} r_{2}
\end{aligned}
$$

Substituting these expressions into Eqn. (3-12) and simplifying yields a second linear relationship for $\mathrm{V}_{\mathrm{q} 2}^{\mathrm{f}}$ and $\mathrm{V}_{\mathrm{d} 2}^{\mathrm{r}}$ based on commanded flux derivative 


$$
\dot{\lambda}_{2}^{\prime *}=\gamma_{1} V_{q 2}^{\prime}+\gamma_{2} V_{d 2}^{\prime}+\gamma_{3}
$$

Combining and solving Eqns. (3-10) and (3-14) leads to the controller equation

$$
\left[\begin{array}{l}
V_{q 2}^{\prime} \\
V_{\alpha 2}^{\prime}
\end{array}\right]=\frac{1}{\beta_{1} \gamma_{2}-\beta_{2} \gamma_{1}}\left[\begin{array}{cc}
\gamma_{2} & -\beta_{2} \\
-\gamma_{1} & \beta_{1}
\end{array}\right]\left[\begin{array}{ll}
t_{c}^{\cdot} & -\beta_{3} \\
\dot{\lambda}_{2}^{\prime} & -\gamma_{3}
\end{array}\right]
$$

Eqn. (3-15) will always provide a unique solution for $V_{q 2}^{\prime}$ and $V_{d 2}$ as long as the matrix is nonsingular. Transients may cause matrix singularities and an error trap routine then solves for a converter output which maximizes the torque derivative in order to reestablish steady state.

Since $t_{c}$ and $\lambda_{2}$ can be directly controlled, a dead-beat type of controller can be used for torque and flux regulation, bringing error to zero within one switching period. While the control equations have been simplified to a second order linear system, the number of measurements and calculations can introduce significant error. Simulation results have shown that at least for the torque loop, a sliding mode algorithm is preferable to the dead-beat structure for improved robustness.

Before implementing variable structure control, however, the direct control is verified using relatively simple PI regulator lops. The resulting system is shown in Fig. 3.1.2. Once speed error has been computed, torque error is determined in an integrator loop essentially representing rotor inertia. Flux control also is achieved through a PI-regulator. The structure of the control system as illustrated, while not representing the optimum in terms of dynamic response, is more forgiving to steady state errors. A more detailed discussion of controller design can be found in Ref. [3.8].

\subsubsection{Simulation Results}

The control system developed has been implemented in the dynamic simulator program (see section 5.3), using the parameters of the experimental, $5 \mathrm{hp}$ laboratory prototype as listed in section 3.3 .

In the inherently stable region of the BDFM [3.1], a simple feedback loop for the $\mathrm{V} / \mathrm{Hz}$ controller can also serve to achieve good steady-state performance. However, the machine is very sensitive to mechanical disturbances. Coupling between torque and flux producing quantities leads 
to oscillatory system response.

The graphs shown in Figs. 3.1.3 and 3.1.4 compare open- and closed-loop performance for a relatively small step change in low.l torque, a decrease by $1 \mathrm{Nm}$. While the open-loop system is.stable, the oscillatory nature of the response is evident, as is the torque-flux interaction. A larger disturbance will cause the machine to lose synchronism in the open-loop mode. In comparison, the closed-loop system shows good nerformance with fast settling of the speed disturbance and only a slight effect on the two-pole flux level.

Figures 3.1.5 and 3.1.6 illustrate drive performance for a step change in commanded speed at constant load torque. In the open-loop system, the two-pole frequency is stepped from $20 \mathrm{~Hz}$ to $13.3 \mathrm{~Hz}$, with an accompanying change in voltage according to a constant $\mathrm{V} / \mathrm{Hz}$ characteristic. The step input leads to an instability much like in an open-loop induction motor drive. Control over the two-pole is lost and the machine falls out of synchronism. Speed returns to an equivalent high-slip six-pole value and both speed and flux curves illustrate that two-pole excitation is now merely oscillating on the six-pole quantities without desirable contribution.

The closed-loop response is well behaved as shown in Fig. 3.1.6. Note that the ramp on the machine speed is caused by a converter current limiter. As the controller attempts to reach the new commanded speed, a very large torque rate of change is commanded with the resulting high two-pole current levels, which cause the limiting action. Note that the illustrated response is for a constant two-pole flux level. The "decoupling" between torque and flux quantities is evident from the flux response, which is only slightly disturbed by the torque transient.

\subsubsection{Control Robustness}

As the controller uses machine parameters in the prediction process, robustness issues relating to parameter accuracy need to be addressed. This is especially true for parameters which can change during normal operation, such as rotor resistance. Based on simulation results using the dynamic simulator, Table 3.1 summarizes the allowable range of some parameters for successful operation. A complete analysis of robustness can be found in Ref. [3.8]. 
TABLE 3.1. Allowable Parameter Errors for Prediction.

\begin{tabular}{|c|c|c|c|}
\hline Parameter & Symbol & $\begin{array}{c}\text { Positive Error } \\
\text { Range }\end{array}$ & $\begin{array}{c}\text { Negative Error } \\
\text { Range }\end{array}$ \\
\hline Rotor Resistance & $\mathrm{r}_{\mathrm{f}}$ & $15 \%$ & $60 \%$ \\
\hline Rotor Inductance & $\mathrm{L}_{\mathrm{r}}$ & $23 \%$ & $3 \%$ \\
\hline $\begin{array}{c}\text { Six-Pole to Rotor Mutual } \\
\text { Inductance }\end{array}$ & $\mathrm{M}_{6}$ & $2 \%$ & $23 \%$ \\
\hline
\end{tabular}

\subsubsection{Conclusions}

A closed-loop torque and flux control strategy for BDFM drives has been developed. The controller utilizes a predictive method which estimates the required change of flux and torque for a given set of input values.

Simulation results for a prototype torque controller illustrate improved system performance over $\mathrm{V} / \mathrm{Hz}$ converter control. Torque and flux responses in the controlled case are "decoupled" and fast response and settling characteristics are achieved. The predictive controller is much more robust to load disturbances than the $\mathrm{V} / \mathrm{Hz}$ scheme and allows for faster speed response.

Further optimization of the direct torque controller is discussed in section 3.2. Experimental verification hardware is presented in section 3.3. A control scheme based on more traditional field orientation principles is currently under investigation. This will be presented in the Phase 4 report. 

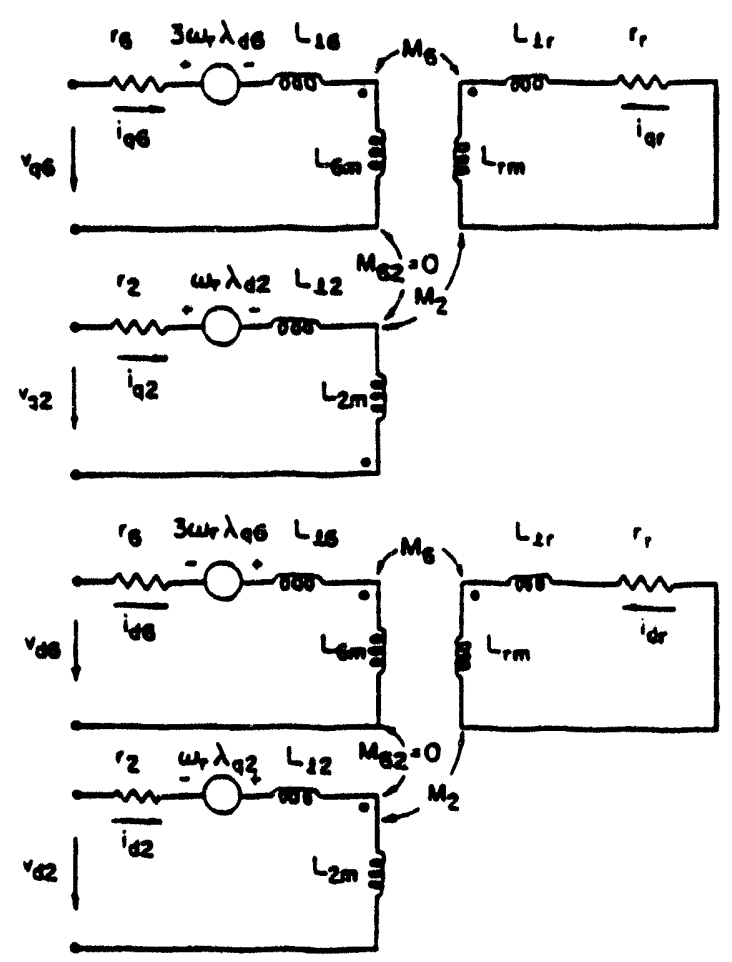

Fig. 3.1.1. BDFM Two-Axis Equivalent Circuit.

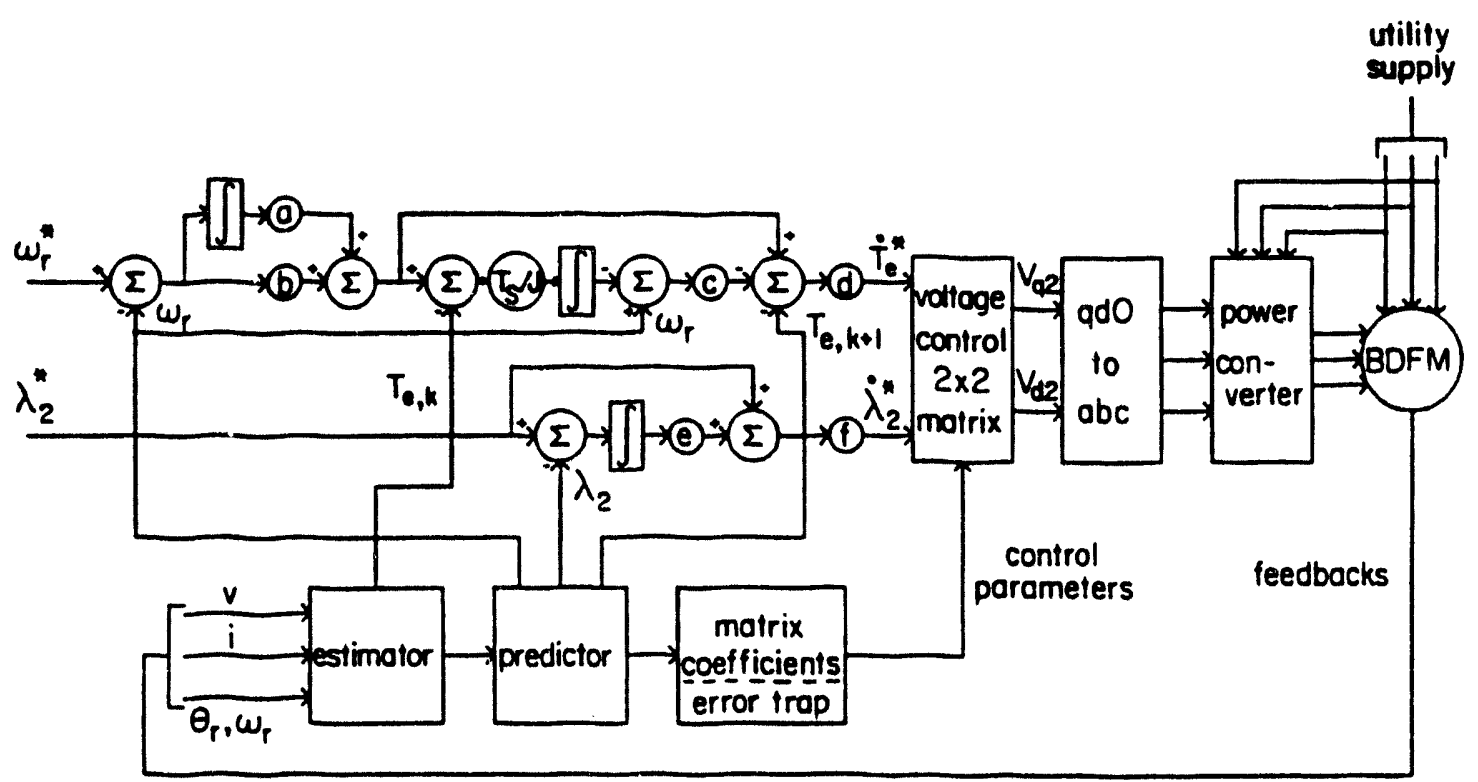

Fig. 3.1.2. Controller Block Diagram. 

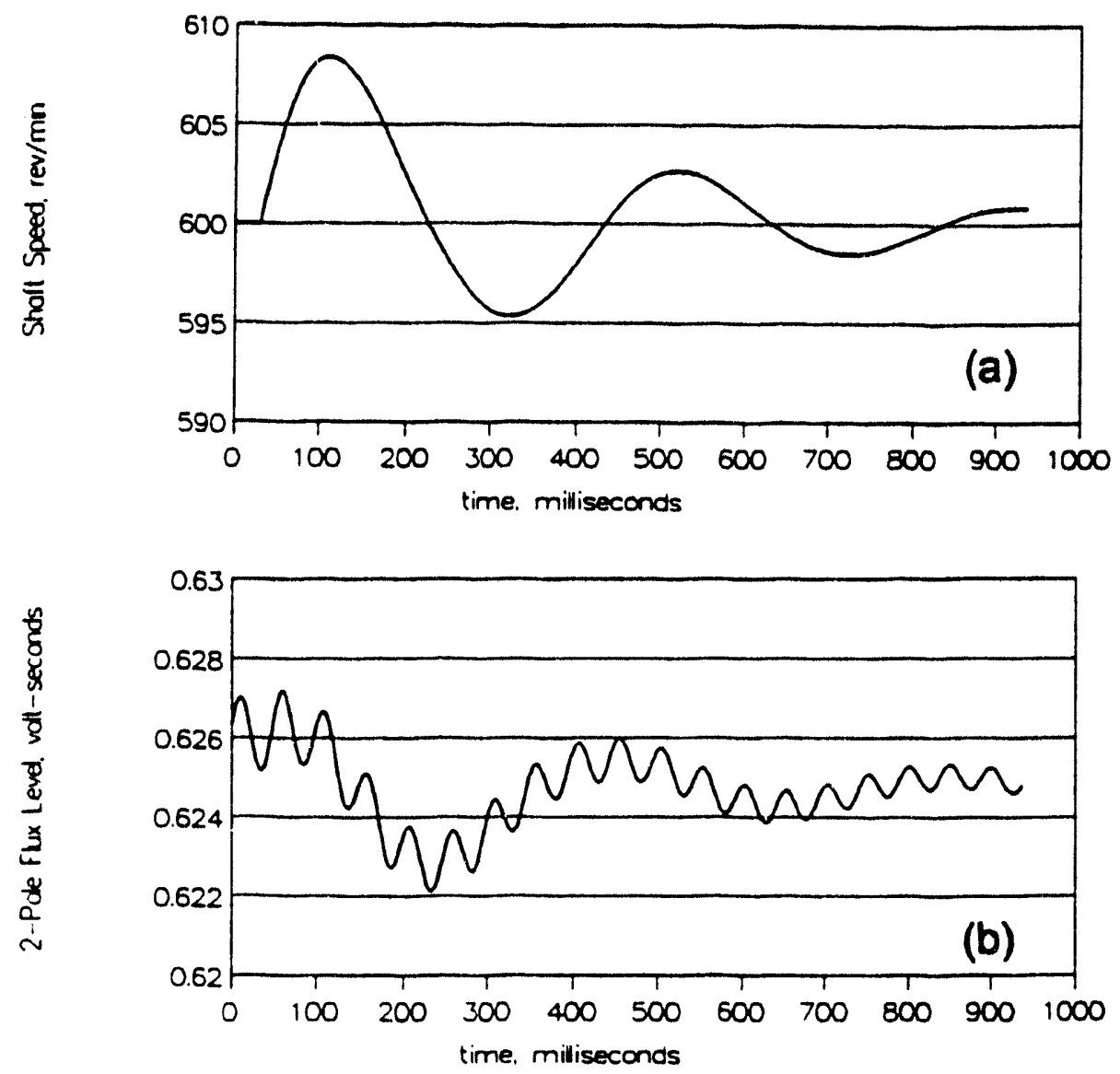

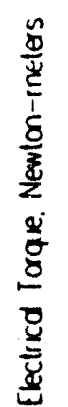

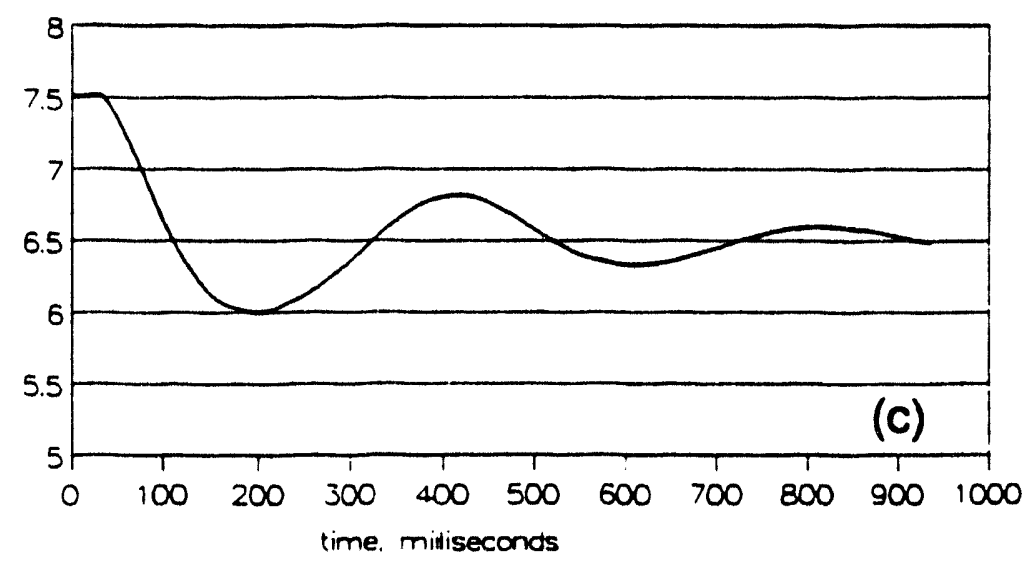

Fig. 3.1.3. Open-Loop Response to Load Torque Disturbance (1 Nm step decrease). (a) shaft speed; (b) two-pole flux; (c) electrical torque. 

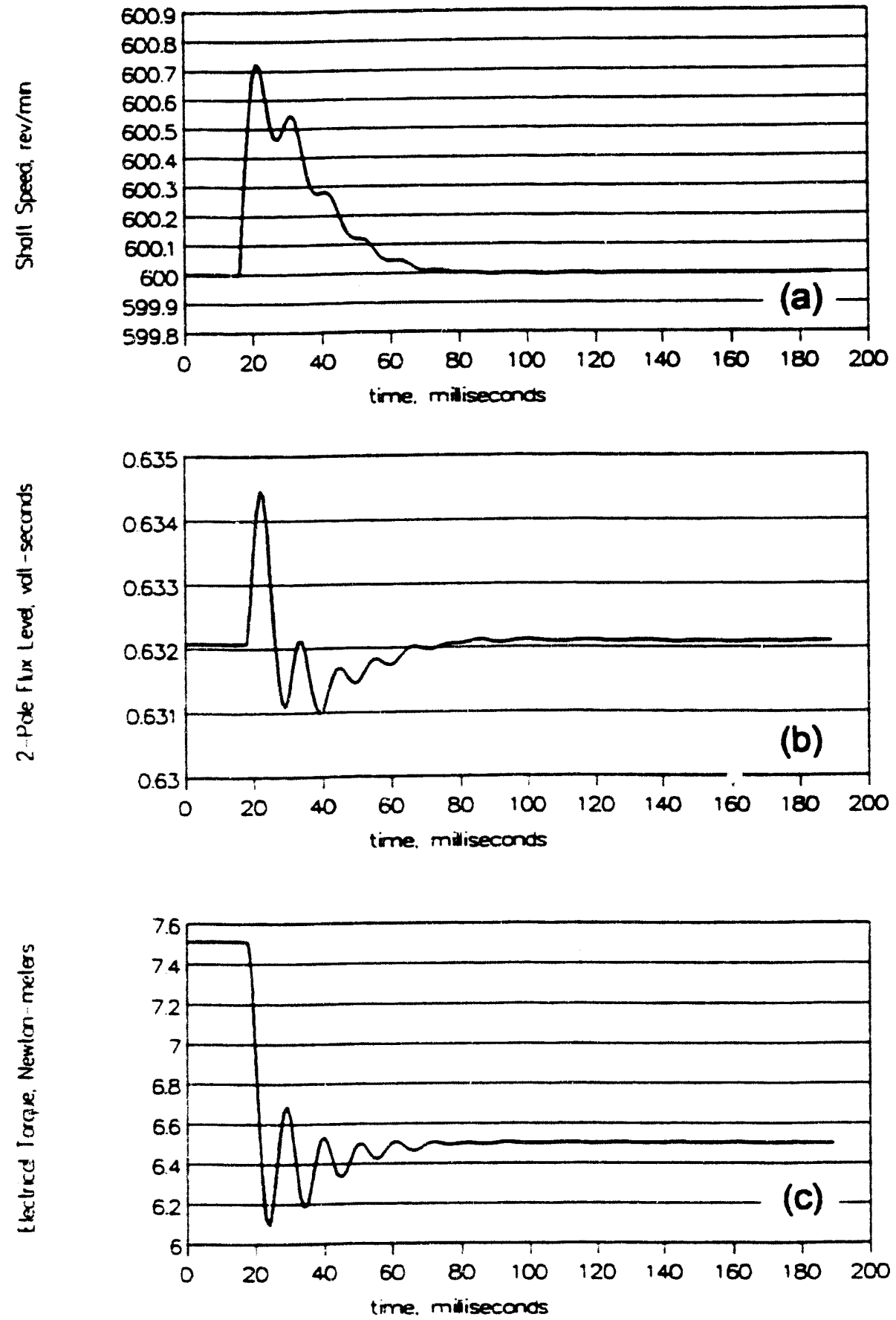

Fig. 3.1.4. Closed-Loop Response to Load Torque Disturbance (1 Nm step decrease). (a) shaft speed; (b) two-pole flux; (c) electrical torque. 

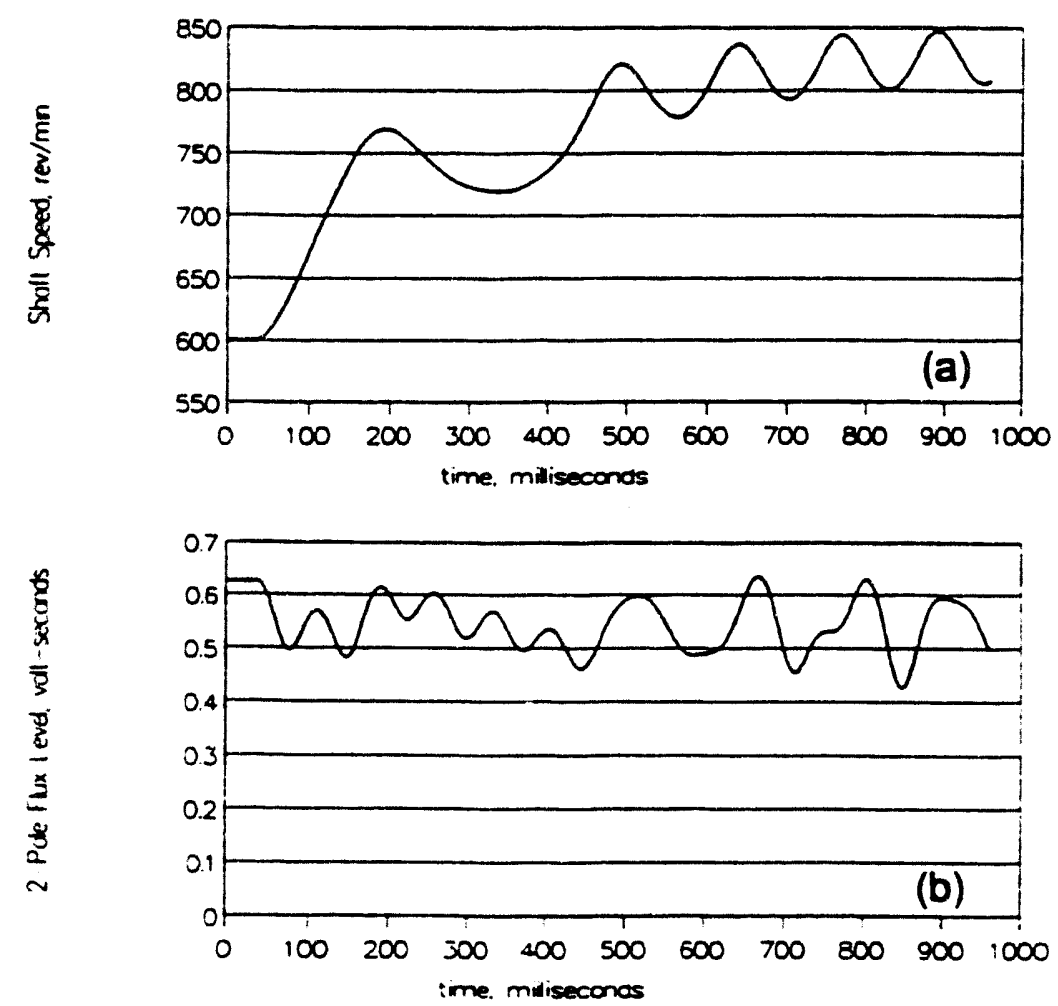

Fig. 3.1.5. Open-Loop Response to Step Change in Speed Command (+ $100 \mathrm{r} / \mathrm{min})$. (a) shaft speed; (b) two-pole flux level.
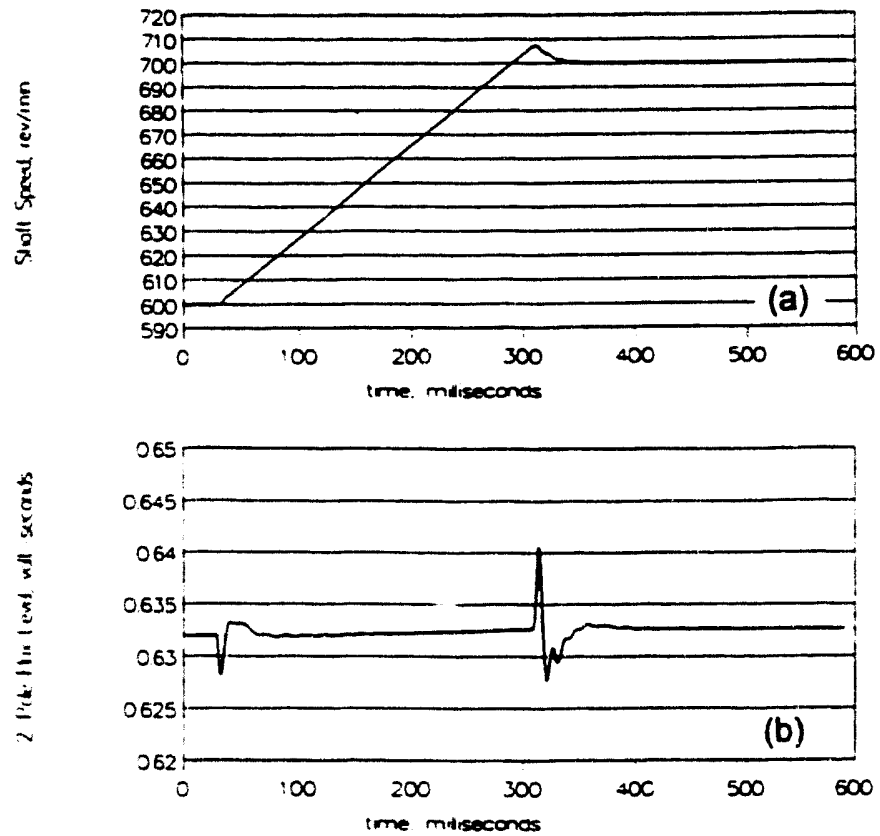

Fig. 3.1.6. Closed-Loop Response to Step Change in Speed Command (+ $100 \mathrm{r} / \mathrm{min})$. (a) shaft speed; (b) two-pole flux level. 


\subsection{Model Reference Control}

This section discusses the improvement of the direct torque controller described in chapter 3.2 by providing for a model reference adaptive control (MRAC) regulator in the speed loop. As with conventional motor drives $[3.9,3.10]$, the goals are improved response and robust control performance. The work described in this section investigates the application of a model reference adaptive speed loop to improve mechanical system robustness and eliminate the over and undershoots associated with the PI-regulator in the speed loop of Fig. 3.1.2 (section 3.1).

\subsubsection{Model Reference Adaptive Control Development}

The block diagram for the model reference adaptive controller (MRAC) is shown in Fig. 3.2.1 [3.11]. Assuming that all electrical transients in the BDFM under direct torque control are much faster than the mechanical speed transient, the BDFM system can be represented by a first order speed state space equation

$$
\frac{d \omega_{r}}{d t}=A_{p} \omega_{r}+B_{p} \Delta \omega_{r}
$$

where $\Delta \omega_{r}^{*}$ is the command input to the BDFM plant system. $A_{p}$ and $B_{p}$ are coefficients which may vary with load and environmental situations.

The reference model chosen as

$$
\frac{d \omega_{m}}{d t}=A_{m} \omega_{r m}+B_{m} \omega_{r}
$$

where $\omega_{m}$ is the model output. $A_{m}$ and $B_{m}$ are coefficients which can be adjusted to achieve desired system performance as the system output will follow the reference model output in this case [3.12].

The block diagram shows the system error as

$$
\mathrm{e}=\omega_{\mathrm{r}}-\omega_{\mathrm{m}}
$$

and the input to the BDFM plant is 


$$
\Delta \omega_{r}^{*}=K_{r} \omega_{r}^{*}-K_{b} \omega_{r}
$$

Taking the derivative with respect to time in Eqn. (3-19) and with Eqns. (3-17) and (3-18) yields

$$
\frac{d e}{d t}=\frac{d \omega_{r}}{d t}-\frac{d \omega_{r m}}{d t}=A_{m} e+\left(A_{p}-A_{m}-B_{p} K_{b}\right) \omega_{r}+\left(B_{p} K_{f}-B_{m}\right) \omega_{r}^{*}
$$

In order to derive the adaptive mechanism of $K_{f}$ and $K_{b}$, the following Lyapunov function is introduced

$$
V\left(e, K_{f}, K_{b}\right)=\frac{1}{2}\left[e^{2}+\frac{1}{B_{p} \gamma}\left(B_{p} K_{f}+A_{m}-A_{p}\right)^{2}+\frac{1}{B_{p} \gamma}\left(B_{p} K_{f}-B_{m}\right)^{2}\right]
$$

where $\gamma$ is a constant such that $B_{p} \gamma>0$. The Lyapunov function $V\left(e, K_{f}, K_{b}\right)$ is positive definite in a global sense. In order for the MRAC controller to be stable, the following condition must be met

$$
\frac{d V\left(e, K_{f}, K_{b}\right)}{d t}<0 \quad \forall e \neq 0
$$

From Eqns. (3-21) and (3-22)

$$
\frac{d V\left(e, K_{r}, K_{b}\right)}{d t}=A_{m} e^{2}+\frac{1}{\gamma}\left(A_{m}-A_{p}+B_{p} K_{b}\right)\left(\frac{d K_{b}}{d t}-\gamma e \omega_{r}\right)+\frac{1}{\gamma}\left(B_{p} K_{f}-B_{m}\right)\left(\frac{d K_{f}}{d t}+\gamma e \omega_{r}^{*}\right)
$$

It is obvious that if the following conditions are satisfied, then $d V\left(e, K_{f}, K_{b}\right) / d t$ will satisfy Eqn. (3-23) and ensure the stability of the MRAC controller.

$$
\begin{aligned}
& \mathrm{A}_{\mathrm{m}}<0 \\
& \mathrm{~B}_{\mathrm{p}} \gamma>0
\end{aligned}
$$




$$
\begin{aligned}
& \frac{d K_{b}}{d t}=\gamma e \omega_{r} \\
& \frac{d K_{f}}{d t}=-\gamma e \omega_{r}
\end{aligned}
$$

Equations (3-26) and (3-27) are the adaptive law of the MRAC controller (3-12).

\subsubsection{Simulation Results}

The response of the MRAC as compared to the PI-based controller is shown in Fig. 3.2.2 for a step change in speed command $(+1001 / \mathrm{min})$ while maintaining a constant load torque of $8 \mathrm{Nm}$. As expected, the MRAC response is much improved. The oscillations at the beginning of the MRAC speed response are due to current limiting in the converter running under direct torque control [3.13].

Figure 3.2.3 illustrates the speed response when the inertia of the system is doubled. The improved performance of the MRAC is even more evident.

As illustrated, the model reference control implemented is very effective with regard to the mechanical system and its parameters. The direct torque controller itself is quite robust for electrical parameter variations; thus, adaptive methods [3.14] for the electrical system are not necessarily required. Fig. 3.2.4 illustrates the MRAC speed response when rotor resistance in the direct torque control prediction algorithm is underestimated by $20 \%$. Dynamic performance is still very good. Note, however, that the oscillations due to current limiting have increased somewhat.

Presently, the direct torque controller is being realized using a Digital Signal Processor (DSP). The laboratory system characteristics are discussed in section 3.4. Correlation of the simulation results with the DSP-based realization of the MRAC will be reported in the Phase 4 report.

\subsubsection{Conclusions}

The model reference adaptive controller outlined improves robustness of the direct torque controller with respect to mechanical parameters and enhances the dynamic speed response. The direct torque controller (DTC) itself is robust to electrical parameter variations. Overall, the 
MRAC-DTC algorithm leads to a robust doubly-fed motor controller with good dynamic performance.

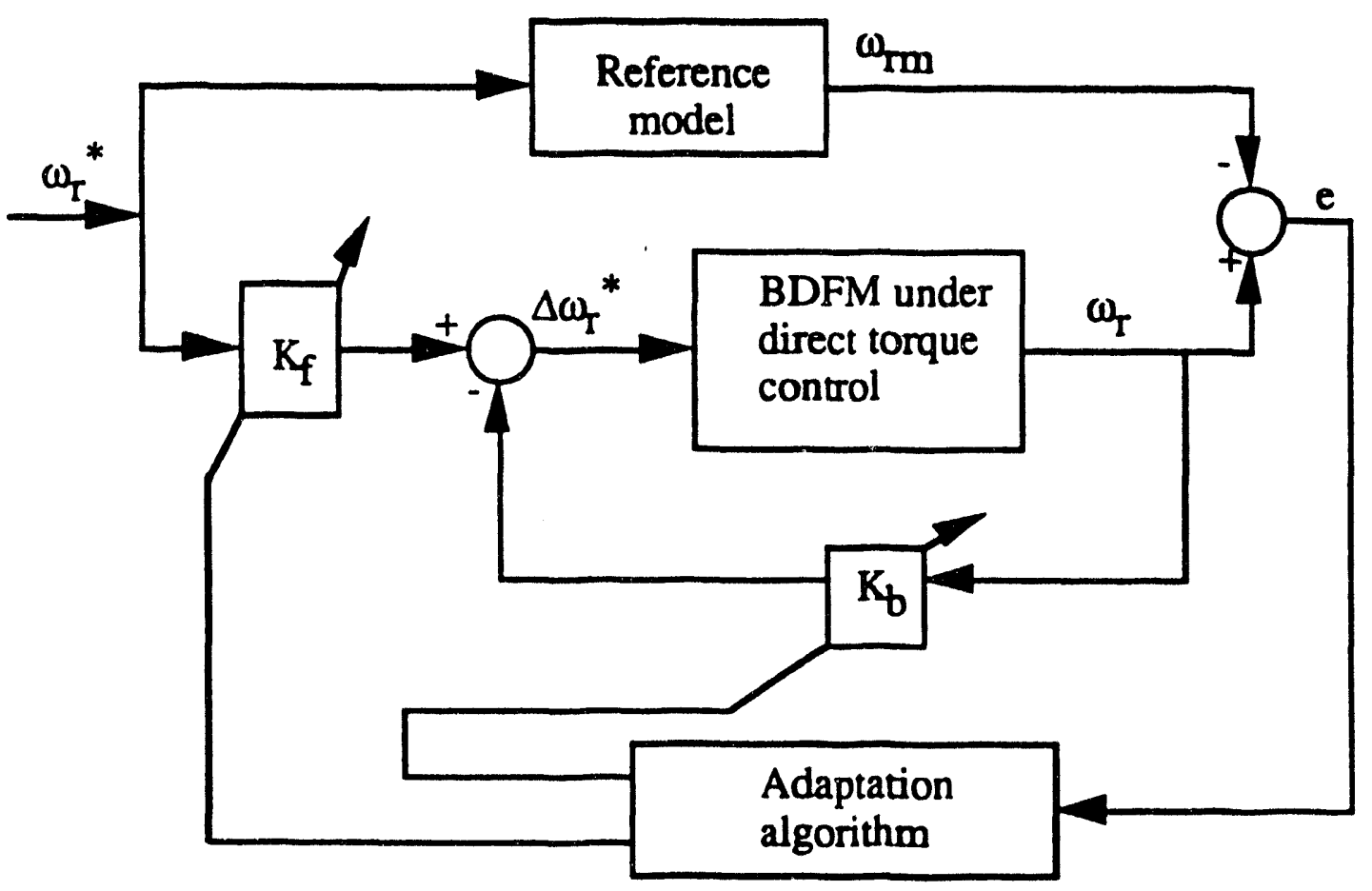

Fig. 3.2.1. MRAC Block Diagram. 

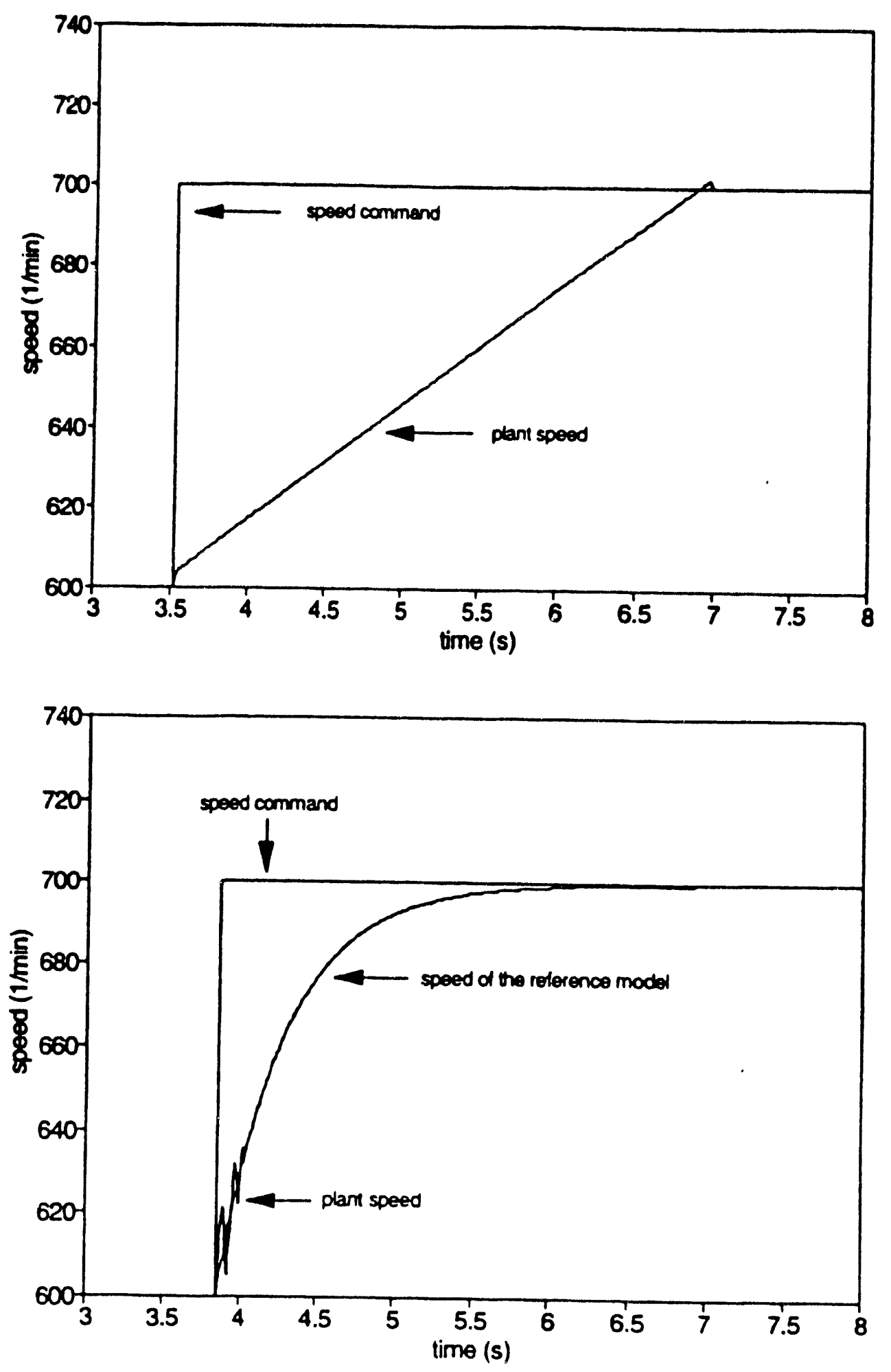

Fig. 3.2.2. System Response to Step Change in Speed Command. Top: PI-Controller; Bottom: MRAC. 

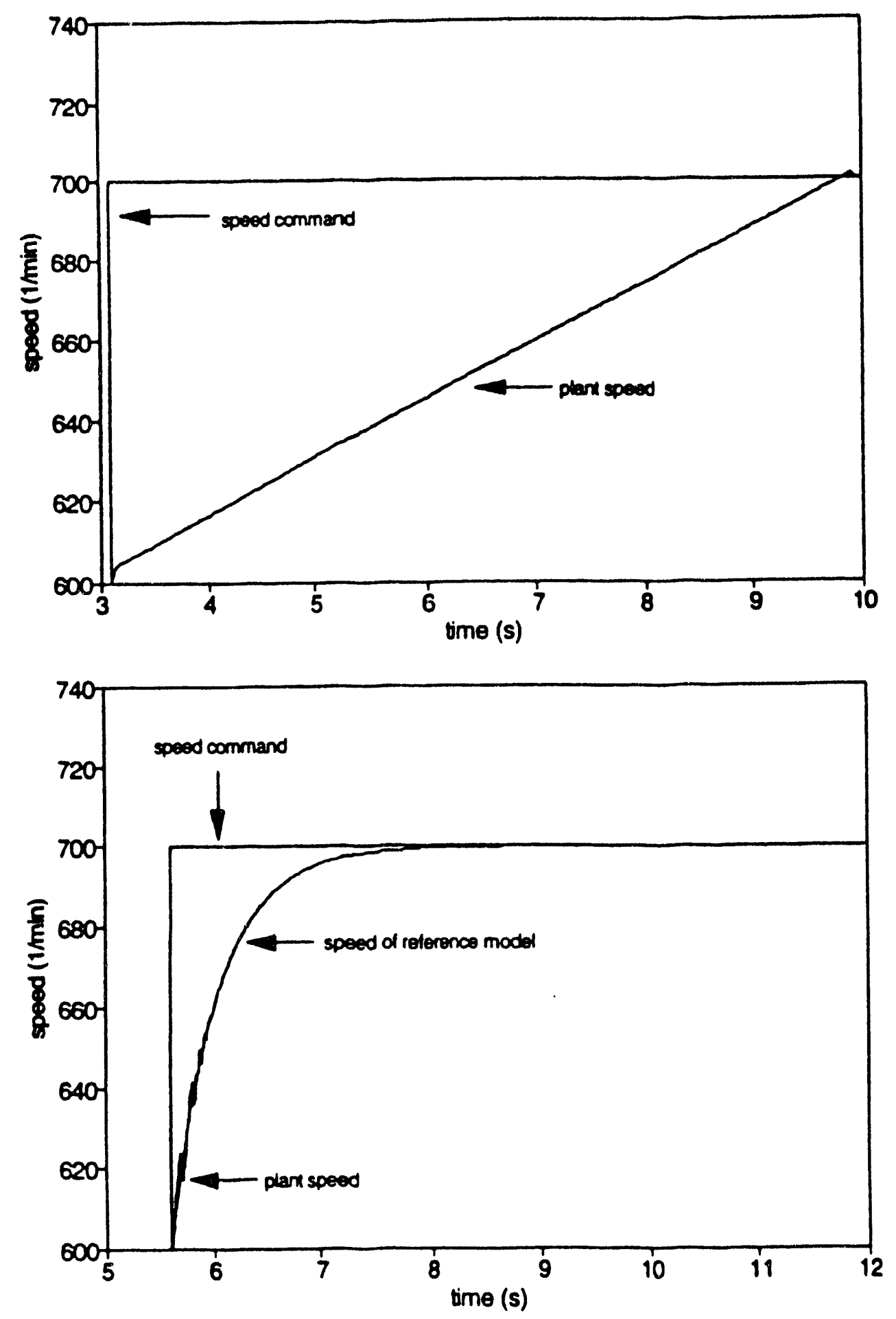

Fig. 3.2.3. System Response to Step Change in Inertia and Speed Command. Top: PI-Controller (inertia doubled at $t=2.75 \mathrm{~s}$ );

Bottom: MRAC (inertia doubled at $\mathrm{t}=5.25 \mathrm{~s}$ ). 


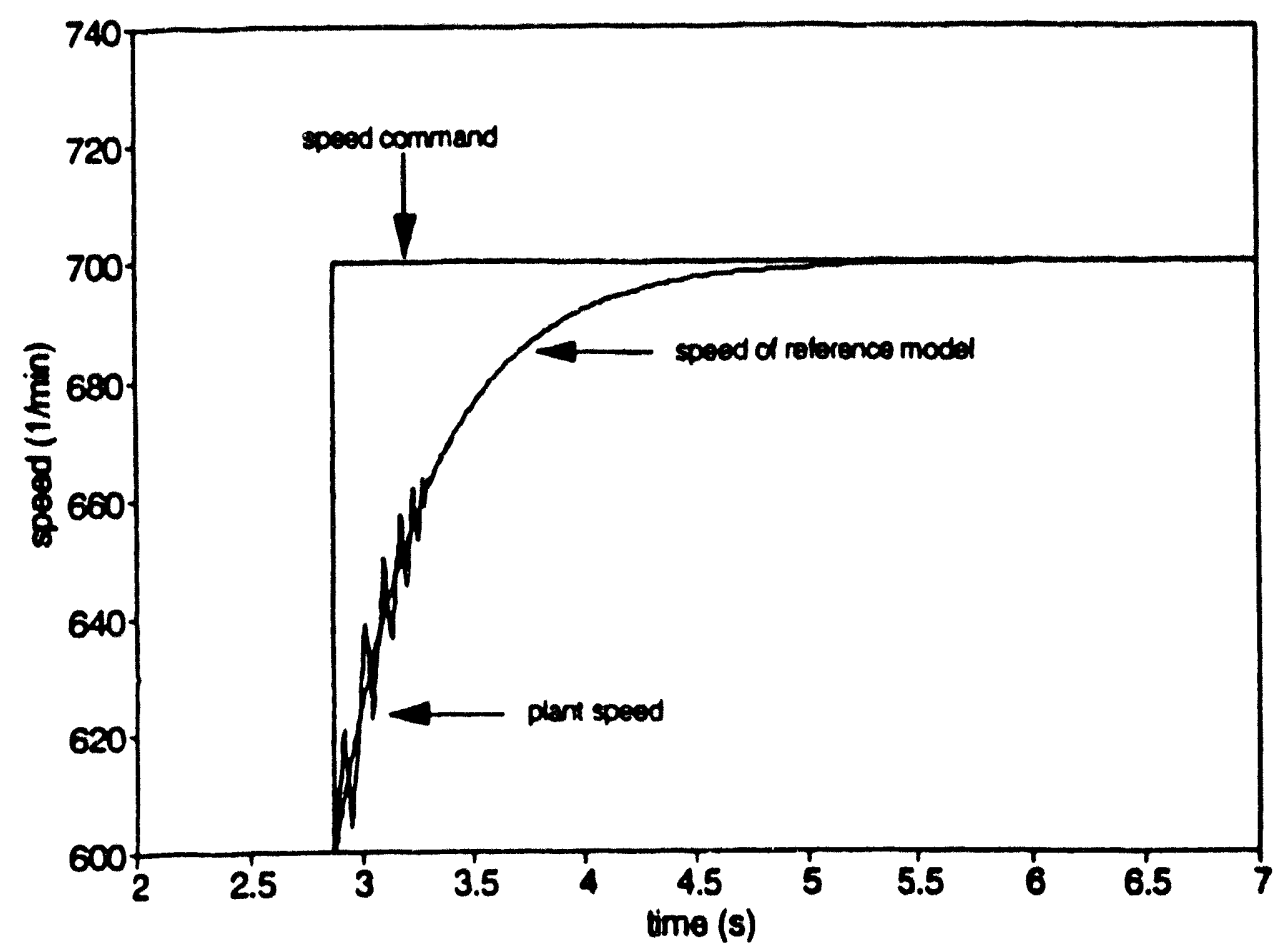

Fig. 3.2.4. MRAC Response to Step in Speed Command with 20\% Rotor Resistance Error in the Direct Torque Controller. 


\subsection{Laboratory Control Implementation}

This section discusses the hardware implementation of the torque control scheme outlined in sections 3.1 and 3.2. The laboratory system utilizes the $5 \mathrm{hp} \mathrm{BDFM}$ with a six-pole power winding and a two-pole control winding, the four-quadrant Series Resonant Converter (SRC) and a real time control system based on a Motorola 56001 Digital Signal Processor (DSP). The control system developed is kept general, such that implementation of new control method can easily be accommodated via software changes. For example, during Phase 4, field orientation principles for the BDFM will be examined and evaluated sing the system presented here.

\subsubsection{Laboratory Hardware Implementation}

The experimental system for laboratory evaluation of the proposed controller has been constructed and is summarized in Table 3.2.

\subsubsection{Preliminary Experimental Results}

Presently, the direct torque control algorithm is being implemented on the digital signal processor. Preliminary experimental studies investigate control of the system via the DSP for relatively slow changes in commanded speed in order to debug the hardware and software.

Figure 3.3.1 shows DSP output (after D/A conversion) for a commanded speed ramp from 600 to $700 \mathrm{l} / \mathrm{min}$ while maintaining constant load torque of $2 \mathrm{Nm}$. For an open loop speed response, shaft speed and torque measured with a strain gauge transducer (not part of the control scheme) are shown in Fig. 3.3.2. Steady state converter current waveforms under DSP control are illustrated in Fig. 3.3.3. 
TABLE 3.2. Experimental System.

\begin{tabular}{|c|c|}
\hline $\begin{array}{l}\text { Brushless Doubly- } \\
\text { Fed Machine }\end{array}$ & $\begin{array}{l}230 \mathrm{~V} ; 5 \mathrm{hp} \text { at } 9001 / \mathrm{min} \text {; six- and two-pole construction with } \\
\text { estimated parameters; see section } 3.4: \\
\text { six-pole resistance } r_{6}=0.81 \Omega \\
\text { six-pole inductance } L_{10}=80 \mathrm{mH} \\
\text { six-pole to rotor mutual } M_{6}=0.89 \mathrm{mH} \\
\text { two-pole resistance } r_{2}=0.81 \Omega \\
\text { two-pole inductance } L_{12}=630 \mathrm{mH} \\
\text { two-pole to rotor mutual } M_{6}=4.3 \mathrm{mH} \\
\text { rotor resistance } r_{r}=1.57 \mathrm{m \Omega} \\
\text { rotor inductance } L_{r}=0.04 \mathrm{mH} \text {. }\end{array}$ \\
\hline Power Converters & $\begin{array}{l}\text { Series Resonant Converter; } 20 \mathrm{kHz} \text { resonant frequency; or } \\
\text { IGBT inverter switching at the controller update frequency. }\end{array}$ \\
\hline Converter Interface & $\begin{array}{l}\text { Three D/A converters interface the DSP with the converters. } \\
\text { These can be configured to drive each of the three phase legs of } \\
\text { the IGBT inverter or to provide magnitude, frequency and phase } \\
\text { commands to the resonant converter. }\end{array}$ \\
\hline Controller & $\begin{array}{l}\text { Motorola } 56001 \text { DSP; controller update frequency of } 1 \mathrm{kHz} \text {, i.e. } \\
1 \mathrm{~ms} \text { is available for data acquisition and control calculations. }\end{array}$ \\
\hline Electrical Inputs & $\begin{array}{l}\text { Two control winding voltages and currents; } \\
\text { Two power winding voltages and currents; } \\
\text { interfaced with the DSP via } 12 \text { bit, } 4 \mu \mathrm{s} \text { A/D converters. }\end{array}$ \\
\hline Mechanical Inputs & $\begin{array}{l}\text { Resolver providing speed and position (14 bits at } 600 \mathrm{l} / \mathrm{min}, 12 \\
\text { bits at } 2400 \mathrm{l} / \mathrm{min} \text { ). }\end{array}$ \\
\hline Load System & $\begin{array}{l}\text { Four-quadrant dc drive with microprocessor control emulating } \\
\text { the desired load characteristics (i.e. constant torque, fain } \\
\text { characteristic, etc.); see also section 5.1. }\end{array}$ \\
\hline
\end{tabular}

Investigation of system performance under direct torque control is presently underway. Programming of the direct torque control algorithm in " $\mathrm{C}$ " language is found to lead to relatively long computational delays; this may necessitate optimization of the DSP code in Assembly language to achieve the desired $1 \mathrm{kHz}$ update frequency. Investigations for step changes in speed command as well as fast changes in applied load torque are underway and will be reported in the Phase 4 report. 


\subsubsection{Conclusions}

A high speed digital platform for control of the BDFM has been implemented. Currently, the system is used to investigate performance of the BDFM under the direct torque control algorithm. The hardware will also be used extensively in the evaluation of future control schemes and application development for the BDFM.
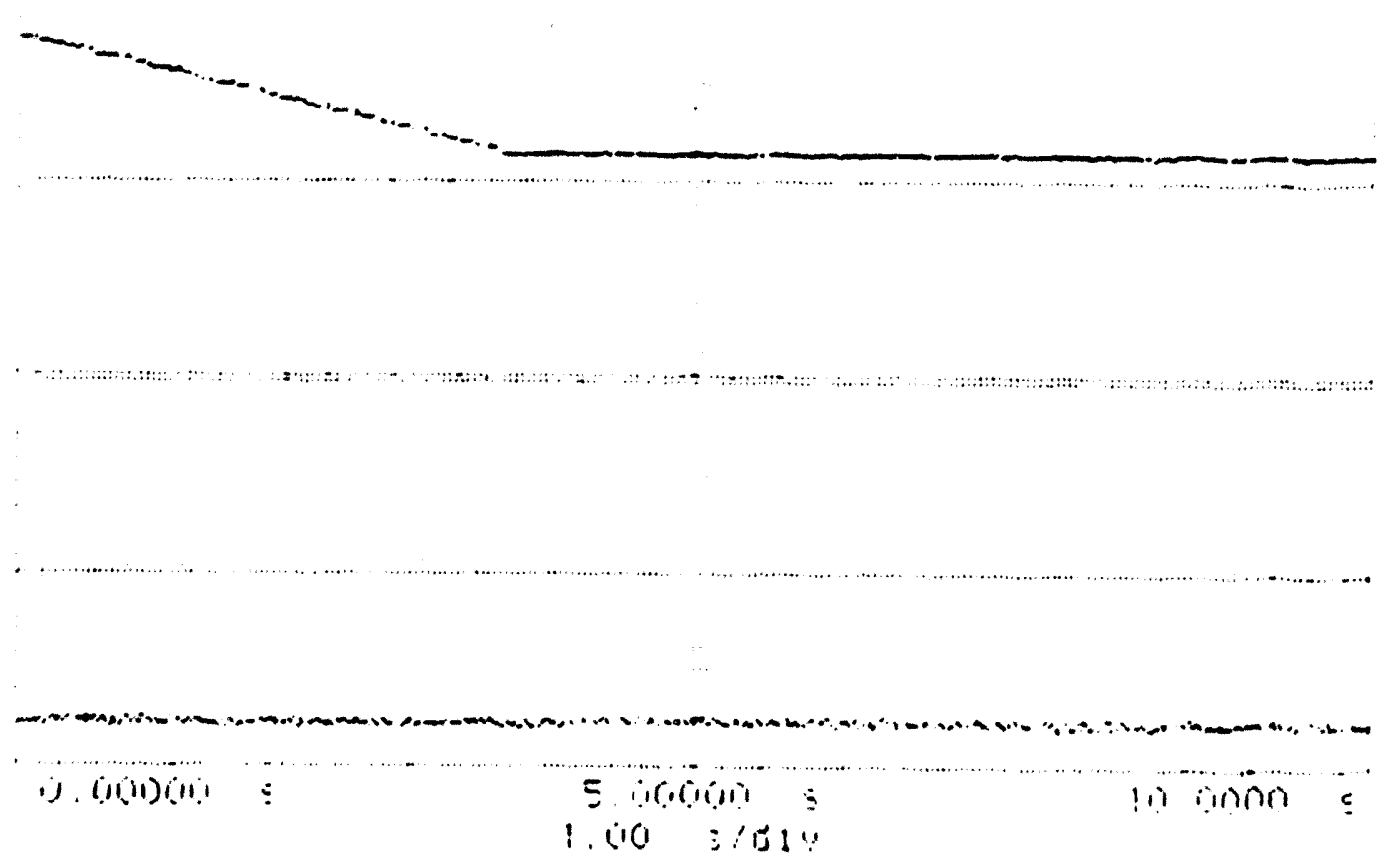

Fig. 3.3.1. DSP Control Outputs for Converter Current Frequency (top trace) and Magnitude (bottom trace). 


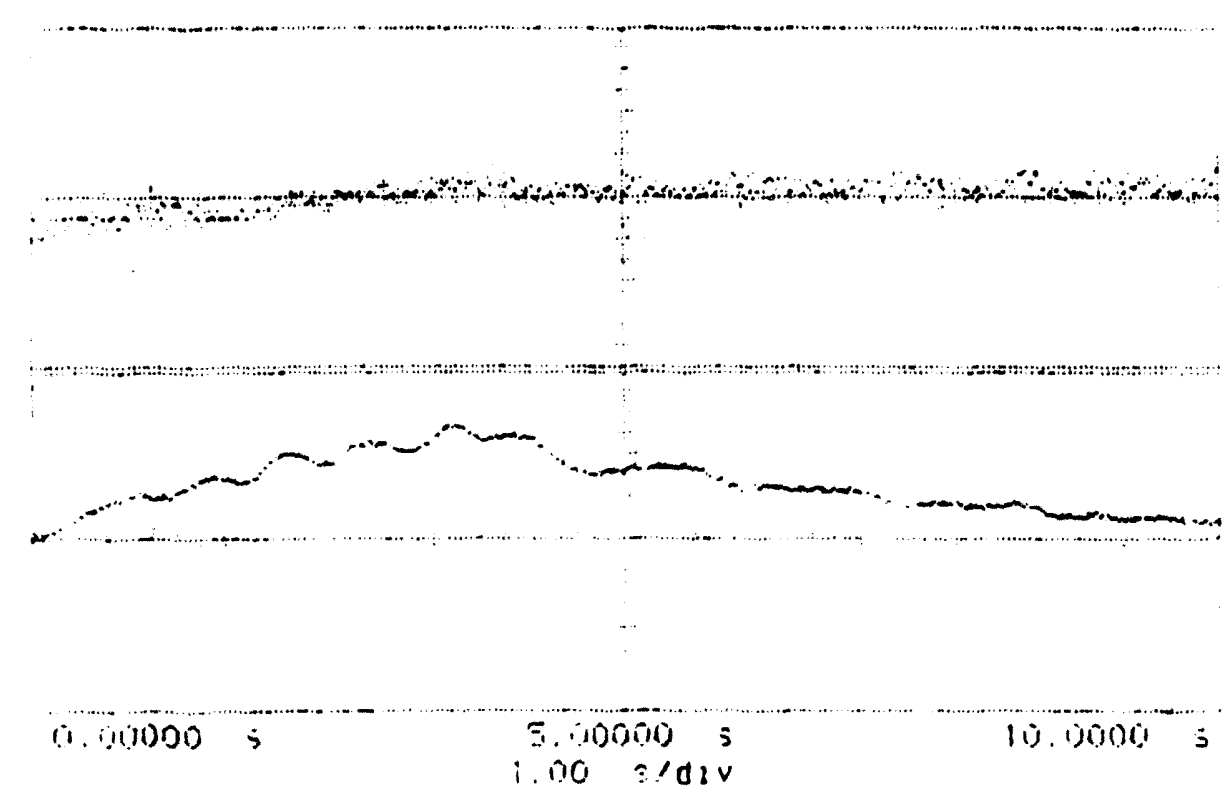

Fig. 3.3.2. Measured Shaft Speed (top trace) and Torque (bottom trace); Open Loop Data.
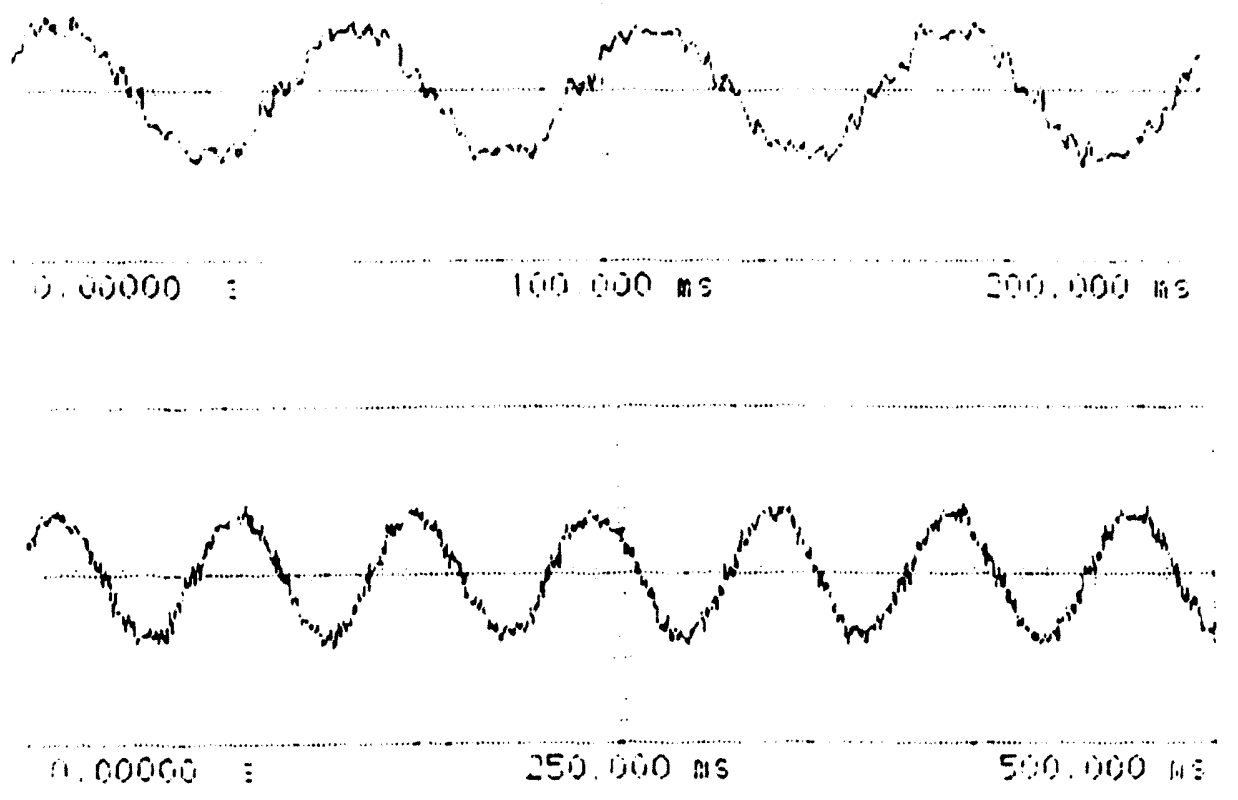

Fig. 3.3.3. Converter Current Waveforms under DSP Control Top trace: at $600 \mathrm{l} / \mathrm{min}$; bottom trace: at $7001 / \mathrm{min}$. 


\subsection{Parameter Estimation Results for the BDFM}

\subsubsection{Introduction}

The objective of our work is to obtain all the electrical parameters for the d-q BDFM model from dynamic measurements. This information is necessary to validate BDFM design modifications, and is also useful for subsequent controller development efforts.

In Phase 2 of this project, it was established that the parameters can be determined by a single corstant-speed test with excitation being supplied to one of the BDFM windings with a current-source converter, while the second winding is short-circuited. Because of problems caused by saturation at low current levels on the control winding of the latest prototype machine, it has been decided to do the initial tests on the BDFM with single-sided excitation, and the second winding open-circuited.

A practical estimation procedure was outlined in phase 2 of the project. Phase 3 describes the procedure in more detail, and the particular constraints that are necessary for successful experimentation.

Theoretical studies have revealed that only the stator parameters can be individually determined for the present BDFM model. Apart from these, it is possible to determine certain ratios that fully characterize the machine operation. The rotor parameters can be determined only if they are referred to the stator. The leakage parameters can be evaluated only if the BDFM model incorporates core-loss.

Finally, results are provided and discussed for both power and control winding parameter identification. The parameters obtained for the lossless BDFM model predict steady-state measurements to within $2 \%$ in magnitude and $4 \%$ in phase.

\subsubsection{Experimental Procedure}

The off-line parameter estimation scherne is to be restricted to the electrical parameters of the machine. The mechanical parameters will be eliminated from consideration by using a variable-speed drive to maintain constant rotor speed. A block diagram of the elements of the estimation procedure is given in Fig. 3.4.1.

The estimation process is carried out in the Fourier domain. The entire procedure can be broadly divided into four groups of functions:

(1) data acquisition from the physical machine; 
(2) processing of the signal samples to remove high-frequency noise and harmonics and to separate the remaining components producing line and continuous spectra;

(3) to convert the remaining signals to the $d-q$ domain and then to the fourier domain;

(4) to carry out the estimation calculations.

The error between estimated and measured spectra is found by taking the magnitude of the difference in the complex values of the spectra at each frequency. The parameters of the machine can be estimated by exciting one set of the machine windings, while the other set of windings is short-circuited. This is not the ideal excitation scheme, but is the most practical. However, the present BDFM model saturates at very low levels of current on the control winding side, as seen from the magnetization curve of Fig. 3.4.2. Because of the very low signal levels which could be used, the experimentation was repeated with excitation being supplied to each of the winding sets with the other winding open-circuited.

The excitation levels were carefully chosen so that the peak amplitudes were below saturation levels. The modulation was adjusted to limit the speed change to within $1 \mathrm{rpm}$, which precludes the need for an additional drive capable of constant speed control. A variation in speed causes the maximum error in the estimation process in the conversion of the a-b-c signals into the $d-q$ domain. This error can be avoided if the speed signal is available as an additional measurement. In the laboratory setup, the raw (unfiltered) speed signal was not used.

The data acquisition system in the laboratory is configured to match the transducer output voltage level of -10 to $+10 \mathrm{~V}$. The transducers reduce actual voltages by a ratio of $30: 1$, and currents by a ratio of 10:1. An additional gain switch is provided on the analog input module of the data acquisition system to amplify each input channel voltage by a factor of $10,100,200,500$ or any sum of these, provided that the absolute value of the amplified signal does not exceed 10 V. The low levels of excitation current used in the experimental process (Tables $3.3,3.4$ ) made it imperative to use a gain of 10 on the current signals. However, the voltage signals could not be amplified, because of the $10 \mathrm{~V}$ restriction. Thus, the peak of the steady state voltage input to the analog-to-digital converter was in the range of $1 \mathrm{~V}$, and the peak of the modulation voltage which is used in the estimation process was only around $0.3 \mathrm{~V}$. Thus, the A/D converter was operating at $3 \%$ of its full-scale voltage. This corresponds to a quantization error of about $1 \%$ 
at each measurement point, and in addition contributes to increased uncertainty in measurements because of a decrease in signal-to-noise ratio.

TABLE 3.3. Operating Conditions for

Six-pole Winding Measurements.

\begin{tabular}{||l|l|}
\hline Speed (mechanical) & $771 \mathrm{rpm}$ \\
\hline Frequency (input) & $39 \mathrm{~Hz}$ \\
\hline Slip & 0.0113 \\
\hline Current (input) & $1.33 \mathrm{~A} \mathrm{Rms}$ \\
\hline Voltage (output) [1-1] & $25.80 \mathrm{~V} \mathrm{Rms}$ \\
\hline
\end{tabular}

TABLE 3.4. Operating Conditions for Two-pole Winding Measurements.

\begin{tabular}{|l|l|}
\hline Speed (mechanical) & $770 \mathrm{rpm}$ \\
\hline Frequency (input) & $13 \mathrm{~Hz}$ \\
\hline Slip & 0.0177 \\
\hline Current (input) & $0.95 \mathrm{~A} \mathrm{Rms}$ \\
\hline Voltage (output) [1-1] & $32.94 \mathrm{~V} \mathrm{Rms}$ \\
\hline
\end{tabular}

3.4.2.1. Experimental Setup. A 16-channel data acquisition system capable of providing 100,000 total samples per second provides the necessary data with sufficient resolution for excitation frequencies at or below $60 \mathrm{~Hz}$ and has relatively modest cost. Ten channels were used to collect the estimation data. The non-linearity of the model is reduced and the mechanical dynamics of the machine are eliminated by holding the rotor shaft speed essentially constant by means of a regulated variable-speed drive connected to the BDFM shaft. The rotor speed control is also necessary to fix the frequency shift introduced by the $d-q$ transformation.

3.4.2.2. Signal Processing. Because of the noise introduced by the converter and the structure of the BDFM (Fig. 3.1.4), the signals are passed through a digital band-pass filter with a $4 \mathrm{~Hz}$ pass-band centered on the carrier (power) frequency provided by the converter. This isolates the carrier along with the desired modulation from the unwanted frequency components.

The use of a digital Butterworth, band-pass filter gives a sufficiently accurate magnitude 
response, but introduces a non-linearity in the phase response. The narrow bandwidth of the desired filter makes it imperative to account for phase-shifts introduced by the filter. For off-line estimation, it is convenient to build a digital filter which introduces no phase-shift. A fourth-order Butterworth, zero-phase, band-pass filter was designed for this purpose. The frequency response of such a filter is shown in Fig. 3.4.3.

The finite sample of the carrier signal will have spurious spectral components when the Fourier transformation is directly applied. These components lie on either side of the carrier and add to the modulation signal. Therefore, for accurate estimation, the spectrum of the carrier signal has to be completely removed, either by removing the carrier signal from the time-domain data or by manipulating the composite transforms. Because of the non-ideal carrier waveform generated in the laboratory, carrier removal in the time-domain has been found to be the most practical.

The separation of the carrier signal from the applied modulation signal is complicated by the presence of additional undesired modulation in the carrier itself, and by small variations in amplitude and frequency of the carrier signal. The amplitude, frequency and phase of the base, sinusoidal component of the carrier are established by sampling the "noisy" carrier for at least one second before and after the desired modulation pulse is applied. Small, periodic variations in converter frequency and amplitude in the absence of the applied modulation can best be compensated for by performing a frequency-domain estimation of the effective carrier signal; because the eventual estimation of the model parameters itself is to be done in the frequencydomain. It can be shown that the frequency-domain magnitude response of the carrier signal will yield accurate values of amplitude and frequency when a simple gradient search is applied to the error-squared cost function. Once the magnitude and frequency are known, the phase can be determined from either the real or imaginary parts of the transformed data.

Because the estimation is to be done off-line, it has been decided to bypass some of the limitations of the Fast Fourier Transform algorithms by evaluating the transform integral directly. A more satisfactory set of spectra to be used in the estimation process has resulted. 


\subsubsection{Estimation Process}

The frequency-domain cost function which is minimized in the estimation process is

$$
J_{\omega}=\int(Y[X(\omega)]-G[P, X(\omega)]) Q(Y[X(\omega)]-G[P, X(\omega)])^{\bullet \top} d \omega
$$

where: $\mathrm{X}$ is the vector of measured inputs,

$Y(X)$ is the vector of measured outputs,

$P$ is the parameter vector,

$G$ is the vector of model outputs, and

$\mathrm{Q}$ is a diagonal weighting factor matrix.

The cost function forms a weighted, least-squares, output-error criterion. The error in spectra is found by taking the square of the magnitude of the difference in the complex values of the spectra at each frequency. The weighting matrix is chosen as the identity matrix, for preliminary experimental work.

The well known time domain model for the BDFM shown in Eqn. (3-29) is reduced to that of Eqn. (3-30) by transformation to the frequency domain and by elimination of the rotor variables. The reduced set of equations is used in calculating the model spectrum for comparison with the measured output spectrum of the machine. While this eliminates the need to estimate rotor currents, it complicates the parameter estimation process by introducing additional nonlinearities among the parameters. 
The $d-q$ axis model for the BDFM:

\begin{tabular}{|c|c|c|c|c|c|c|c|c|c|}
\hline$\left[V_{96}\right]$ & {$\left[r_{6}+L_{26} p\right.$} & $3 L_{s 6} \omega_{r}$ & 0 & 0 & 0 & 0 & $\mathrm{M}_{6} \mathrm{p}$ & $3 M_{6} \omega_{r}$ & {$\left[i_{q 0}\right]$} \\
\hline$V_{d \omega}$ & $-3 L_{86} \omega_{r}$ & $\mathrm{r}_{6}+\mathrm{L}_{26} \mathrm{P}$ & 0 & 0 & 0 & 0 & $-3 M_{6} \omega_{r}$ & $\mathrm{M}_{6} \mathrm{p}$ & $i_{d 6}$ \\
\hline $\mathrm{V}_{06}$ & 0 & 0 & $\mathrm{r}_{6}+\mathrm{L}_{86} \mathrm{P}$ & 0 & 0 & 0 & 0 & 0 & $\mathrm{i}_{06}$ \\
\hline $\mathrm{v}_{\mathrm{q} 2}$ & 0 & 0 & 0 & $\mathrm{r}_{2}+\mathrm{L}_{32} \mathrm{p}$ & $\mathrm{L}_{\mathrm{B} 2} \omega_{\mathrm{r}}$ & 0 & $-M_{2} p$ & $M_{2} \omega_{r}$ & $i_{q 2}$ \\
\hline $\mathrm{v}_{\mathrm{d} 2}$ & 0 & 0 & 0 & $-L_{s 2} \omega_{r}$ & $\mathrm{r}_{2}+\mathrm{L}_{\mathrm{s} 2} \mathrm{p}$ & 0 & $\mathrm{M}_{2} \omega_{\mathrm{r}}$ & $\mathbf{M}_{2} \mathrm{p}$ & $\mathrm{i}_{\mathrm{d} 2}$ \\
\hline$v_{02}$ & 0 & 0 & 0 & 0 & 0 & $\mathrm{r}_{2}+\mathrm{L}_{\imath 2} \mathrm{P}$ & 0 & 0 & $\mathfrak{i}_{02}$ \\
\hline$V_{q r}$ & $\mathrm{M}_{6} \mathrm{p}$ & 0 & 0 & $-\mathrm{M}_{2} \mathrm{p}$ & 0 & 0 & $\mathrm{r}_{\mathrm{r}}+\mathrm{L}_{\mathrm{rp}}$ & 0 & $\mathrm{i}_{\mathrm{qr}}$ \\
\hline $\mathrm{v}$ & 0 & $\mathrm{M}_{6} \mathrm{P}$ & 0 & 0 & $\mathrm{M}_{2} \mathrm{p}$ & 0 & 0 & $+L_{m}$ & $i_{d r}$ \\
\hline
\end{tabular}

The parameters to be estimated: $R_{6}, L_{6}, M_{6}, R_{2}, L_{2}, M_{2}, R_{r}, L_{r}$

A Fletcher-Powell gradient search algorithm is used for the minimization process. Though this may not be the most sophisticated choice for a non-linear minimization algorithm, it has been found satisfactory for preliminary studies in this off-line estimation problem.

A careful inspection of the BDFM equations of Eqn. (3-30) reveals that the BDFM model (without losses), is not completely defined witi respect to its parameters, because the rotor currents are not directly measurable. As a result, it is not possible to estimate all parameters of the model directly. The only parameters that can be estimated directly are the stator resistances, $R_{6}$ and $R_{2}$, and the sum of the leakage and magnetizing components of the stator inductances, $L_{6}$ and $L_{2}$. The leakage inductances cannot be individually determined in the model. It is also possible to estimate the ratios $L_{r} / R_{r}, M_{6}{ }^{2} / R_{r}$ and $M_{2}{ }^{2} / R_{r}$. The actual rotor impedance elements cannot be evaluated, because the rotor has not been referred to the stator, as is conventionally done in the case of induction machine models.

The BDFM model in the frequency-domain: 


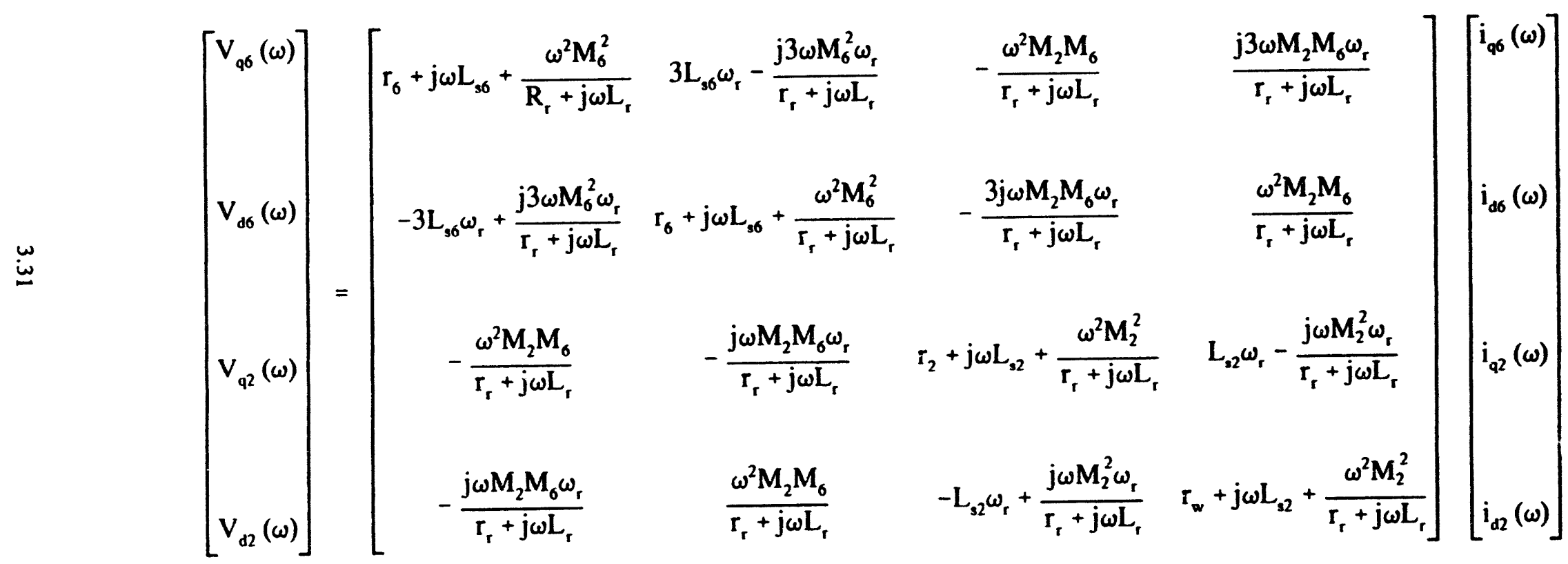


This is a restriction of the model, and not of the estimation scheme employed. It should also be noted that these observable quantities are sufficient to describe the terminal characteristics of the machine completely. Furthermore, investigation and simulation of a BDFM core-loss model shows that incorporating core-loss into the equations not only gives a better model for the physical system, but also helps in isolating the leakage inductances from the magnetizing components.

\subsubsection{Results}

The parameter estimation procedure shown in Fig. 3.4.1 was implemented in the laboratory. Tests were done alternately on the two-pole and the six-pole sides. A sample waveform of the six-pole current generated by the converter is shown in Fig. 3.4.4, (data acquisition sample errors appear as spikes in Fig. 3.4.4) and the output from the digital filter is shown in Fig. 3.4.5(a). The smaller section shown in Fig. 3.4.5(b) shows that the apparent breaks in the acquired sinusoidal signal of Fig. 3.4.5(a) are caused by the program used for plotting the data. The unfiltered steady-state waveform shows a sub-harmonic modulation at one-third the excitation frequency, which has been reduced after filtering.

The applied input modulation current, along with the carrier, is shown in Fig. 3.4.6. The tests were done close to zero-slip, and the operating conditions are summarized in Tables 3.3 and 3.4 for the six-pole and two-pole tests respectively.

The parameters obtained after estimation are as shown in Tables 3.5 and 3.6. Table 3.5 shows the six-pole winding parameters, and Table 3.6 the two-pole winding parameters. The initial guesses for the estimation process have been chosen after numerous experimental trials at modelling the machine. It is seen that the rotor time constant is different in the two cases. It is important to note that the representation of the time constant in this model is not in the conventional manner; because the inductance that makes up this time constant is the sum of leakage and magnetizing components. Moreover, a look at Tables 3.3 and 3.4 show that the tests were done at different bias points of the saturation curve. Therefore, it is unreasonable to expect the rotor time constants in the two tests to be equal.

The estimated parameters were incorporated into a BDFM steady-state model to test the validity of the parameters to predict steady-state operation. It should be noted that only the modulation signal, after the steady-state signal is subtracted from the total signal, was used in the estimation process. The voltage output was calculated from the model with input being the 
measured current. The voltage output from the model matches very closely to the measured value, both in magnitude and phase, as can be seen from Tables 3.5 and 3.6.

TABLE 3.5. Parameter Estimation Results for the Six-pole Winding.

\begin{tabular}{|l|l|l|l|l|l|}
\hline Parameter & $\mathrm{R}_{6}$ & $\mathrm{~L}_{6}$ & $\mathrm{M}_{6}{ }^{2} / \mathrm{R}_{\mathrm{r}}$ & $\mathrm{L}_{r} / \mathrm{R}_{\mathrm{r}}$ & $\begin{array}{l}\text { Difference from } \\
\text { Steady State Response }\end{array}$ \\
\hline Initial Guess & 0.8 & 0.08 & 0.0029 & 0.127 & Magnitude $=1.3 \%$ \\
\hline Estimated Value & 0.7 & 0.049 & 0.0027 & 0.174 & Phase $=3.8 \%$ \\
\hline
\end{tabular}

TABLE 3.6. Parameter Estimation Results for the Two-pole Winding.

\begin{tabular}{|l|l|l|l|l|l||}
\hline Parameter & $\mathrm{R}_{2}$ & $\mathrm{~L}_{2}$ & $\mathrm{M}_{2}{ }^{2} / \mathrm{R}_{\mathrm{r}}$ & $\mathrm{L}_{\mathrm{r}} / \mathrm{R}_{\mathrm{r}}$ & $\begin{array}{l}\text { Difference from } \\
\text { Steady State Response }\end{array}$ \\
\hline Initial Guess & 0.8 & 0.6 & 0.055 & 0.127 & Magnitude $=1.3 \%$ \\
\hline Estimated Value & 1.8 & 0.247 & 0.0338 & 0.214 & Phase $=4.4 \%$ \\
\hline
\end{tabular}

The six-pole q-axis and d-axis voltage spectra which are obtained from the estimated model, are shcwn in Fig. 3.4.7 and Fig. 3.4.8 respectively, alongside their measured counterparts. The input current spectrum used for these plots is the measured current modulation, which is shown in Fig. 3.4.9. This sample result shows that the estimated model is close to actual measurements over the frequency range of the modulation signal.

A close look at the last column in Tables 3.5 and 3.6 shows that the parameters that were estimated also predicts the steady-state operating point closely. It should be noted that only the modulation signal, after the steady-state signal is subtracted from the total signal, was used in the estimation process.

\subsubsection{Conclusions}

The results shown prove the feasibility of the proposed parameter estimation scheme for the BDFM. Further improvements can be made in the estimation process if the following problems can be solved or accounted for:

(1) Low signal levels that were used to avoid saturation,

(2) Extraneous modulation produced by non-linear phenomena that are not 
accounted for in the model,

(3) Core losses that are not included.

Further work is to be done to study parameter variation over different operating conditions. 


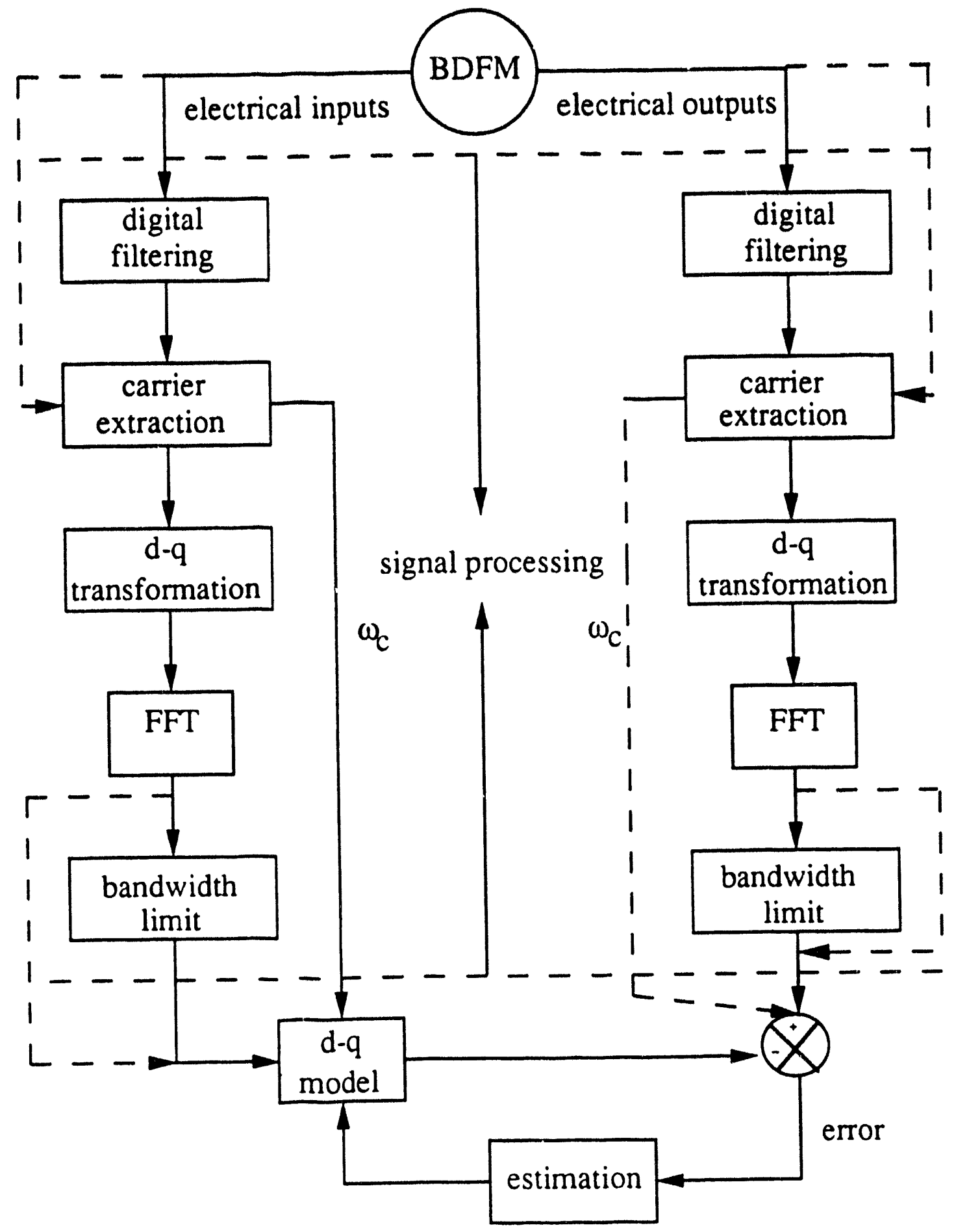

Fig. 3.4.1. Flow Chart of the Parameter Estimation Procedure. 


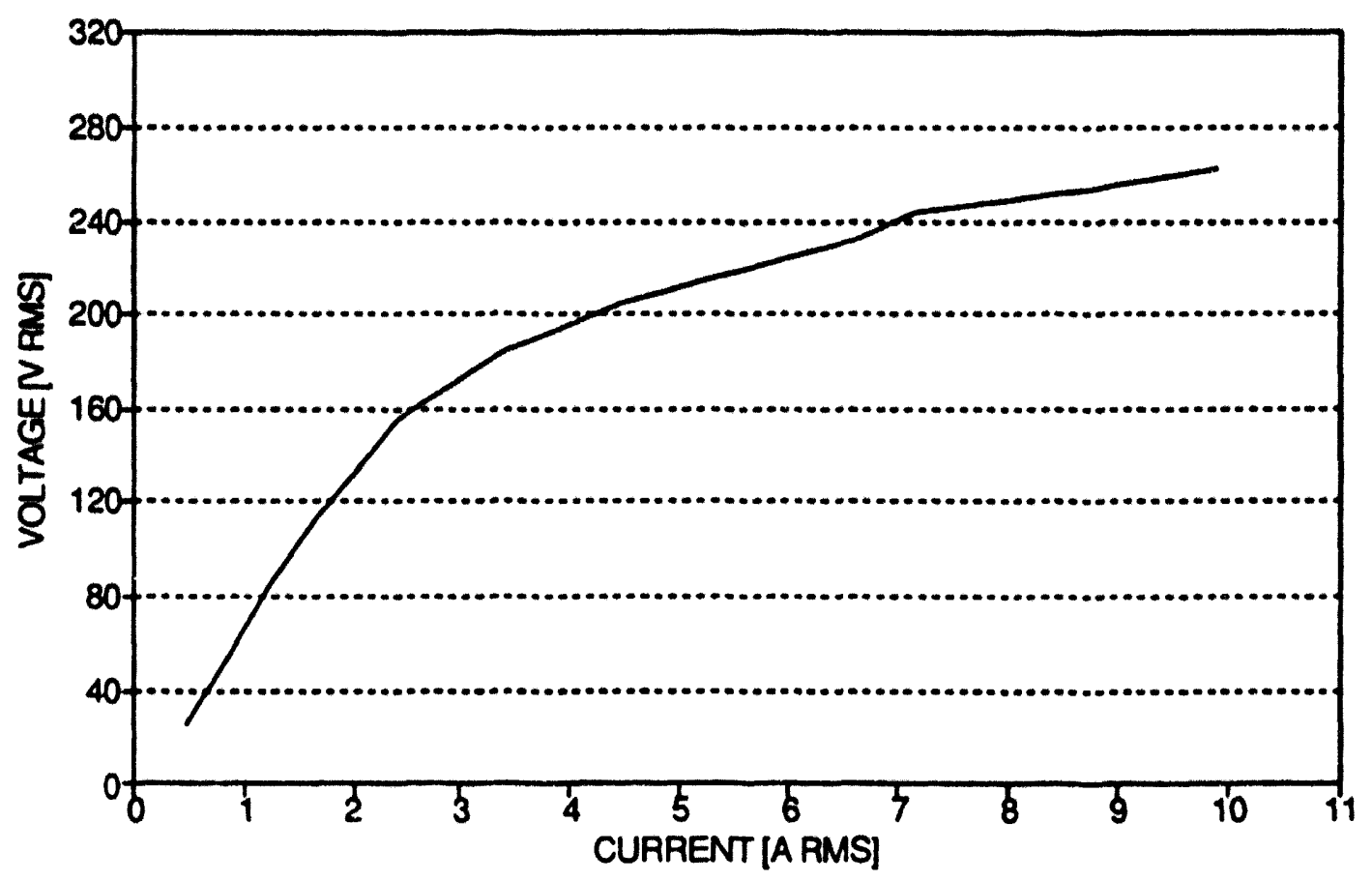

Fig. 3.4.2. Open-circuit Magnetization Curve for the Two-pole Winding.

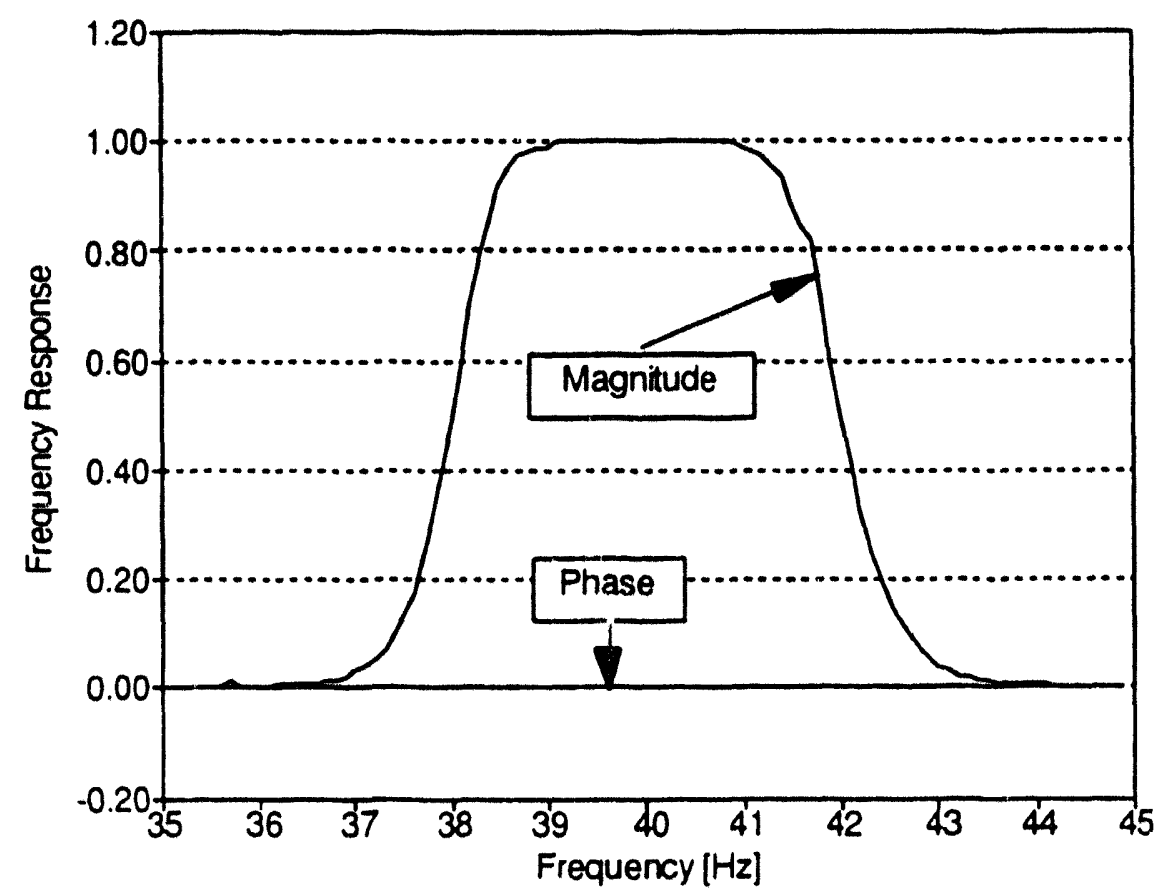

Fig. 3.4.3. Frequency Response of a Butterworth, Zero-phase Digital Filter. 


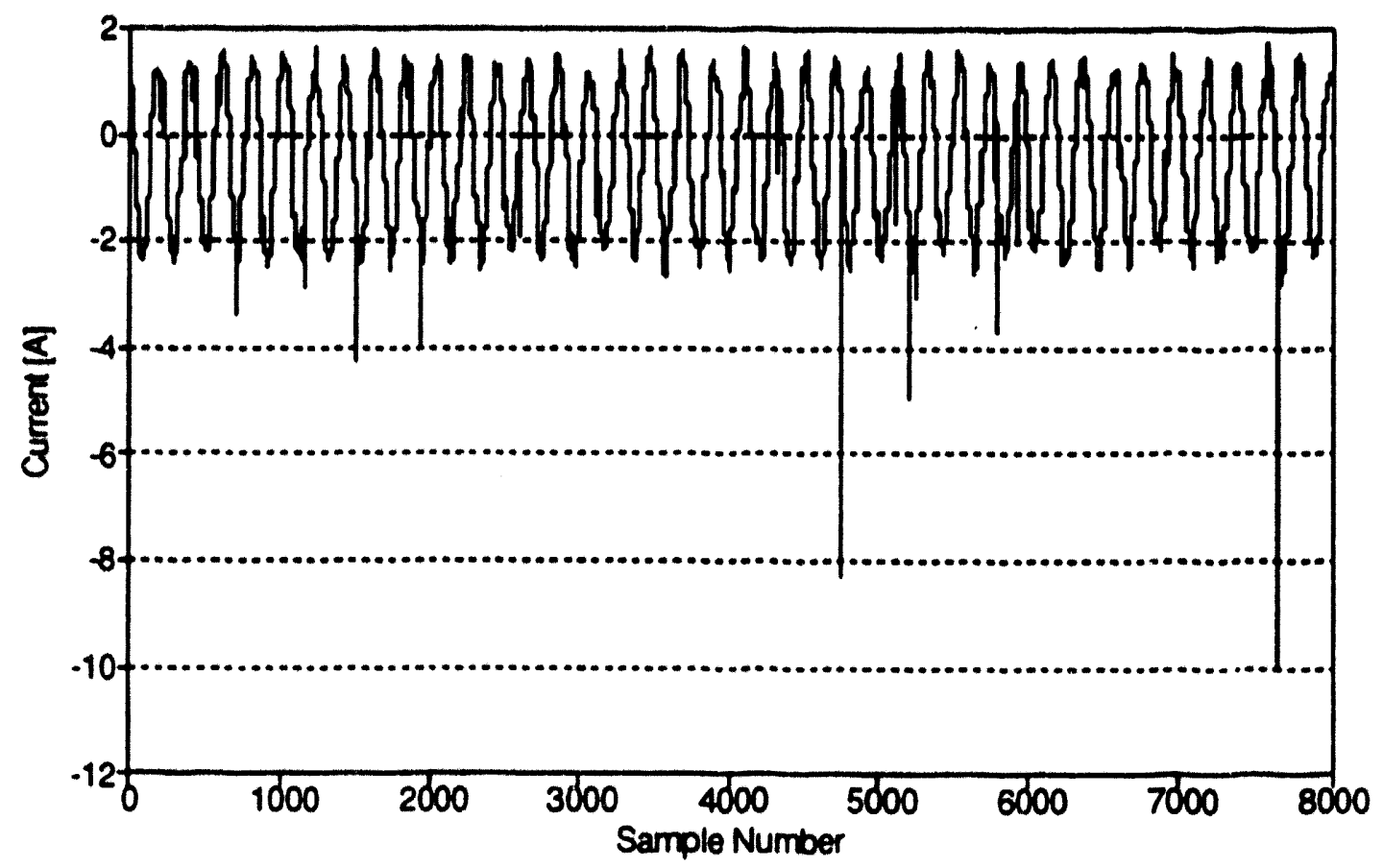

Fig. 3.4.4. Sampled Current Input to the Six-pole Winding. 


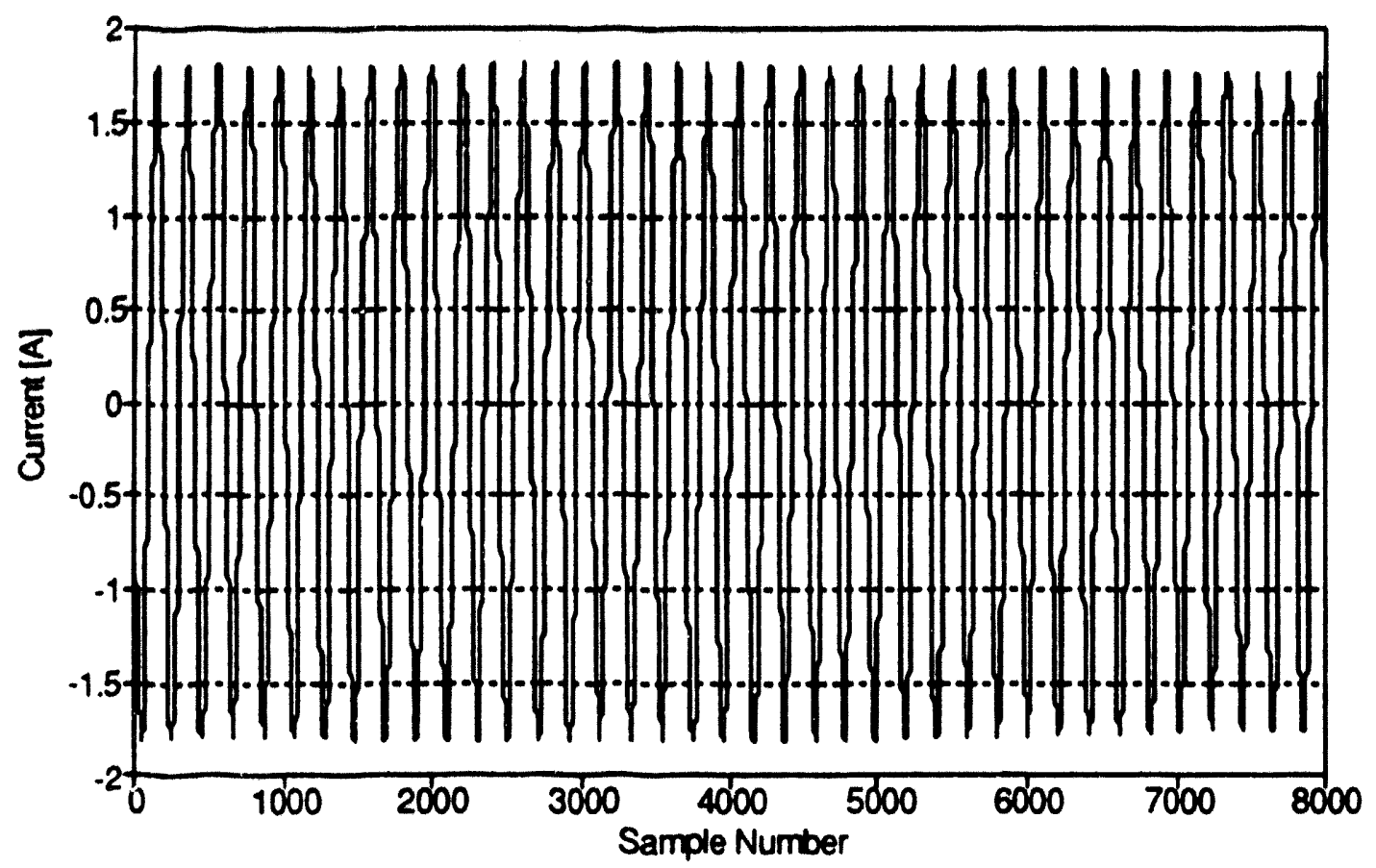

Fig. 3.4.5(a). Input Current After Filtering.

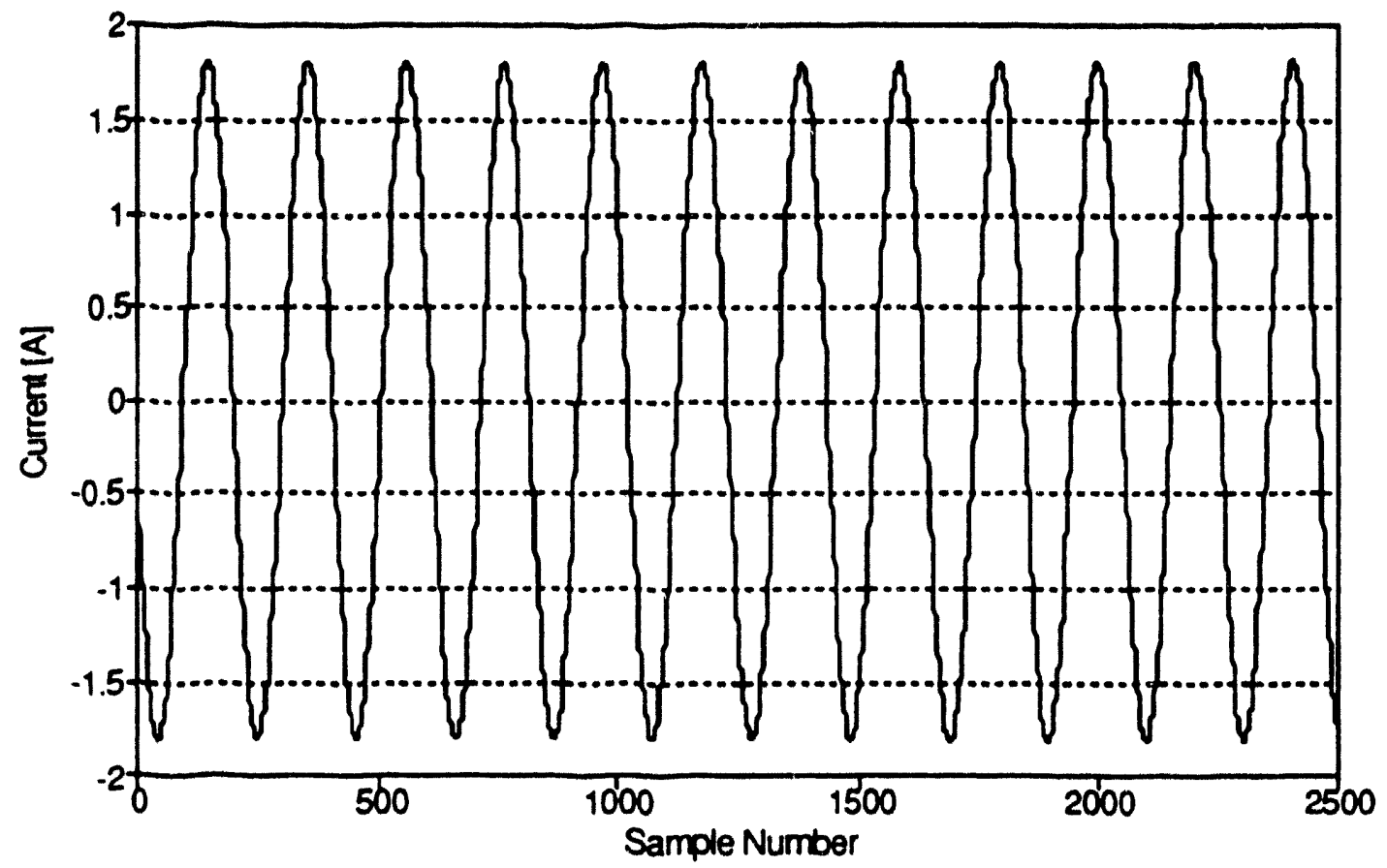

Fig. 3.4.5(b). Input Current After Filtering (Enlarged). 


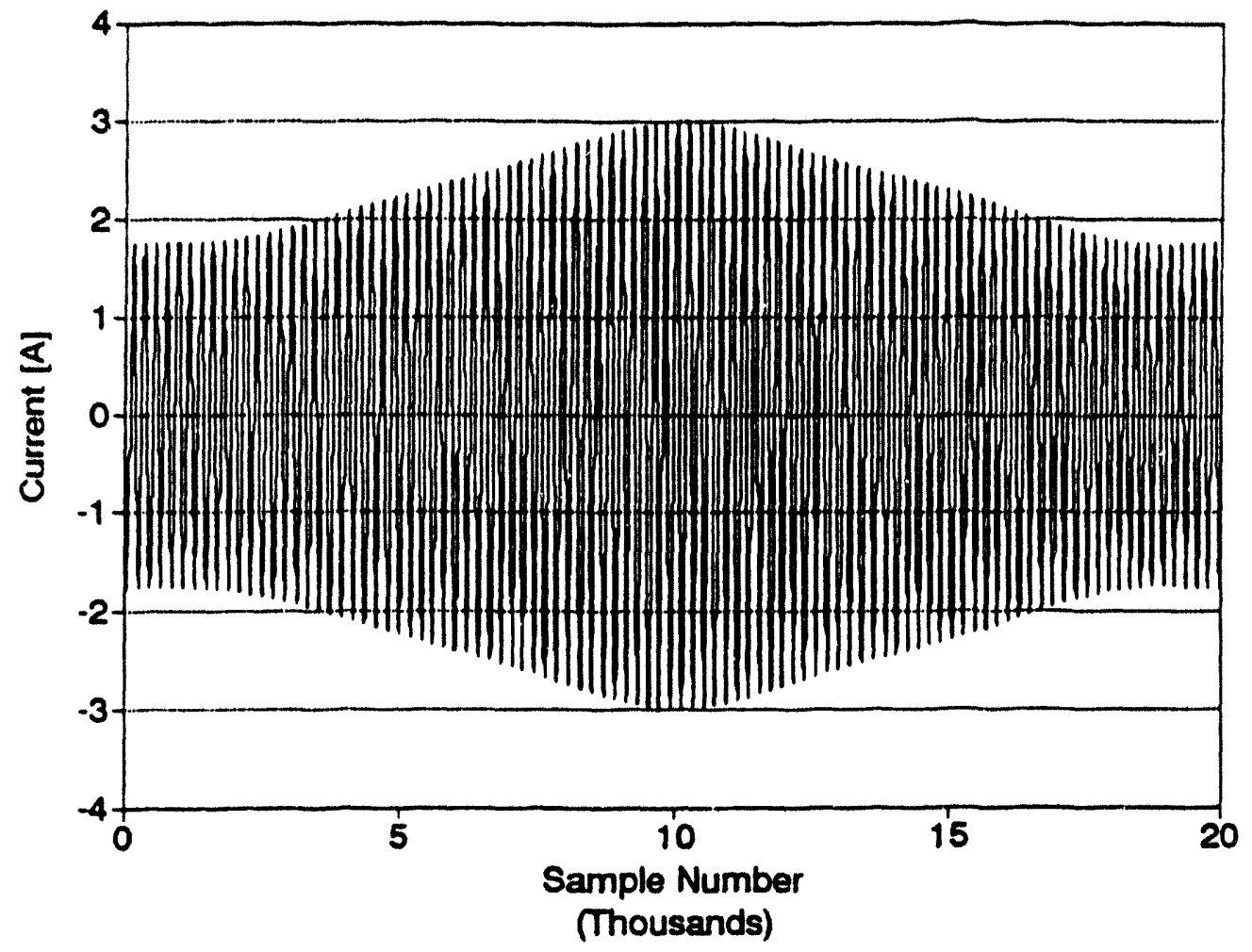

Fig. 3.4.6. Input Current Showing Modulation.

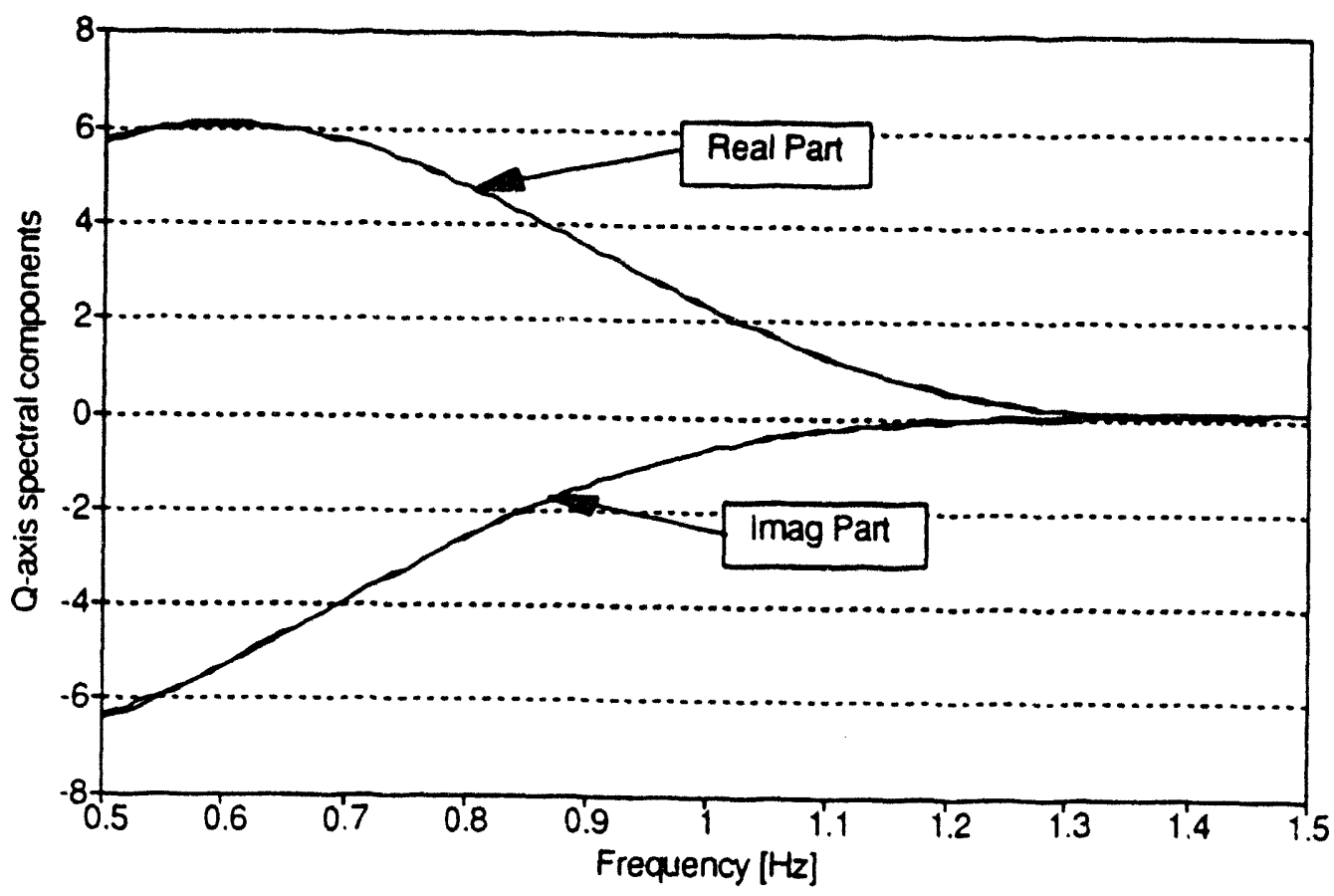

Fig. 3.4.7. Comparison of Measured and Estimated q-axis Frequency Response of Six-pole Winding, with Two-pole Open. 


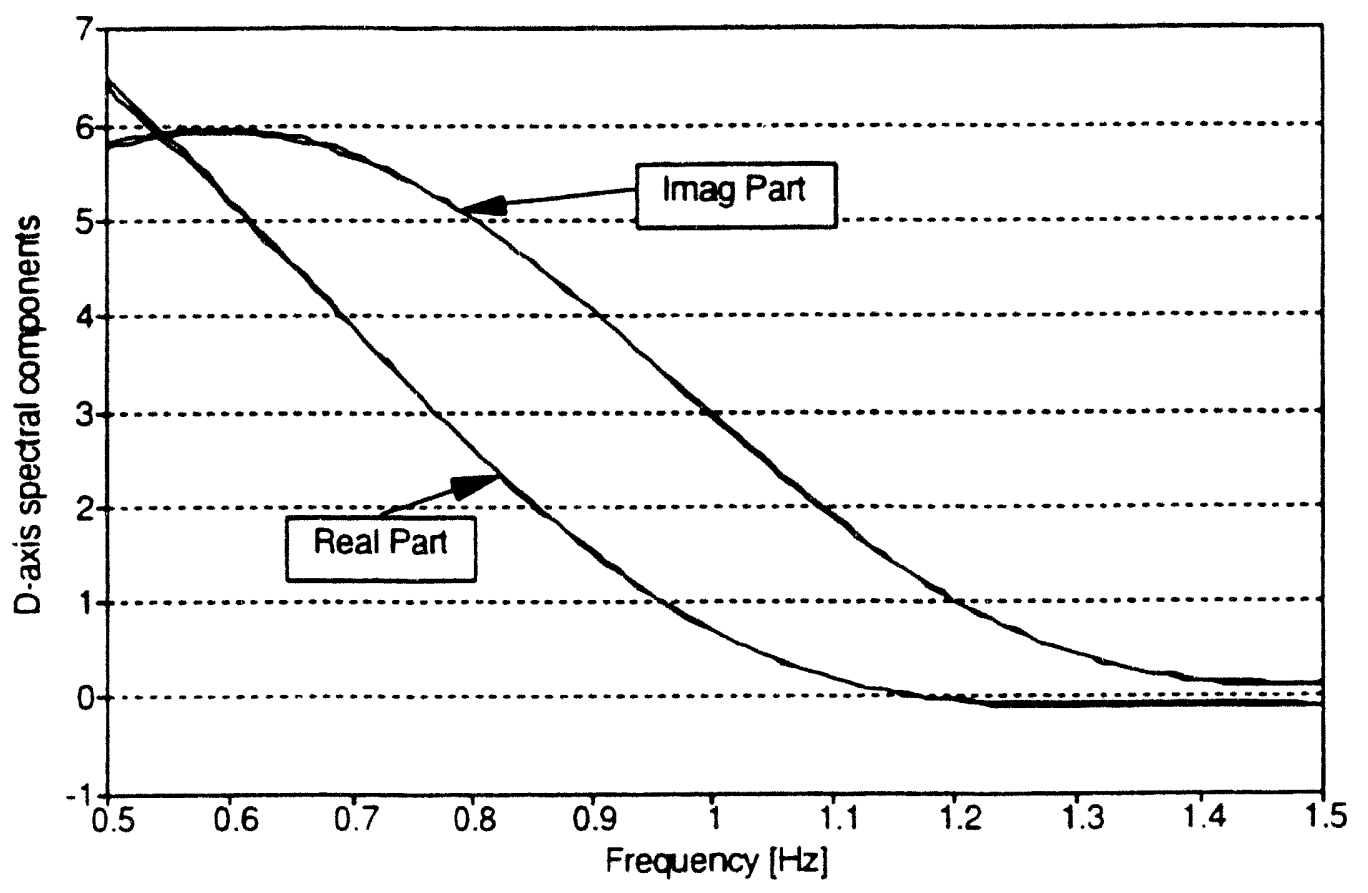

Fig. 3.4.8. Comparison of Measured and Estimated d-axis Frequency Response of Six-pole Winding, with Two-pole Open.

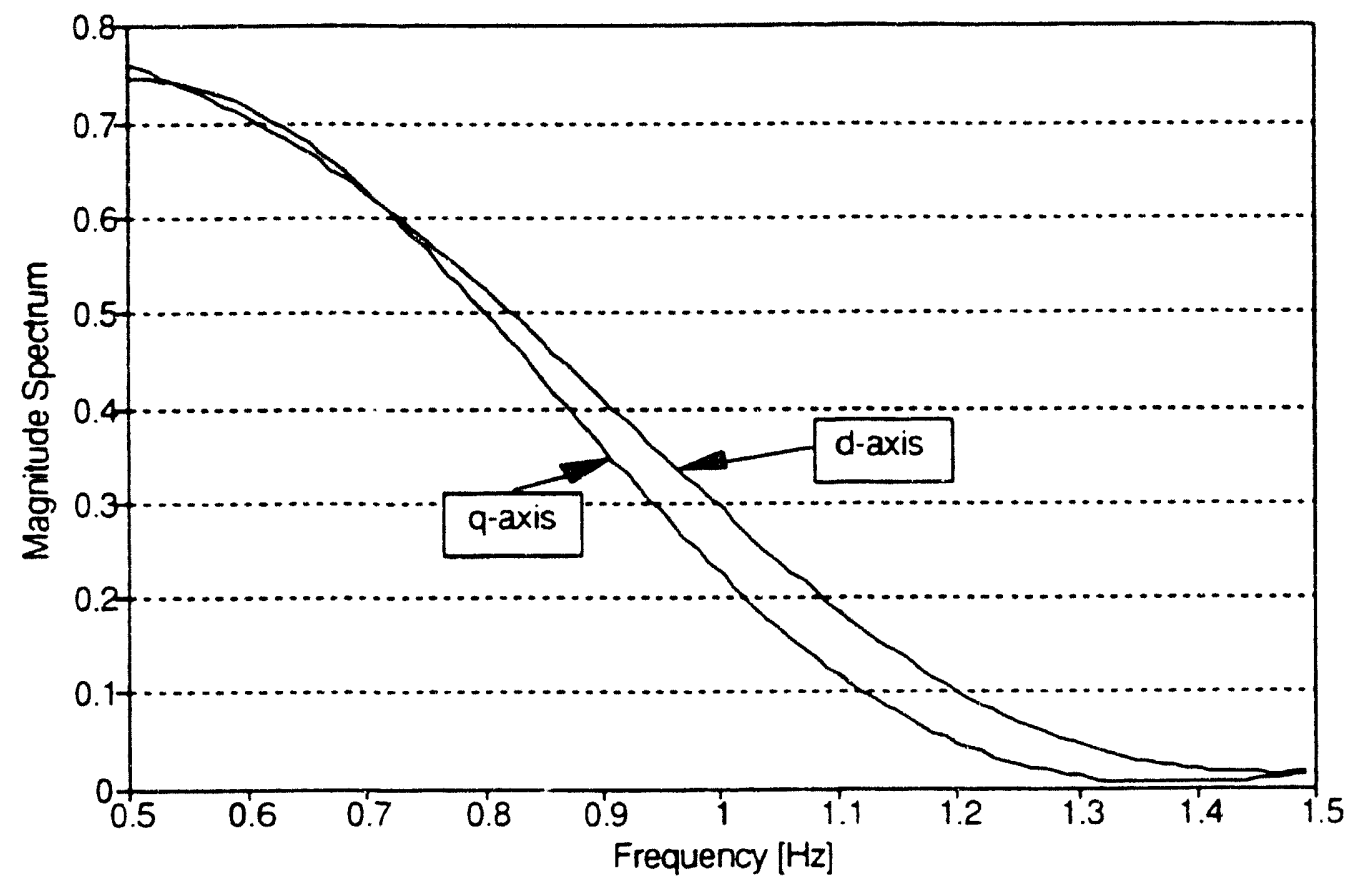

Fig. 3.4.9. Magnitude Spectrum of Input Modulation Current in the q-d Domain. 


\subsection{References}

[3.1] R. Li, A.K. Wallace and R. Spée, "Determination of Converter Control Algorithms for Stable Brushless Doubly-Fed Drives Using Floquet and Lyapunov Techniques," IEEE PESC, pp 571-577, 1991.

[3.2] M. Depenbrock, "Direct Self Control (DSC) of Inverter-Fed Induction Machines," IEEE Trans. Power Electronics, Vol. 3, No. 4, pp 420-429, 1988.

[3.3] I. Takahashi and T. Noguchi, "A New Quick-Response and High-Efficiency Control Strategy of an Induction Motor," IEEE Trans. LAS, Vol. IA-22, No. 5, pp 820-827, 1986.

[3.4] I. Boldea and J.A. Trica, "Torque Vector Controlled (TVC) Voltage-Fed Induction Motor Drives - Very Low Speed Performance via Sliding Mode Control, "International Conference on Electric Machines, pp 1212-1217, 1990.

[3.5] A. Sabanovic and F. Bilalovic, "Sliding Mode Control of AC Drives," IEEE Trans. LAS, Vol. IA-25, No. 1, pp 70-75, 1989.

[3.6] T.G. Habetler, F. Profumo, M. Pastorelli and L.M. Tolbert, "Direct Torque Control of Induction Machines Using Space Vector Modulation," IEEE-LAS Annual Meeting Conference Record, pp 428-436, 1991

[3.7] R. Li, A.K. Wallace and R. Spée, "Two-Axis Model Development of Cage-Rotor Brushless Doubly-Fed Machines," IEEE Trans. Energy Conversion, Vol. 6, No. 3, pp 453-460, 1991.

[3.8] W.R. Brassfield, "Direct Torque Control for Brushless Doubly-Fed Machines," M.S. Thesis, Oregon State University, 1993.

[3.9] S.M. Islam, C. B. Somuah, M. Shahgir-Ahmed and Y.L. Abdel-Magid, "Improved Speed Regulation of an Excitation Controlled Induction Motor," IEEE Transactions on Industry Applications, pp 694-701, Vol. 28, No. 3, 1992.

[3.10] H. Naitoh and S. Tadakuma, "Microprocessor-Based Adjustable-Speed DC Motor Drives Using Model Reference Adaptive Control," IEEE Transactions on Industry Applications, pp 313-318, Vol. 23, No. 2, 1987.

[3.11] B.K. Bose, "Power Electronics and AC Drives," Prentice Hall, 1986.

[3.12] K.J. Ȧström and B. Wittenmark, "Adaptive Control," Addison-Wesley, 1989.

[3.13] W. Brassfield, R. Spée and T. Habetler, "Direct Torque Control for Brushless DoublyFed Machines," IEEE Industry Applications Sociery Annual Meeting, pp 615-622, 1992.

[3.14] K. Ohnishi, Y. Ueda and K. Miyachi, "Model Reference Adaptive System Against Rotor Resistance Variation in Induction Motor Drive," IEEE Transaction on Industrial Electronics, pp 217-223, Vol. 33, No. 3, 1986. 


\section{LABORATORY PROTOTYPE}

The major objective in the construction of the Phase 3 prototype was to develop a machine which was to overcome the perceived problems of the Phase 1 and 2 machines, namely:

(i) magnetically inefficient rotors constructed in "deep bar" induction motor laminations;

(ii) electrically inefficient rotors due to inadequate bars and poor endring connections;

(iii) laminations damaged by removal of previous windings resulting in poor interlamination electrical integrity; and

(iv) stator winding distribution harmonics.

In addition, the BDFM needed comparison with an existing commercial induction motor from the point of view of efficiency and power factor and rating available from a given frame size.

Consequently, the laboratory prototype was constructed in the frame and stator laminations of four-pole induction motor using custom rotor parts. Laboratory evaluation of the original fourpole induction machine, a subsequent rewind to an eight-pole configuration, and the newly constructed BDFM allows for convenient comparison of the two technologies and illustrates the benefits of the BDFM topology.

\subsection{BDFM Design}

The stator laminations which are shown half size, with a full size slot, in Fig. 4.1.1 are exactly as used for the induction machine. A stack length of $100 \mathrm{~mm}$ was employed in the induction machine and was also adopted for the BDFM, although this is not truly optimal for either a certain commonality of configuration was necessary for the comparison process.

The rotor laminations are shown full size in Fig. 4.1.2. These were custom made, by laser cutting, to give an airgap in the range of 0.6 to $0.8 \mathrm{~mm}$ depending on tolerances. The surface insulation material is in accordance with AISI standard C-5: "an inorganic insulation with ceramic fillers" .... "it will withstand stress-relief annealing in a neutral or slightiy reducing atmosphere." This material is noted for a very high level of interlaminar resistance and is probably better than required for the application and is certainly far superior to the stator laminations.

As shown in Fig. 4.1.2, the rotor is designed with 40 slots (slot pitch $9^{\circ}$ ). For the six- 
pole/two-pole BDFM, the required 4 nests have 5 loops each of spans $9^{\circ}, 27^{\circ}, 45^{\circ}, 63^{\circ}$, and $81^{\circ}$ and no common cage. The rotor slots are designed to accommodate copper wire of $\# 2$ gauge as the bars: this gives rotor conductors of 0.258 " diameter. Fig. 4.1.3(a) shows the common endring of the rotor circuits which is constructed from $1 / 4$ " copper plate. The problems of (i) formation of loop rings and (ii) connection of bars to loop rings were solved by 1 " $\times 1 / 16$ " copper strips and $3 / 8$ " copper cylinders as shown in Fig. 4.1.4. All electrical connections within the rotor system were made using "SYLFOS 15", a soldering compound containing $15 \%$ silver commonly employed for the manufacture and repair of high quality copper rotors for induction motors. This form of brazed connection has good electrical and thermal properties but, because of the high temperatures required, negated efforts to insert insulation between the rotor bars and the laminations. The completed loop-ring assembly is shown in Fig. 4.1.3(b).

The specifications of the 36-slot stator windings are as follows:

\section{Six-Pole System}

2 coils per pole; $5 / 6$ pitch ( 5 slots); 12 turns/coil of two $\# 17$ gauge wires in parallel; $Y$ connected.

Two-Pole System

6 coils per pole; $15 / 18$ pitch (15 slots); 10 turns/coil of \#17 and \#18 gauge wires in parallel; $Y$ connected.

Schematics of the winding layouts and typical mmfs are shown in Figs. 4.1.5 and 4.1.6. 


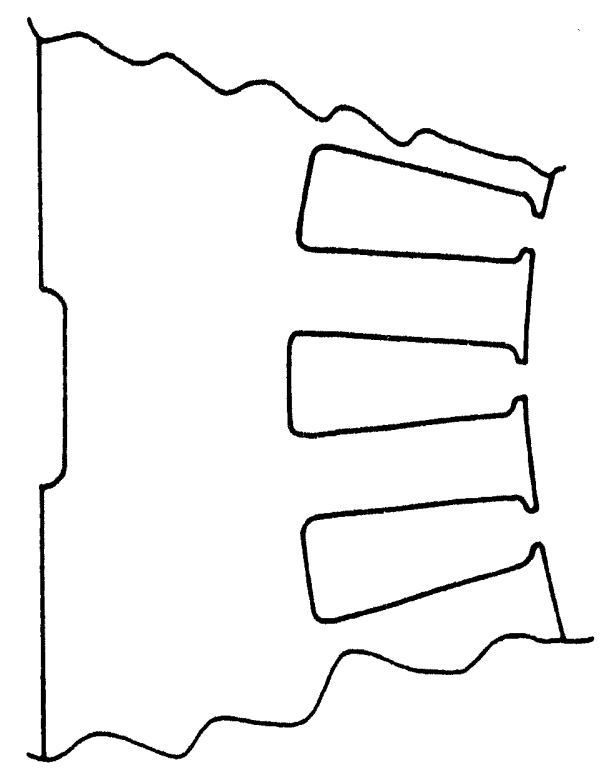

$\frac{0}{0}$
$\overline{0}$
$\overline{3}$
$\overline{2}$
$\overline{0}$
$\frac{0}{0}$
$\frac{5}{0}$
$\frac{0}{0}$

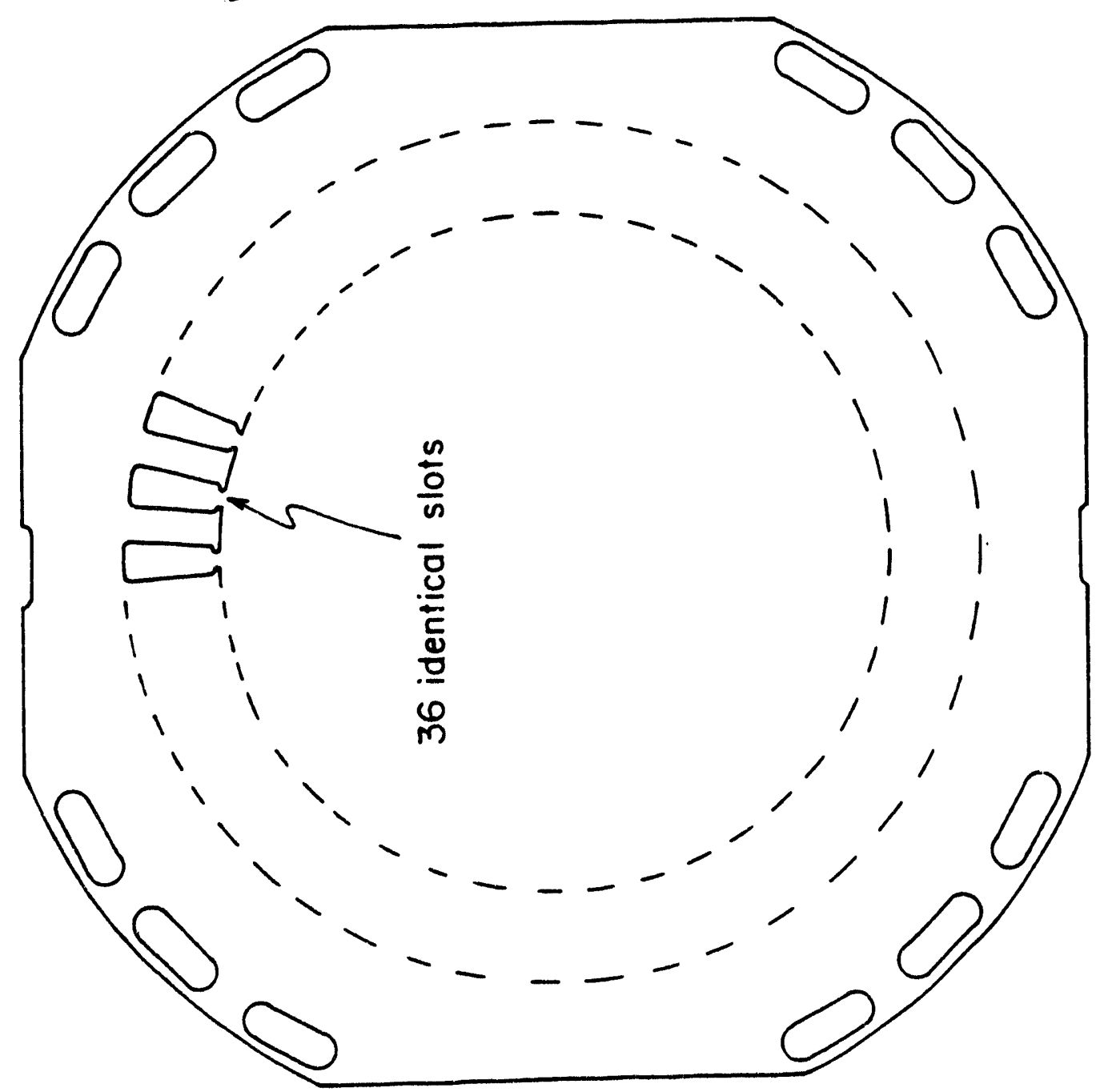

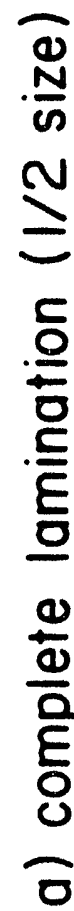




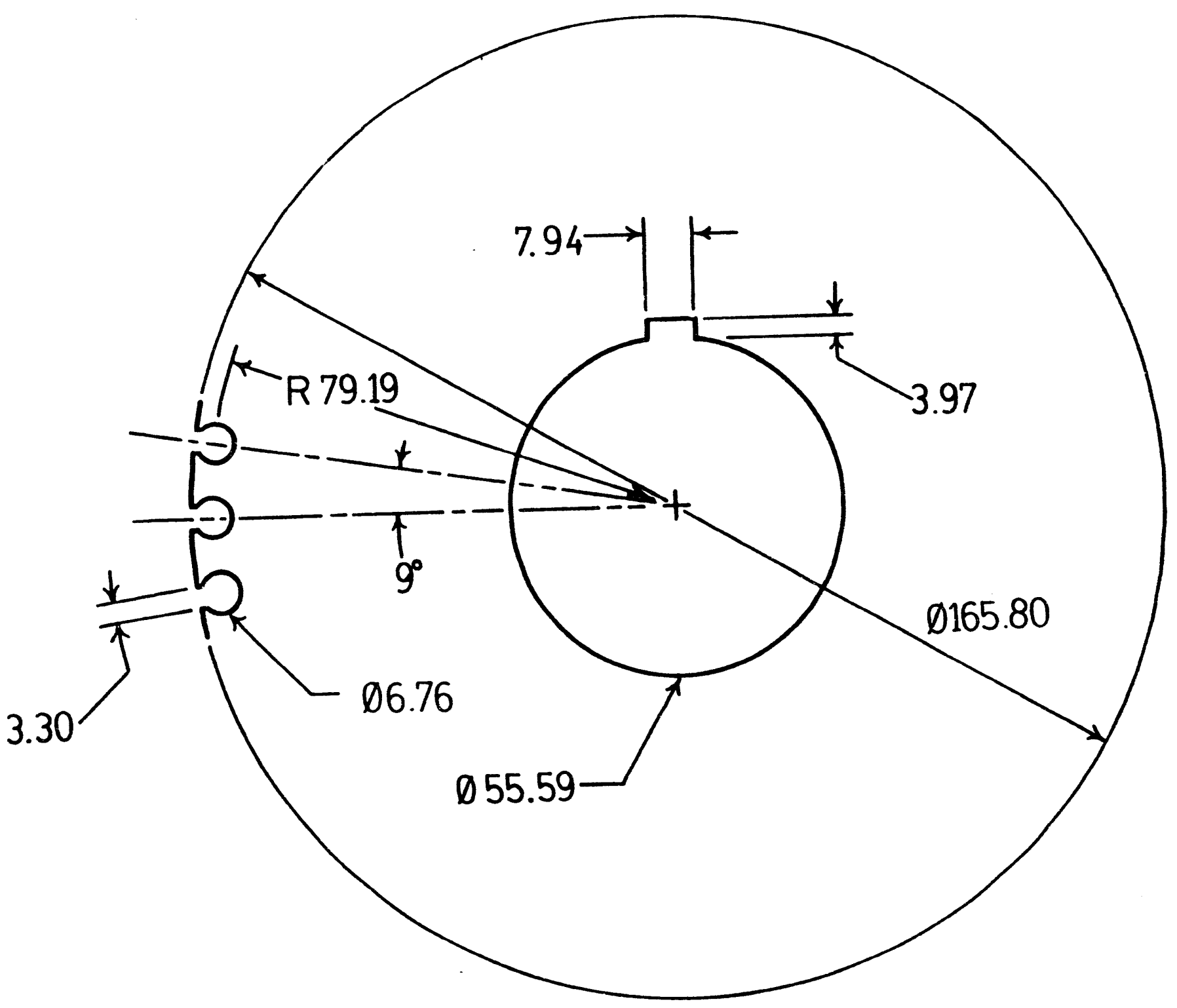

Fig. 4.1.2. Custom Made Rotor Laminations. 

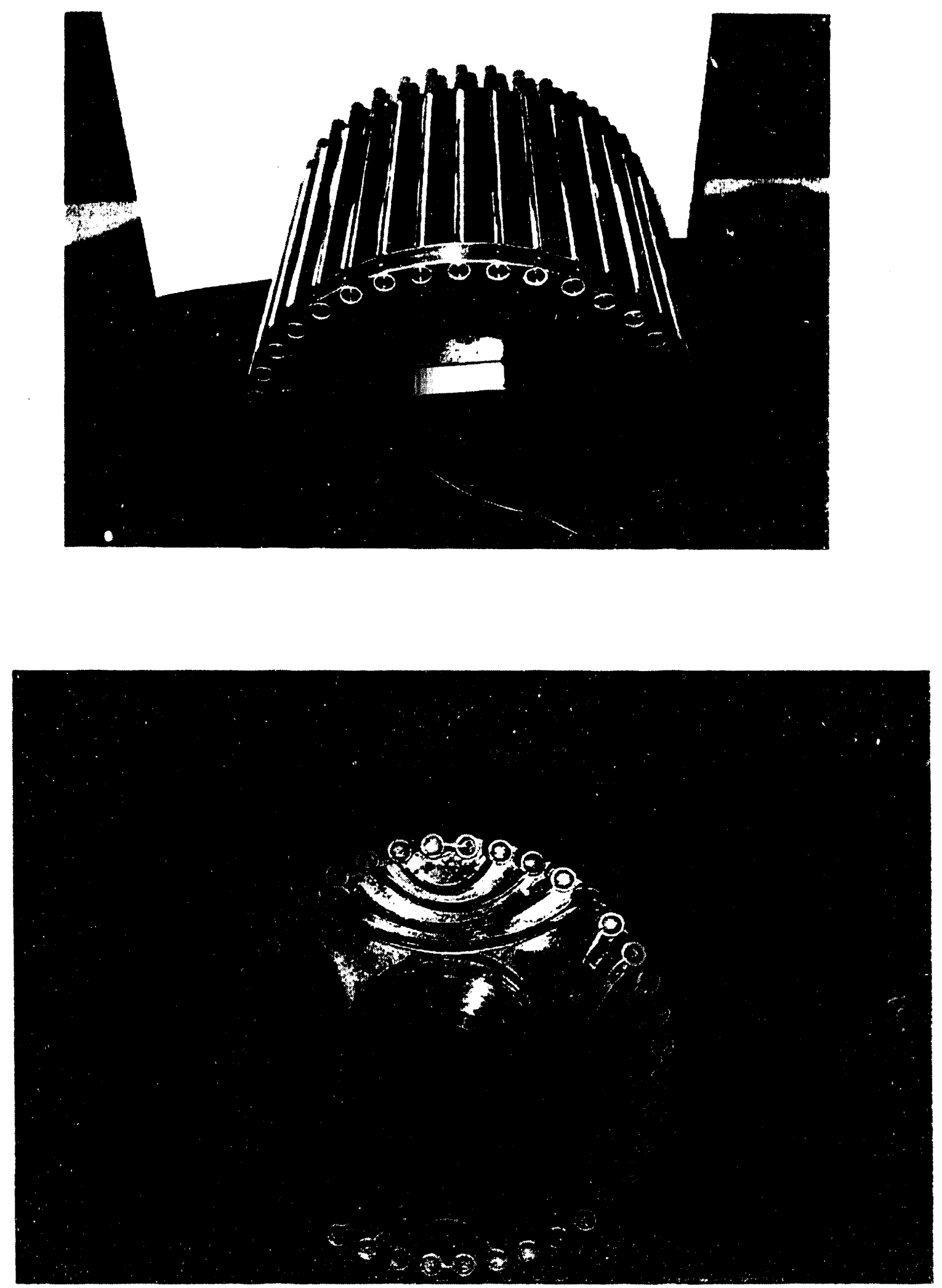

Fig. 4.1.3. BDFM Rotor During Assembly;

(a) View of Common Endring; (b) View of Isolated Endrings. 

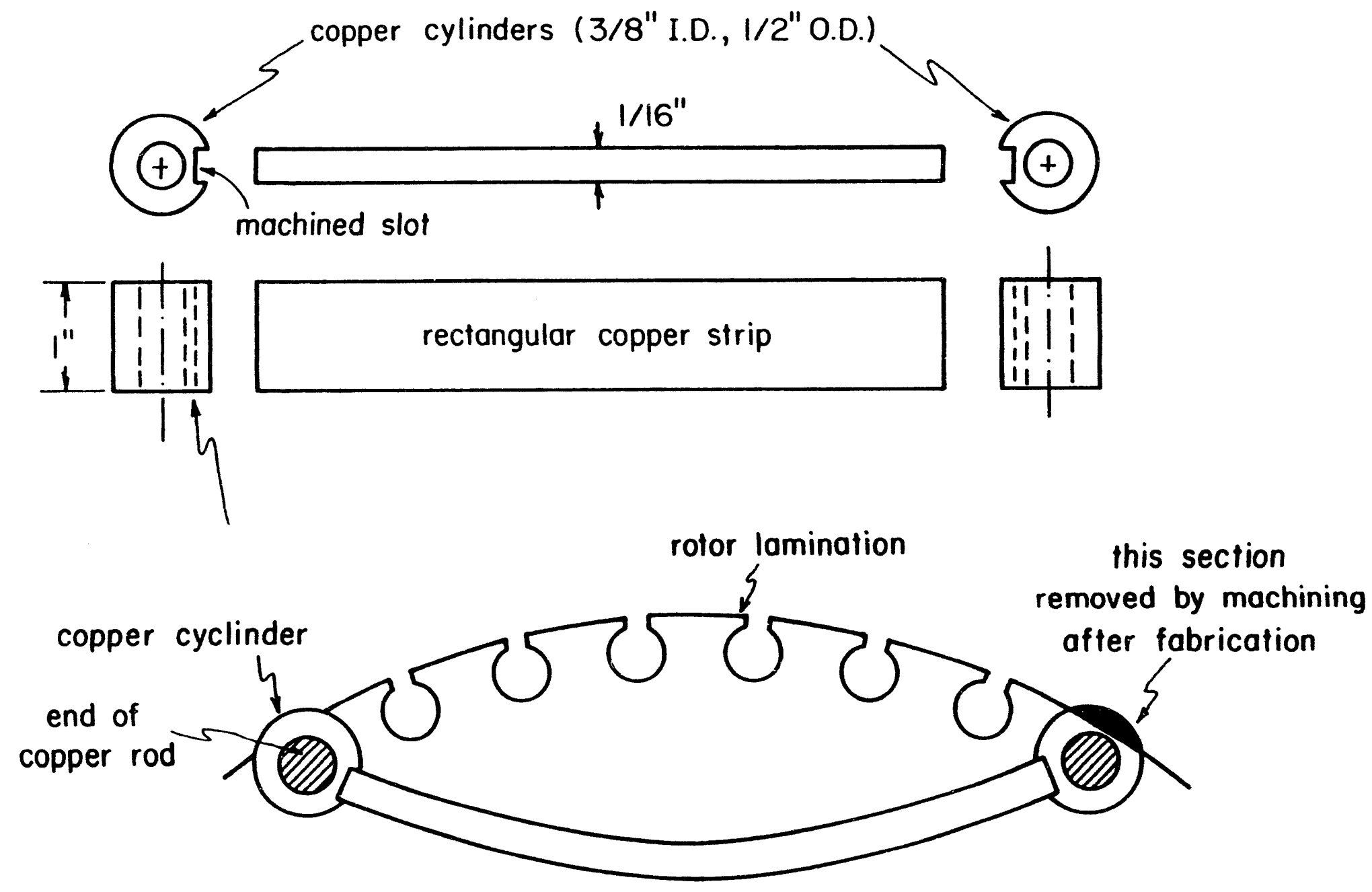

Fig. 4.1.4. Details of Isolated Endring Construction. 

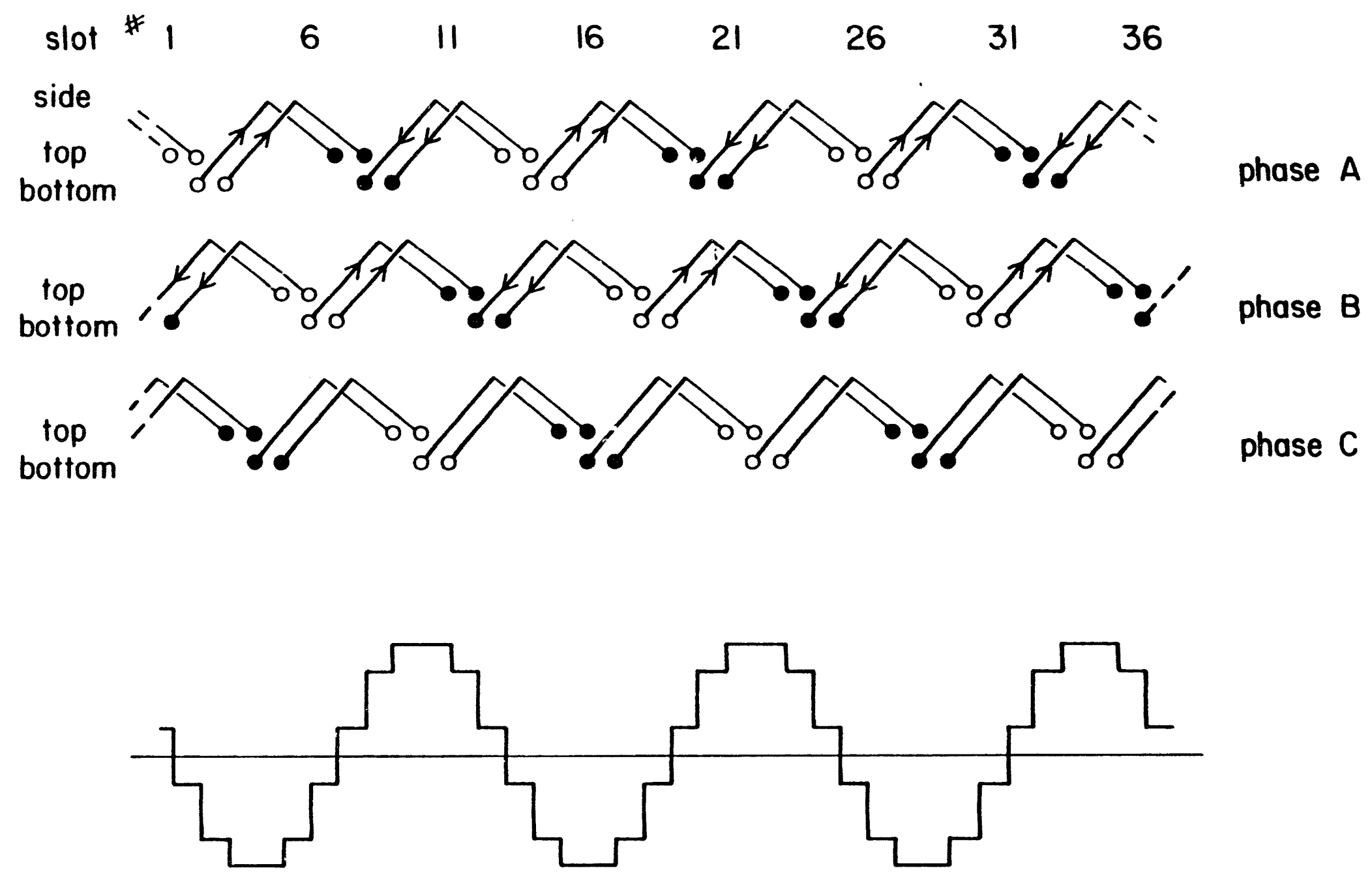

airgap MMF for $i_{A}=-i_{B} ; i_{C}=0$

Fig. 4.1.5. Schematic of Winding Layout and Resulting MMF: Six-Pole System. 


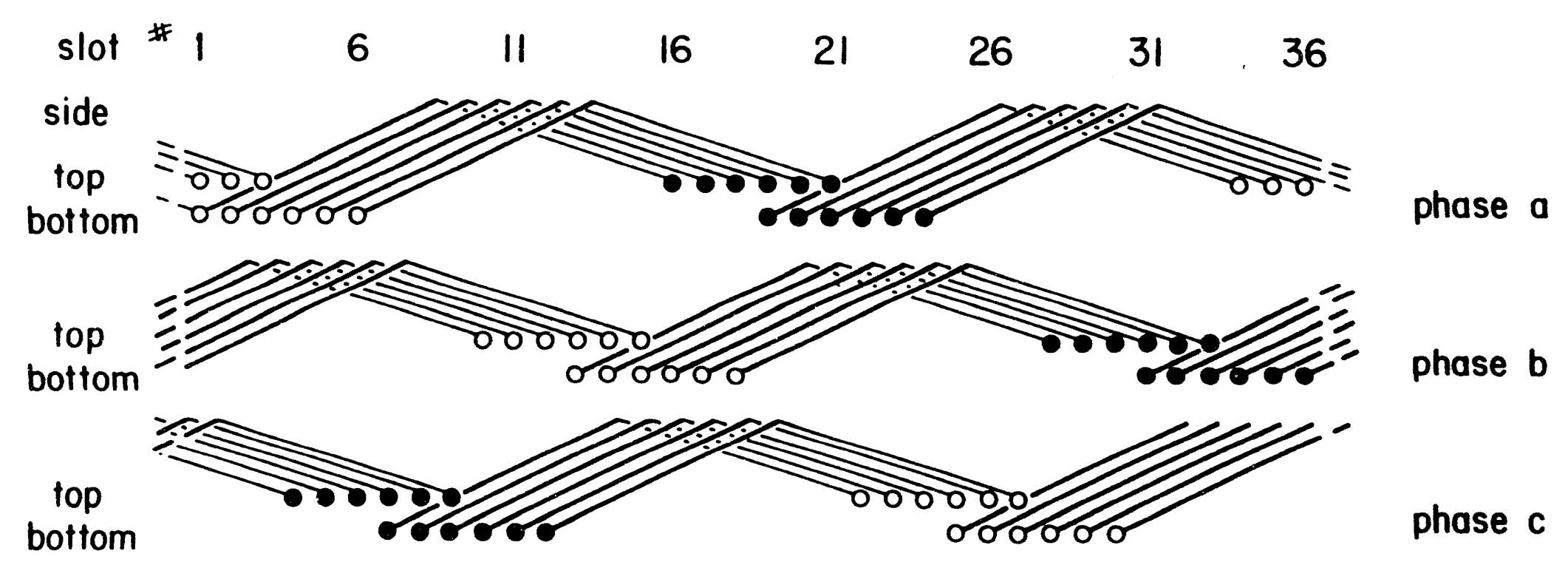

$\vec{\infty}$

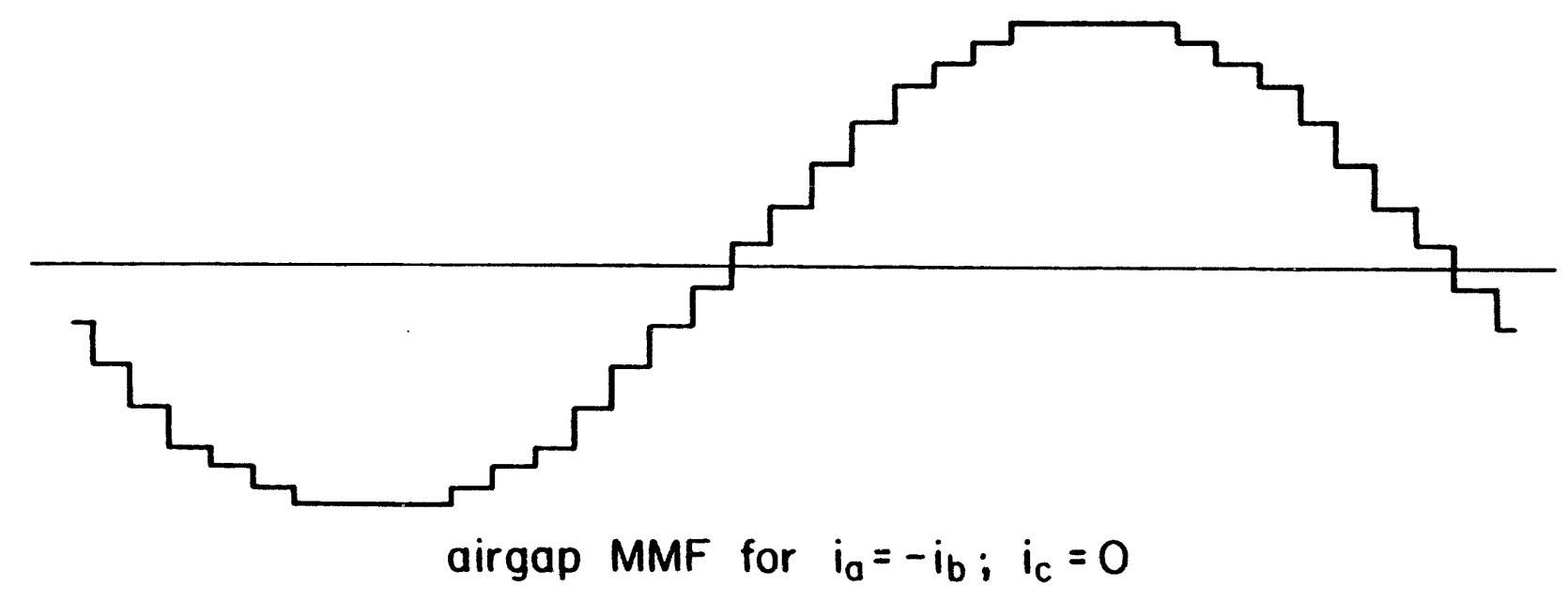

Fig. 4.1.6. Schematic of Winding Layout and Resulting MMF: Two-Pole System. 


\subsection{Induction Machine Performance}

Prior to construction of the optimized BDFM described in the previous section, the induction machine used as a base was carefully characterized in order to allow for performance comparison with the BDFM. To keep with prior prototypes, a new $15 \mathrm{hp}$, four-pole induction machine was purchased. Name plate data is illustrated in Table 4.1.

TABLE 4.1. Induction Motor Nameplate Data.

\begin{tabular}{||l|l||}
\hline Manufacturer & Baldor \\
\hline Classification & Regular Efficiency \\
\hline Frame & $254 \mathrm{~T}$ \\
\hline Enclosure & Open, Drip-proof \\
\hline Voltage & $230 / 460 \mathrm{~V}$ \\
\hline Rated Speed & $1760 \mathrm{r} / \mathrm{min}$ \\
\hline Nominal Power & $15 \mathrm{hp}$ \\
\hline Nominal Efficiency & $86 \%$ \\
\hline Nominal Power Factor & 0.81 \\
\hline
\end{tabular}

Extensive tests were performed on the machine before rewinding it to an eight-pole, $5 \mathrm{hp}$ configuration. Again, testing was performed before constructing the BDFM in the induction machine frame. For both induction machine topologies, equivalent circuit parameters were determined; this allows future comparison of BDFM performance with calculated induction machine results based on the parameters obtained. It should be noted that the induction machine purchased is not a high efficiency, high performance unit. Performance of subsequent rewinds have to be judged on the basis of the original motor and not on absolute terms. Moreover, care was taken during the rewind process to control the burn-out temperatures to a minimum. Yet, the magnetic circuit will suffer and efficiency will decrease somewhat from one rewind to the next.

\subsection{1. $15 \mathrm{hp}$ Induction Machine Performance}

Standard tests (open circuit, locked rotor) were used to determine the steady state circuit parameters (Fig. 4.2.1) of the $15 \mathrm{hp}$, four-pole induction machine. The results are listed in Table 4.2 . 
TABLE 4.2. Induction Machine Parameters (15 HP).

\begin{tabular}{||l|l||}
\hline Number of Poles & 4 \\
\hline Rated Torque & $60 \mathrm{Nm}$ \\
\hline Rated Frequency & $60 \mathrm{~Hz}$ \\
\hline Stator Resistance & $0.15 \Omega$ \\
\hline Stator Leakage & $0.93 \mathrm{mH}$ \\
\hline Core Resistance & $180 \Omega$ \\
\hline Magnetizing Inductance & $15.4 \mathrm{mH}$ \\
\hline 60 Hz Rotor Resistance & $0.19 \Omega$ \\
\hline dc Rotor Resistance & $0.08 \Omega$ \\
\hline Rotor Leakage Inductance & $0.93 \mathrm{mH}$ \\
\hline Friction and Windage Loss (at $1800 \mathrm{r} / \mathrm{min})$ & $150 \mathrm{~W}$ \\
\hline
\end{tabular}

The induction machine performance was also measured as a function of applied load. Efficiency and power factor results are shown in Figs. 4.2.2 and 4.2.3, respectively, along with representative model predictions using the parameters form Table 4.2. As illustrated, the parameter values predict machine performance quite well. Thus, if a future BDFM design is to be compared with the induction machine, the parameter values can be used to approximate induction machine performance.

The induction machine was also evaluated in two representative adjustable speed drive configurations, using the $15 \mathrm{kVA}$ laboratory Series Resonant Converter. Fig. 4.2.4 shows measured efficiency performance over a range of speeds for a constant load torque of $22.5 \mathrm{Nm}$, i.e. 37\% of full load torque. A square law fan characteristic is shown in Fig. 4.2.5, where the drive produces $45 \mathrm{Nm}$ at $1754 \mathrm{r} / \mathrm{min}$, i.e. about $75 \%$ of rated torque at rated speed. At low speeds the efficiency is seen to drop significantly, corresponding to the low values of output power at those operating points.

\subsubsection{5 hp Induction Machine Performance}

The $15 \mathrm{hp}$ induction machine discussed above was rewound to an eight-pole equivalent, which is a better comparison to the BDFM structures evaluated to date. In the given frame size, the eight-pole induction machine has a rating of only $5 \mathrm{hp}$. It should be noted that the $15 \mathrm{hp}$ 
frame with the attendant aspect ratio and slot numbers is not optimum for an eight-pole induction machine nor for a BDFM. Nevertheless, for comparison purposes, the eight-pole data should be representative.

Again, standard test procedures (open circuit, locked rotor) were used to determine the steady state parameters of the $5 \mathrm{hp}$, eight-pole induction machine. The results are listed in Table 4.3.

TABLE 4.3. Induction Machine Parameters (5 hp).

\begin{tabular}{|l|l|}
\hline Number of Poles & 8 \\
\hline Rated Torque & $40 \mathrm{Nm}$ \\
\hline Rated Frequency & $60 \mathrm{~Hz}$ \\
\hline Stator Resistance & $0.50 \Omega$ \\
\hline Stator Leakage & $3.90 \mathrm{mH}$ \\
\hline Core Resistance & $210 \Omega$ \\
\hline Magnetizing Inductance & $22.8 \mathrm{mH}$ \\
\hline 60 Hz Rotor Resistance & $0.70 \Omega$ \\
\hline dc Rotor Resistance & $0.26 \Omega$ \\
\hline Rotor Leakage Inductance & $3.90 \mathrm{mH}$ \\
\hline Friction and Windage Loss (at 900 r/min) & $80 \mathrm{~W}$ \\
\hline
\end{tabular}

Induction machine performance was again measured as a function of applied load. Efficiency and power factor results are shown in Figs. 4.2.6 and 4.2.7, respectively, along with model predictions. Again, simulation and measurement are in good agreement.

Adjustable speed drive performance was again evaluated in the laboratory using the Series Resonant Converter. Figs. 4.2.8 and 4.2.9 show efficiency performance for constant load torque values of $50 \%$ and $80 \%$ of the $40 \mathrm{Nm}$ rating, respectively. A square law fan characteristic is shown in Fig. 4.2.10, where the drive produces $32 \mathrm{Nm}$ at $867 \mathrm{r} / \mathrm{min}$, i.e. about $80 \%$ of rated torque at rated speed. 


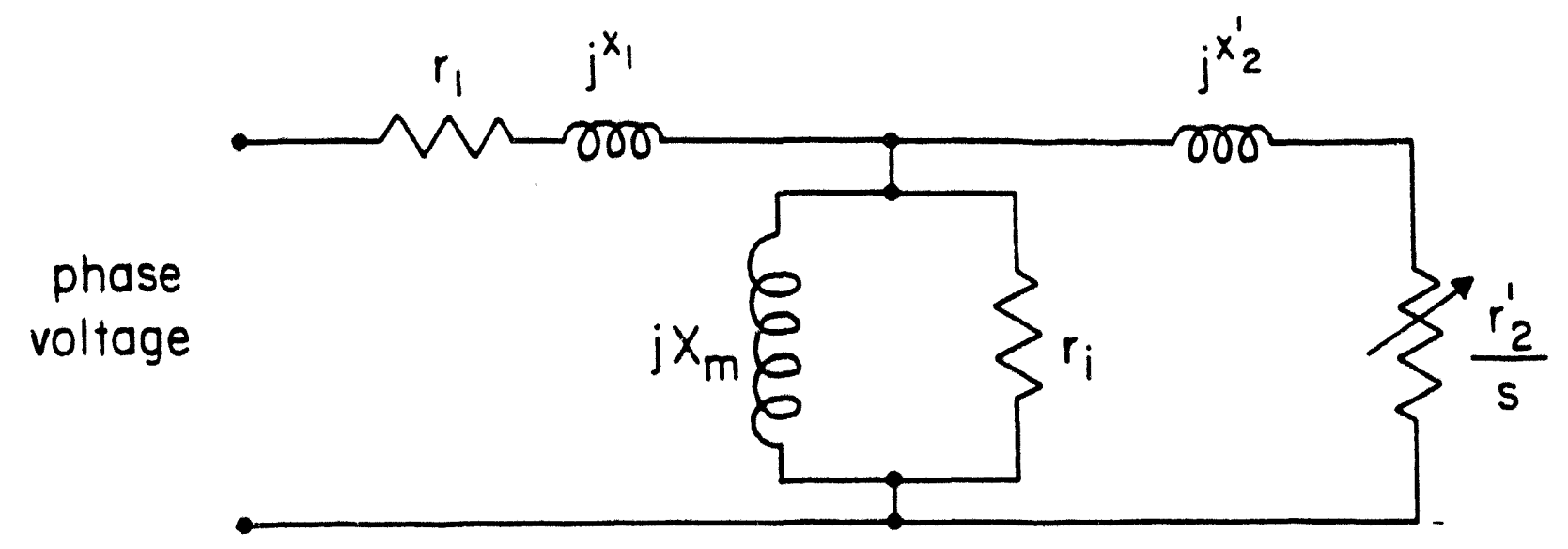

Fig. 4.2.1. Induction Machine Steady State Equivalent Circuit.

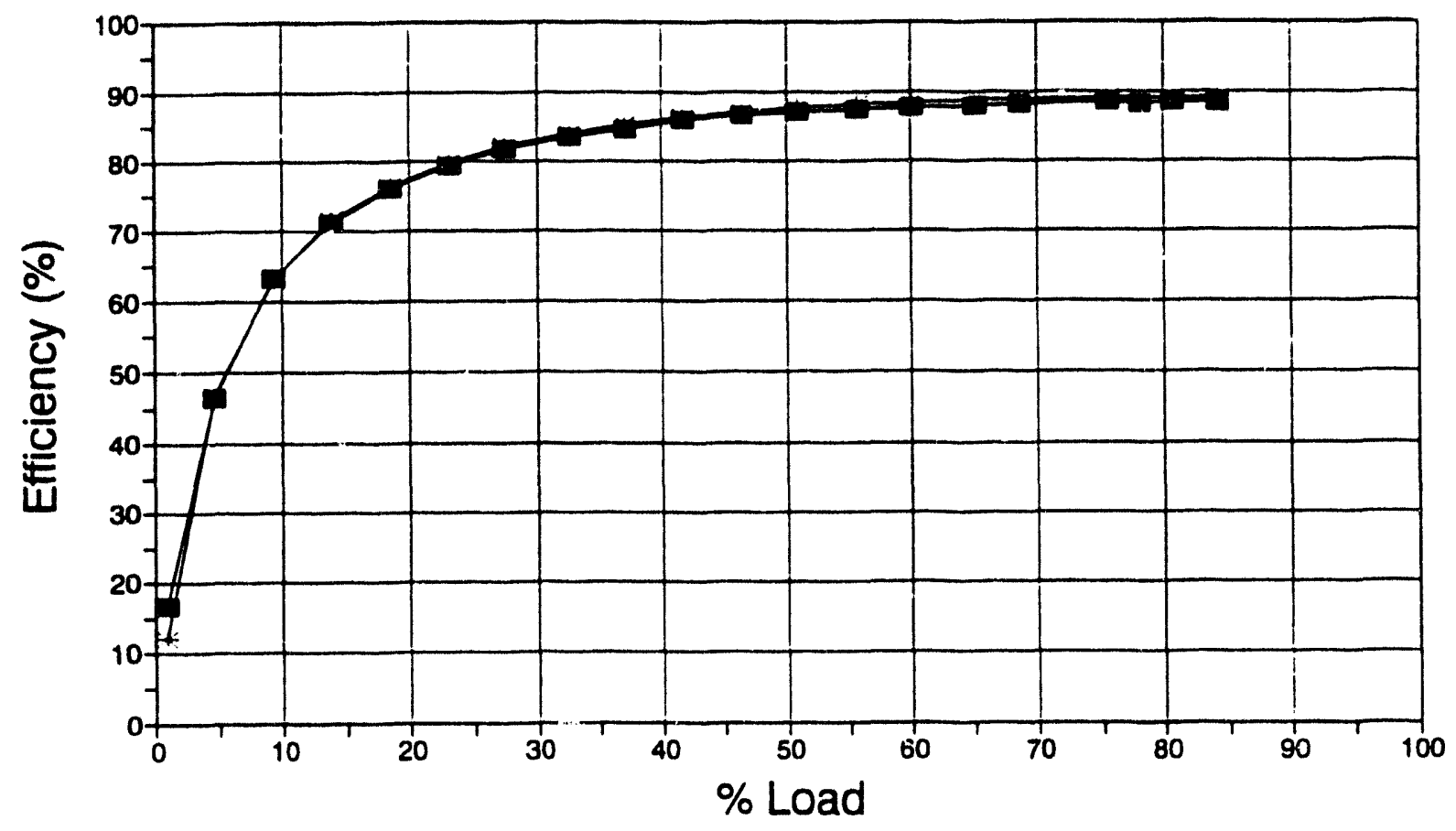

$\rightarrow$ - Measured Simulation

Fig. 4.2.2. Induction Machine Efficiency (four-pole, $15 \mathrm{hp}$ ). 


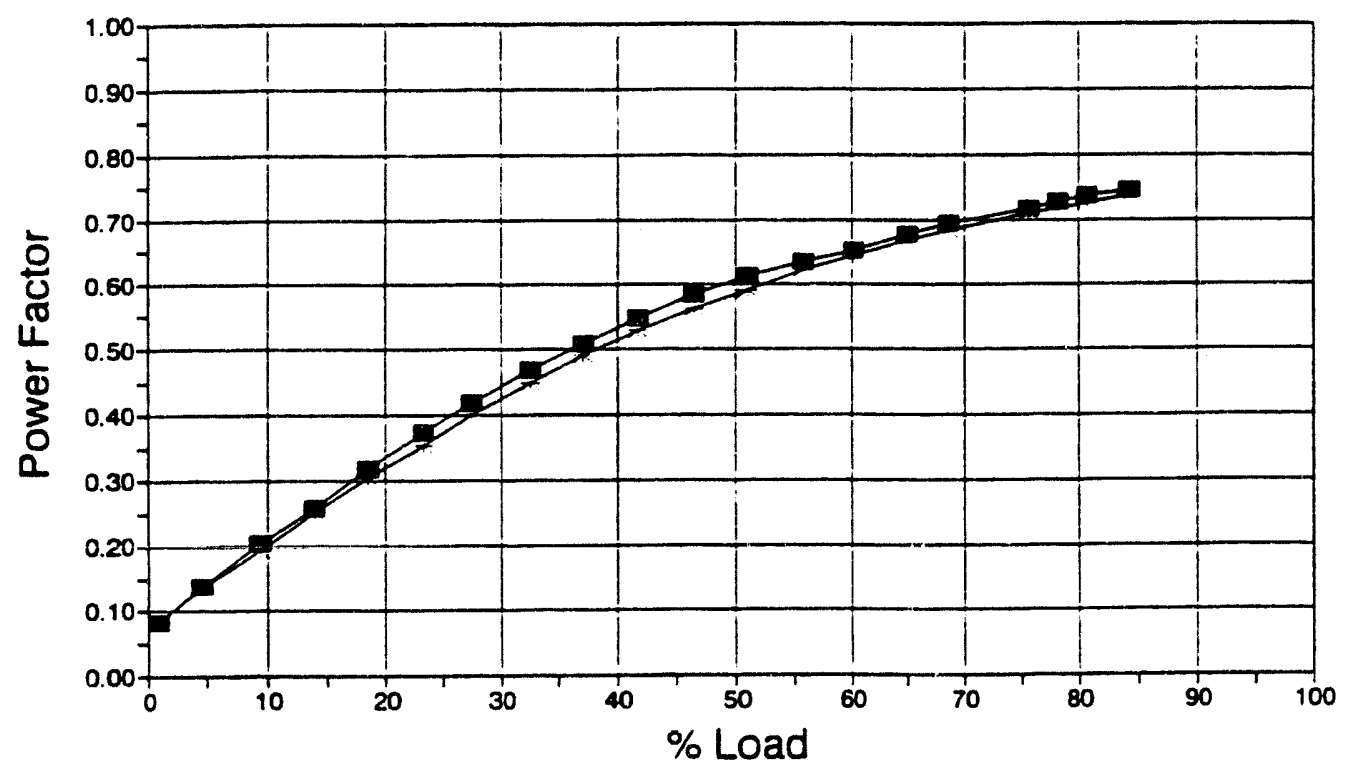

$\rightarrow$ Measured - Simulation

Fig. 4.2.3. Induction Machine Power Factor (four-pole, $15 \mathrm{hp}$ ).

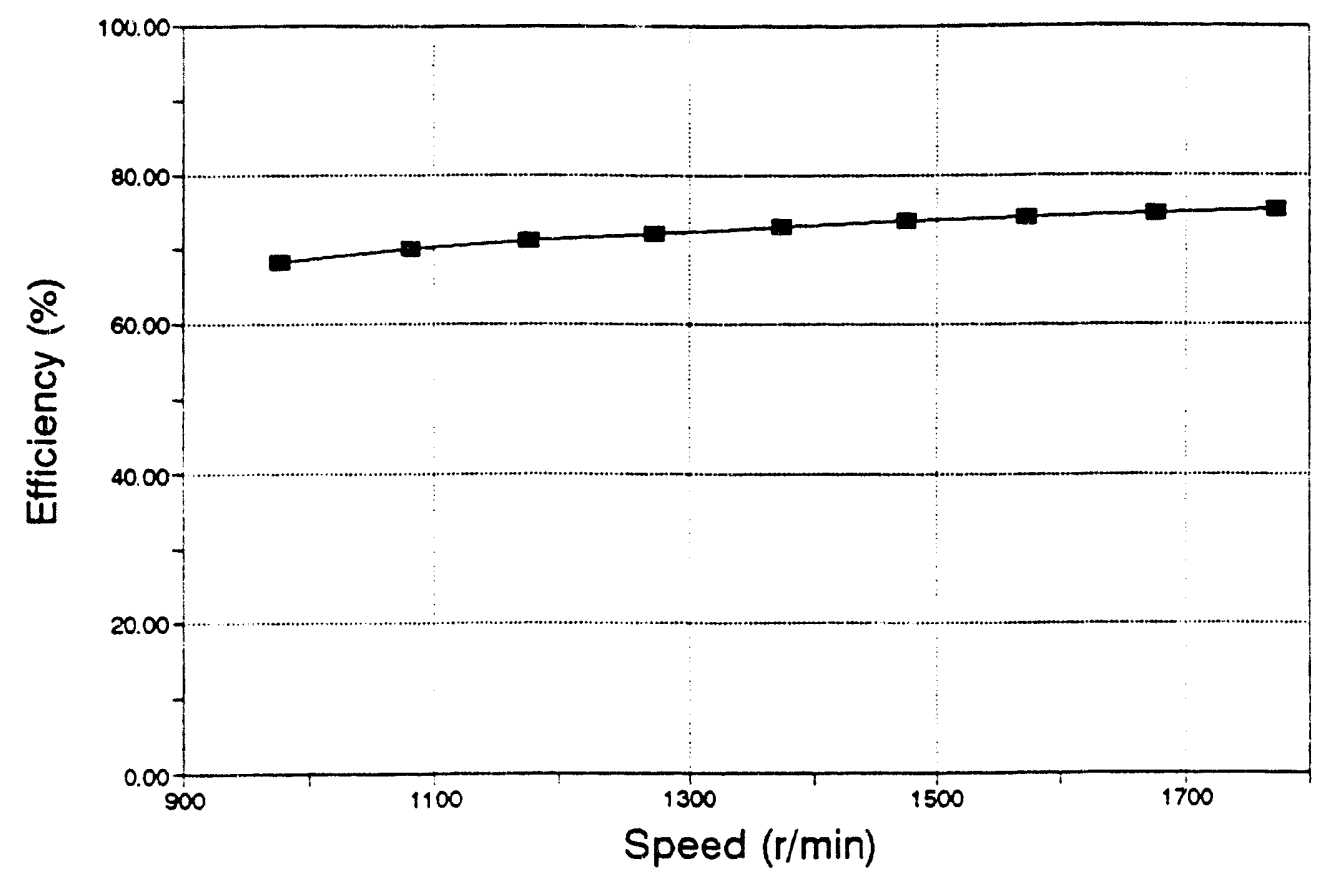

Fig. 4.2.4. Adjustable Speed Induction Machine Drive Performance for Constant Load Torque (37\% of Rating, 15 hp IM, SRC-fed). 


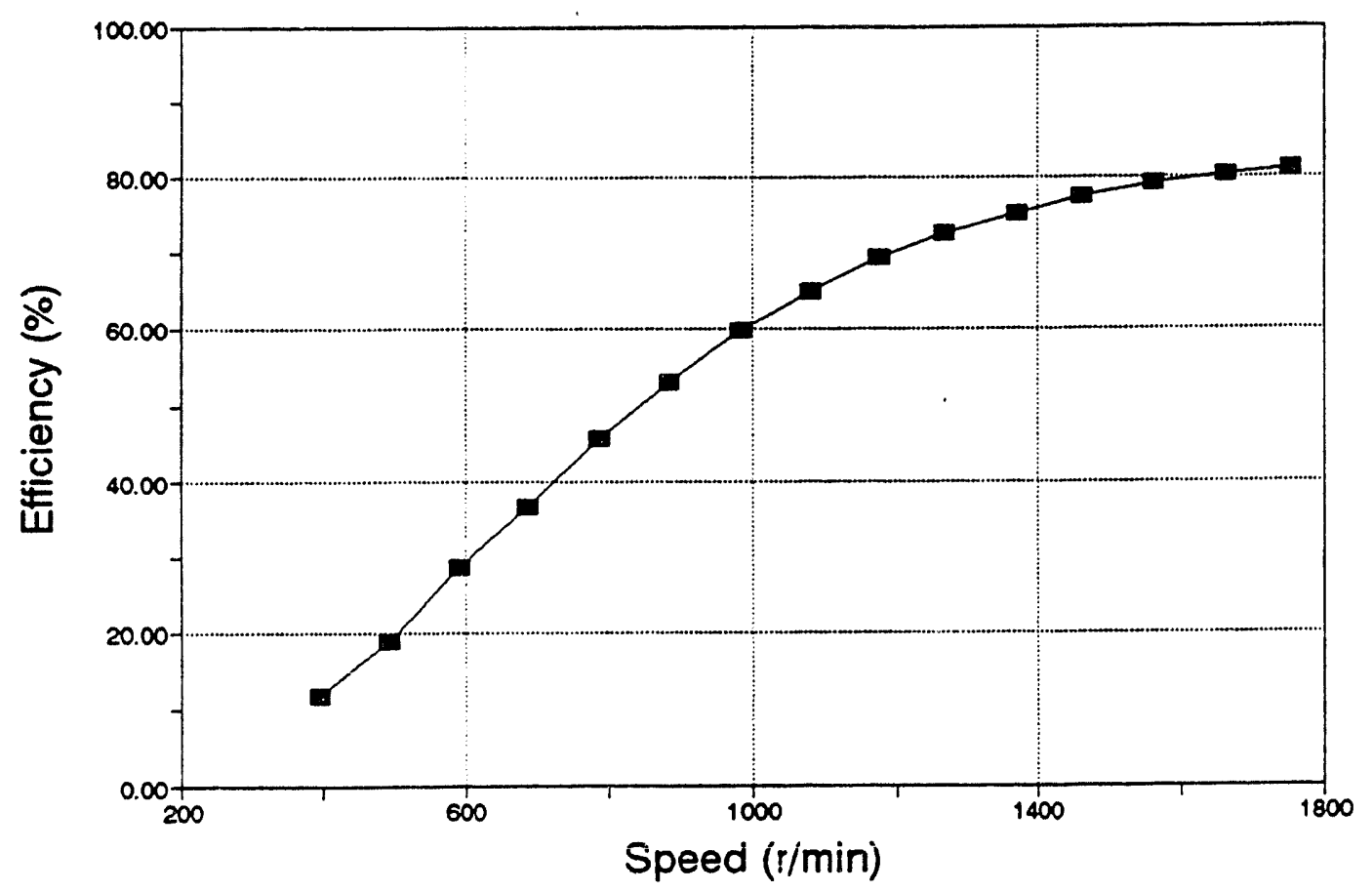

Fig. 4.2.5. Adjustable Speed Induction Machine Drive Performance for Fan Load (75\% of Rating at Rated Speed, 15 hp IM, SRC-fed).

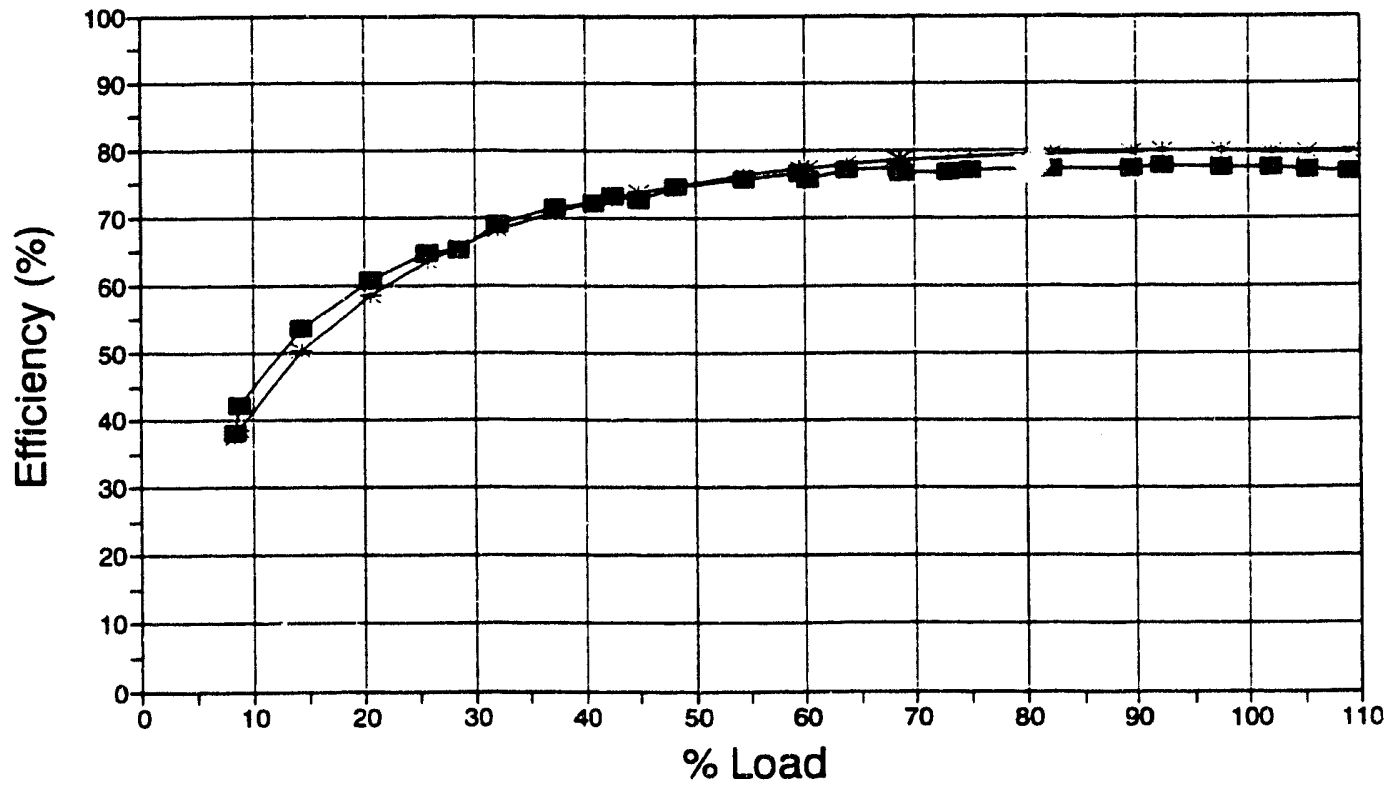

Measured $\nVdash$ Simulation

Fig. 4.2.6. Induction Machine Efficiency (eight-pole, $5 \mathrm{hp}$ ). 


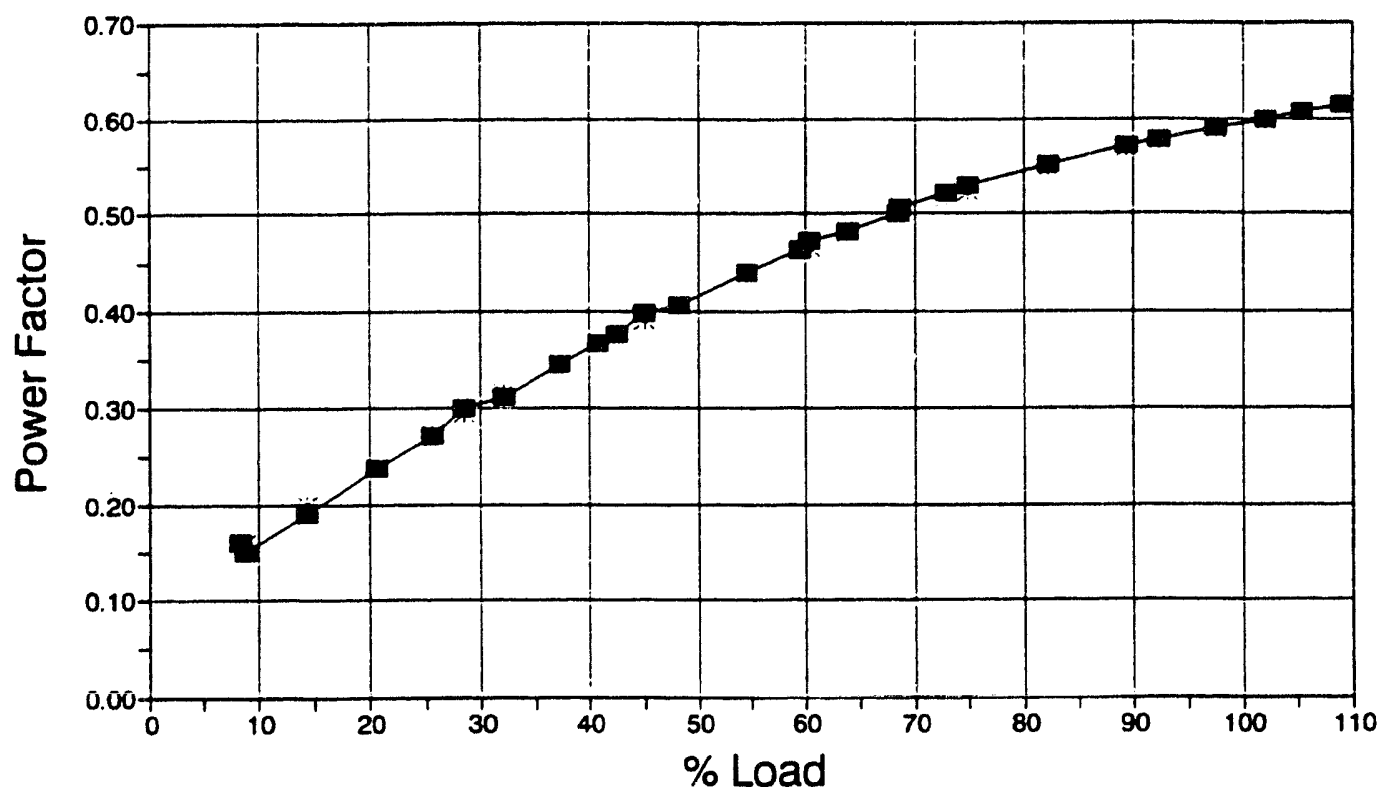

$\rightarrow$ Measured - Simulation

Fig. 4.2.7. Induction Machine Power Factor (eight-pole, 5 hp).

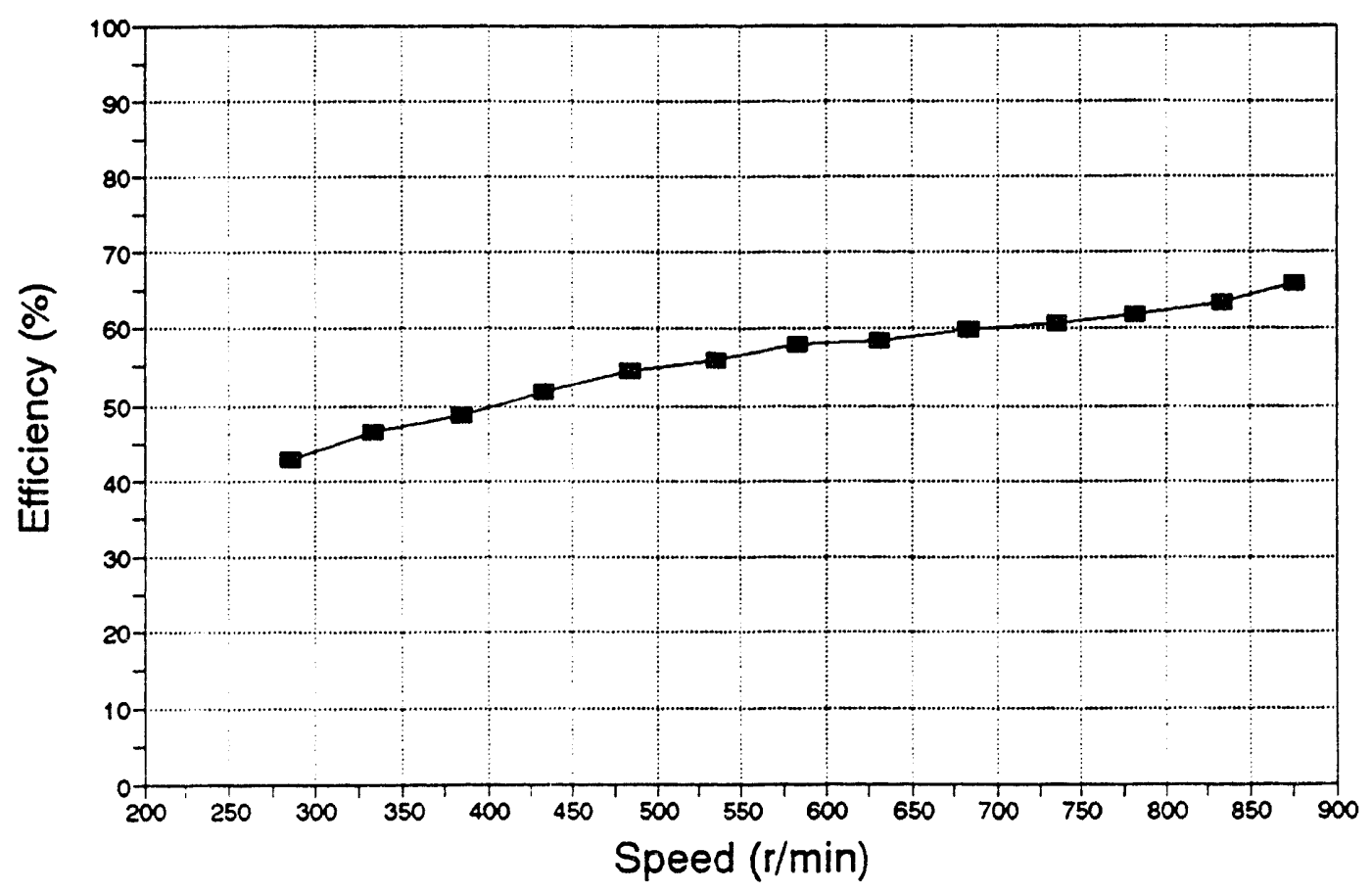

Fig. 4.2.8. Adjustable Speec' Induction Machine Drive Performance for Constant Load Torque (50\% of Rating, 5 hp IM, SRC-fed). 


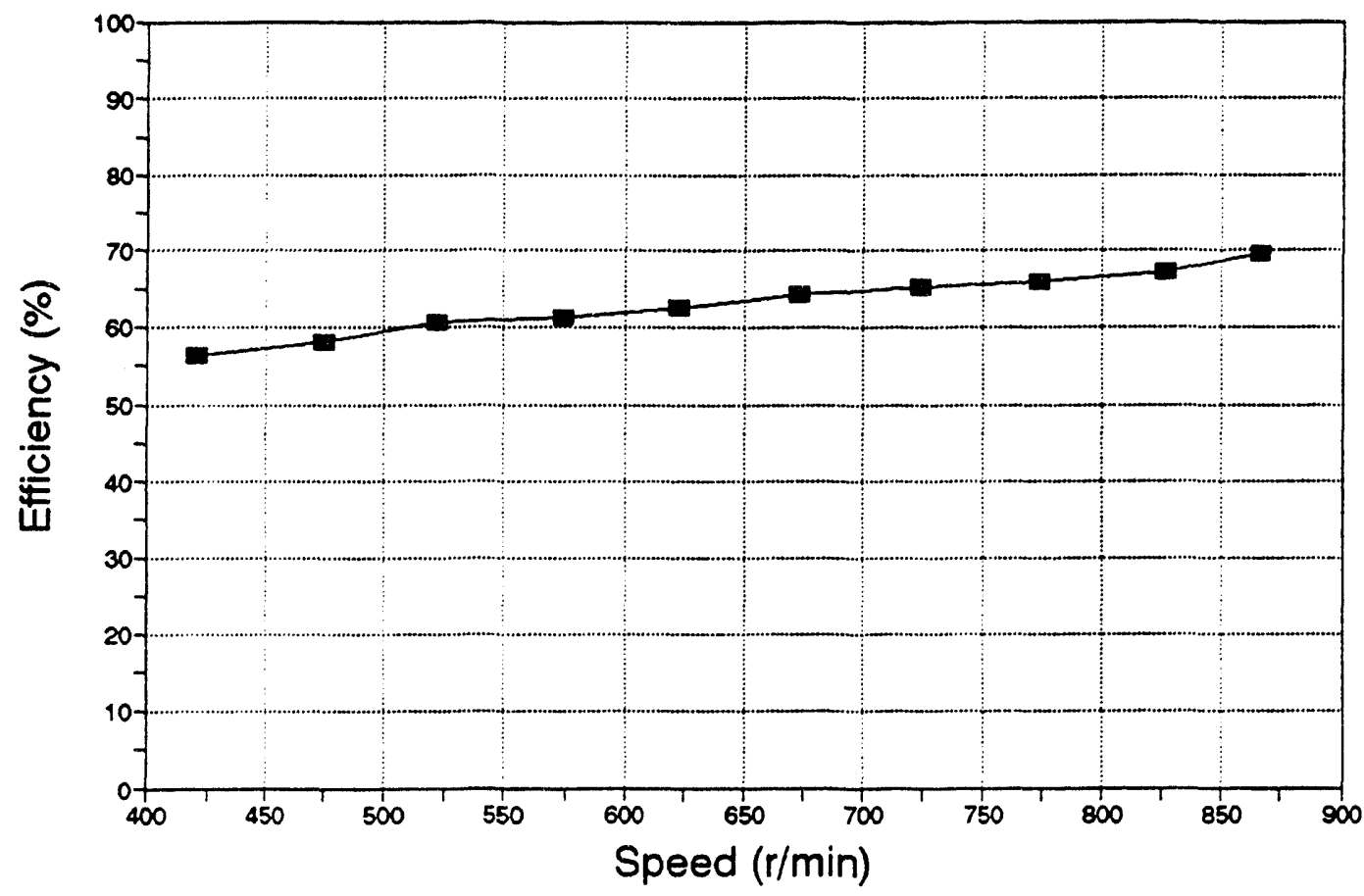

Fig. 4.2.9. Adjustable Speed Induction Machine Drive Performance for Constant Load Torque (80\% of Rating, 5 hp IM, SRC-fed).

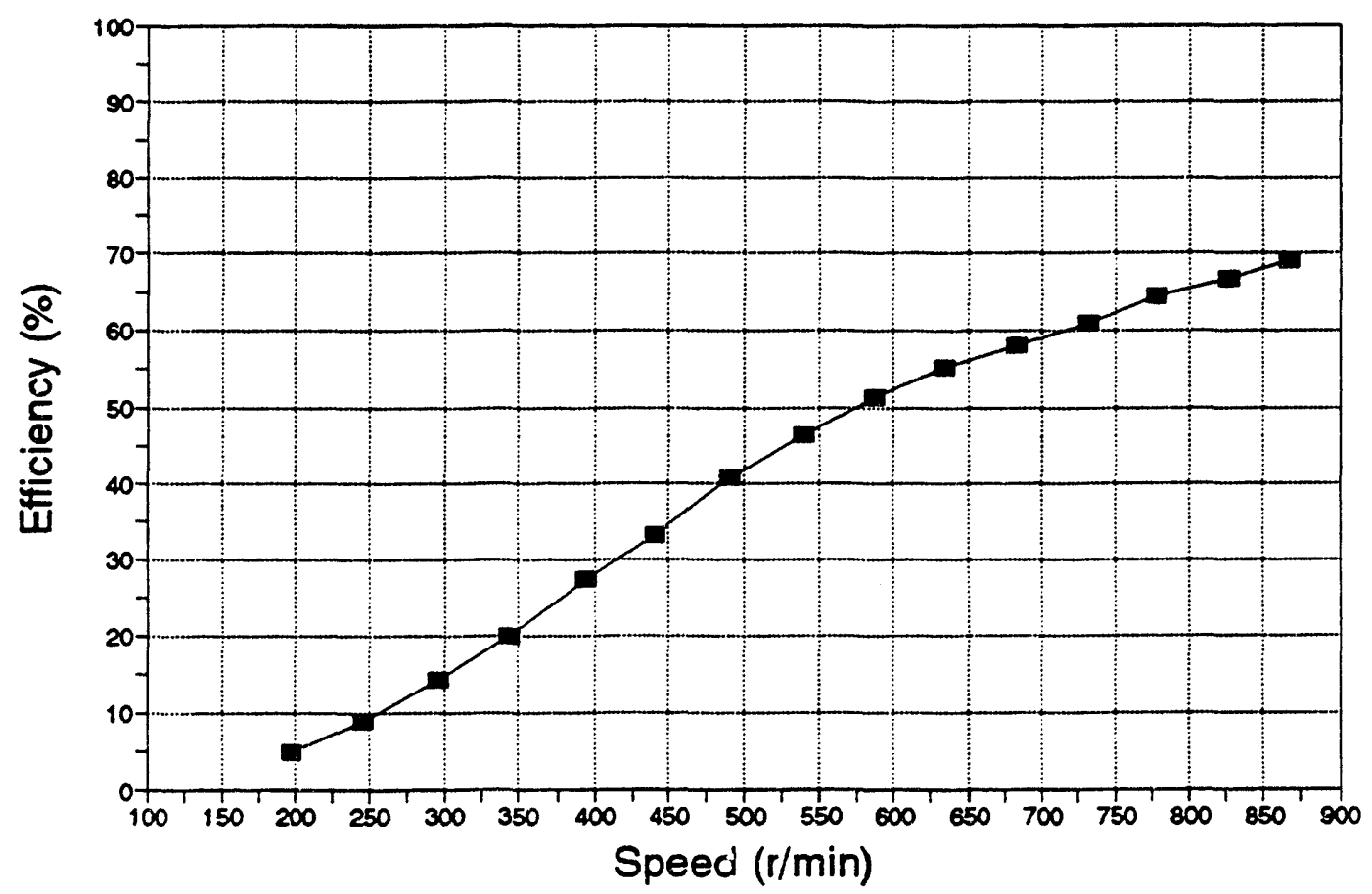

Fig. 4.2.10. Adjustable Speed Induction Machine Drive Performance for Fan Load (80\% of Rating at Rated Speed, $5 \mathrm{hp} \mathrm{IM,} \mathrm{SRC-fed).}$ 


\subsection{BDFM Performance}

The BDFM laboratory prototype discussed in section 4.1 was subjected to extensive laboratory tests to establish the quality of the design and to give a representative basis for comparison with induction machine drive performance. The BDFM prototype constructed was optimized to operate in the $0-1200 \mathrm{r} / \mathrm{min}$ speed range. This allows a scaled down evaluation of the $45 \mathrm{~kW}$ pump drive prototype to be constructed during Phase 4 . However, performance at the high band speed (i.e. $1200 \mathrm{r} / \mathrm{min}$ to $1800 \mathrm{r} / \mathrm{min}$ ) is far from optimum for this design as the number of stator winding turns selected leads to high excitation voltage requirements. Thus, performance results are only reported for the equivalent of a $5 \mathrm{hp}$, eight-pole induction motor drive. It should be noted again that the aspect ratio of the machine is based on a four-pole design. Neither the eight-pole induction machine drive discussed in section 4.2, nor the BDFM will be optimized designs in themselves, but will allow a comparative evaluation of relative performance.

Figures 4.3.1 and 4.3.2 show BDFM performance for a constant load torque value of 50\% of the $40 \mathrm{Nm}$ rating. This compares with the induction machine results shown in Fig. 4.2.8. Measured efficiency results in Fig. 4.3.2 illustrate performance of the machine in comparison with the overall drive. As evident from Fig. 4.3.2, the $15 \mathrm{kVA}$ series resonant converter only processes around $0.5 \mathrm{kVA}$. Thus, converter losses in this test are exaggerated significantly. With a converter of appropriate rating, the overall BDFM drive efficiency will be much closer to the machine efficiency.

Figures 4.3.3 and 4.3.4 show BDFM performance for a square law fan characteristic, where the drive produces $32 \mathrm{Nm}$ at $867 \mathrm{r} / \mathrm{min}$, i.e. about $80 \%$ of rated torque at rated speed. Fig. 4.3.4 compares with the induction machine performance illustrated in Fig 4.2.10. As in the constant load case, the drive efficiency measurement is penalized by excessive converter loss in the experimental system.

With regard to the pump drive development planned for Phase 4, it is illustrative to compare induction machine and BDFM drive performance for the square law torque load. Fig. 4.3.5 compares converter ratings required for the eight-pole induction machine and the BDFM. Note that in the induction machine, poor machine power factor and relatively poor efficiency combine to yield a converter rating of almost $300 \%$ of output shaft power. For the BDFM, the converter only needs to process approximately $15 \%$ of maximum output power. (It should be noted, 
however, that the BDFM still draws reactive power directly from the grid and has a power factor similar to an eight-pole induction machine.) A comparison of efficiencies for the two drives is shown in Fig. 4.3.6, where the measured results for the BDFM were adjusted to account for the excessive converter rating (i.e. converter losses were scaled to the actual current/voltage requirements). It is evident that the BDFM drive performs quite favorably with respect to the conventional induction motor drive configuration.

While the BDFM laboratory prototype performs quite well, the design needs to be optimized with regard to aspect ratio and slot allocation for the pump drive to be developed during Phase 4. Other issues to be resolved include loss distribution between converter and machine as well as loss allocation in the machine, machine temperature rise and insulation stresses. These items will be addressed in conjunction with a motor manufacturer during the Phase 4 design activities. The results shown here indicate that the BDFM can indeed be superior to conventional, low-speed induction motor drives. 


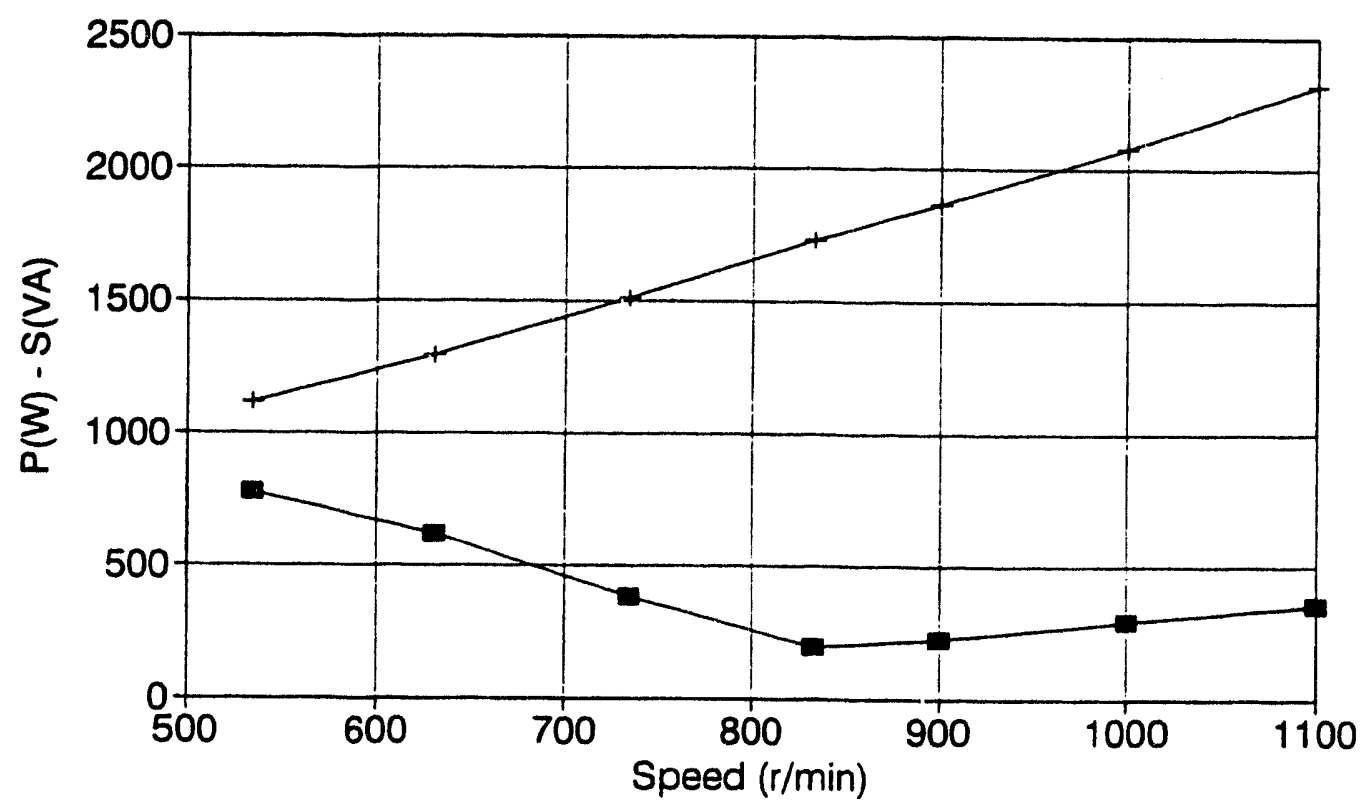

Fig. 4.3.1. BDFM Output Power and Converter Rating for Constant Load Torque (50\% of Rating, 5 hp Nominal Rating, SRC-control).

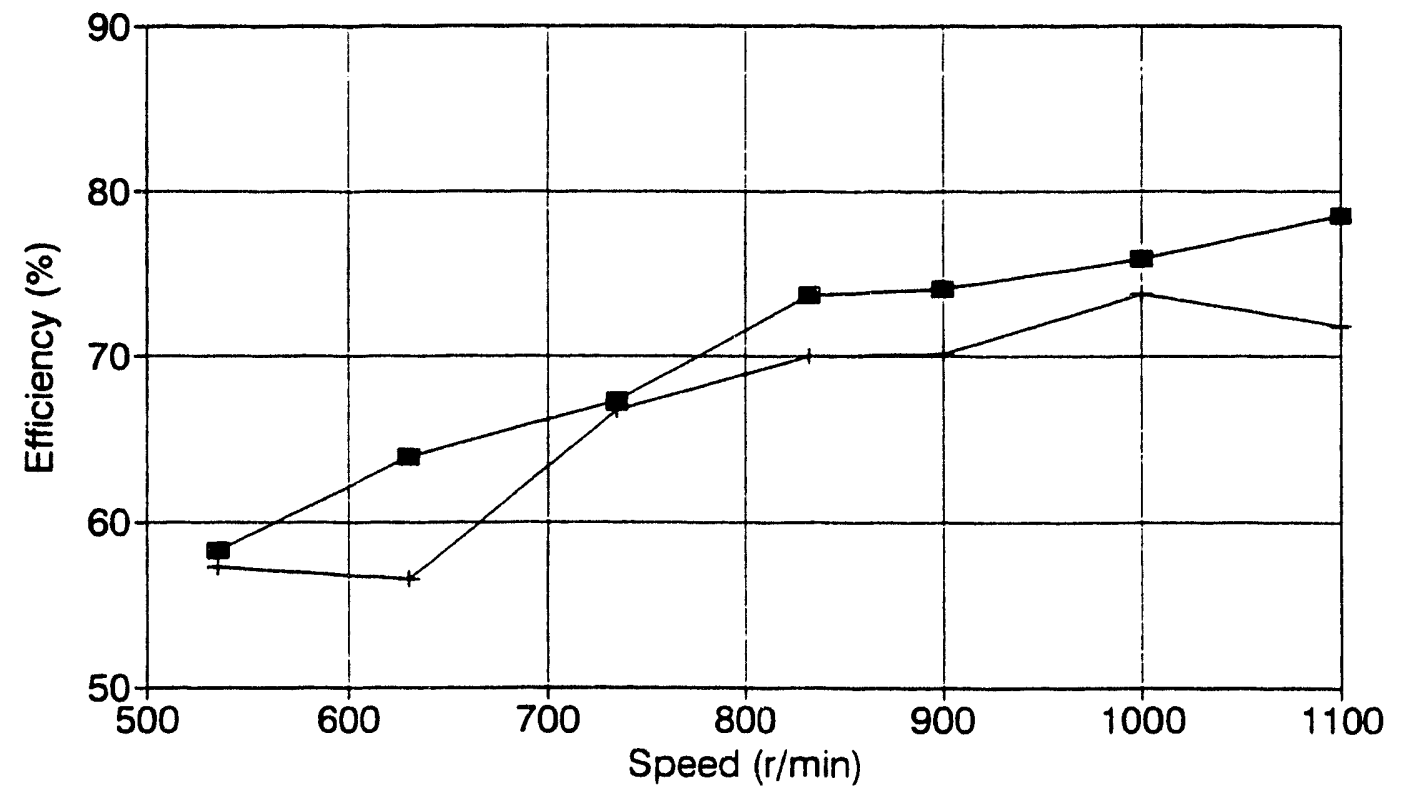

$\rightarrow$ Machine + Drive

Fig. 4.3.2. BDFM Efficiency for Constant Load Torque (50\% of Rating, 5 hp Nominal Rating, SRC-control). 


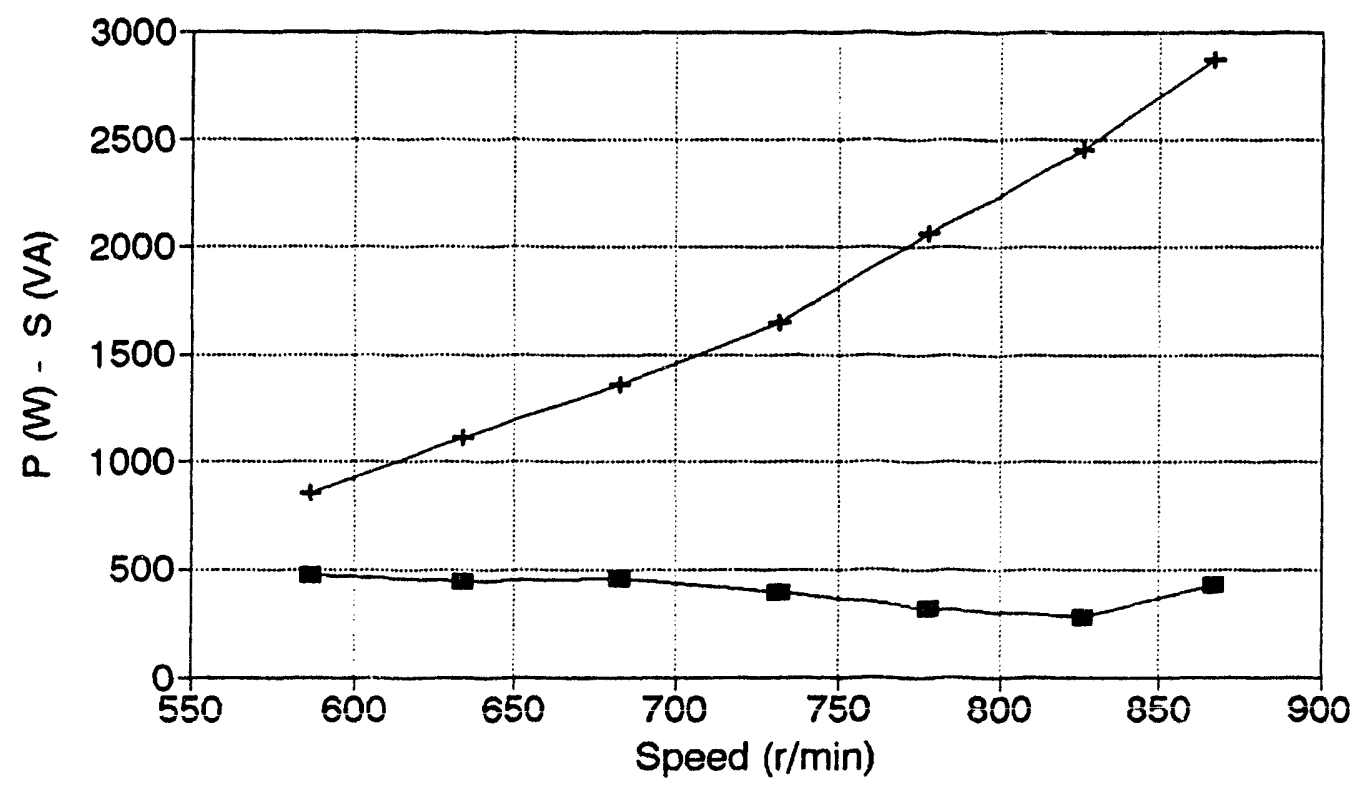

$$
\rightarrow \text { 2-Pole VA } \rightarrow \text { Shaft Power }
$$

Fig. 4.3.3. BDFM Output Power and Converter Rating for Fan Load ( $80 \%$ of Rating at Rated Speed, $5 \mathrm{hp} \mathrm{Nominal} \mathrm{rating,} \mathrm{SRC-control).}$

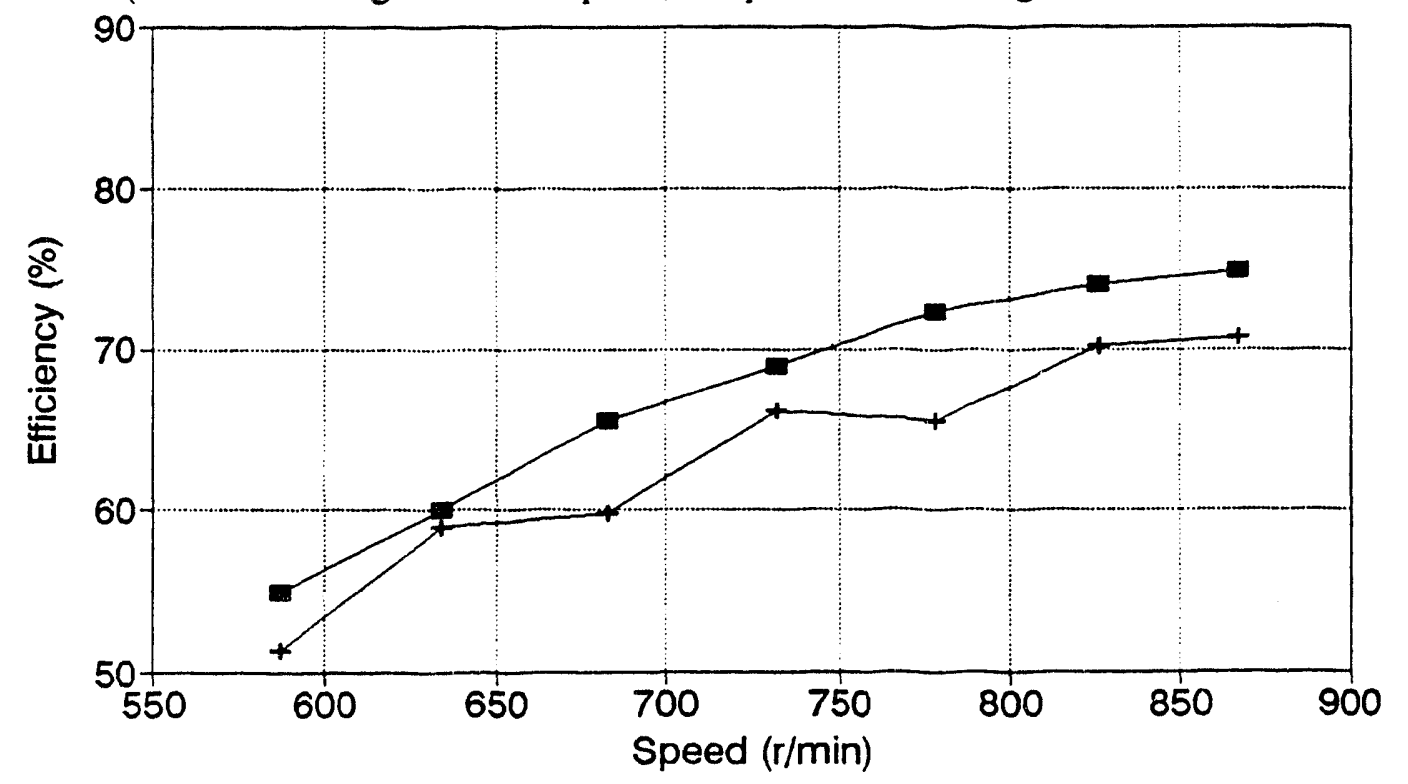

$$
\rightarrow-\text { Machine }+ \text { Drive }
$$

Fig. 4.3.4. BDFM Efficiency for Fan Load (80\% of Rating at Rated Speed, 5 hp Nominal rating, SRC-control). 


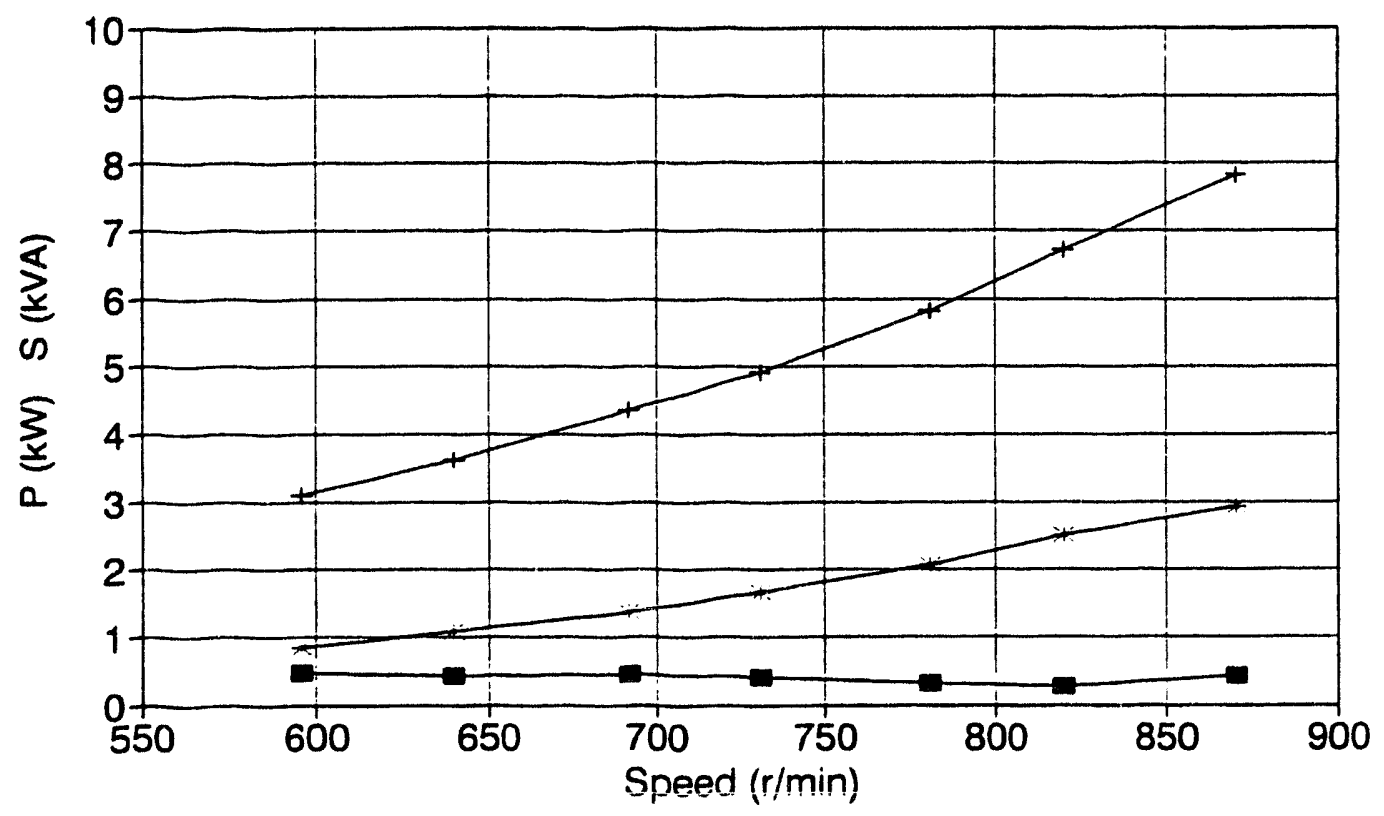

- BDFM Drive kVA — IM Drive kVA — Output Power

Fig. 4.3.5. Comparison of Converter Ratings - BDFM vs. IM.

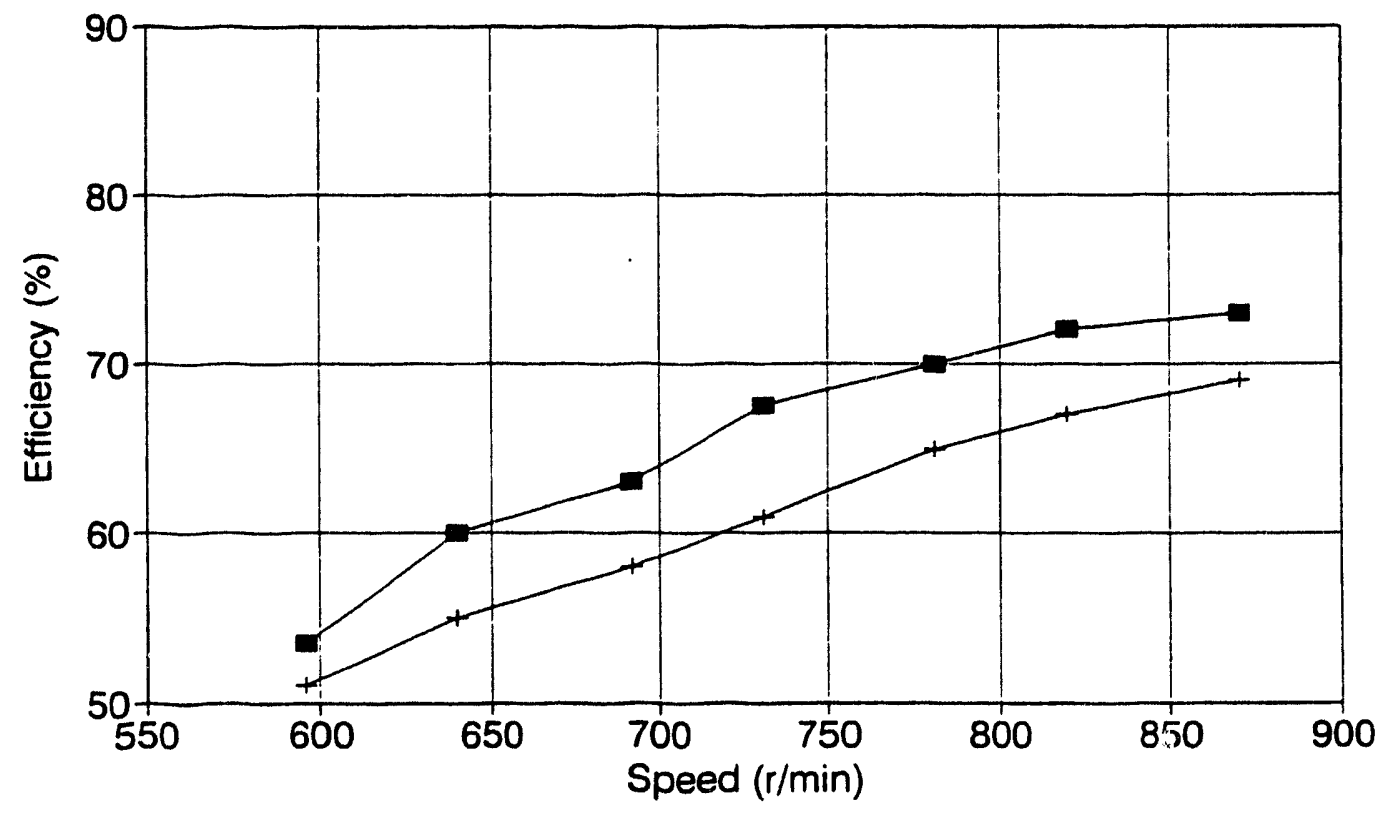

$\rightarrow-$ BDFM $\leftarrow$ IM Drive

Fig. 4.3.6. Comparison of Drive Efficiencies - BDFM vs. IM. 


\section{LABORATORY IMPROVEMENT}

In order to better evaluate BDFM prototype systems and to improve the demonstration capabilities to interested parties, the laboratory setup has been improved. This includes a computer controlled load simulator as well as an update of transducer equipment and cosmetic improvements. The status of the laboratory is described in the following sections.

\subsection{Load Controller}

On the BDFM test stand, loads are provided through a regenerative, thyristor-controlled dc drive. To date, evaluating varying load conditions involved varying the armature voltage manually while observing torque and speed displays provided by a shaft transducer. This procedure is quite cumbersome and, depending on the desired torque/speed characteristic, rather difficult. Moreover, the manual torque adjustment does not lend itself well to smooth demonstrations of BDFM performance. Thus, the dc drive was interfaced to a microprocessor controller which is pre-programmed with some popular torque-speed curves, such as fan, pump and compressor characteristics. Interface with a personal computer allows the graphical representation of the load characteristic as well as system operating points. Presently, only BDFM motor operation is considered. Future work may address the extension of the dc drive control to include emulation of prime mover characteristics for BDFM generator evaluation.

Figure 5.1.1 shows the block diagram of the laboratory system. As illustrated, the shaft transducer outputs (torque and speed) are sampled and provided to the microprocessor via analogto-digital (A/D) converters. Dc machine control is achieved via setting of the armature voltage by the microprocessor through a digital-to-analog (D/A) converter. The microprocessor used is an 8-bit Intel 8031. In order to achieve satisfactory resolution for machine control, 12 bits of accuracy are required. This is achieved by splitting digital signals into two sequential words of 8 and 4 bits length, respectively. This procedure results in slowing down the clock frequency of the microprocessor. However, since only steady-state and very slow dynamics are of interest for the load controller desired, the resulting computational speed is still sufficient. Fig. 5.1.2 shows the schematics of the controller, including memory and serial communication hardware. Fig. 5.1.3 illustrates the hardware used for $\mathrm{A} / \mathrm{D}$ and $\mathrm{D} / \mathrm{A}$ conversion. As configured, the dc controller performs satisfactorily for speeds up to $1800 \mathrm{r} / \mathrm{min}$ and torque values of up to $300 \mathrm{lb}$-in $(34 \mathrm{Nm}$ ). 
The microprocessor control is achieved via an assembly language routine stored in EPROM. An interface program for a personal computer establishes a link between the microprocessor and the system user. Control input, such as desired speed rating and load constants can be entered via the personal computer; system shaft performance is graphically displayed on the monitor.

Control software provides for five distinct operating characteristics:

(i) Constant speed control;

(ii) Constant torque control;

(iii) Linear torque vs. speed control;

(iv) Square law torque vs. speed control; and

(v) Cubic law torque vs. speed control.

The constant speed control is not intended for operation with the BDFM system, but is provided as a tool for establishing dc drive operating speeds in the motoring regime. Fig. 5.1.4 illustrates the constant speed dc drive control.

For all other operating modes, the dc drive operates as a generator. In constant torque operation, the BDFM can operate either in the synchronous or in the induction mode. The armature voltage of the dc drive is set by the microprocessor using the torque command and the feedback signal from the shaft transducer. This operating mode is illustrated in Fig. 5.1.5.

The remaining controls (linear, square and cubic torque speed laws) are mainly used for synchronous mode operation. Shaft speed is determined by the BDFM control winding frequency. Upon reading shaft speed, the microprocessor calculates the appropriate torque for the characteristic selected and sets the required dc armature voltage. Adjustable torque control displays are illustrated in Fig. 5.1.6. 


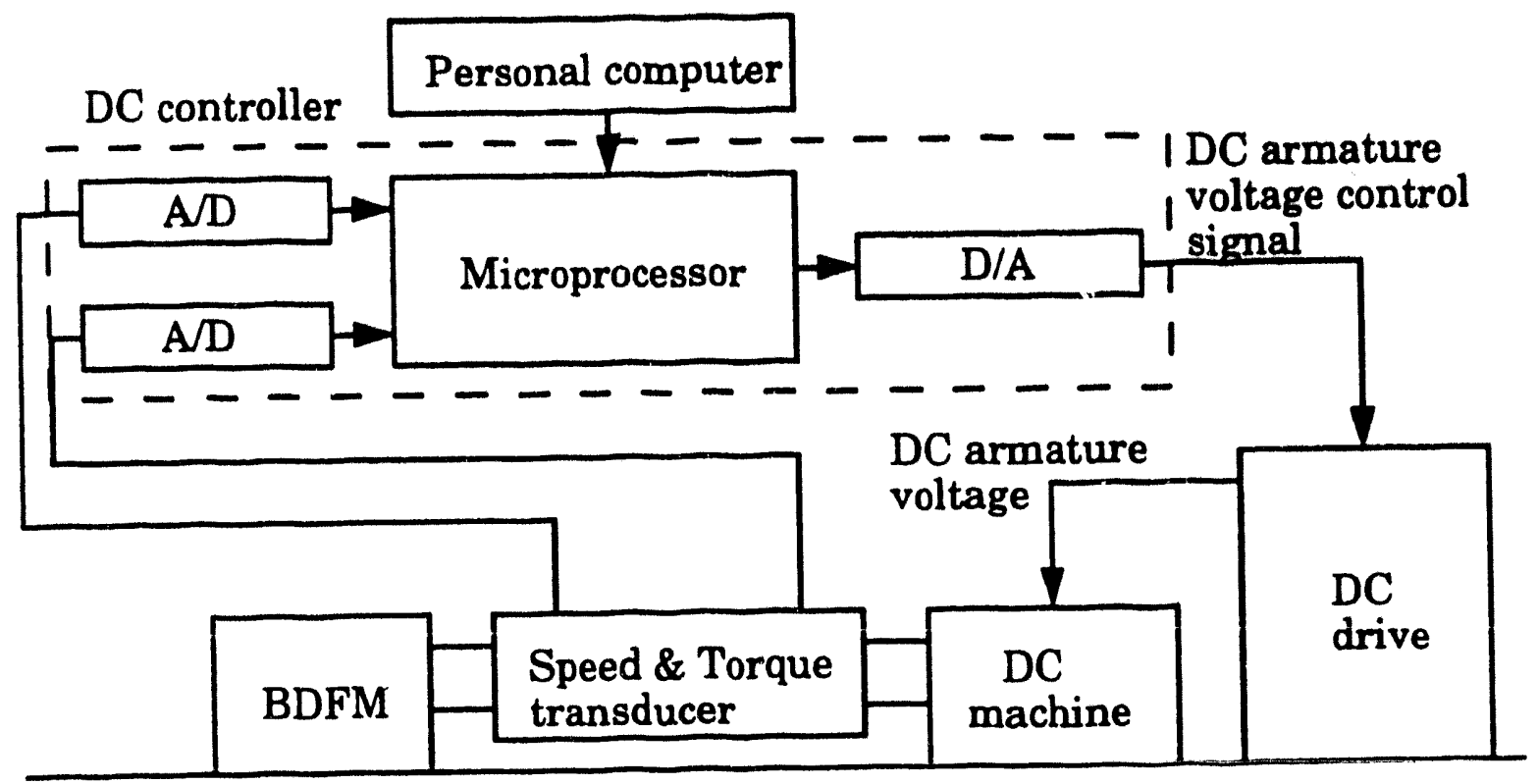

Fig. 5.1.1. System Configuration. 


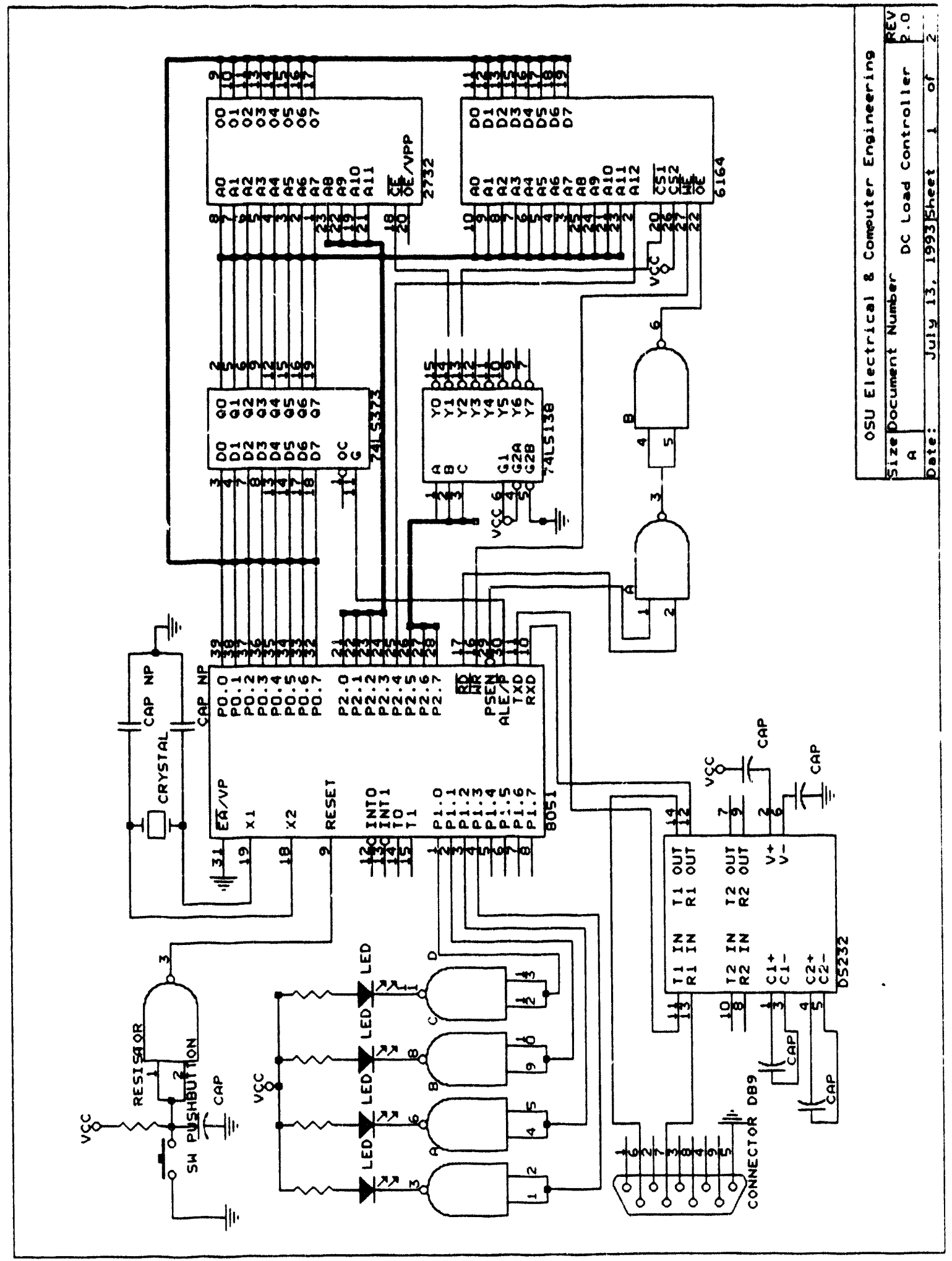

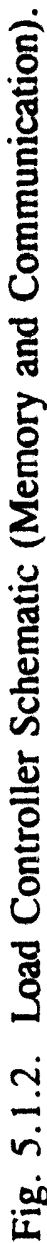




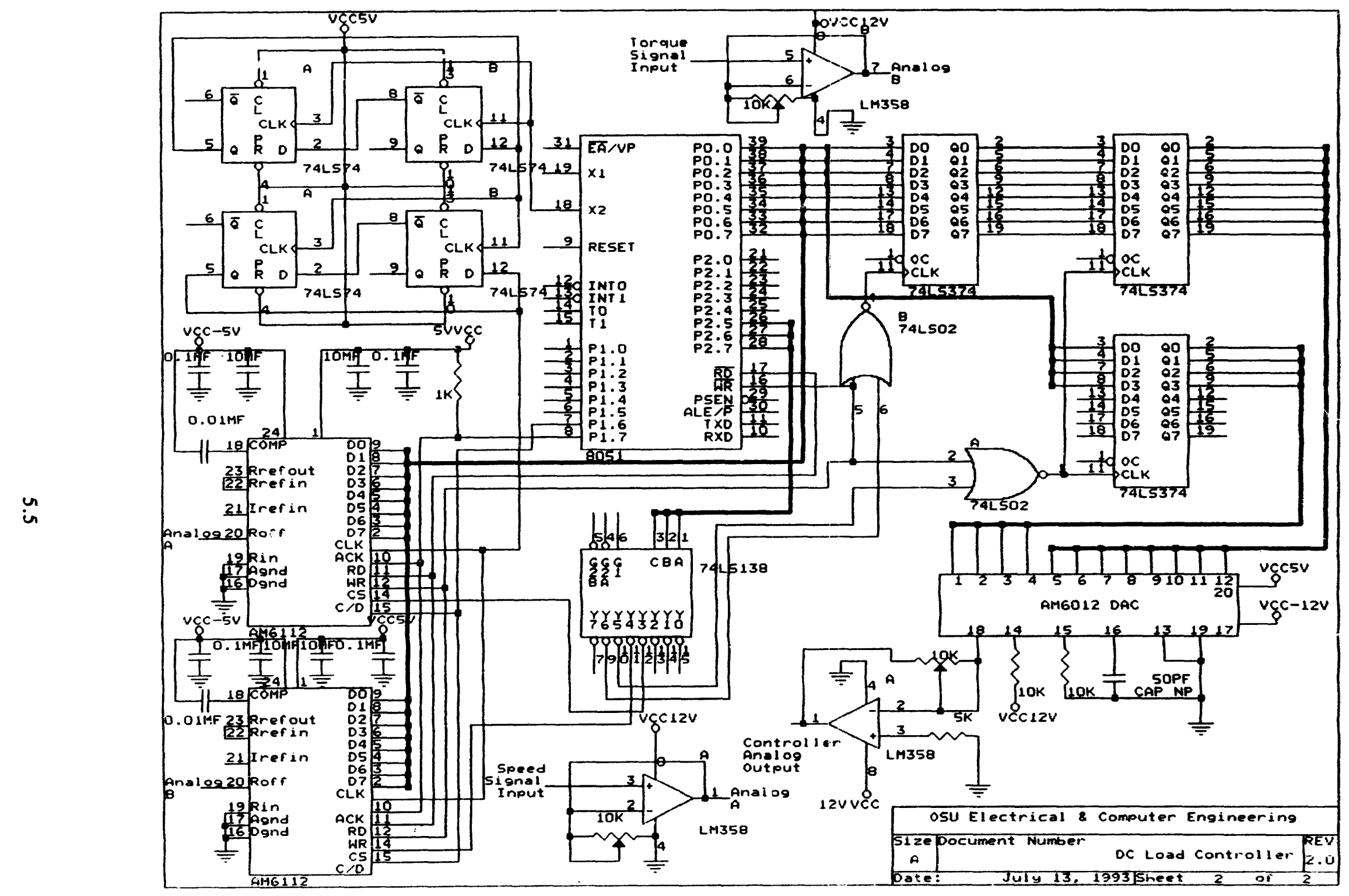

Fig. 5.1.3. Load Controller Schematic (Input/Output). 

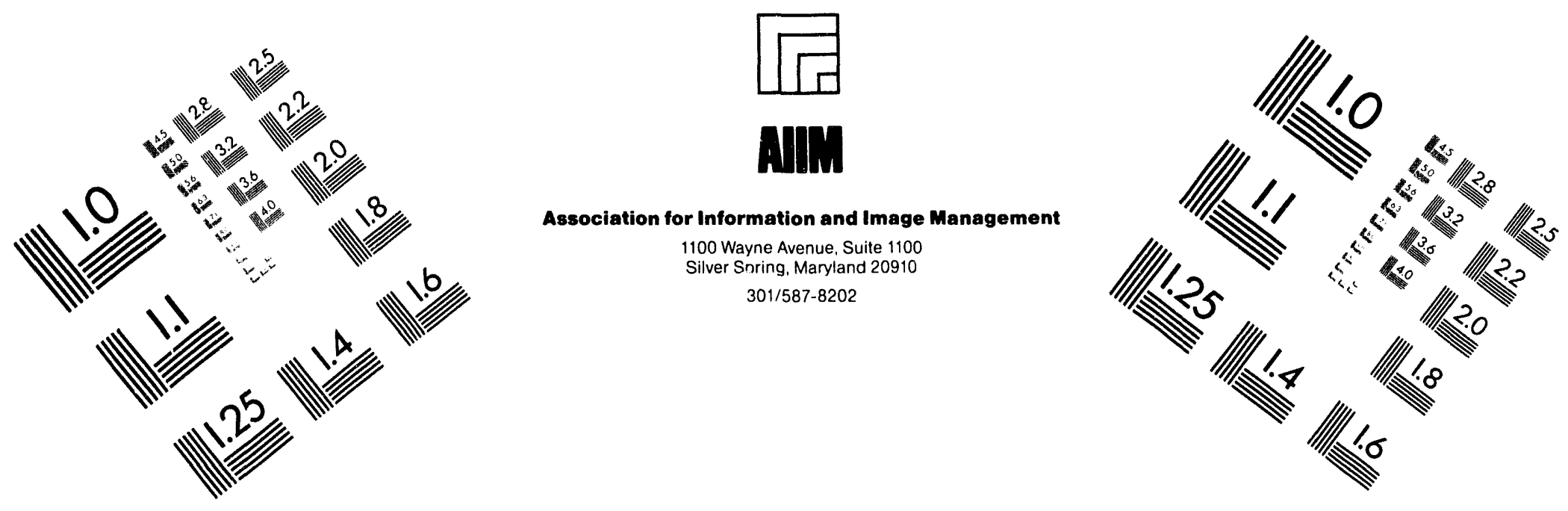

Centimeter

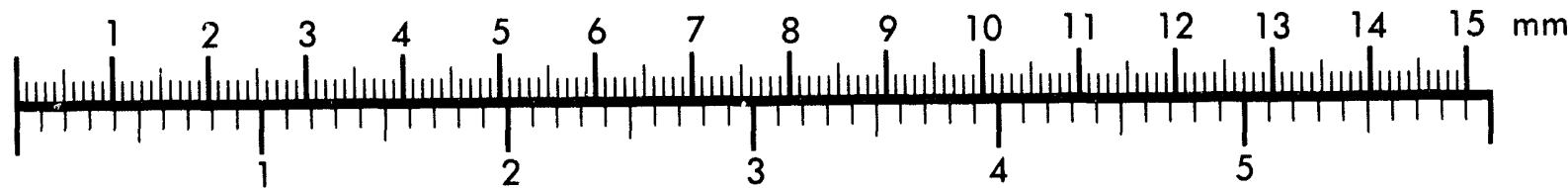
Inches
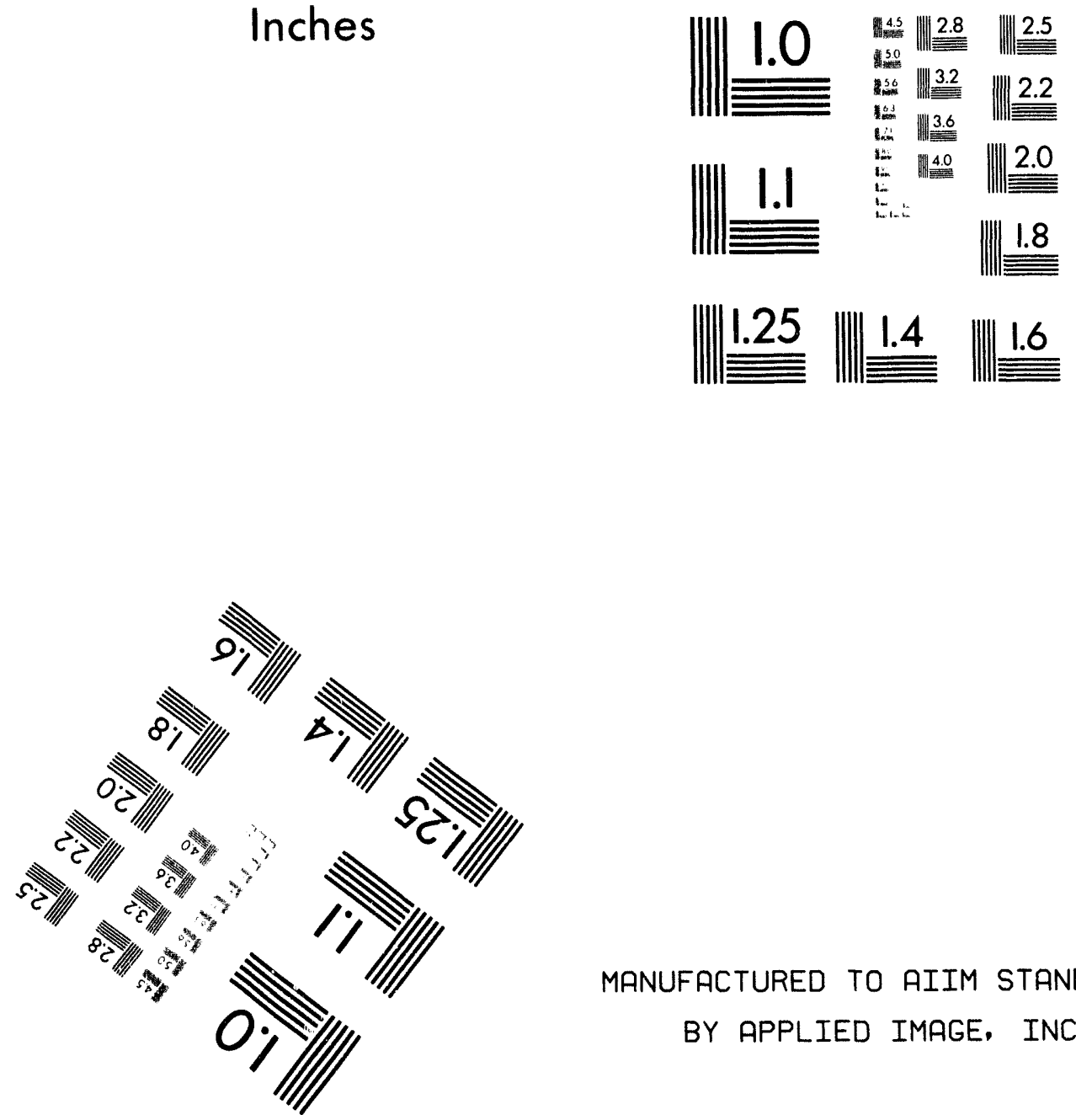

MANUFACTURED TO AIIM STANDARDS

BY APPLIED IMAGE, INC.

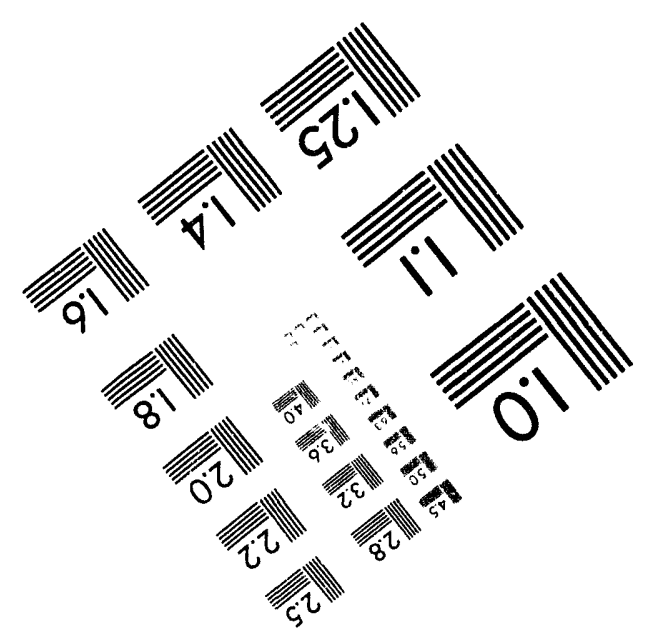



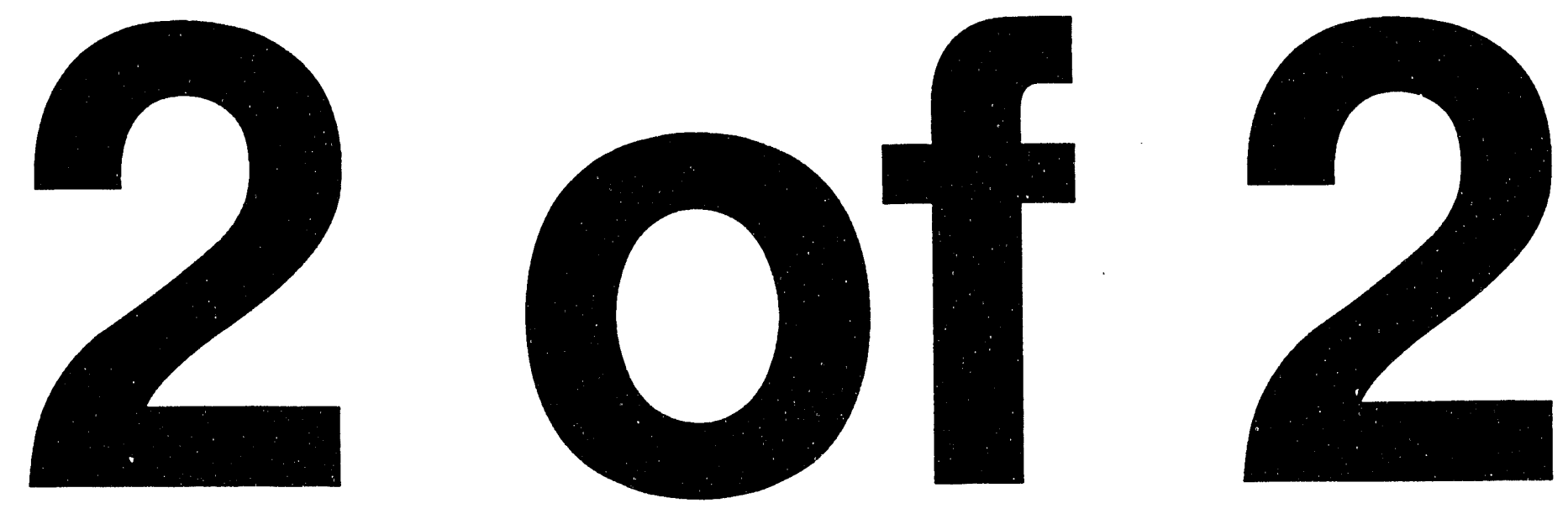


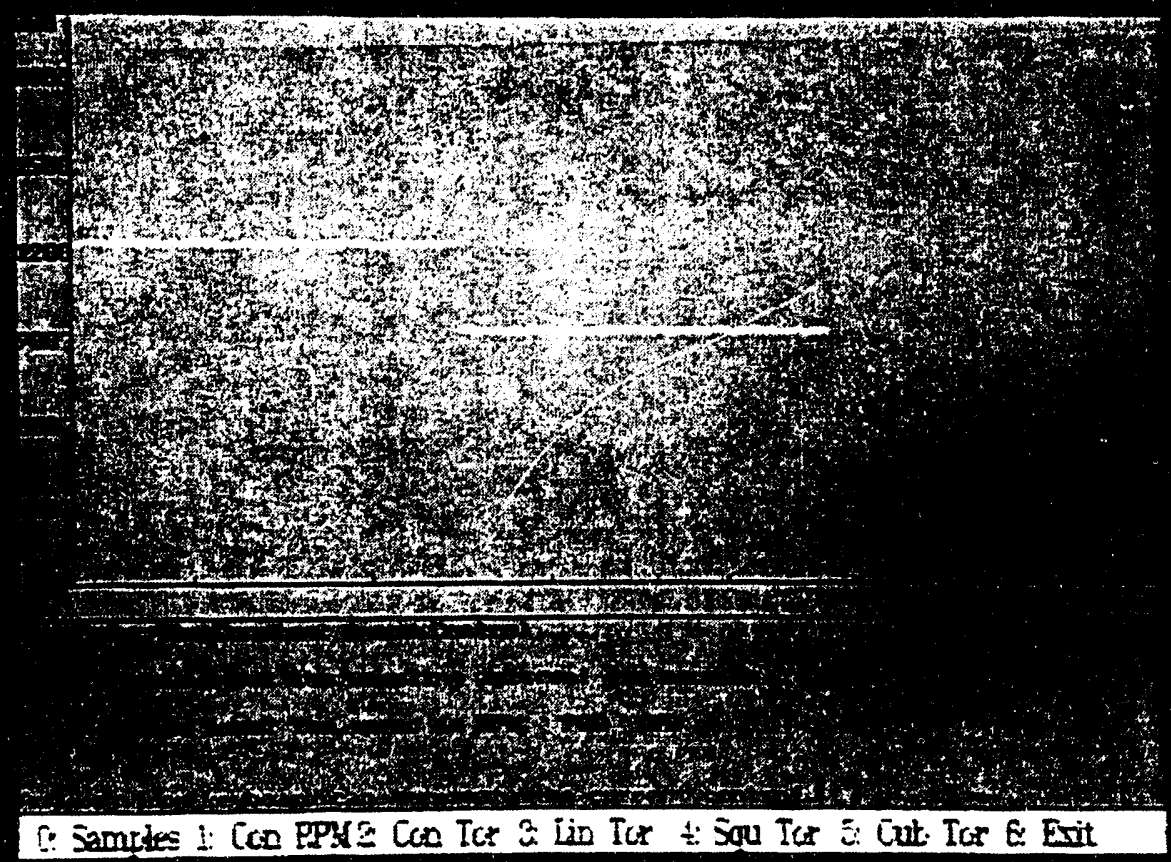

Fig. 5.1.4. Constant Speed Control Display.

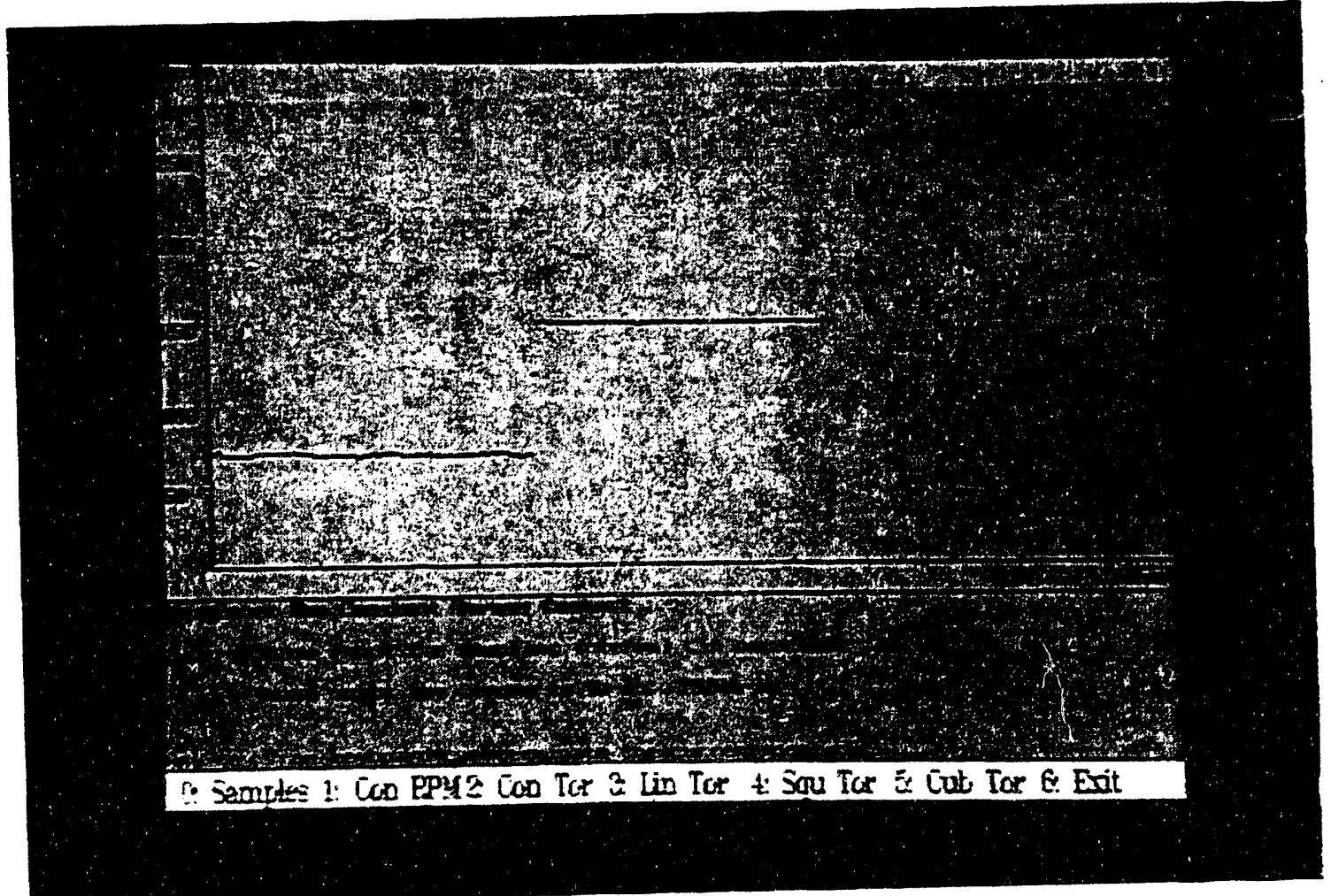

Fig. 5.1.5. Constant Torque Control Display. 


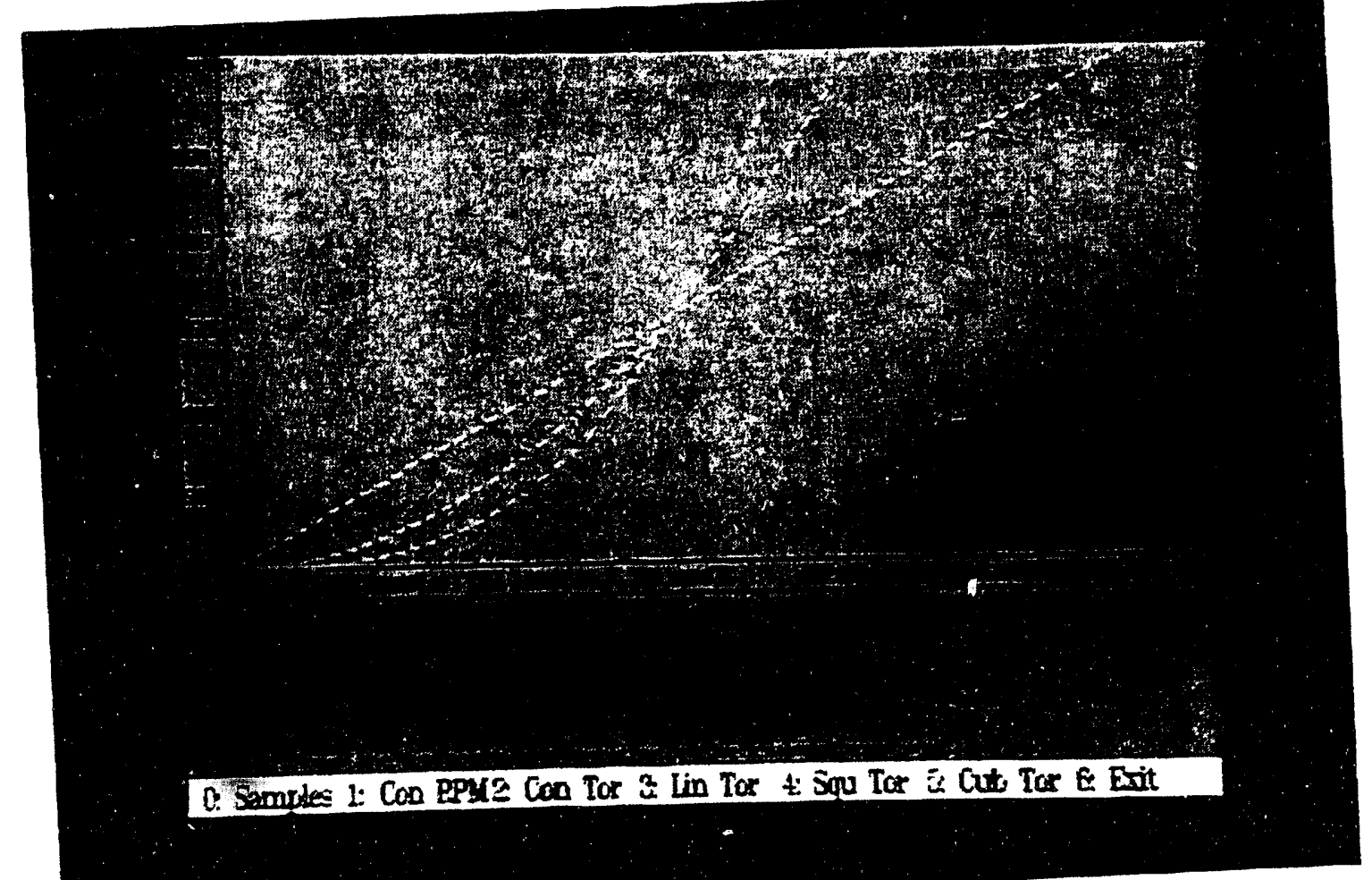

Fig. 5.1.6. Adjustable Torque Control Display. 


\subsection{BDFM Laboratory Test Stand and Instrumentation}

\subsubsection{Introduction}

The test equipment in the BDFM laboratory has been steadily expanded and improved to the point that a full range of diagnostic and performance tests can be readily carried out for machines rated at 5 to 15 horsepower at 115 or $230 \mathrm{~V}$, three-phase. The features of the test facility and the most significant specifications of the test equipment are summarized in this section.

\subsubsection{Overview of the Test Stand}

The electrical features of the BDFM test stand are shown schematically in Figs. 5.2.1 and 5.2.2. Not shown are the power circuit breakers and the $115 \mathrm{~V}$, single-phase circuits required for all the instrument and control electronics. The connections necessary to reduce noise in possible ground loops of the instrumentation systems has also been omitted.

In Fig. 5.2.1, the boxes labeled "RMS" and "INST" represent chassis on which are mounted sets of voltage and current transducers which produce outputs proportional to the rms or instantaneous values, respectively, of their inputs. The "INST" chassis also have three-phase power transducers mounted on them which are connected for three-wire measurement (twowattmeter method) of the power and control circuits. All three line voltages and all three line currents can be measured by each chassis unit. The schematic of the connections of the transducer outputs to digital data acquisition systems is given in Fig. 5.2.2. Transducer terminal connections are also brought out to the front panel of each unit. An exception is the "INST" unit in the input lines to the converter. A single current and a single voltage transducer are mounted on this chassis.

The in-line torque/speed transducer produces an analog output proportional to torque and a sequence of pulses whose frequency is proportional to speed. The "readout" unit converts the torque signal to digital form for display, measures the frequency of the speed pulses and provides analog output proportional to torque and speed. The analog signals are connected to the load controller and the data acquisition systems.

The load for motor operation (or the power for generator operation) of the BDFM is provided by a $15 \mathrm{hp} \mathrm{DC}$ machine controlled by a four-quadrant, thyristor drive-unit. The load controller acts through the drive to provide programmed torque-speed load curves.

A closed-loop controller for the control winding (two-pole winding in the prototype BDFM) 
is being developed. Signals from the instantaneous transducers of both windings and from a position encoder mounted on the DC machine shaft are processed and the requisite control signals are fed to the converter driving the control winding. To eliminate common-mode voltage problems and ground-loop noise, transformer-coupled, carrier-frequency-operated isolation amplifiers are mounted in a metal enclosure placed inside the converter cabinet and connected to the external voltage and frequency controls of the converter. Also indicated in Fig. 5.2.1 are alternative analog inputs to the converter which are used to provide amplitude-modulated or other outputs from the converter.

Transformer-coupled isolation amplifiers are also used in the speed- and torque-signal paths to the load controller. The isolation makes it possible to operate the load controller in conjunction with either of the data acquisition systems without upsetting the system gro!nding paths.

The layouts of the "instantaneous" and "rms" data acquisition systems are shown in Fig. 5.2.2. The 16 signal channels are duplicates in function; although the data acquisition hardware and software are substantially different. Although two sets of power transducers are shown in Fig. 5.2.2, only one set is used in the laboratory. For simplicity, the switches which are used to connect the outputs of the power transducers to either data acquisition system were omitted. The transducer switches, along with the switches in the torque- and speed-signal paths, are necessary to provide proper ground isolation between the single-ended inputs of the "rms" system and the differential inputs of the "instantaneous" system.

The data rates are a maximum of 100 kilosamples/second for the "instantaneous" system and 19 kilosamples/second for the "rms" system. When all 16 channels are sampled, the rates translate to $6250 \mathrm{kilosamples} / \mathrm{second} / \mathrm{channel}$ and $1185 \mathrm{kilosamples} / \mathrm{second} / \mathrm{channel}$, respectively. The per-channel rate for the "instantaneous" systems limits acquisition to signals with no frequencies above $3 \mathrm{kHz}$, in order to avoid aliasing.

The specifications accuracy, resolution and dynamic characteristics of the transducers and data acquisition systems are given in Table 5.2.

In addition to the fixed equipment of the test stand, the BDFM laboratory is equipped with quality instruments which can be moved from circuit to circuit in order to simplify diagnostic and preliminary measurements. The instruments are described in Tables 5.1 and 5.3. 


\subsubsection{Catalog of Instruments and Test-Stand Equipment}

Table 5.1 lists the types of instruments and equipment, and the number on hand, which are available for use in the BDFM Laboratory. Both test stand and movable instruments are included in Table 5.1. Of particular interest is the Fourier Analysis System used in conjunction with the instantaneous data acquisition system. The instrument makes it possible to investigate the harmonic distortion and noise characteristics of a machine under test. Associated software provides numerous analysis functions plus control system parameter estimation. The digital storage oscilloscopes and the BMI Power Profiler provide wide-ranging diagnostic capabilities.

\subsubsection{Instrumentation Specifications}

The detailed descriptions of the electrical and mechanical instrumentation of the BDFM Laboratory are given in Tables 5.2 and 5.3.

The test stand transducers were all purchased with 10-volt maximum outputs. They all respond to input signal bandwidths $(-3 \mathrm{~dB})$ of $\mathrm{DC}$ to $5 \mathrm{kHz}$ and provide accuracies of $0.5 \%$ of full-scale range. However, the power transducers only provide $1(+) \%$ accuracy. The BMI 3030 Power Profiler (end of Table 5.3) is used to calibrate the power transducers when more precise measurements are required (such as efficiency determinations).

The data acquisition systems both use IBM-compatible personal computers as the host. The primary components of the systems are printed-circuit boards which mount in one of the expansion slots of the host. Each system has a 12-bit A/D converter, which gives a full-span resolution of 1 part in 4095 . This means a quantization error of $4.88 \mathrm{mV}$ for the systems as used in the laboratory to match the 10-volt signals from the transducers. The fixed error at the converter output translates to an error of $0.1 \%$ at 5 -volt signal levels.

The "instantaneous" data acquisition system is equipped with a set of sample and hold amplifiers which are simultaneously switched from the TRACK to HOLD modes. This eliminates skew of the data as the input channels are multiplexed to the A/D converter; which significantly simplifies the processing of the acquired data samples. The operation of the system is improved substantially in the electrically noisy environment of the laboratory by using the differential input connections made possible by the sample/board.

The "instantaneous" data acquisition system is supported by a commercial set of data acquisition software, which simplifies the control of the hardware and the storage and display of 
the acquired data. In order to achieve the maximum data rate made possible by the relatively high speed A/D converter, data is streamed through the direct-memory access channel to a virtual disk memory in the extended memory of the host computer.

Because the required data rate and number of samples per reading are much less for the rms data, acquisition software for the "rms" system was written by members of the laboratory team. Direct streaming of data to memory is not used for this system. The effect of the higher noise level associated with the single-ended input channels is reduced by averaging 10 to 100 samples taken for one operating point of the unit under test. The accuracy of the system depends upon the care with which the gain of the buffer amplifier is calibrated.

The general test instrumentation listed in Table 5.3 provides either convenience or special features which do not need to be duplicated. For convenience, the following hand-held, batteryoperated instruments are available: a clamp-on "current gun", an optical tachometer with digital display and Fluke 8060A digital multimeters. Special features are provided by the Tektronix 2230 digital storage oscilloscope, the Tektronix current probes and the BMI Power Profiler. The broad and powerful capabilities of these instruments are outlined in Table 5.3. 
TABLE 5.1. BDFM Laboratory Test Equipment and Instrumentation.

NOTE: See Tables 5.2 and 5.3 for a detailed description of the listed equipment.

\begin{tabular}{|c|c|}
\hline TYPE/FUNCTION & $\begin{array}{c}\text { NUMBER ON } \\
\text { HAND }\end{array}$ \\
\hline \multicolumn{2}{|c|}{ ELECTRICAL TRANSDUCERS: INSTANTANEOUS, LOW-FREQUENCY } \\
\hline $\begin{array}{l}\text { Current; Chassis mounted } \\
\text { Voltage; Chassis mounted } \\
\text { Power; Chassis mounted }\end{array}$ & $\begin{array}{l}7 \\
7 \\
2\end{array}$ \\
\hline \multicolumn{2}{|l|}{ ELECTRICAL TRANSDUCERS: RMS, LOW-FREQUENCY } \\
\hline $\begin{array}{l}\text { Current; Chassis mounted } \\
\text { Voltage; Chassis mounted }\end{array}$ & $\begin{array}{l}6 \\
6\end{array}$ \\
\hline \multicolumn{2}{|l|}{ MECHANICAL TRANSDUCERS } \\
\hline $\begin{array}{l}\text { In-line torque/speed transducer and signal conditioning and display unit } \\
\text { Shaft-mounted, high-resolution position encoder with interface electronics } \\
\text { Battery-operated, reflective sensing, digital tachometer }\end{array}$ & $\begin{array}{l}3 \\
1 \\
1\end{array}$ \\
\hline \multicolumn{2}{|c|}{ DATA ACQUISITION SYSTEMS: INSTANTANEOUS-SIGNAL SAMPLING } \\
\hline $\begin{array}{l}\text { Simultaneous sample/hold board; A/D converter and system control board } \\
\text { Host PC and commercial data acquisition software } \\
\text { PC-controlled Fourier analyzer system } \\
\text { DeskJet printer } \\
\text { Digital plotter }\end{array}$ & 1 system \\
\hline \multicolumn{2}{|c|}{ DATA ACQUISITION SYSTEMS: RMS-SIGNAL SAMPLING } \\
\hline $\begin{array}{l}\text { Multiplexer/buffer board; A/D converter and system control board } \\
\text { Host PC and student-developed data acquisition and display software } \\
\text { Spreadsheet data-manipulation software }\end{array}$ & 1 system \\
\hline \multicolumn{2}{|l|}{ ELECTRICAL RMS MEASUREMENTS } \\
\hline $\begin{array}{l}\text { True-rms digital multimeter; battery operated } \\
\text { True-rms digital multimeter; line-operated bench model } \\
\text { True-rms digital current probe; battery operated }\end{array}$ & $\begin{array}{l}5 \\
1 \\
1\end{array}$ \\
\hline \multicolumn{2}{|l|}{ WAVEFORM DISPLAYS } \\
\hline $\begin{array}{l}100 \mathrm{MHz} \text {, Digital storage oscilloscope } \\
100 \mathrm{MHz} \text {, Current-probe amplifier } \\
50 \mathrm{MHz} \text {, Current probe, } 5 \mathrm{~A} \\
15 \mathrm{MHz} \text {, Current probe, } 100 \mathrm{~A}\end{array}$ & $\begin{array}{l}2 \\
3 \\
2 \\
1\end{array}$ \\
\hline \multicolumn{2}{|l|}{ POWER SYSTEM MEASUREMENTS } \\
\hline BMI Model 3030 power system profiler & 1 \\
\hline \multicolumn{2}{|l|}{ TEST STAND POWER EQUIPMENT } \\
\hline $\begin{array}{l}\text { Series-resonant, } 15 \mathrm{kVA} \text {, power-electronic converter } \\
\text { Thyristor-controlled, regenerative DC drive with } 15 \mathrm{hp} \mathrm{DC} \text { motor }\end{array}$ & $\begin{array}{l}1 \\
1\end{array}$ \\
\hline
\end{tabular}


TABLE 5.2. BDFM 13 KVA/10hp Test Stand Instrumentation Specifications.

\begin{tabular}{|c|c|c|c|c|}
\hline \multicolumn{5}{|c|}{$\begin{array}{l}\text { ELECTRICAL TRANSDUCERS: INSTANTANEOUS, LOW-FREQUENCY } \\
\text { All electrical transducers listed below were purchased from Ohio Semitronics, } 1205 \text { Chesapeake } \\
\text { Avenue, Columbus, OH } 483212-2287 \text {, and have Semitronics model numbers. }\end{array}$} \\
\hline \multirow[b]{2}{*}{ Specification } & \multirow[b]{2}{*}{ Voltage } & \multicolumn{2}{|c|}{ Current } & \multirow[b]{2}{*}{ Power } \\
\hline & & Transducer & Amplifier & \\
\hline Model & VT7-7D & CT50L & CTA101 & P-32-D \\
\hline $\begin{array}{l}\text { Input: } \\
\text { Range }\end{array}$ & $\begin{array}{l}\text { Single Phase } \\
\pm 300 \text { V DC } \\
0 \text { to } 5 \mathrm{kHz}\end{array}$ & $\begin{array}{l}50 \mathrm{~A} \text { rms } \\
0 \text { to } 5 \mathrm{kHz}\end{array}$ & $\begin{array}{l}\text { Matched to CT5OL } \\
0 \text { to } 5 \mathrm{kHz}\end{array}$ & $\begin{array}{l}3 \phi, 3 \text { wire } \\
0-300 \mathrm{~V} \text { AC rms line } \\
0-100 \text { A rms } \\
40 \mathrm{~kW} \text {, any pf } \\
5 \text { to } 500 \mathrm{~Hz}\end{array}$ \\
\hline \begin{tabular}{|l} 
Output: \\
Range \\
Frequency \\
Response Time \\
Accuracy \\
Linearity \\
Ripple
\end{tabular} & $\begin{array}{l} \pm 10 \mathrm{~V} \mathrm{DC} \\
0 \text { to } 5 \mathrm{kHz} \\
50 \mu \mathrm{Sec} \\
\pm 0.5 \% \text { F.S. }\end{array}$ & $\begin{array}{l}\text { Matched to CTA101 } \\
0 \text { to } 5 \mathrm{kHz} \\
50 \mu \mathrm{Sec} \\
\pm 0.5 \% \text { F.S. }\end{array}$ & $\begin{array}{l} \pm 10 \mathrm{~V} \text { peak @ CT50L } \\
\quad \text { max Amperes } \\
0 \text { to } 5 \mathrm{kHz} \\
40 \mu \mathrm{Sec} \\
\pm 0.1 \% \text { RO }\end{array}$ & $\begin{array}{l} \pm 10 \mathrm{~V} \text { peak } \\
5 \text { to } 500 \mathrm{~Hz} \\
500 \mathrm{mSec} \\
\pm 1 \% \text { F.S. \& } \pm 1 \% \text { of rdng } \\
< \pm 1 \% \text { rdng } @ 60 \mathrm{~Hz}\end{array}$ \\
\hline $\begin{array}{c}\text { Temperature: } \\
\text { Variation } \\
\text { Range }\end{array}$ & $\begin{array}{l} \pm 1 \% \text { RDG } \\
-10^{\circ} \mathrm{C} \text { to } 60^{\circ} \mathrm{C}\end{array}$ & $\begin{array}{l}-0.15 \% /{ }^{\circ} \mathrm{C} \\
-40^{\circ} \mathrm{C} \text { to } 60^{\circ} \mathrm{C}\end{array}$ & $\begin{array}{l} \pm 0.005 \% /{ }^{\circ} \mathrm{C} \\
0^{\circ} \mathrm{C} \text { to } 70^{\circ} \mathrm{C}\end{array}$ & $\begin{array}{l} \pm 1 \% \text { rdng \& } \pm 0.1 \% \text { F.S. } \\
0^{\circ} \mathrm{C} \text { to } 40^{\circ} \mathrm{C}\end{array}$ \\
\hline \multicolumn{5}{|c|}{ ELECTRICAL TRANSDUCERS: RMS, LOW-FREQUENCY } \\
\hline Model & VT8-7D & CT50L & CTA113 & P-32-D \\
\hline $\begin{array}{l}\text { Input: } \\
\text { Range }\end{array}$ & $\begin{array}{l}\text { Single Phase } \\
\pm 300 \mathrm{VDC} \\
0 \text { to } 5 \mathrm{kHz}\end{array}$ & $\begin{array}{l}50 \mathrm{~A} \text { rms } \\
0 \text { to } 5 \mathrm{kHz}\end{array}$ & $\begin{array}{l}\text { Matched to CT5OL } \\
0 \text { to } 5 \mathrm{kHz}\end{array}$ & $\begin{array}{l}3 \phi, 3 \text { wire connection } \\
\text { gives nearly DC output for } \\
\text { balance in the AC steady } \\
\text { state }\end{array}$ \\
\hline \begin{tabular}{||} 
Output: \\
Range \\
Frequency \\
Response Time \\
Accuracy \\
Linearity \\
\end{tabular} & $\begin{array}{l} \pm 10 \mathrm{~V} \mathrm{DC} \\
0 \text { to } 5 \mathrm{kHz} \\
50 \mu \mathrm{Sec} \\
\pm 0.5 \% \text { F.S. }\end{array}$ & $\begin{array}{l}\text { Matched to CTA113 } \\
0 \text { to } 5 \mathrm{kHz} \\
50 \mu \mathrm{Sec} \\
\pm 0.5 \% \text { F.S. }\end{array}$ & $\begin{array}{l} \pm 10 \mathrm{~V} \text { peak } @ \text { CT50L } \\
\quad \max \text { Amperes } \\
0 \text { to } 5 \mathrm{kHz} \\
40 \mu \mathrm{Sec} \\
\\
\pm 0.1 \% \text { RO } \\
\end{array}$ & \\
\hline $\begin{array}{l}\text { Temperature: } \\
\text { Variation } \\
\text { Range }\end{array}$ & $\begin{array}{l} \pm 1 \% \text { RDG } \\
-10^{\circ} \mathrm{C} \text { to } 60^{\circ} \mathrm{C}\end{array}$ & $\mid \begin{array}{l}-0.15 \% /{ }^{\circ} \mathrm{C} \\
-40^{\circ} \mathrm{C} \text { to } 60^{\circ} \mathrm{C}\end{array}$ & $\begin{array}{l} \pm 0.005 \% / /^{\circ} \mathrm{C} \\
0^{\circ} \mathrm{C} \text { to } 70^{\circ} \mathrm{C}\end{array}$ & \\
\hline
\end{tabular}


TABLE 5.2. BDFM $13 \mathrm{KVA} / 10 \mathrm{hp}$ Test Stand Instrumentation Specifications.

(Continued)

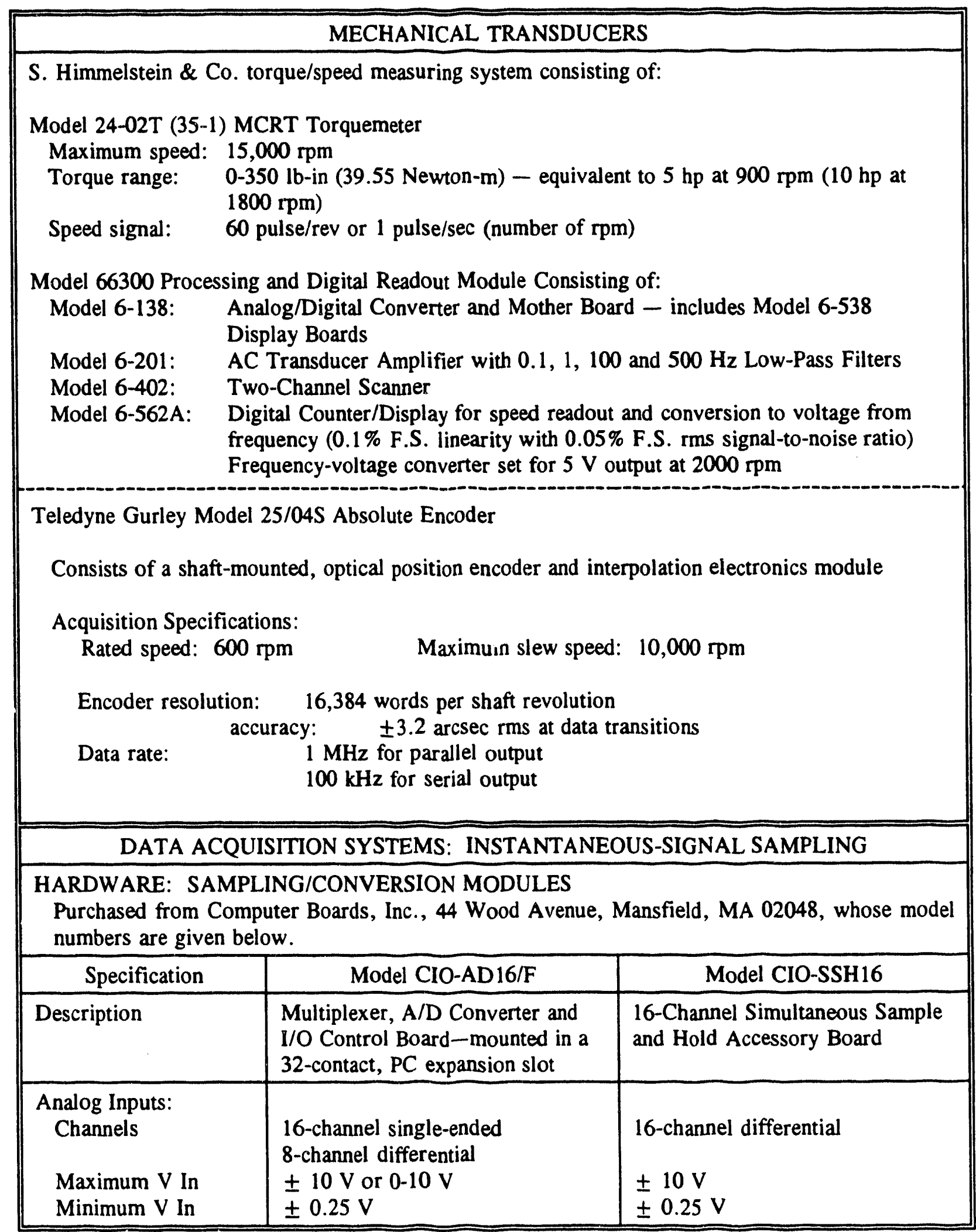


TABLE 5.2. BDFM 13 KVA/10hp Test Stand Instrumentation Specifications.

(Continued)

\begin{tabular}{|c|c|c|}
\hline \multicolumn{3}{|c|}{ DATA ACQUISITION SYSTEMS: INSTANTANEOUS-SIGNAL SAMPLING (Continued) } \\
\hline \multicolumn{3}{|c|}{ HARDWARE: SAMPLING/CONVERSION MODULES (Continued) } \\
\hline Specification & Model CIO-AD16/F & Model CIO-SSH16 \\
\hline Analog Channel Elements: & $\begin{array}{l}\text { multiplexer;switched-gain ampli- } \\
\text { fier; sample/hold ckt; A/D con- } \\
\text { verter }\end{array}$ & $\begin{array}{l}\text { switched-gain amplifier; } \\
\text { sample/hold circuit }\end{array}$ \\
\hline $\begin{array}{l}\text { Amplifier: } \\
\text { Gain } \\
\text { Accuracy } \\
\text { Linearity } \\
\text { Drift } \\
\text { Bandwidth }\end{array}$ & $\begin{array}{l}\text { Switch-selectable at } 0.5,1,2,5 \\
\quad \text { and } 10 \\
0.01 \% \pm 1 \mathrm{LSB} \\
\pm 1 \mathrm{LSB} \text { integral } \\
\pm 25 \mathrm{ppm} /{ }^{\circ} \mathrm{C} \text { gain max. } \\
\pm 10 \mathrm{ppm} /{ }^{\circ} \mathrm{C} \text { zero } \max . \\
\text { above } 5 \mathrm{kHz}\end{array}$ & $\begin{array}{l}\text { Switch-selectable at } 1,10,100 \\
200,300,500, \ldots 800 \\
0.01 \% \text { of reading } \pm 1 \text { bit } \\
0.01 \% \\
\pm 20 \mathrm{ppm} /{ }^{\circ} \mathrm{C} \text { gain max. } \\
\pm 15 \mu \mathrm{V} /{ }^{\circ} \mathrm{C} \text { zero } \max . \\
\quad \text { above } 5 \mathrm{kHz}\end{array}$ \\
\hline $\begin{array}{l}\text { Sample/Hold: } \\
\text { Acquisition Time } \\
\text { Aperture Times } \\
\text { Droop Rate } \\
\text { Noise }\end{array}$ & $\begin{array}{l}1 \mu \mathrm{Sec} \text {. to } 1 \% \text { F.S. step } \\
0.3 \mathrm{nSec} \text { uncertainty }\end{array}$ & $\begin{array}{l}10 \mu \mathrm{Sec} \text { max. } \\
175 \mathrm{nSec} \text { average; } \pm 25 \mathrm{nSec} \\
\text { uncertainty } \\
\pm 100 \mu \mathrm{V} / \mathrm{mSec} \\
10 \mu \mathrm{V} \mathrm{RMS}(10-100 \mathrm{kHz})\end{array}$ \\
\hline $\begin{array}{l}\text { A/D Converter: } \\
\text { Conversion } \\
\text { Linearity } \\
\text { Resolution }\end{array}$ & $\begin{array}{l}12 \text { bits } @ 8.5 \mu \text { Sec } \max . \\
\pm 1 \text { bit } \\
1 / 4095 \text { parts of F.S. }\end{array}$ & \\
\hline $\begin{array}{l}\text { Control Elements } \\
\text { Timing } \\
\text { Digital I/O } \\
\text { Digital In } \\
\text { Digital Out } \\
\text { Synchronizing }\end{array}$ & $\begin{array}{l}1 / 10 \mathrm{MHz} \text { counter/timer } \\
\text { Three } 8 \text {-bit ports } \\
4 \text { bits } \\
4 \text { bits } \\
\text { Channel } 0 \text { triggering gives pulse } \\
\text { to drive } 16 \text { simultaneous sam- } \\
\text { ple/hold circuits }\end{array}$ & $\begin{array}{l}\text { Sample/hold tracking is synchro- } \\
\text { nized with channel } 0 \text { of the CIO- } \\
\text { AD16/F }\end{array}$ \\
\hline $\begin{array}{l}\text { Outputs } \\
\text { D/A Output } \\
\text { Analog }\end{array}$ & $2 \mathrm{D} / \mathrm{A}$ channels & $\begin{array}{l}16 \text { single-ended channels to the } \\
\text { CI0-AD } 16 / F \text { multiplexers }\end{array}$ \\
\hline $\begin{array}{l}\text { Data Transfer } \\
\text { Modes } \\
\text { Rate }\end{array}$ & $\begin{array}{l}\text { Direct memory access, polled or } \\
\text { interrupt-service } \\
100,000 \text { samples/sec on DMA }\end{array}$ & \\
\hline
\end{tabular}


TABLE 5.2. BDFM $13 \mathrm{KVA} / 10 \mathrm{hp}$ Test Stand Instrumentation Specifications.

(Continued)

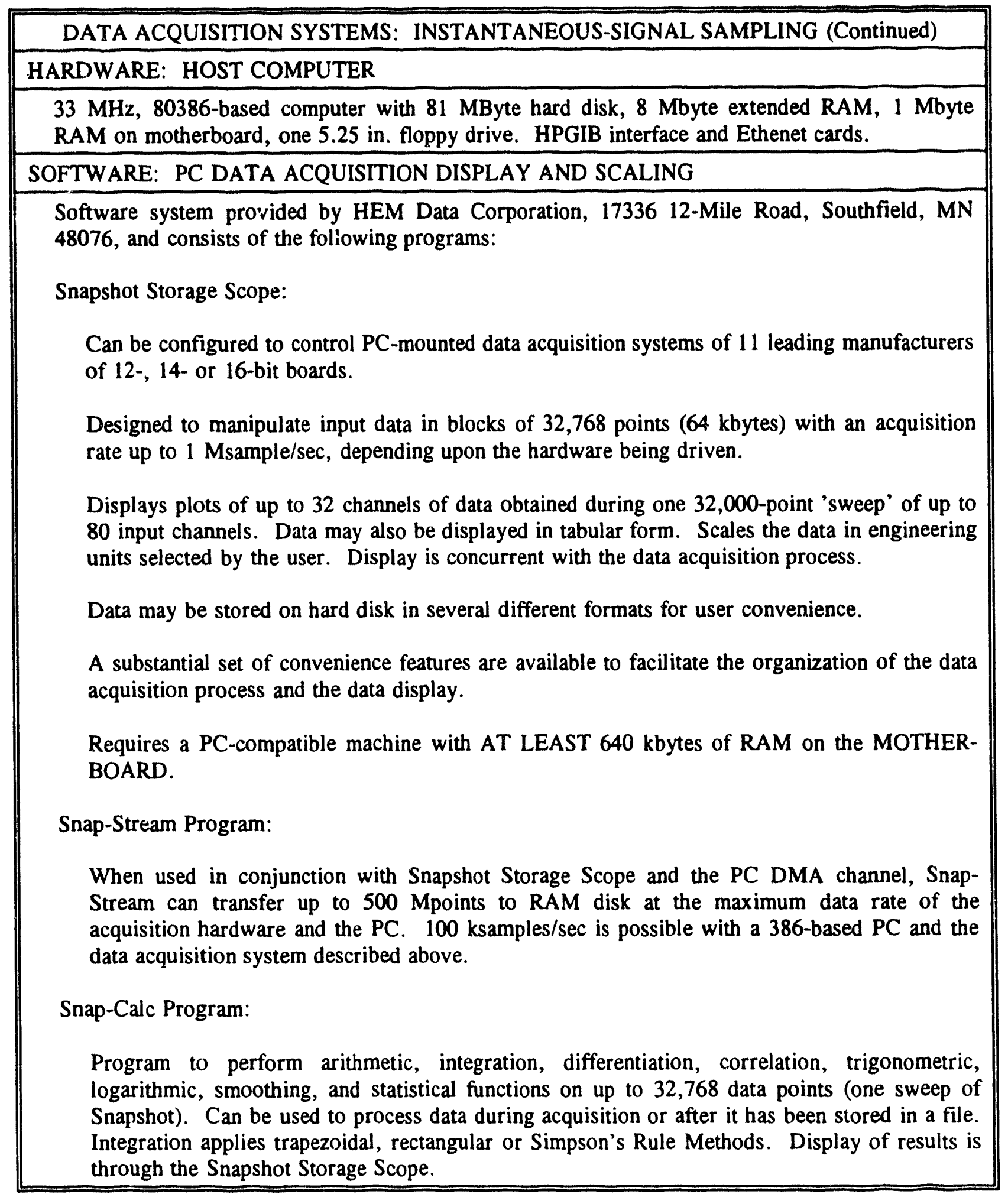


TABLE 5.2. BDFM 13 KVA/10hp Test. Stand Instrumentation Specifications. (Continued)

\begin{tabular}{|c|c|c|}
\hline \multicolumn{3}{|c|}{ DATA ACQUISITION SYSTEMS: INSTANTANEOUS-SIGNAL SAMPLING (Continued) } \\
\hline \multicolumn{3}{|c|}{ SOFTWARE: PC DATA ACQUISITION DISPLAY AND SCALING (Continued) } \\
\hline \multicolumn{3}{|c|}{$\begin{array}{l}\text { Snap-Print Program: } \\
\text { Provides the driver interface between Snapshot Storage Scope displays and most printers } \\
\text { currently in use. }\end{array}$} \\
\hline \multicolumn{3}{|c|}{ DATA ACQUISITION SYSTEMS: RMS-SIGNAL SAMPLING } \\
\hline \multicolumn{3}{|c|}{$\begin{array}{l}\text { HARDWARE: SAMPLING/CONVERSION MODULES: } \\
\text { Purchased from Omega Engineering, Inc., Box 4047, Stamford, CT 06907-0047, whose model } \\
\text { numbers are given below. }\end{array}$} \\
\hline Specification & Model WB 820 & Model OMX-STB-HL \\
\hline Description: & $\begin{array}{l}\text { A/D Converter and } \mathrm{I} / \mathrm{O} \text { Control } \\
\text { Board - mounted in a long PC } \\
\text { expansion slot }\end{array}$ & $\begin{array}{l}\text { 16-Channel, Multiplexer, Buffer } \\
\text { Input; 4-Channel D/A Output } \\
\text { Board }\end{array}$ \\
\hline $\begin{array}{l}\text { Analog Inputs: } \\
\text { Channels } \\
\text { Maximum } V \text { in }\end{array}$ & $\begin{array}{l}1 \text { channel, single-ended from } \\
\quad \text { OMX-STB-HL } \\
\pm 5 \mathrm{~V}\end{array}$ & $\begin{array}{l}16 \text { channel, single-ended } \\
\pm 5, \pm 10 \mathrm{~V} \text { or } 0-10 \mathrm{~V}\end{array}$ \\
\hline Analog Channel Elements: & $\begin{array}{l}\text { buffer amplifier; sample/hold } \\
\text { circuit; A/D converter }\end{array}$ & $\begin{array}{l}\text { multiplexer; amplifier; sample/ } \\
\text { hold circuit }\end{array}$ \\
\hline $\begin{array}{l}\text { Amplifier: } \\
\text { Gain } \\
\text { Accuracy } \\
\text { Linearity } \\
\text { Bandwidth }\end{array}$ & $\begin{array}{l}1 \\
0.025 \% \pm 1 \mathrm{LSB} \\
\pm 1 \mathrm{LSB} \text { integral } \\
\text { above } 5 \mathrm{kHz}\end{array}$ & $\begin{array}{l}0.5 \text { or } 1.0 \\
0.05 \% \text { of span } \\
\text { above } 5 \mathrm{kHz}\end{array}$ \\
\hline $\begin{array}{l}\text { A/D Converter: } \\
\text { Conversion } \\
\text { Linearity } \\
\text { Resolution } \\
\end{array}$ & $\begin{array}{l}12 \text { bits @ } 35 \mu \text { Sec max. } \\
\pm 1 \text { bit } \\
1 / 4095 \text { parts of F.S. }\end{array}$ & \\
\hline $\begin{array}{l}\text { Control Elements: } \\
\text { Digital I/O } \\
\text { D/A Channel Selection } \\
\text { A/D Channel Selection }\end{array}$ & $\begin{array}{l}\text { Three 8-bit ports } \\
16 \text { possible channels } \\
16 \text { channels/input panel }\end{array}$ & Handshaking w/WB-820 \\
\hline $\begin{array}{l}\text { Outputs: } \\
\text { D/A Output }\end{array}$ & & $4 \mathrm{D} / \mathrm{A}$ channels \\
\hline $\begin{array}{l}\text { Data Transfer: } \\
\text { Modes } \\
\text { Rate }\end{array}$ & $\begin{array}{l}\text { polled status, interrupt service } \\
19,000 \text { samples/sec max }\end{array}$ & \\
\hline
\end{tabular}


TABLE 5.2. BDFM 13 KVA/10hp Test Stand Instrumentation Specifications.

(Continued)

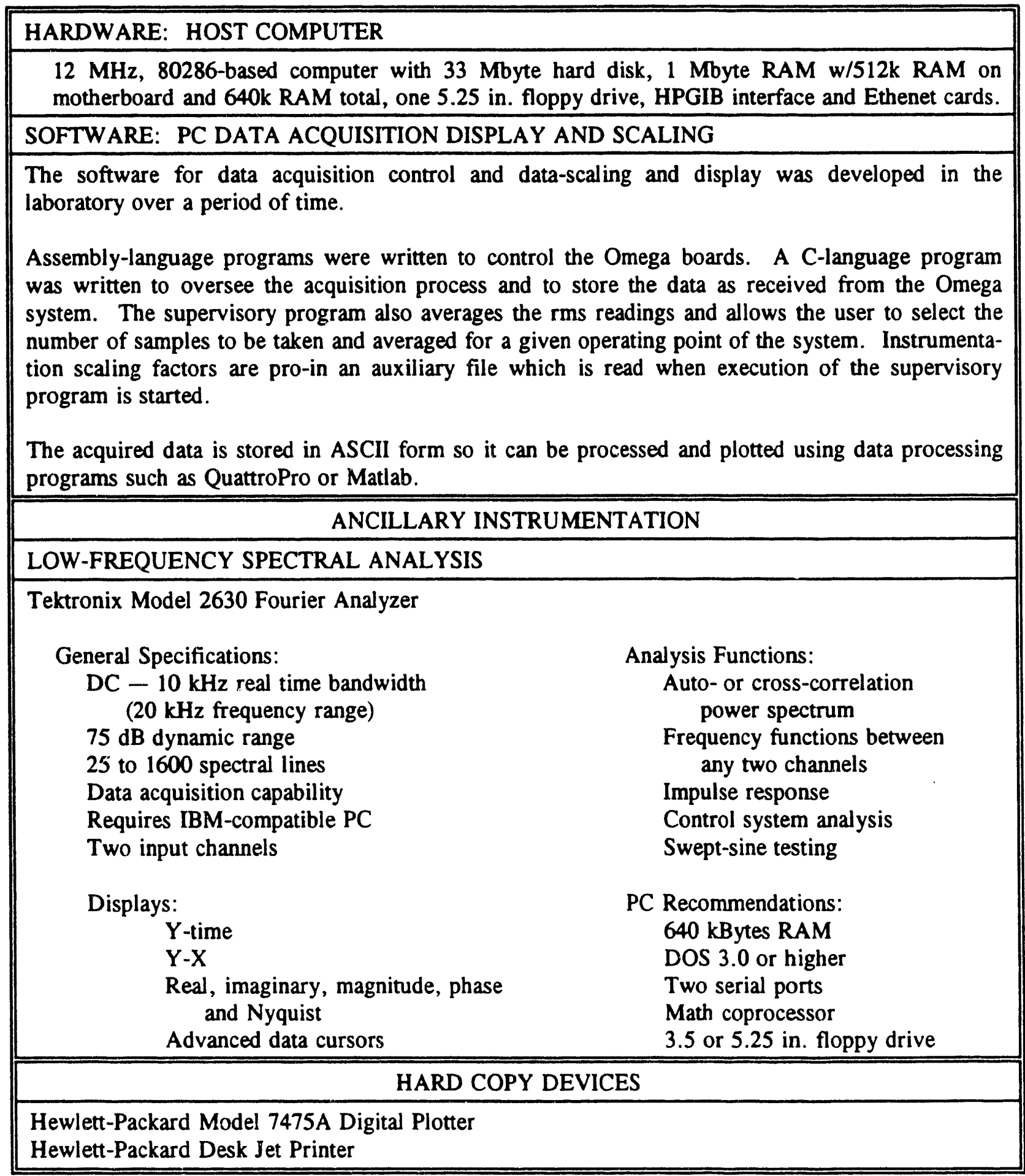


TABLE 5.3. BDFM Laboratory Undedicated Instrumentation Specifications.

\begin{tabular}{|c|c|c|c|c|}
\hline \multicolumn{5}{|c|}{ ELECTRICAL RMS MEASUREMENTS } \\
\hline \multicolumn{5}{|c|}{ CURRENT } \\
\hline \multicolumn{2}{|c|}{ FW Bell Current Gun: } & \multicolumn{3}{|c|}{$\begin{array}{l}\text { Model CG-100 D } \\
100 \mathrm{~A} \mathrm{rms} \\
480 \mathrm{~V} \text { rms insulation level } \\
\text { Battery operated }\end{array}$} \\
\hline \multicolumn{5}{|c|}{ MULTIPLE FUNCTION (Digital Multimeter) } \\
\hline \multicolumn{5}{|c|}{$\begin{array}{l}\text { Fluke: Model } 8060 \mathrm{~A} \\
\text { Functions and General Characteristics: } \\
\text { Except as noted, the sample rate is } 2.5 \text { readings/sec. } \\
\text { For AC components, the true rms value is displayed (AC-Coupled) } \\
\text { Battery operated }\end{array}$} \\
\hline Mode & Function & Range Limit & Sample Rate & Notes \\
\hline $\mathrm{DC}$ & $\begin{array}{l}\text { Resistance } \\
\text { Voltage } \\
\text { dBm 'volts' } \\
\text { dBV 'volts' } \\
\text { Current } \\
\text { Conductance } \\
\text { Continuity } \\
\text { Diode }\end{array}$ & $\begin{array}{l}0.2 \Omega \text { to } 300 \mathrm{M} \Omega \\
2 \mathrm{mV} \text { to } 1000 \mathrm{~V} \\
2 \mu \mathrm{A} \text { to } 2 \mathrm{~A} \\
0.1 \mathrm{nS} \text { to } 2 \mu \mathrm{S} \\
(\mathrm{S}=\text { siemens })\end{array}$ & $\begin{array}{l}1.4 / \mathrm{sec} \\
1.4 \mathrm{sec}\end{array}$ & $\begin{array}{l}\text { Autoranging is available. } \\
\text { Lowest range }=2 \mathrm{k} \Omega \\
\text { Input impedance }=10 \mathrm{M} \Omega \text {; } \\
10^{10} \text { available to } 2 \mathrm{~V} \\
\text { Referred to } 600 \Omega \\
\text { Referred to } 1 \mathrm{~V} \text {. Dynamic } \\
\text { range }=136 \mathrm{dBm} \\
0.3 \mathrm{~V} \text { series drop; internally } \\
\text { fused } \\
\text { Visual and aural indication in } \\
50 \mu \mathrm{sec} \\
\text { Limits current }\end{array}$ \\
\hline $\mathrm{AC}$ & $\begin{array}{l}\text { Voltage } \\
\text { dBm 'volts' } \\
\text { dBV 'volts' } \\
\text { Current } \\
\text { Frequency }\end{array}$ & $\begin{array}{l}2 \mu \mathrm{A} \text { to } 2 \mathrm{~A} \\
12 \mathrm{~Hz} \text { to } 200 \mathrm{kHz}\end{array}$ & $\begin{array}{l}1.4 / \mathrm{sec} \\
1.4 / \mathrm{sec}\end{array}$ & $\begin{array}{l}\text { Input impedance }=10 \mathrm{M} \Omega \\
\text { Shunt } C<100 \mathrm{pf} \\
\text { Referred to } 600 \Omega \\
\text { Referred to } 1 \mathrm{~V} \text {. Dynamic } \\
\text { range }=110 \mathrm{dBm} \\
0.3 \mathrm{~V} \text { series drop; internally } \\
\text { fused } \\
\text { Signal applied as voltage }\end{array}$ \\
\hline & Relative & \multicolumn{3}{|c|}{$\begin{array}{l}\text { Stores a value which is subtracted from subsequent readings for all } \\
\text { modes and functions, except continuity. Stores the resistance value for } \\
\text { a continuity test. }\end{array}$} \\
\hline
\end{tabular}


TABLE 5.3. BDFM Laboratory Undedicated Instrumentation Specifications.

(Continued)

\begin{tabular}{|c|c|c|c|c|}
\hline \multicolumn{5}{|c|}{ ELECTRICAL RMS MEASUREMENTS (Continued) } \\
\hline \multicolumn{5}{|c|}{ MULTIPLE FUNCTION (Digital Multimeter) (Continued) } \\
\hline \multicolumn{5}{|c|}{$\begin{array}{l}\text { Fluke: Model } 8060 \mathrm{~A} \text { (continued) } \\
\text { Specifications: } \\
\text { Except as noted, the resolution of any reading is } 5 \times 10^{-5} \text { (range). } \\
\text { Voltage input resistance is } 10 \mathrm{M} \Omega \text { (Shunt } \mathrm{C}<100 \mathrm{pf} \text { for } \mathrm{AC} \text { ). }\end{array}$} \\
\hline Mode & Function & $\begin{array}{c}\text { Accuracy } \\
\pm(\% \text { rdg }+ \text { dig })\end{array}$ & $\begin{array}{l}\text { Response Time } \\
\text { Sec } \\
\end{array}$ & Notes \\
\hline DC & $\begin{array}{l}\text { Resistance } \\
\text { Voltage } \\
\text { dBm 'volts' } \\
\text { dBV 'volts' } \\
\text { Current } \\
\text { Conductance } \\
\text { Continuity } \\
\text { Diode }\end{array}$ & $\begin{array}{ccc}0.07 & 1 & 2 \\
2 \text { max; } \mathrm{M} \Omega & \\
0.05 & 1 & 2 \\
\pm 0.04 \mathrm{~dB} & \\
\pm 0.04 \mathrm{~dB} & \\
0.3 & 1 & 2 \\
0.5 & 1 & 20 \\
& 1 & \\
0.05 & 1 & 2\end{array}$ & $\begin{array}{c}2 \\
8 \text { on } \mathrm{M} \Omega \\
1 \\
1 \\
1 \\
1 \\
2 \\
2\end{array}$ & $\begin{array}{l}\text { Ranges: } 200,2 \mathrm{k}, 20 \mathrm{k}, 200 \mathrm{k} \text {, } \\
\quad \mathrm{M} \Omega(100 \Omega-300 \mathrm{M} \Omega) \\
\text { Above } 5 \% \mathrm{~F} . \mathrm{S} . ; \\
\text { Resolution: } 0.01 \mathrm{~dB}(<5 \%) \\
\text { Resolution is } 0.1 \text { nsiemen } \\
10 \% \text { of range threshold } \\
1 \mathrm{~mA}( \pm 10 \%) \text { test current }\end{array}$ \\
\hline $\mathrm{AC}$ & $\begin{array}{l}\text { Voltage } \\
\text { dBm 'volts' } \\
\text { dBV 'volts' } \\
\text { Current } \\
\text { Frequency }\end{array}$ & $\left.\begin{array}{llr}0.5 & 1 & 10 \\
& 1 & \\
\pm 0.15 \mathrm{~dB} & \\
\pm & 0.15 \mathrm{~dB} & \\
0.75 & 1 & 10 \\
0.05 & 1 & 1\end{array}\right]$ & $\begin{array}{l}5 \\
5 \\
5 \\
5\end{array}$ & $\begin{array}{l}45 \mathrm{~Hz}-1 \mathrm{kHz} \text {; Crest Factor } \\
\text { less than } 3:: 1 \\
20 \mathrm{~Hz}-10 \mathrm{kHz} \\
\\
45 \mathrm{~Hz}-3 \mathrm{kHz} \\
\text { All voltage ranges }\end{array}$ \\
\hline \multicolumn{5}{|c|}{ WAVEFORM DISPLAYS } \\
\hline \multicolumn{5}{|c|}{ OSCILLOSCOPE: TEKTRONIX MODEL 2230, DIGITAL STORAGE } \\
\hline \multicolumn{5}{|c|}{$\begin{array}{l}\text { The } 2230 \text { has the usual features of a top-of-the-line, analog oscilloscope with dual channels and } \\
\text { dual time-base sweeps. It also provides CRT display of many function settings. With the x10 } \\
\text { voltage probes provided, } 400 \mathrm{~V} \text { peak-to-peak voltages may be displayed (141 V rms sinusoid). } \\
\text { The normal bandwidth is } 100 \mathrm{MHz} \text {. }\end{array}$} \\
\hline \multicolumn{5}{|c|}{$\begin{array}{l}\text { The } 2230 \text { also performs high-frequency sampling, storage, and playback of the input signals, } \\
\text { along with CRT display of the necessary menus for controlling the microprocessor operation in } \\
\text { the digital mode. Provision is made for output to an analog X-Y plotter and for an external } \\
\text { clock to control the digital sampling process. }\end{array}$} \\
\hline $\begin{array}{l}\text { Th } \\
\text { int }\end{array}$ & sion in th & M laboratory & ed & ktronix GPIB in \\
\hline
\end{tabular}


TABLE 5.3. BDFM Laboratory Undedicated Instrumentation Specifications. (Continued)

\begin{tabular}{|c|}
\hline WAVEFORM DISPLAYS (Continued) \\
\hline OSCILLOSCOPE: TEKTRONIX MODEL 2230, DIGITAL STORAGE (Continued) \\
\hline Digital Operating Features: \\
\hline $\begin{array}{l}\text { Waveforms are sampled at a maximum of } 20 \text { Msamples/sec. } 4096 \text { samples (or 1024) are stored } \\
\text { in a buffer as a record while } 100 \text { samples/div are simultaneously displayed; so the sample rate } \\
\text { depends upon the sweep-speed setting. A new record is acquired and displayed each time a } \\
\text { trigger is generated by the horizontal deflection system. (A number of special display and } \\
\text { storage modes can be used as well.) When dual-channel operation is selected, the samples are } \\
\text { split equally between the two signals. A record of } 4096 \text { samples can be vieweal by displaying } \\
\text { every fourth point of the record. The continuous acquisition process can be interrupted for the } \\
\text { inspection of any record. }\end{array}$ \\
\hline $\begin{array}{l}\text { Additional memory is available for storage of three 1024-point (or one 4096-point) records for } \\
\text { future use. }\end{array}$ \\
\hline $\begin{array}{l}\text { Cursors can be used with stored wave forms to measure voltage and time differences and delay } \\
\text { time. Pre- and post-triggering operation is available. Averaging of repetitive waveforms can be } \\
\text { requested. }\end{array}$ \\
\hline $\begin{array}{l}26 \mathrm{k} \text { of additional memory is available for waveform storage when the GPIB communications } \\
\text { option is added. This memory is manipulated by the host to which the } 2230 \text { is connected. The } \\
\text { memory is non-volatile for a period of up to three years. }\end{array}$ \\
\hline $\begin{array}{l}\text { Default settings for the digital system can be changed and the sampling and storage features } \\
\text { modified through a set of control menus which can be displayed on the screen, or through control } \\
\text { from the host. }\end{array}$ \\
\hline Detailed Specifications: \\
\hline $\begin{array}{l}\text { The horizontal sweep has calibrated steps in the sequence } 1-2-5 \text { from } 50 \text { ns/div to } 0.5 \mathrm{~s} / \mathrm{div} \text { ( } 50 \\
\text { ns/div to } 0.05 \mathrm{~s} / \mathrm{div} \text { for the B sweep) in all modes plus } 1,2 \text { and } 5 \mathrm{~s} / \mathrm{div} \text { in the STORE mode. A } \\
\text { magnifier control raises the analog sweep speeds by a factor of } 10 \text {. Variable sweep speed can be } \\
\text { selected at any calibrated step. }\end{array}$ \\
\hline $\begin{array}{l}\text { The vertical sensitivities are calibrated in the sequence } 1-2-5 \text { from } 2 \mathrm{mV} / \mathrm{div} \text { to } 5 \mathrm{~V} / \mathrm{div} \text {. } 8 \\
\text { divisions are shown on the screen. Data is stored for } 10 \text { divisions at } 100 \text { points/division. }\end{array}$ \\
\hline $\begin{array}{l}\text { The vertical channel input impedance is }(1 \mathrm{M} \Omega \pm 2 \%) \text { resistance in shunt with ( } 20 \mathrm{pF} \pm 2 \mathrm{pF} \text { ) } \\
\text { capacitance). }\end{array}$ \\
\hline
\end{tabular}


TABLE 5.3. BDFM Laboratory Undedicated Instrumentation Specifications. (Continued)

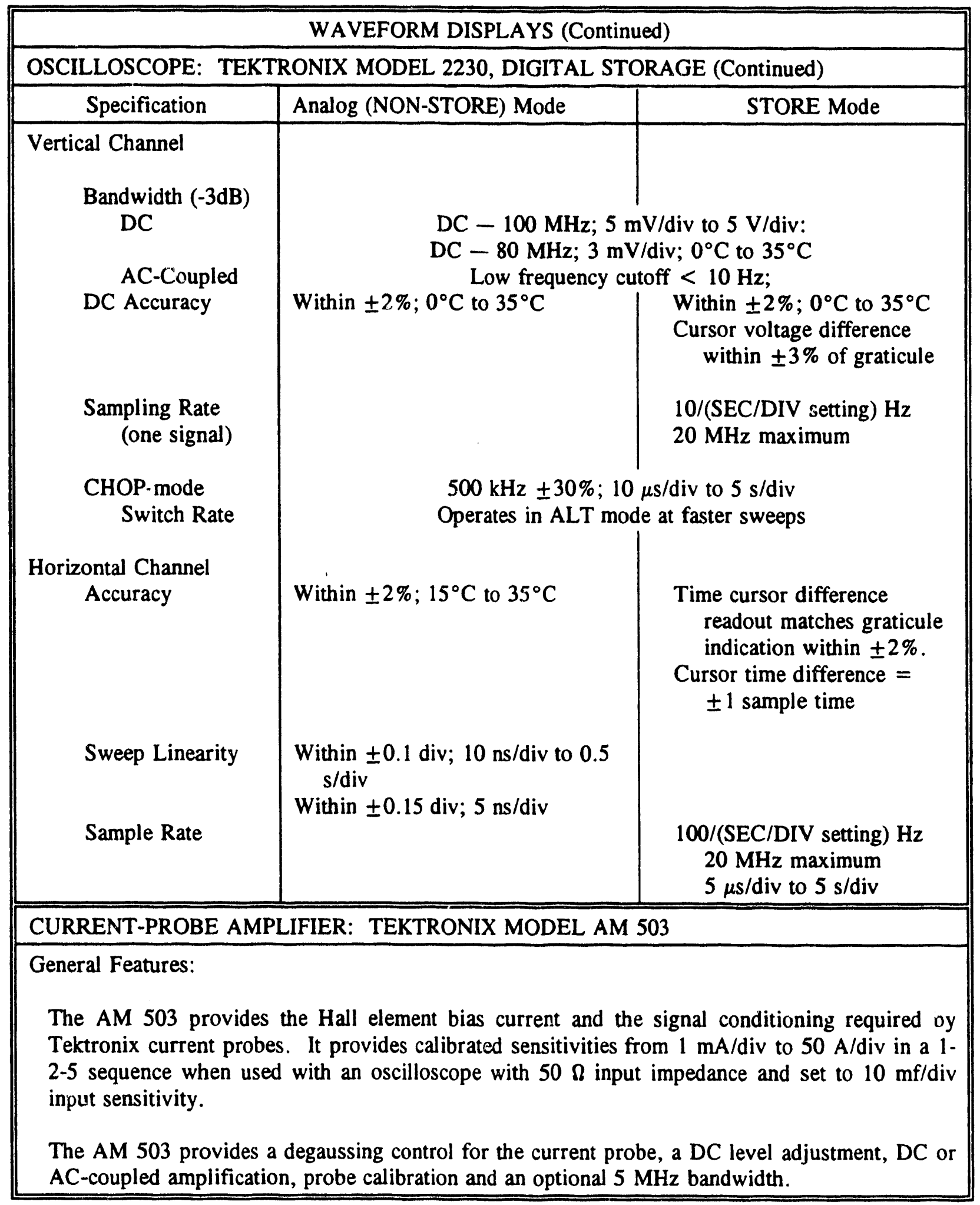


TABLE 5.3. BDFM Laboratory Undedicated Instrumentation Specifications.

(Continued)

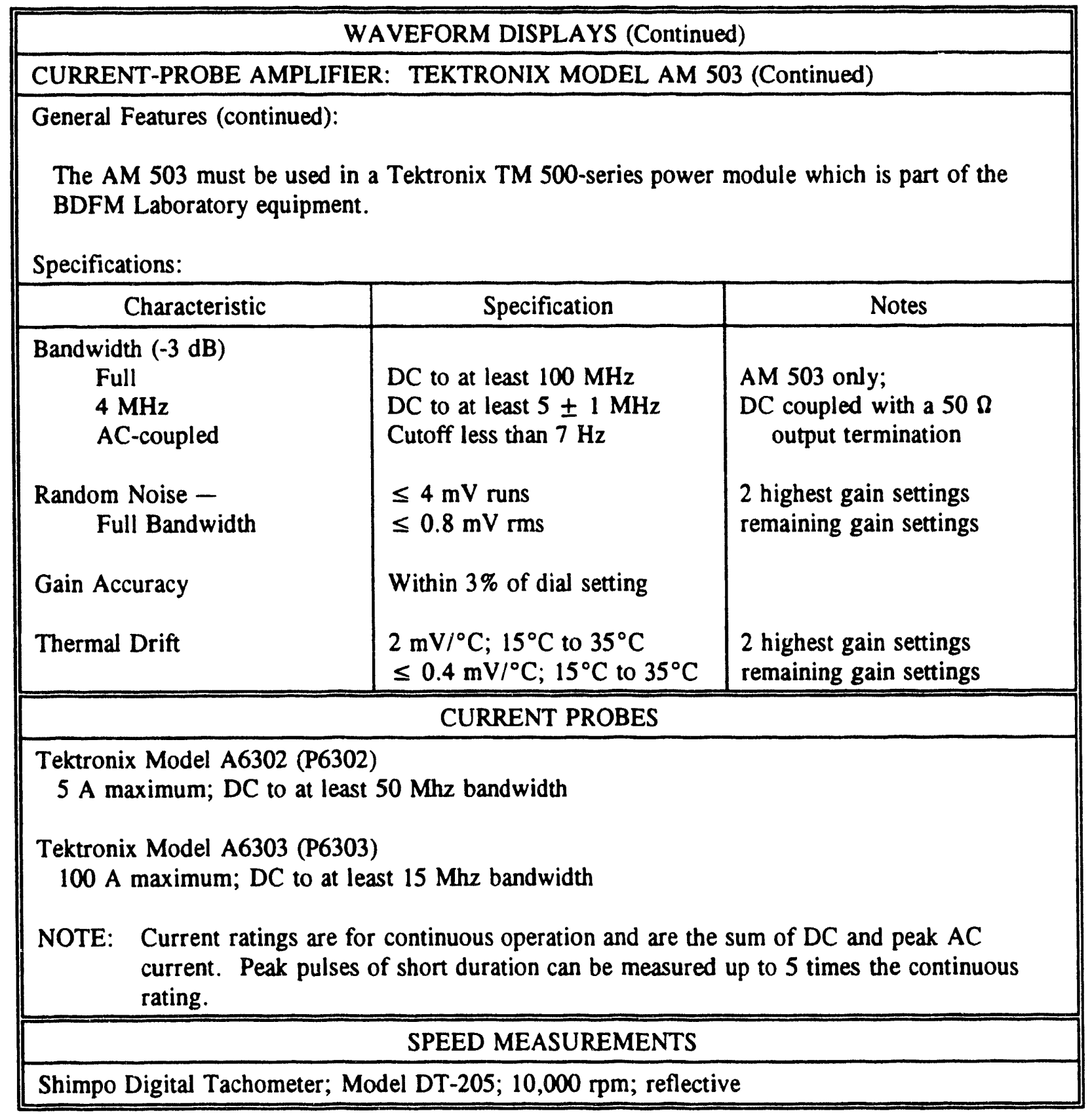


TABLE 5.3. BDFM Laboratory Undedicated Instrumentation Specifications.

(Continued)

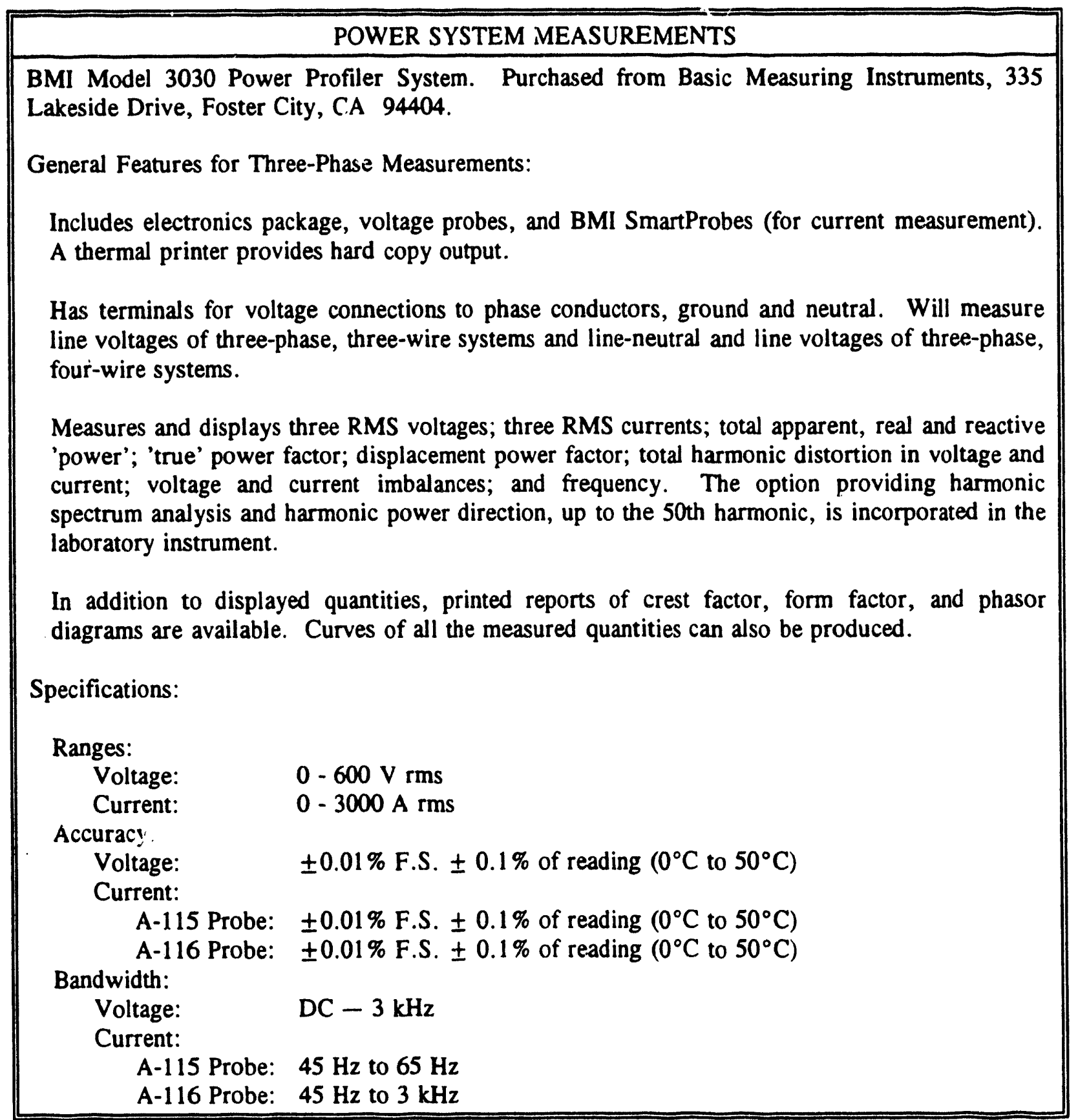




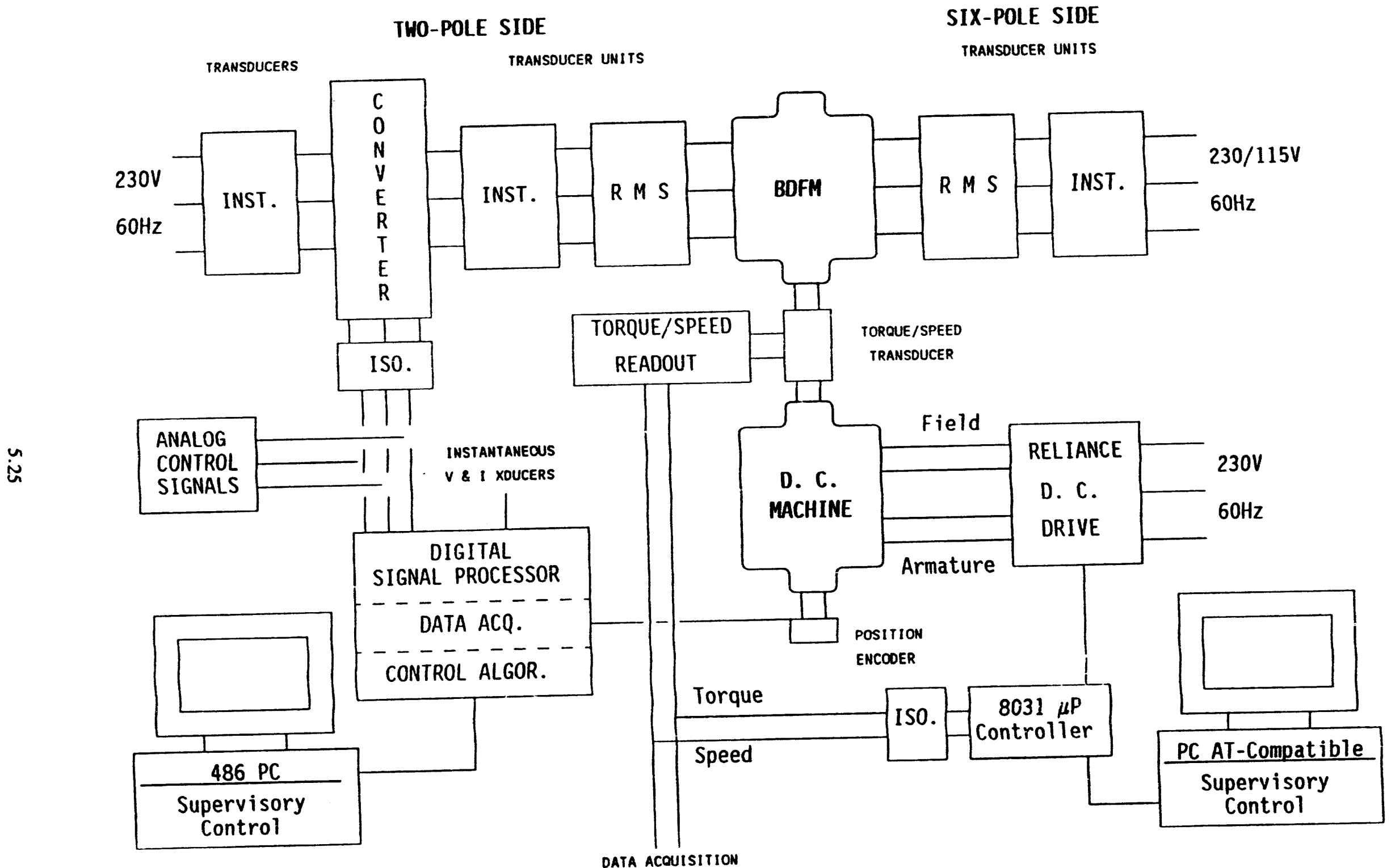

Fig. 5.2.1. Fixed-Equipment Components of the BDFM Test Stand and Their Interconnection Links. 


\section{STEADY-STATE DATA ACQUISITION SYSTEM}

TWO-POLE SIDE

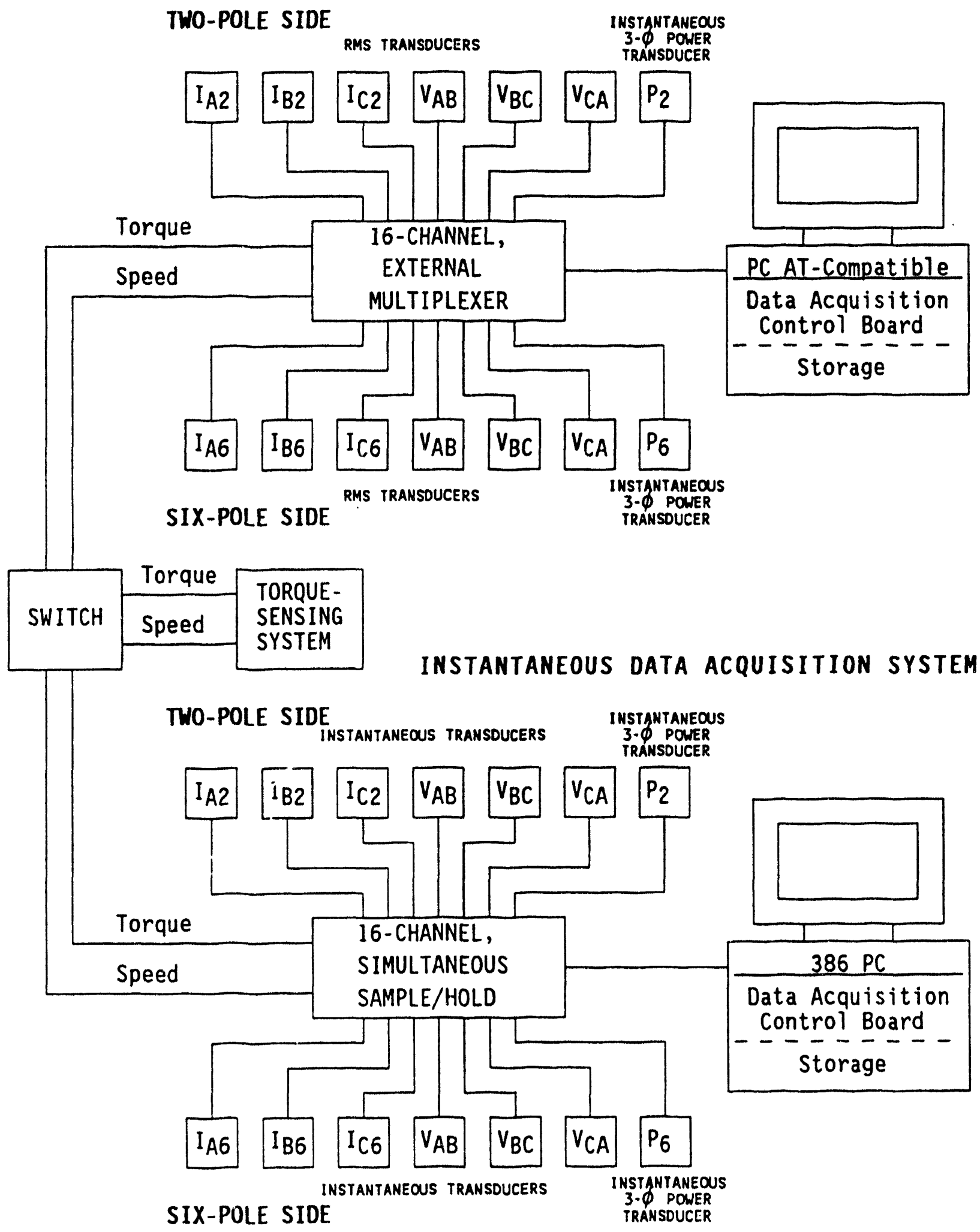

Fig. 5.2.2. The Interconnections of the Steady-State (rms) and Instantaneous Data Acquisition Systems. 


\section{BDFM MODELING ACTIVITIES}

\subsection{Steady-State Model and Simulator}

The progression of modeling techniques used for BDFM analysis and design has gone from the early "dynamic detailed model" [6.1] through the two-axis $(d, q)$ model $[6.2,6.3,6.4]$ to the single-axis model [6.5] which can be represented in the equivalent circuit of Fig. 6.1.1. As is explained in Ref. [6.5], although the model is far simpler than previously used techniçues, being a voltage driven model, it requires the determination of a fictitious phase angle between referred power winding and control winding voltages. This angle becomes specified by knowledge of the required torque. The model has been incorporated as a BDFM steady-state simulator.

The BDFM Steady-State Simulator was developed to provide a simple method for extracting steady-state performance data on the BDFM. Current dynamic simulations take a long time to get one steady-state set of data. By utilizing the steady-state model of the BDFM quick evaluation may be made of machine parameter changes. The program is based on earlier work with a steady-state induction motor simulator. The program, in Turbo Pascal, is written to run on any IBM PC compatible computer.

One of the primary goals of the program is to provide a simple interactive interface that anyone can use. The program does not require the use of an external editor or data display program. All performance data is displayed instantly on the screen for immediate evaluation.

This program is an interactive simulation of the steady-state operation of the BDFM. The program solves the seven non-linear equations that describe the operation of the BDFM in the synchronous mode with nonzero control winding frequency [6.5].

The Newton-Rhapson method is used to solve the nonlinear equations utilizing the Hamiltoninan matrix to iteratively solve the equations. A typical operating point is solved in less than 10 iterations. Computation time for any operating point is usually less than 5 seconds, even on a XT type PC. A 386 type PC will make computation time nearly instantaneous. Certain operating points may not converge to a solution, this is thought to be related to attempted operation of the BDFM in an unstable region.

The simulation uses lumped machine parameters to calculate the current and electrical torque developed in the steady-state. The lumped parameters are stored in files with extension ".DAT". Included in this distribution are parameters for 3 different machines here at OSU. A typical user screen is shown in Fig. 6.1.2. 
As shown the program calculate many useful quantities so that performance may be evaluated. At the bottom of the screen the program displays the current set of machine parameters. This may be changed interactively.

When the simulation is running there are five control variables:

(1) Load Torque (Nm)

(2) Power Winding Voltage (1-1)

(3) Control Winding Voltage (1-1)

(4) Power Winding Frequency $(\mathrm{Hz})$

(5) Control Winding Frequency $(\mathrm{Hz})$

After setting the control variables to the desired operating point the user presses a key $(x)$ and the simulation proceeds. While the simulation is running the computer displays the iteration number and error at the top of the screen. When the error drops below a certain threshold the current data is considered valid. If the iteration number reaches 25 then the current operating point is assessed to be invalid. A fter the operating point is calculated the screen shows the different characteristics of that paricular operating point. By pressing a key the user can choose to output that particular opersing point to a file. The user can continue to output different operating points to the file (each operating point is appended to the end of the current file). These data points may be used in a spreadsheet program for graphically display performance trends.

The program offers the following main menu options:

Option 1: Loads data file from the disk. The data file contains machine parameters and output file specifications.

Option 2: Saves data file to the disk.

Option 3: Allows user to change machine parameters. Useful for first defining parameters. The simulation (Option 4) can crash if there are illegal parameters.

Option 4: Runs the simulation. There are five control modes in the simulation. The following describes how to change the control variable. The keys F1 through F5 select which variable to change. 


\begin{tabular}{||l|l||}
\hline Key & Control Variable \\
\hline F1 & Load Torque $(\mathrm{Nm})$ \\
\hline F2 & Power Winding Voltage $(1-1)$ \\
\hline F3 & Control Winding Voltage $(1-1)$ \\
\hline F4 & Power Winding Frequency $(\mathrm{Hz})$ \\
\hline F5 & Control Winding Frequency $(\mathrm{Hz})$ \\
\hline
\end{tabular}

The controlled variable value may be changed by using the following keys:

\begin{tabular}{||l|l|l|}
\hline Sensitivity & Increase & Decrease \\
\hline Low & "Insert" & "Delete" \\
\hline Medium & "Home" & "End" \\
\hline High & "Page Up" & "Page Down" \\
\hline
\end{tabular}

The current mode is indicated in the upper-right corner. The sensitivity can be decreased by using the SHIFT key in combination with F1-F5. If the mode is in all CAPS the sensitivity is in the HIGH mode. If the mode is in lower case the sensitivity is in the low mode. Use " $x$ " to calculate the current operating point. Operating point data may be saved to disk by using " $p$ ". The data is saved in a columnar format. Use " $c$ " to close the current output data file. Use "q" to quit the simulation.

Option 5: Changes the operating point variables that are saved to disk.

Option 9: Displays this file.

Option Q: Quit the program.

The two-axis model used to date in the simulation was developed specifically of the original BDFMs, and as such, is basically restricted to machines which are configured with 6 power winding poles and 2 control winding poles. However, recent studies into certain applications such as the automotive alternator and the wind-turbine generator indicate that pole number combinations other than $6 / 2$ may be advantageous. Consequently, work has been undertaken to extend the derivation of the two-axis theory to other pole number combinations. This has been achieved in a general manner and will be evaluated in Phase 4 with analyses and performance predictions of 
the new $12 / 4$ pole automotive generation and a potential 10/6 adaptation using the same rotor.

In addition the simulator has been adapted to predict the operation of a linear BDFM (LBDFM) as a proposed traction motor for mass transit vehicles. Results for the experimental laboratory LBDFM performance, which are shown in Fig. 6.1.3, will be presented at the 1993 European Power Electronics Conference [6.6].

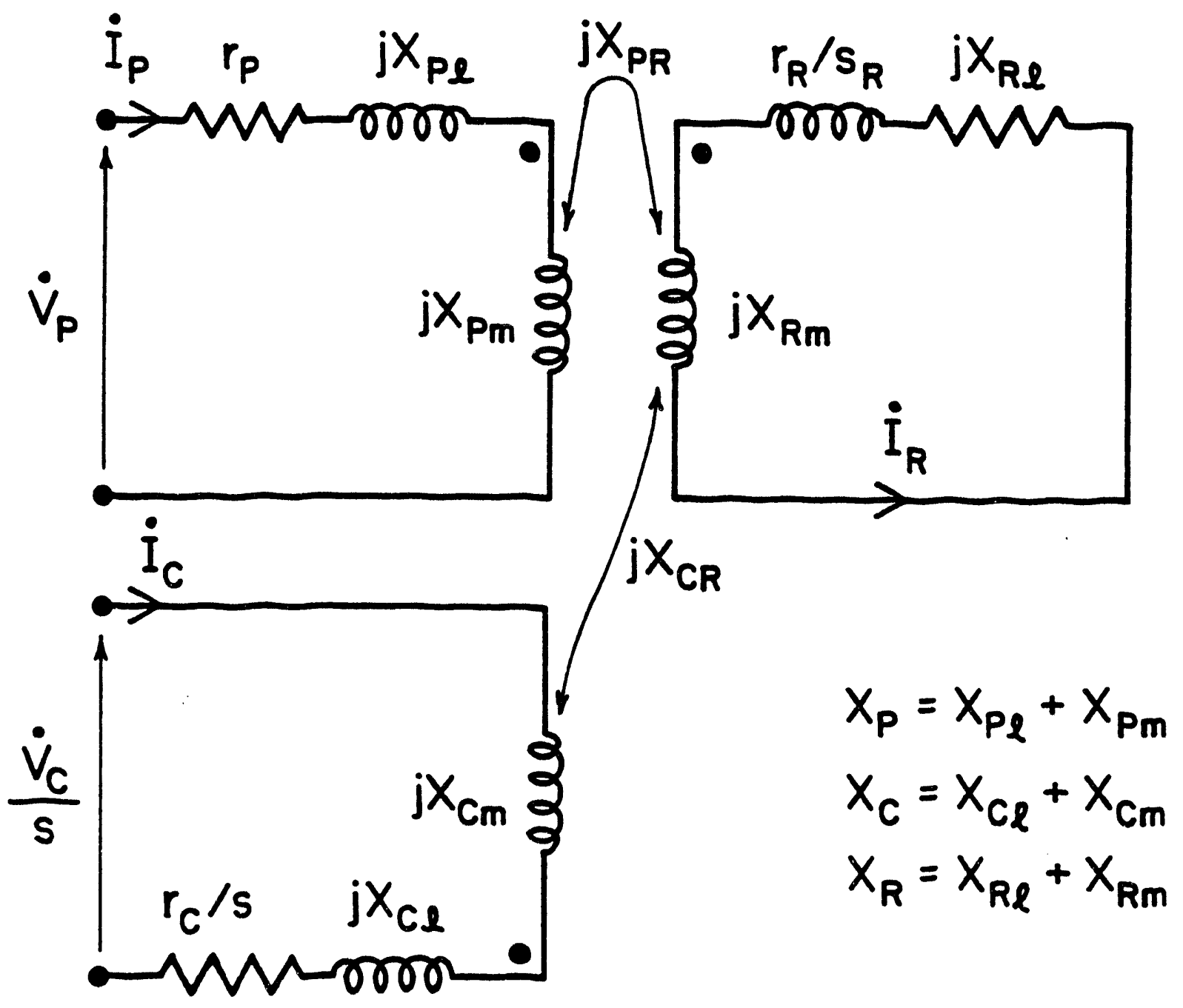

Fig. 6.1.1. Steady State Equivalent Circuit of BDFM. 
Load Torque : 20.00

PW Voltage $(1-n): 132.79 \mathrm{~V}(1-1): 230.00 \mathrm{~V}$

Mode: LOAD TORQUE

$\mathrm{CW}$ Voltage $(1-\mathrm{n}): 32.9 \mathrm{~V}(1-1): 57.0 \mathrm{~V}$

Power Frequency: 60.00

Control Frequency: 10.00

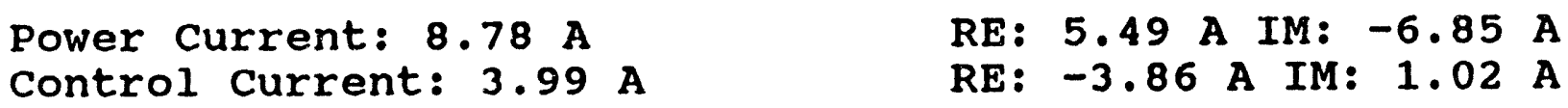

(1) Power R: 0.97000 (5) Control L: 0.38728

(2) Control R: 0.71000 (6) Power M: 0.00127

(3) Rotor R: 0.00033 (7) Control M: 0.00382

(4) Power L: 0.12467

F1 - Load Torq F2 - Power V F3 - cont. V F4 - Power Frq F5 - Cont. Frq p - output data to file c-close data file q-quit

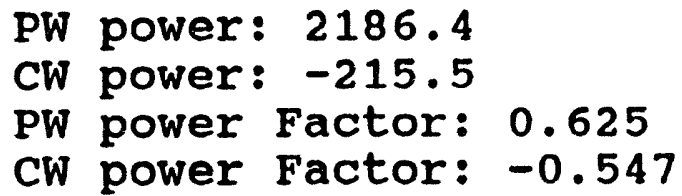

(8) Rotor L: 0.00004 

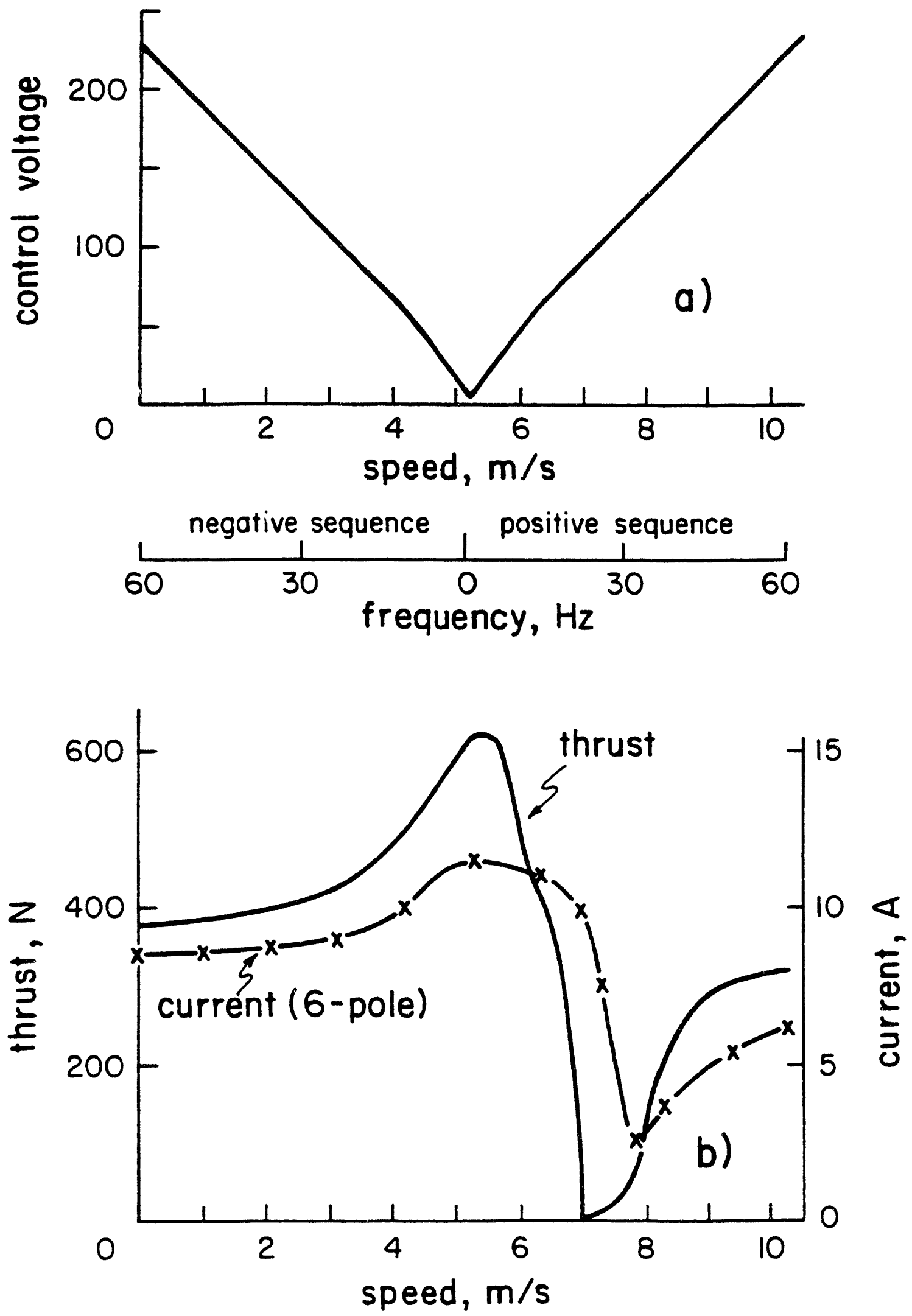

Fig. 6.1.3. Performance Prediction Obtained from Simulator for LBDFM. 


\subsection{Multiple Harmonic Theory (MHT) Model}

During the academic year 1991-92, a proposed new analytical/design tool was developed for BDFM in unfunded cooperation with Cambridge University (UK). This MHT model provides design guidelines for BDFM and allows for non-ideal stator winding distribution, rotor loop construction effects and high frequency "skin effects" in the large section rotor conductors, which have to be neglected in order to make the transformations necessary for two-axis $(d-q)$ theory. Thus, it is potentially a more powerful tool for practical BDFMs.

A program implementing the equations of the multiple harmonic theory has been written during 1992-93 academic year and is currently in the process of being debugged. The program is written in the $\mathrm{C}++$ language in order to take advantage of the superior matrix operations available from commercial software packages, compared to other languages.

Preliminary results of the program show qualitative agreement with the " $V$ " curves measured in the laboratory and also reproduce the general shape of the observed power factor versus control current. However, the required magnitude of the control winding voltages and rotor torques resulting from the simulation do not agree with measurements. This may be partially because the program is dependent on machine electrical circuit parameters which must be calculated from machine dimensions at the beginning of the program. These parameters are not, for the most part, easily measurable. This introduces some difficulty in reconciling the simulation with the laboratory tests. One parameter which can be easily measured, the power winding selfinductance, has been examined in some detail and does match the simulation calculations to within about $10 \%$. This result was obtained by calculation of the effective air gap from measurements of the actual air gap and calculation of fringing effects due to the measured slot openings of the stator and rotor. Future efforts will be directed towards devising laboratory tests which may be used to adjust the machine parameters input to the program so that the simulation results match the measured quantities.

In addition, a conceptual problem exists in the theory in order to account for the sequence of the multiple fields with respect to that of the power winding fundamental field and the rotor rotational direction (which are taken as the reference sequence direction). This problem, which is unique to BDFM analysis, is important for defining the nature of the cross-coupling that exists between power and control windings, via the rotor nests. In order to finally clean up details of the theory, Professor Steve Williamson from Cambridge, will visit OSU in August 1993. 


\subsection{Dynamic BDFM Simulator}

The dynamic simulator described in the Phase 2 report has been extended to enable simulation of the direct torque controller discussed in Chapter 5. The salient features of the simulation program are reviewed in this section. A more complete discussion of simulator capabilities and shortcomings can be found in [6.6]

The heart of the dynamic simulator is a 4th order Runge-Kutta (RK-4) algorithm, which is used to integrate the BDFM system differential equations, in the rotor reference frame. The program presently is only able to simulate BDFM structures with six- and two-pole stator geometries.

In the closed-loop, all simulation must be done with $0.1 \mathrm{~ms}$ step size or lower, because of the $1 \mathrm{~ms}$ update period assumad for the direct torque control algorithm developed. As hardware development for the direct torque controller progresses, an update of the program to allow adjustable control update periods is desirable.

The BDFM simulation package is written in Turbo Pascal 6.0 and is interactive and graphical in nature. The BDFM was originally simulated in Fortran [6.2], using the reduced-order or d-q model. While this program provided some important information, it lacked a graphical display, and furthermore was non-interactive. This inspired the development of the simulator described here, to gain intuitive insight into machine operation.

The graphical display of the simulator is centered around the shaft speed of the machine; this is the quantity being controlled. The behavior, or "personality" of the machine is readily apparent by observing the speed response of the machine to various disturbances. Other state variables may also be plotted if desired, but they are generally of secondary importance and are superimposed over the speed display. Fig. 6.3.1 shows a typical screen, with the machine operating in the open-loop.

Time-scaling is fixed throughout the execution of the program but may be user-chosen by changing the value in the input file. Vertical scaling (of shaft speed) is changeable at any time, with the use of "zoom-in", "zoom-out", "offset-up", and "offset-down" options. Vertical scaling for the other state variables is more limited; the "zoom" feature is not present. Only pure scaling factors (without offsets) are allowed.

Outside the plotting screen border, other critical quantities of the machine are displayed in numeric format. These numeric displays (the dynamic quantities) are updated every time a new 
pixel is plotted on the screen, which is typically every millisecond (or, more precisely, 1000 times per screen width.) In order to increase simulation speed, the displays are designed to be toggled on or off by the user.

The program's interactiveness originates from its wide selection of "function keys", which can be used to change simulation parameters, program parameters, or display parameters. These function keys, and their operations, are listed in Table 6.1

The simulation program is able to accept machine parameters from an external data file; the format is illustrated in Table 6.2. Simulation results can be exported to text files, for detailed analysis with a spreadsheet or signal processing software. The data written include six-pole, twopole, and total torque; two-pole flux level; six- and two-pole voltages and currents in (abc quantities). Data is recorded every $1 \mathrm{~ms}$. 
TABLE 6.1. Dynamic Simulator Function Keys.

\begin{tabular}{|c|c|}
\hline key & Function \\
\hline $\begin{array}{l}\text { space } \\
q, Q \\
\text { m,M } \\
t, T \\
i, I \\
\text { p,P } \\
r, R \\
Z \\
z \\
\text { PageUp } \\
\text { PageDn } \\
x, X\end{array}$ & $\begin{array}{l}\text { freeze/unfreeze simulation } \\
\text { quit } \\
\text { "more" -- simulate another screen } \\
\text { toggle torque display on/off } \\
\text { toggle current display inst/rms/off } \\
\text { toggle phase-angle/power-factor display } \\
\text { toggle } \mathrm{r} / \mathrm{min} \text { display on/off } \\
\text { zoom out vertically, for speed display } \\
\text { zoom in vertically, for speed display } \\
\text { offset vertical speed display, higher } \mathrm{r} / \mathrm{min} \\
\text { offset vertical speed display, lower } \mathrm{r} / \mathrm{min} \\
\text { open/close data output to disk file. }\end{array}$ \\
\hline $\mathrm{b}, \mathrm{B}$ & $\begin{array}{l}\text { back-up - freezes simulation, allows user to select previous operating point (open-loop } \\
\text { only). }\end{array}$ \\
\hline $\begin{array}{l}\text { right } \\
\text { left } \\
\text { up } \\
\text { down } \\
7 \\
1 \\
9 \\
3 \\
8 \\
2\end{array}$ & $\begin{array}{l}\text { select large value changes } \\
\text { select small value changes } \\
\text { aigher speed; lower f2 } \\
\text { lower speed; higher } \mathrm{f} 2 \\
\text { increase six-pole voltage } \\
\text { decrease six-pole voltage } \\
\text { increase two-pole voltage (open loop); increase two-pole flux level (closed loop) } \\
\text { decrease two-pole voltage (open loop); decrease two-pole flux level (closed loop) } \\
\text { increase load torque } \\
\text { decrease load torque }\end{array}$ \\
\hline $\mathrm{H}, \mathrm{h}$ & increase or decrease integration step size \\
\hline $\begin{array}{l}\mathrm{V} \\
\mathrm{v} \\
\mathrm{C} \\
\mathrm{c} \\
\mathrm{E} \\
\mathrm{e} \\
\mathrm{l}, \mathrm{L}\end{array}$ & $\begin{array}{l}\text { "viewstates" on -- display other state variables. } \\
\text { Turns "viewstates" off. } \\
\text { Close the loop, activate direct torque controller. } \\
\text { Open the loop, deactivate controller. } \\
\text { "Efficalc" on. Causes more accurate, window-averaged calculation of torque and } \\
\text { efficiency. } \\
\text { "Efficalc" off. This reduces the calculation load, increasing simulation speed. } \\
\text { Capture value of the 2-pole flux level to be used as command value for the direct } \\
\text { torque controller. }\end{array}$ \\
\hline $\begin{array}{l}\text { Insert } \\
\text { Delete } \\
\text { Home } \\
\text { End } \\
\text { d,D }\end{array}$ & $\begin{array}{l}\text { select next state variable for display } \\
\text { select previous state variable for display } \\
\text { compress vertically, for state variable display } \\
\text { magnify vertically, for state variable display } \\
\text { toggle state variable display on/off; displays index number of state variable being } \\
\text { plotted [6.6] }\end{array}$ \\
\hline
\end{tabular}


TABLE 6.2. Dynamic Simulator Input File.

Below is the list of machine parameters, default parameters, integration step sizes, and display ranges to be used in the BDFM Dynamic Simulator Program. To change a machine parameter, simply alter the value. Only simple math operations (a single,+- , *, or /) may be used in data values. DO NOT change anything to the left of the equals sign, and always leave one space on each side of the equals sign.

$\mathrm{mp}[1](\operatorname{Lm} 6)=0.0679$

$\mathrm{mp}[2](\mathrm{L} 16)=0.012$

$\mathrm{mp}[3](\mathrm{M} 6)=0.00057 * 1.556$

$\mathrm{mp}[4](\mathrm{Lmr})=0.000125 / 6.0$

$\mathrm{mp}[5](\mathrm{Lir})=0.000125 / 6.0$

$\mathrm{mp}[6](\mathrm{r} 6)=2.42 / 3.0$

$\mathrm{mp}[7](\mathrm{r})=0.001572$

$\mathrm{mp}[8](\mathrm{Lm} 2)=0.61921$

$\mathrm{mp}[9](\mathrm{LL} 2)=0.012$

$\mathrm{mp}[10](\mathrm{M} 2)=0.00430422276$

$\mathrm{mp}[11](\mathrm{r} 2)=2.42 / 3.0$

$\mathrm{jj}$ (rotor moment of inertia in $\left.\mathrm{kg}^{*} \mathrm{~m}^{\wedge} 2\right)=0.05$

six-pole frequency in Hertz $=60$

default six-pole voltage (line-line RMS) $=230$

time range in display (seconds) $=1$

$\mathrm{rpm}$ range in display $=1300$

rpm change with PageUp/PageDown $=600$

default RK-4 integration step size in seconds; choice $=10$ choices are

1) 0.000001 , 2) 0.000002 , 3) 0.000005 , 4) 0.00001 ,

5) 0.00002 , 6) 0.00005, 7) 0.0001 , 8) 0.0002

$\begin{array}{llll}\text { 9) } 0.0005 & \text { 10) } 0.001 & \text { 11) } 0.002 & \text { 12) } 0.003\end{array}$

end of data file 


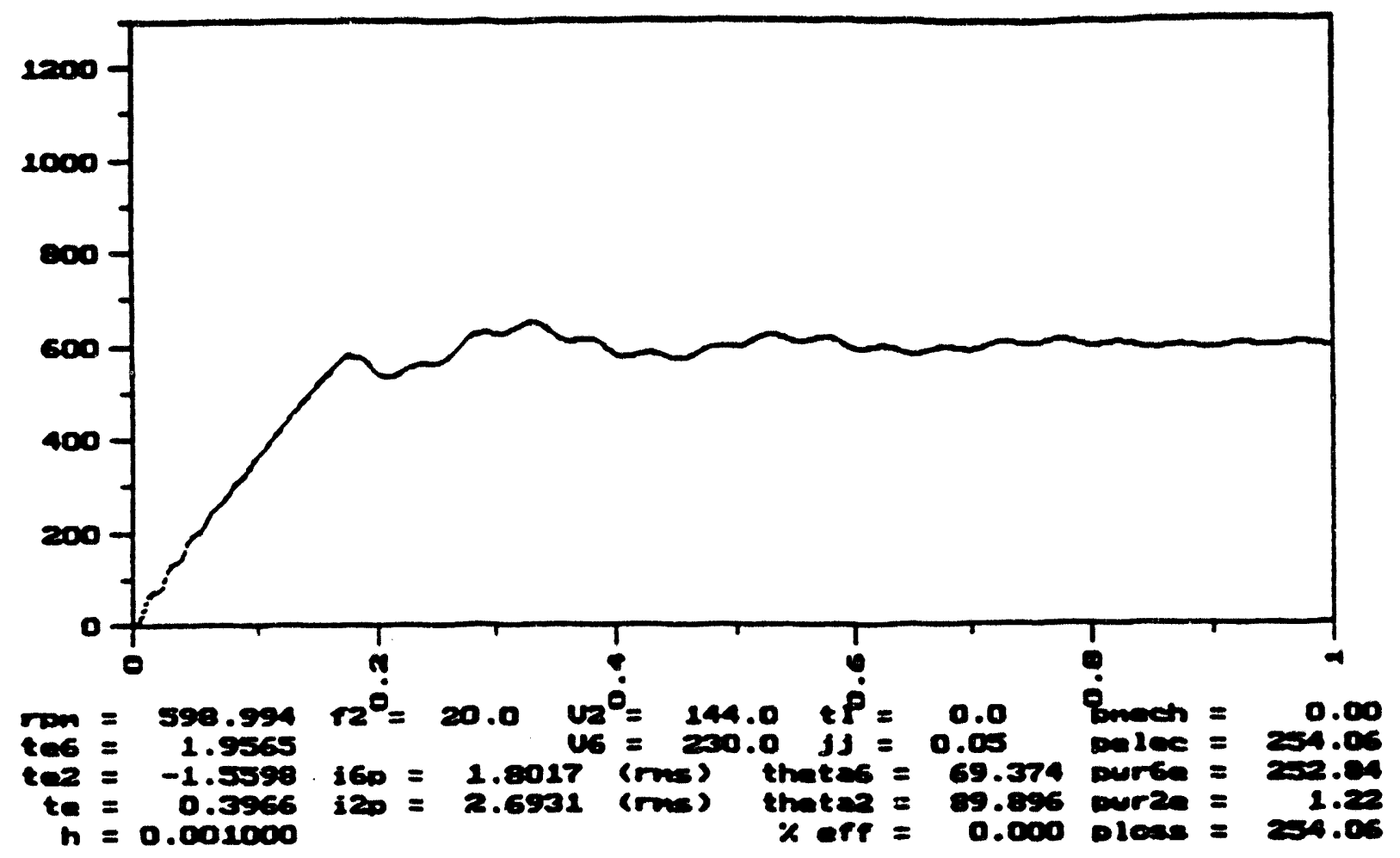

Fig. 6.3.1. Dynamic Simulator Display in Open-Loop Mode. 


\subsection{Finite Element Modeling}

Finite Element (FE) analysis is used extensively in the design of BDFM prototypes. Presently, only two-dimensional modeling capabilities are available. Thus, modeling of the BDFM is only approximate, as the loop connections cannot be modeled accurately. However, insight can be gained into optimum shaping of the rotor bars. Three-dimensional modeling capability is being added for Phase 4 design investigations; details will be reported in the Phase 4 report.

Another complicating issue in the FE analysis of BDFM geometries is the fact that accurate representation requires the capability to account for two frequency values. As FE software solves the magnetic problem at a single frequency, this complicates the analysis. However, modeling both power winding to rotor and control winding to rotor interactions at the appropriate slip frequency allows for superposition of the results to obtain results for the doubly-fed case. However, the use of superposition does not allow for investigation of non-linear magnetics; saturation needs to be investigated separately.

This section describes the application of two-dimensional FE software to the design of BDFM geometries (see also Phase 2 report). A more detailed discussion and several design examples can be found in Refs $[6.7,6.8]$.

\subsubsection{Finite Element Assisted Analysis of the BDFM}

Finite Element (FE) analysis techniques have been successfully used for some time in the design of induction, reluctance and permanent magnet machines. Neglecting end effects, these machines can easily be investigated using two-dimensional FE analysis. Application of these techniques to the BDFM is difficult due to the following considerations:

(1) By nature of the nested loop rotor structure, i.e. the absence of a solid end ring on one side, the BDFM analysis problem is three-dimensional in nature.

(2) The doubly-fed characteristics always require the consideration of two frequencies at any time. For true representation, the appropriate frequency relations need to be enforced.

Despite these restrictions, a commercially available two-dimensional FE package [6.9] has been successfully utilized in estimating BDFM performance characteristics. The machine design procedure follows these steps: 
(1) Analyze individual bar geometry in terms of resistance and inductance. Bar resistance can readily be evaluated using Joule losses per unit length, while bar inductance can be determined by established FE procedures for open [6.10] and closed slots [6.11]. While FE analysis is used in the following, analytical techniques are also applicable [6.12].

(2) Separately investigate six-pole and two-pole induction machine characteristics assuming a squirrel cage connection of the bars analyzed in step (1). As discussed in [6.13], torque-frequency characteristics are best obtained using rotor loss, i.e.

$$
T_{c}=\frac{P_{\text {rolor }}}{S \omega}
$$

This avoids the use of the Maxwell stress tensor and accompanying differentiation.

(3) Analyze the loop characteristics of the BDFM rotor by setting appropriate symmetrical boundary conditions enabling loop currents which are equal in magnitude but opposite in direction in the loop bars. This allows for determination of current distribution and torque contributions associated with the individual loops. This design step is required to investigate mutual interactions between bars and address the variations in stator/rotor coupling factors for the different values of rotor loop spans.

(4) Interface the two-dimensional FE analysis with a state variable machine model [6.1] which appropriately represents the rotor bar connections. This necessarily involves the whole machine rather than a section or pole pitch as in induction machine analysis [6.14].

The application of this design procedure to the six/two-pole alternator is discussed in Refs. $[6.7,6.8]$ and in the Phase 2 report.

\subsubsection{Finite Element Analysis Using Superposition}

As mentioned in the previous section, accurate two-dimensional finite element analysis of the BDFM is impossible due to the loop structure, which effectively necessitates a three-dimensional model. Moreover, finite element software eddy current solvers only account for a single 
frequency. For induction machine modeling this is no problem, as the simulation can be carried out at slip frequency. For the BDFM, with its three frequencies present in synchronous operation, this adds another degree of comp.exity. However, using superposition, the power winding to rotor and control winding to rotor effects can be analyzed at the appropriate slip frequency for the cage rotor bars, i.e. for the two-dimensional part of the BDFM rotor. In synchronous operation, power and control winding induced :otor currents are of the same frequency; thus, the simulation results for a common rotor frequency can be added.

The superposition feature was used in the design of the new, hign power alternator rotor (see also chapter 2), which has 12-pole power and four-pole control windings with an "eight-pole" rotor structure. Fig. 6.4.1 shows the flux plot for the system when the 12-pole winding is excited. Note that only the common or cage rotor bars are active, the effect of the loop bars is not taken into account (the loop bars are effectively modeled as non-conductors). Fig. 6.4.2 illustrates the same effect for excitation of the four-pole stator winding. Finally, the superposition of the two results is shown in Fig. 6.4.3. Note that the eight-pole structure of the resulting field is quite apparent. The final result can now be analyzed for airgap fields, current distribution and flux density distribution (for a judgement on possible saturation effects).

\subsubsection{Three-Dimensional Finite Element Analysis}

The most realistic magnetic analysis of the BDFM is three-dimensional model to take into account the loop effects. Modeling of the different frequencies present will involve a superposition approach as outlined in 6.4.2. Three-dimensional analysis will be used extensively during Phase 4, i.e. in the design of the sewage pump BDFM drive. A computer workstation powerful enough to simulate the BDFM problem, which is very memory intensive, is being acquired. An example of the three-dimensional geometry to be solved is shown in Figs. 6.4.4 and 6.4.5. Simulation results and design examples will be discussed in the Phase 4 report. 


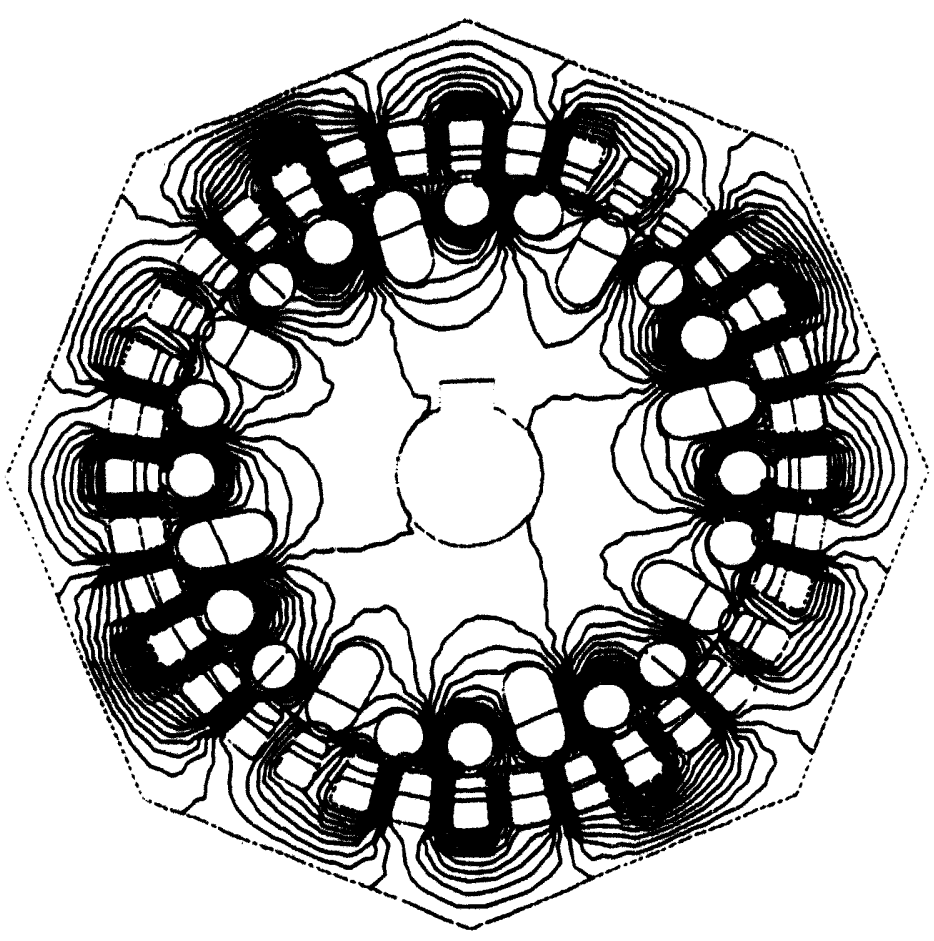

Fig. 6.4.1. 12-Pole Flux Plot - Eddy Current Solution (200 A total 12-pole current, $22 \mathrm{~Hz}$ rotor frequency).

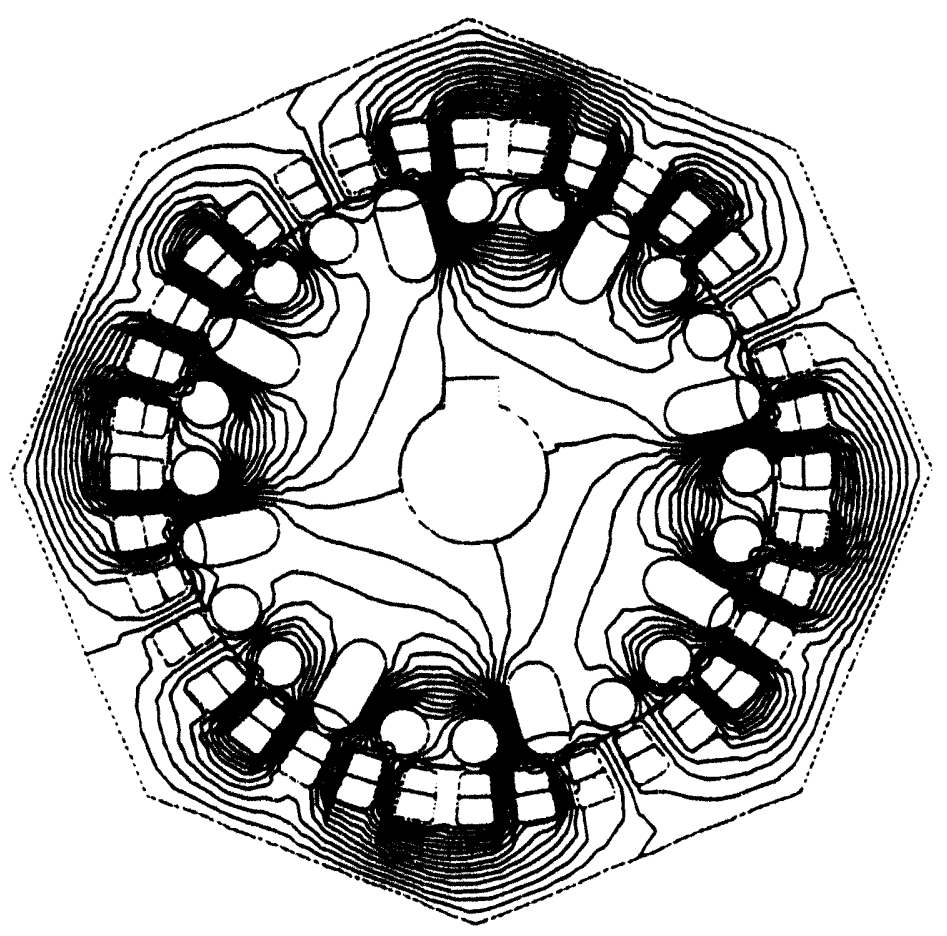

Fig. 6.4.2. Four-Pole Flux Plot - Eddy Current Solution (200 A total Four-pole current, $22 \mathrm{~Hz}$ rotor frequency). 


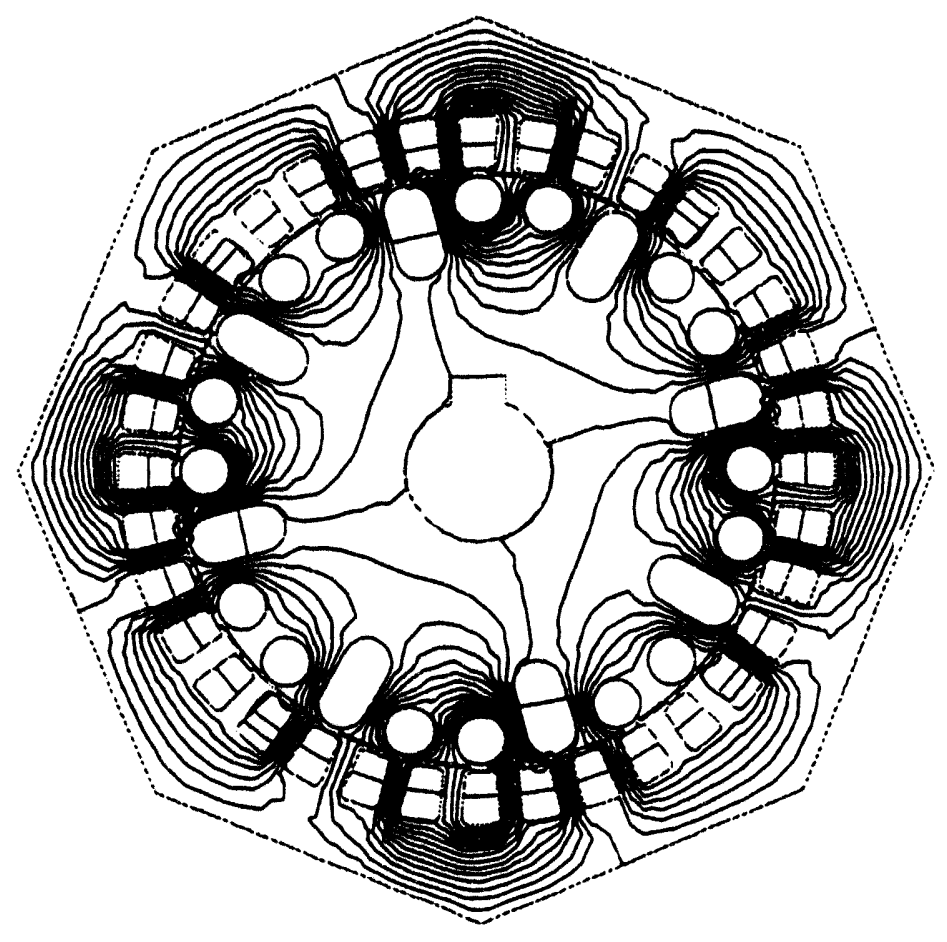

Fig. 6.4.3. Doubly-Fed Flux Plot - Superposition.

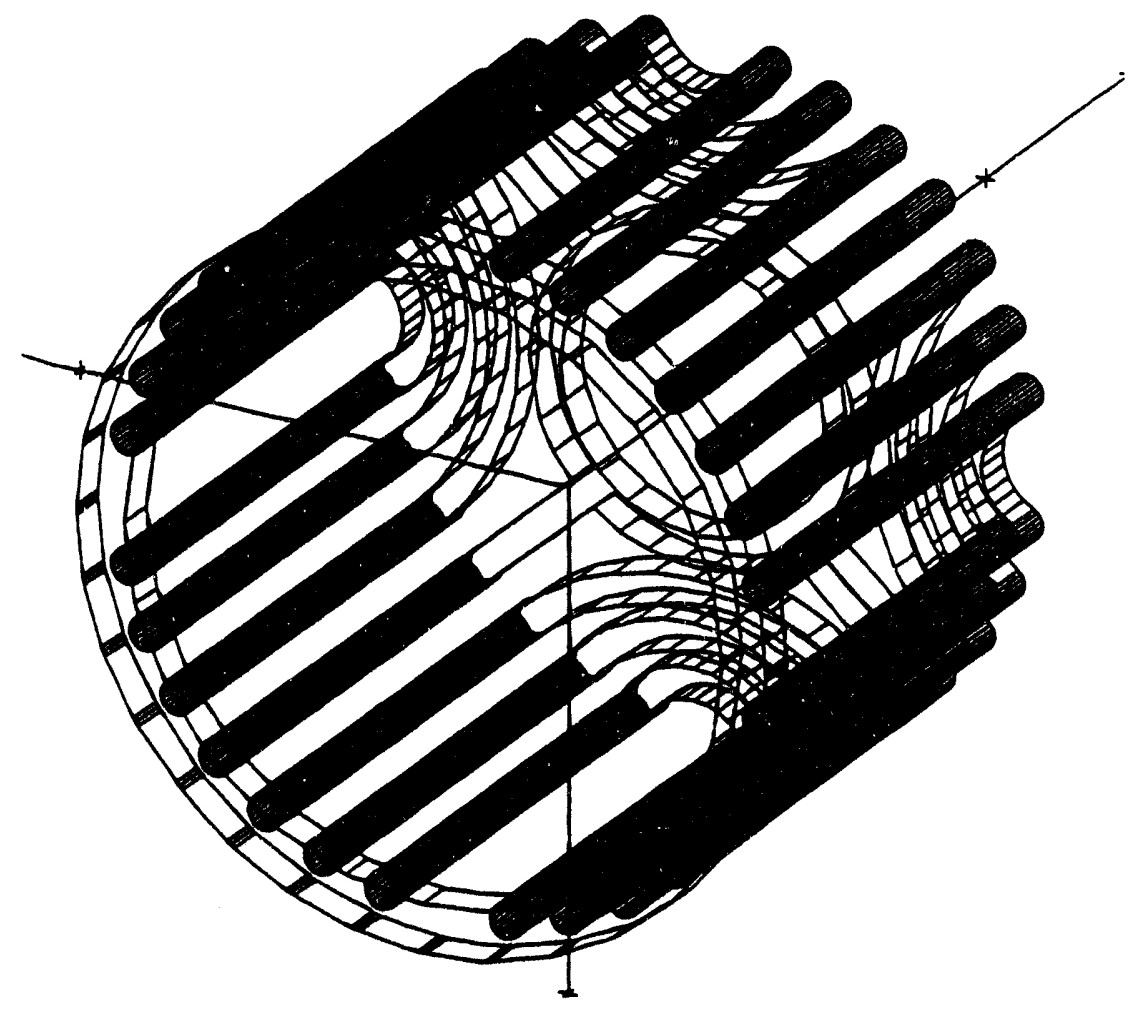

Fig. 6.4.4. Three-Dimensional Rotor Structure. 


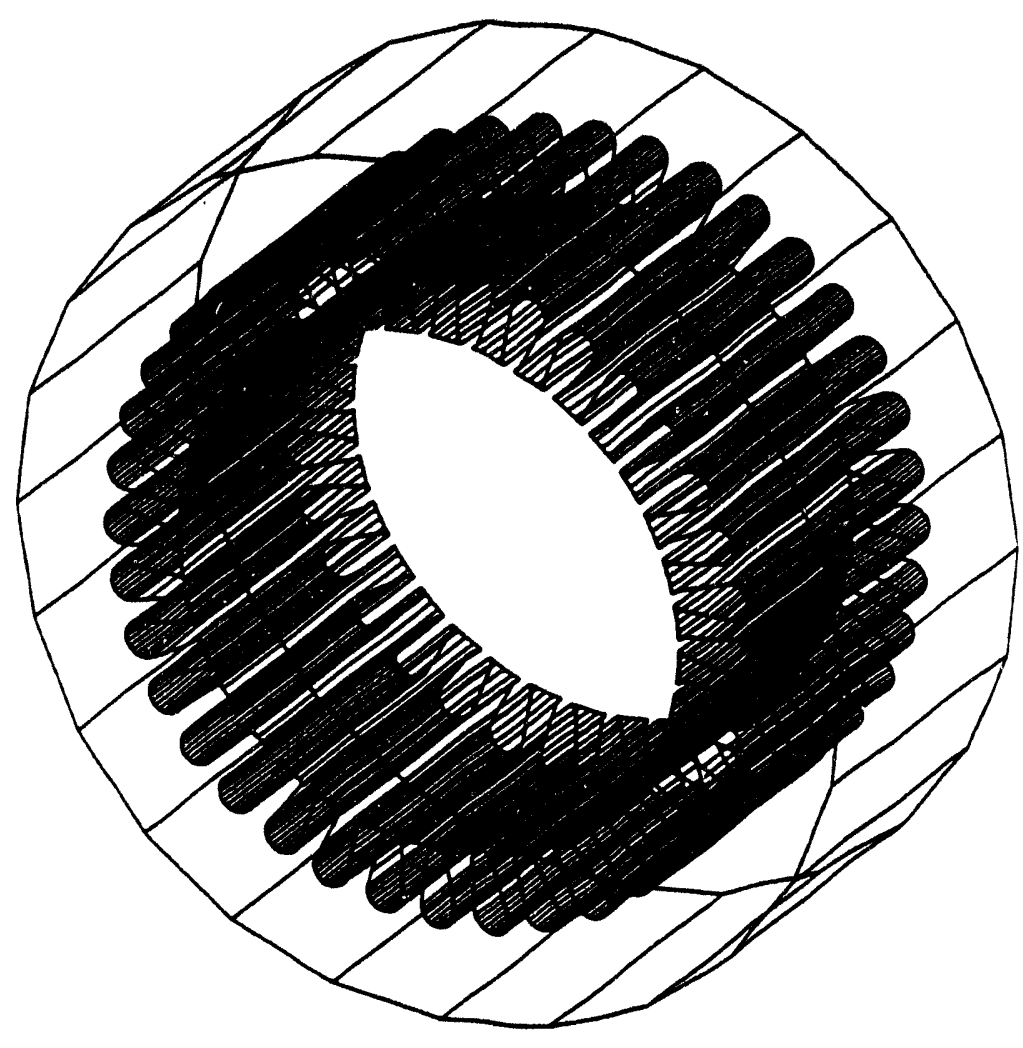

Fig. 6.4.5. Three-Dimensional Stator Structure. 


\subsection{Detailed Machine Model}

The detailed model program was originally written in FORTRAN by Patrick Rochelle as part of his master's thesis $[6.15,6.16]$ and was also described in the Phase 1 report. The program had undergone several revisions, becoming somewhat unwieldy. Furthermore, the model as programmed did not reflect the physical configuration of the present motor design. As written, the program modeled a stator winding which had a neutral connected. To model the case where the neutral is not connected, the program added a large fictitious impedence which forced the neutral currents to approach zero.

To restore structure to the program, it was completely rewritten. The $\mathrm{C}$ language was used rather than FORTRAN, to take advantage of the more elegant construction possible with that language. The result is a more orderly and efficient program using double precision calculations yet executing at a faster speed.

The new program reproduced the results of the FORTRAN program for the case with grounded neutral and without neutral impedences. For the case with no neutral connection, the program enforced the condition of no neutral current by eliminating one of the three phase currents from the equations to be solved and setting it equal to the negative sum of the two remaining currents. The simulation for this case showed that the stator currents resulting from the application of balanced three phase voltages were unbalanced. Laboratory tests confirmer that some unbalance exists; however, the simulation indicated a much greater imbalance than was measured. This is presently an unresolved issue with the detailed modelling program.

Another result of both the original and rewritten simulation programs was that the rotor currents are unbalanced. The rotor simulated has four separate nests of loops. The currents in nests 180 degrees apart were equal in magnitude but opposite in phase for the respective loops. The currents in adjacent nests were expected to be equal in magnitude for a given loop, but with the phase shifted by 90 degrees for two pole excitation. This was not found to be the case in the simulation. Results from ongoing work with the multiple harmonic model confirm that this simulation result is correct. The multiple harmonic model predicts that the rotor will support traveling current waves at pole numbers matching those of the stator windings, not at its own pole number. The phase shift between adjacent nests is therefore not 90 degrees.

The present programming effort is in finishing the multiple harmonic theory simulation program (see section 6.2). After this is completed, the detailed model will again be examined to 
confirm agreement between the two models.

\subsection{Current-Forced Model}

\subsubsection{Model Development}

The analysis of the brushless doubly-fed machine has been done mostly with the control winding side operating in the voltage-forced mode $[6.3,6.4,6.6]$. This section presents the model development of the BDFM with the control winding side operating in the current-forced mode.

In the synchronous mode of operation, the shaft speed can be controlled by controlling the frequency, and the torque of the BDFM can simply be controlled by adjusting the frequency and/or amplitude of the current in the control winding, which is connected to the fixed frequency utility supply through a power electronic converter.

The basis for the derivation of this current-forced model is the voltage-forced dynamic model in the $\mathrm{d}-\mathrm{q}$ domain derived by Ruqi $\mathrm{Li}$ [6.3]. In that model, all the currents are the states and the voltages are the forcing functions. But during the process of deriving the control winding currentforced model, it was found that it is not possible to model the BDFM with control winding voltages as states. Instead, the control winding voltage equations are considered in the equivalent circuit form. The result is a reduced order model with four states, instead of six states, and four forcing functions. The control winding voltages are represented as auxiliary equations. Also, this model is more detailed in that magnetizing inductances are explicitly represented, separately from the leakage inductances.

The resulting dynamic model is given in Eqn. (6-1):

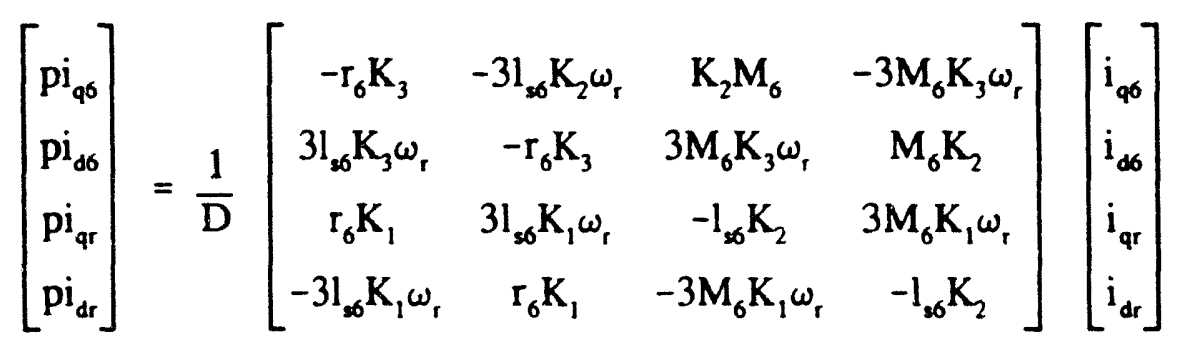




$$
+\frac{1}{D}\left[\begin{array}{cccc}
\mathrm{K}_{3} & 0 & -\mathrm{M}_{6} & 0 \\
0 & \mathrm{~K}_{3} & 0 & \mathrm{M}_{6} \\
-\mathrm{K}_{1} & 0 & \mathrm{l}_{s 6} & 0 \\
0 & -\mathrm{K}_{1} & 0 & -\mathrm{l}_{36}
\end{array}\right]\left[\begin{array}{c}
\mathrm{v}_{\mathrm{q}} \\
\mathrm{v}_{\mathrm{d6}} \\
\mathrm{pi}_{\mathrm{q} 2} \\
\mathrm{pi}_{\mathrm{d} 2}
\end{array}\right]
$$

where

$$
\begin{aligned}
& \mathrm{D}=\mathrm{l}_{66} \mathrm{~K}_{3}-\mathrm{M}_{6} \mathrm{~K}_{1} \text {; } \\
& K_{1}=M_{2} M_{6} / I_{2 m} l_{\text {ma }} ; \\
& \mathrm{K}_{2}=\mathrm{r}_{\mathrm{r}} \mathrm{M}_{2} / \mathrm{l}_{2 \mathrm{~m}} \mathrm{I}_{\mathrm{rm}} ; \\
& K_{3}=l_{r m} / M_{2}+l_{\vec{r}} M_{2} / l_{2 m} l_{m m} \text {; }
\end{aligned}
$$

Also, the steady state model is given as a set of five non-linear equations as in Eqn. (6-2):

$$
\begin{aligned}
& r_{6} I_{\phi 6 r}-\omega_{6} L_{96} I_{q 6 i}-\omega_{6} M_{6} I_{q i}-V_{q 6 r}=0 \text {; } \\
& I_{6} I_{q 6 i}+\omega_{6} L_{86} I_{q 6 r}+\omega_{6} M_{6} I_{q \pi}=0 \text {; } \\
& K_{1} I_{q 6 r}+K_{3} I_{q \pi}+\left(\frac{K_{2}}{\omega_{R}}\right) I_{q r i}-I_{q 2} \cos \theta=0 \\
& K_{1} I_{q 6 i}+K_{3} I_{q r i}-\left(\frac{K_{2}}{\omega_{R}}\right) I_{q \pi}+I_{q 2} \sin \theta=0 ; \\
& 6 M_{6} I_{q b} I_{q r} \sin \left[\tan ^{-1}\left(\frac{I_{q r}}{I_{q r}}\right)-\tan ^{-1}\left(\frac{I_{q \sigma i}}{I_{q \sigma r}}\right)\right]+2 M_{2} I_{q 2} I_{q r} \sin \left[\tan ^{-1} \theta-\tan ^{-1}\left(\frac{I_{q r i}}{I_{q r}}\right)\right]-T_{L}=0 \text {; }
\end{aligned}
$$

where subscripts $r$ and $i$ denote the real and imaginary parts of a parameter; $\theta$ is the angle between $V_{\phi 6}$ and $I_{q 2}$.

\subsubsection{Simulation Results in the Induction Mode of Operation}

The current-forced model has been simulated with the power winding in the induction mode of operation with a supply frequency of $60 \mathrm{~Hz}$. Fig. 6.6.1 shows the free-acceleration speed 
response and as expected takes much longer time than is the case in a voltage-forced model. The reason for this longer start-up time is the absence of the torque component due to the control winding currents. Fig. 6.6.2 shows the power winding currents in the d-q domain and Fig. 6.6.3 shows the rotor currents in the d-q domain.

\subsubsection{Converter Topologies for Current-Forced Operation}

The current-forced model development necessitated a study of the available current-mode converters and a brief summary of the same is given below. The following operating characteristics were used in evaluating each converter topology.

Flexibility of control: The capability of four-quadrant operation is of paramount importance in choosing a converter. Also, the range of output current/frequency for any given converter are to be considered.

Types and ease of control: The complexity and robustness of hardware implementation is evaluated for each topology. Also, the types of control viz., the hysteresis control (PWM circuits), discrete time current regulator control (resonant circuits), etc., were considered. The cost of a control unit is directly proportional to the complexity of the control technique used.

Output harmonic generation: The total harmonic distortion produced on the load side by each topology is considered because the harmonics produce torque pulsations and over-heating in the load. Subharmonics of the link frequency (as were produced in the DC resonant-link converters) appear in the output and are difficult to eliminate.

Effects on the input side: The need for an active power circuit on the supply side is to be considered, for a converter to maintain near unity power factor and reasonably sinusoidal waveforms on the supply lines.

Effects on the output side: Reasonably good sinusoidal output waveform generation is an important criterion in choosing a converter. Also, the effects of a circuit configuration on the transient and steady state responses on the load side are to be considered. The criterion of allowable harmonic generation is to be combined with this operating characteristic in evaluating a converter.

Device count and their ratings: Though this criterion is secondary in nature while choosing a converter, one needs to consider the number of devices and their required ratings for each converter circuit. The cost of a converter goes up as the number of active devices and their 
ratings, especially current ratings, go to higher levels.

Additional component count and ratings: Additional reactive components eg., link inductance/capacitance and their ratings are to be evaluated. Also considered were the necessary filter circuit components.

By considering the aforementioned characteristics, the following observations were made. Most of the converter topologies, discussed in recent literature, offer four quadrant operation. The complexity of control increases as we move from PWM to resonant to direct link converters. All the converters use some form of filter components on the supply and/or load side. Direct link converters have an inherent limitation on the output to input frequency ratio that they can produce and also, the nonavailability of a bidirectional semiconductor switch necessitates a high count of active devices [6.17]. At first, the current source inverter circuit looks like the natural choice for any current mode operation. But the presence of a link inductance makes the transient response of this circuit extremely slow for any load changes; and, also, the converter unit becomes bulky [6.18]. Recent developments in the soft switching converters $[6.19,6.20]$ have brought in a variety of topologies. Because of the discrete time modulation, all the resonant converters, with the exception of the series $\mathrm{AC}$ link converter, produce sub-harmonics of the link frequency and the elimination of these harmonics is difficult. As a result, the output wave forms of these converters are distorted sinusoidal.

The current-regulated, voltage-source inverter circuit using hysteresis PWM control [6.21] seems to be a suitable topology because of faster transient response capability, ease in harmonic elimination, reasonably good output waveforms (on the supply side as well, with an active power circuit on the input side) and a good overall performance.

Among the recently introduced topologies, the series-resonant, AC link converter [6.22] shows promise as a viable alternative with a lot of merits, such as producing near unity power factor on the supply side, good flexibility of control, less harmonic distortion, near sinusoidal output waveforms and load side short circuit protection. The one drawback of this converter is the high device count. An alternate circuit configuration for the series resonant AC-AC converter with only 12 thyristors [6.23] was also proposed but, the disadvantage is that the power factor of the source current can not be controlled. Either of the above mentioned converters can be used for BDFM current control. 


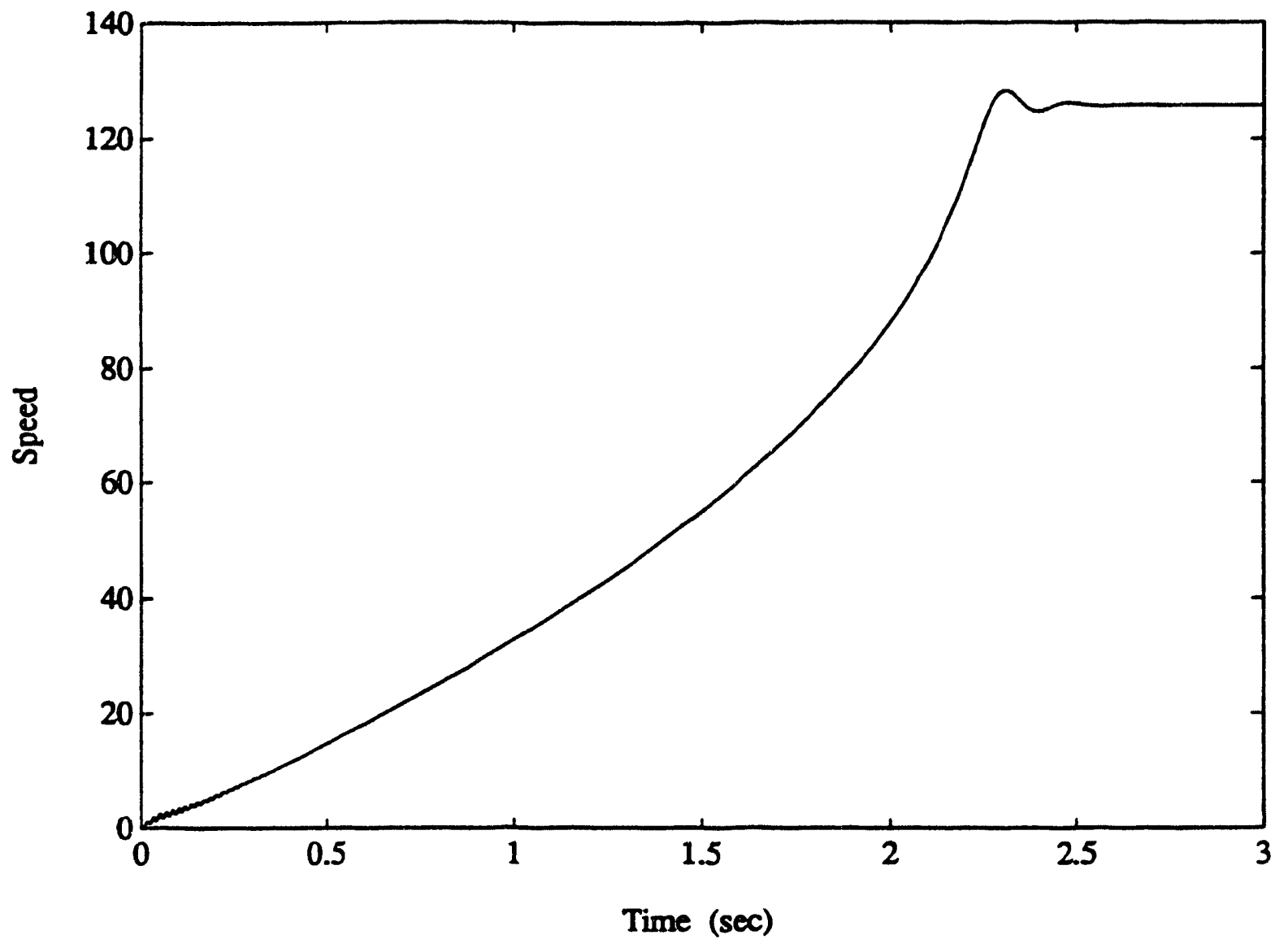

Fig. 6.6.1. Free acceleration speed response in mech. $\mathrm{rad} / \mathrm{sec}$. 


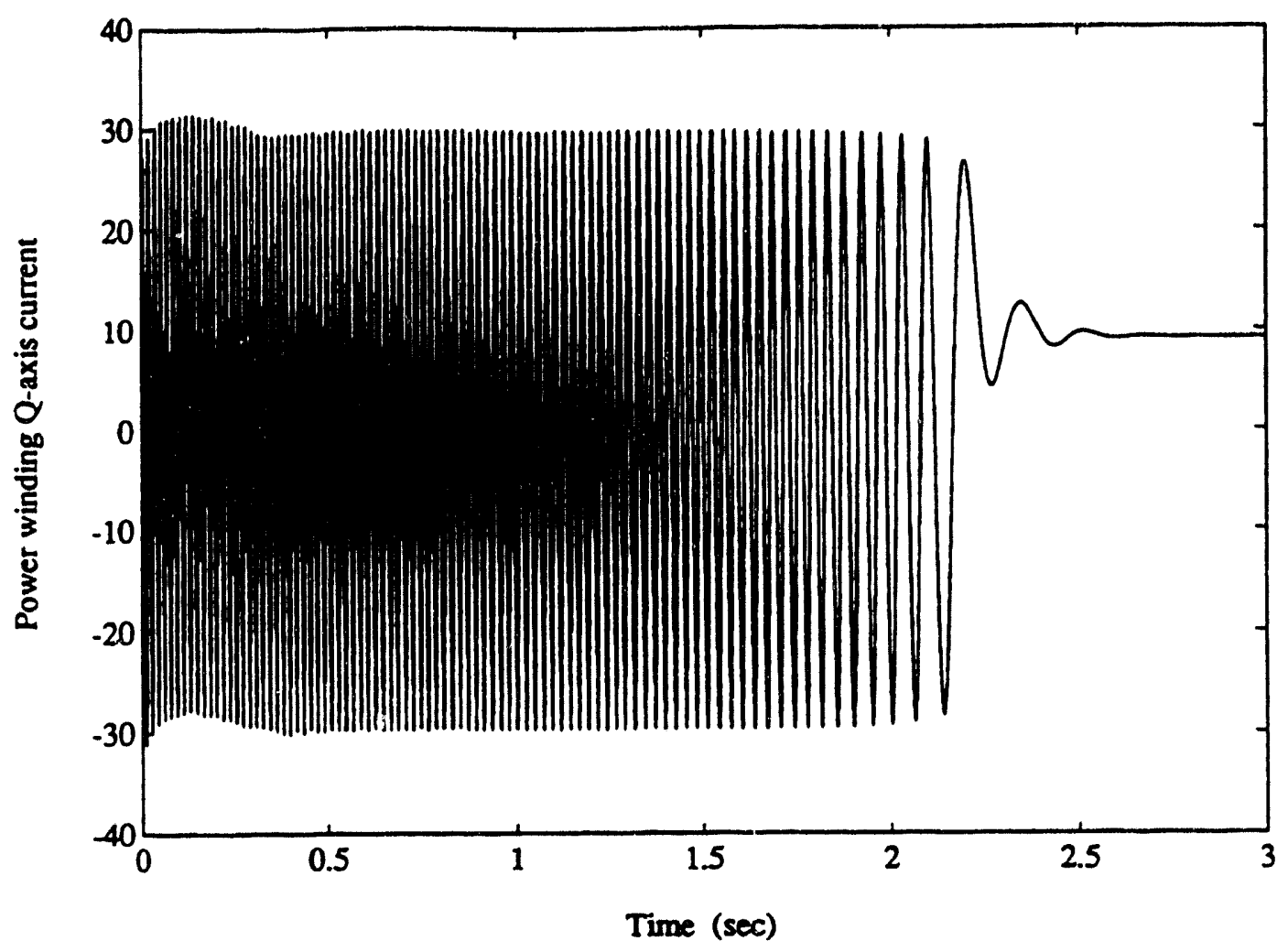

Fig. 6.6.2(a). Q-axis current in the power winding.

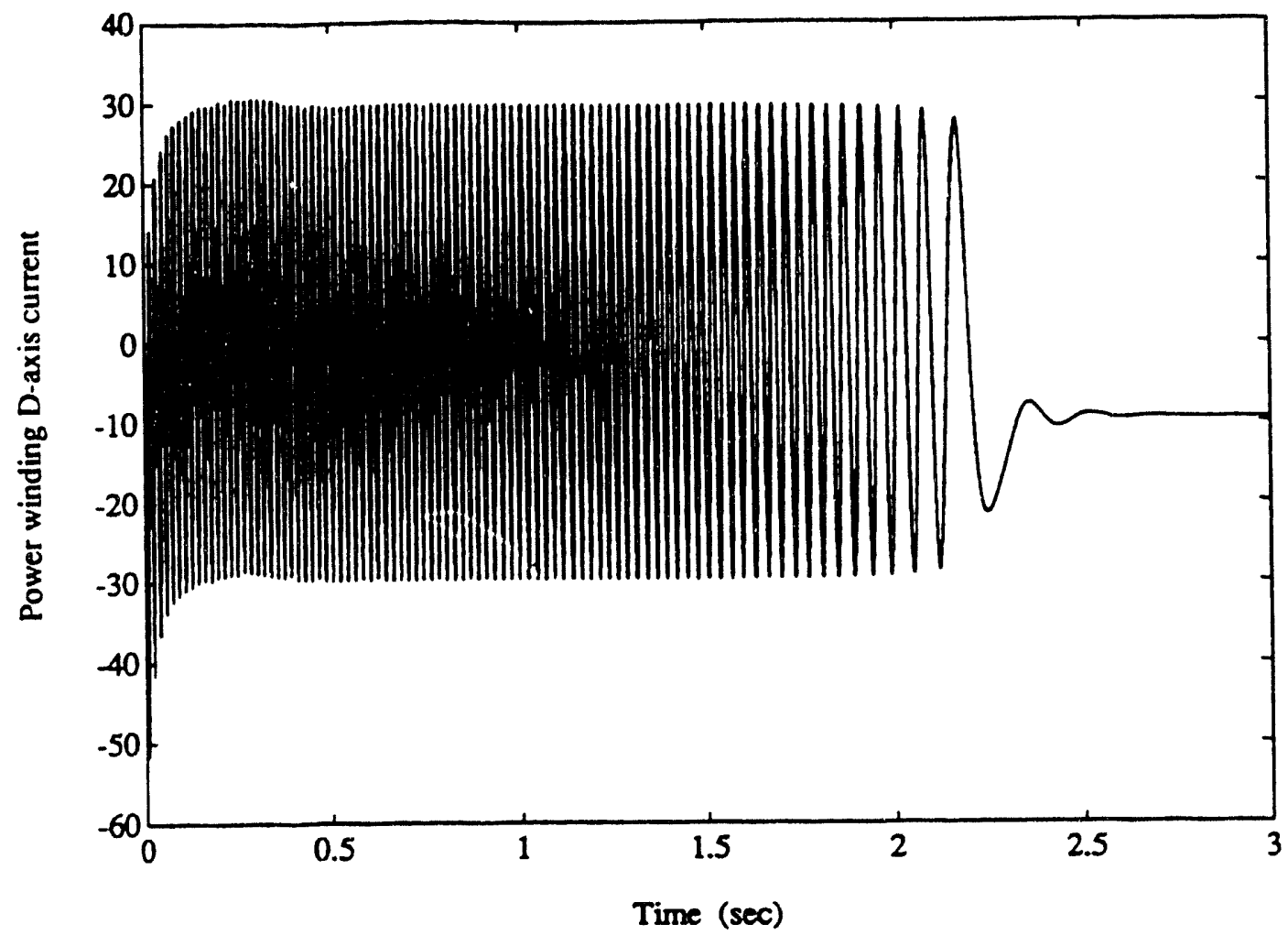

Fig. 6.6.2(b). D-axis current in the power winding. 


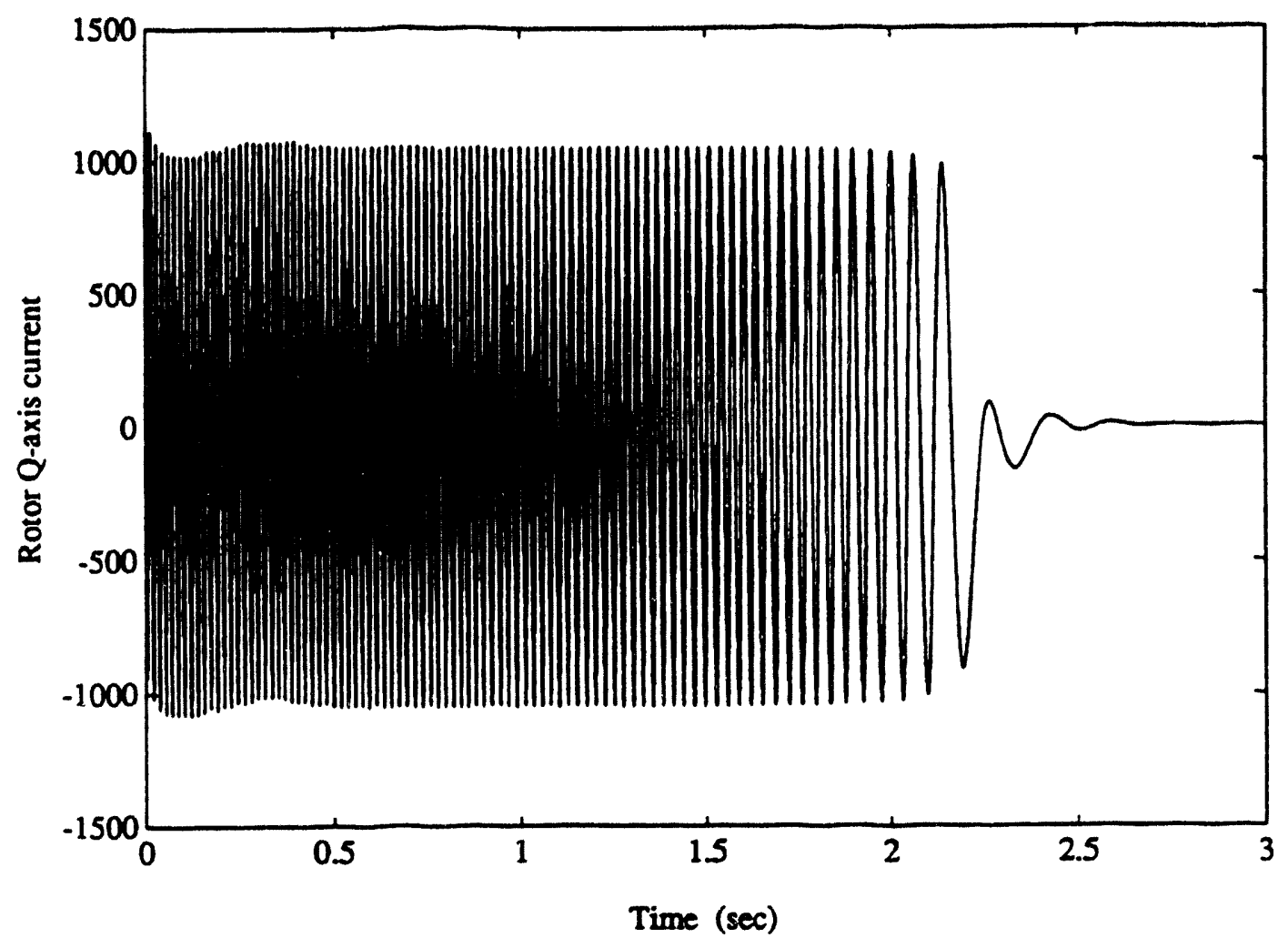

Fig. 6.6.3(a). Q-axis current in the rotor circuit.

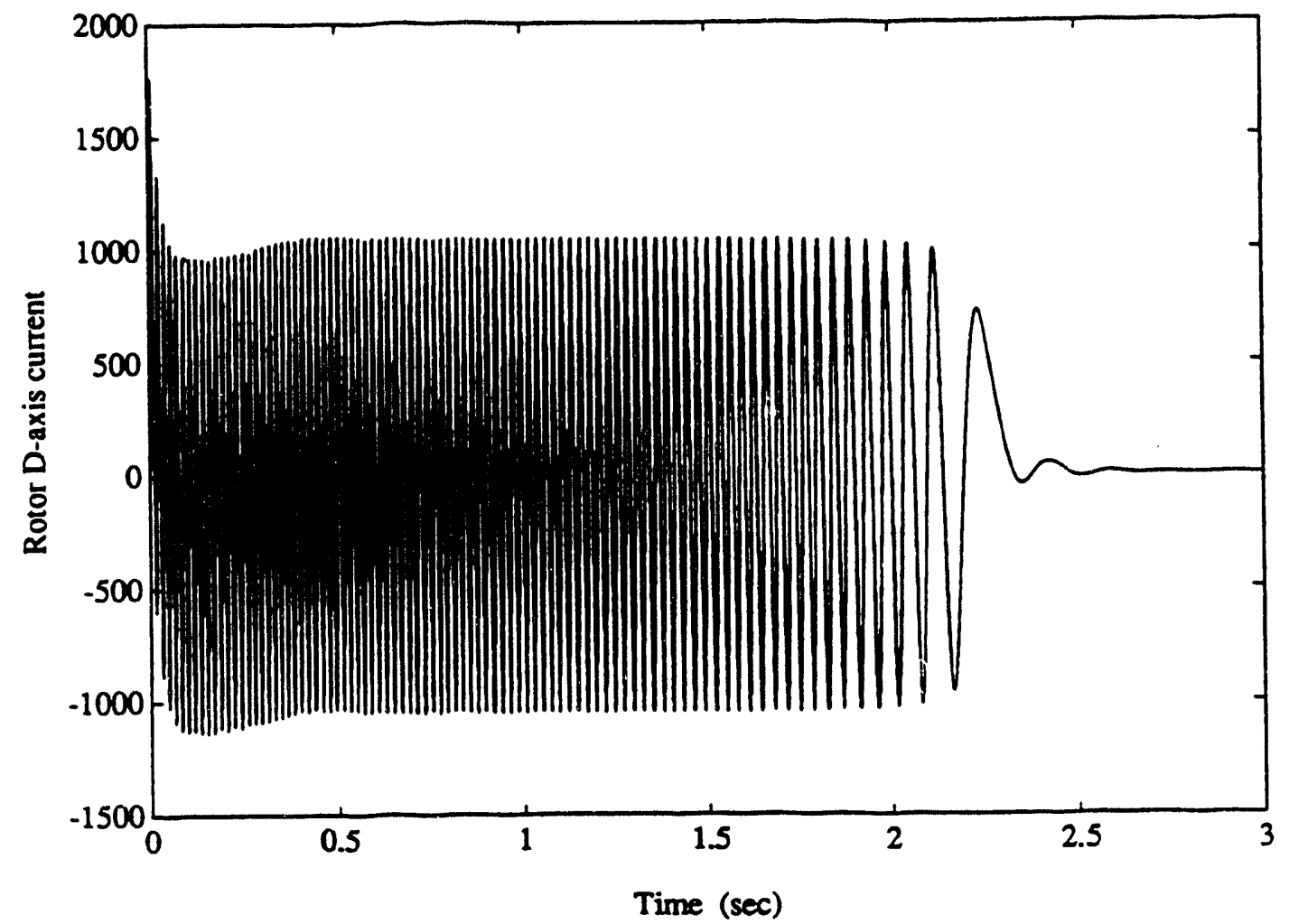

Fig. 6.6.3(b). D-axis current in the rotor circuit. 


\subsection{Stator Design Optimization}

The steady state BDFM equations as developed in the Phase 2 report and in Ref. [6.5] can be used in developing an optimized BDFM design routine. The following section describes an optimized stator design philosophy for a six-pole/two-pole BDFM with single-layer stator windings. Results obtained using the optimization program were used as starting point in the design of the optimized laboratory BDFM discussed in Chapter 4. A more detailed discussion of the optimizing design approach is found in [6.23]. Presently, efforts are underway to translate this procedure into a generalized design program suitable for use in designing the pump drive for Phase 4.

The optimal stator design can be treated as a constrained optimization problem [6.24] of the form:

$$
\begin{array}{cl}
\text { minimize } & f(x) \quad \quad x \in \mathbf{R}^{\mathbf{n}} \\
\text { subject to } & c_{i}(x)=0, \quad i \in E \\
& c_{i}(x) \geq 0, \quad i \in I
\end{array}
$$

where $f(x)$ is the "cost" or "the objective function", with the "constraint functions" $c_{i}(x)$, $i=1,2, \ldots . p .{ }^{~ "} E^{n}$ is the index set of equality constraints and " $I "$ is the set of inequality constraints in the problem; both sets being finite.

A substantial part of BDFM system cost is that of the electronic power converter. Overall system design involves a trade-off between device ratings of the converter and the overall system performance. It is necessary to minimize the current flowing through the converter, i.e. the twopole current, which helps to reduce the current rating of the power electronic devices in the converter and thus its cost. Moreover, the current in the rotor needs to be kept within limits to reduce the rotor $I^{2} r$ losses. It is also desirable to optimize the six-pole current to minimize the overall $I^{2} r$ loss in the machine model. The optimized two-pole and six-pole current will reduce the investment made for the converter and provide stator parameters efficient enough to conform to the constraints laid down by the designer. Thus the modif: $2 d$ constrained optimization problem appears as 


$$
\begin{array}{cc}
\operatorname{minimize} & \left|I_{6}\right| \\
\operatorname{minimize} & \left|I_{2}\right| \\
\text { minimize } & \left|I_{1}\right| \\
\text { subject to } & C_{i}(P) \leq 0, \quad i \in I
\end{array}
$$

where $I_{6}, I_{2}$ and $I_{r}$ are the d-q rms currents in the six-pole, two-pole and the rotor respectively. $C_{i}(p)$ is the set of constraints involving current carrying limitations in the windings, power factor requirement on the six-pole side and a minimum overall efficiency.

The optimization as outlined in Eqn. (6-4), with the three objective functions, is a relatively involved problem. Besides, it may be difficult to determine a set of parameters which would simultaneously satisfy all the constraints and optimize all three objective functions. So a single objective function was developed which reflects the effect of each of those in Eqn. (6-4). This function uses the sum of the weighted squares of the currents. The currents were squared to account for the magnitudes of the currents in the objective function. This is similar to a function of the sum of the resistive losses in the machine model, but the weights can be adjusted to reflect other losses in different regions of the machine. Thus, the new optimization model for the BDFM is

$$
\begin{aligned}
& \text { minimize }\left\{\alpha \mathrm{I}_{6}^{2} \mathrm{r}_{6}+\beta \mathrm{I}_{2}^{2} \mathrm{r}_{2}+\gamma \mathrm{I}_{r}^{2} \mathrm{r}_{r}\right\} \\
& \text { subject to } \text { (i) } \cos \left\{\tan ^{-1}\left(\frac{\mathrm{I}_{6 \mathrm{i}}}{\mathrm{I}_{6 \mathrm{r}}}\right)\right\} \geq \mathrm{pf}_{\min } \\
& \text { (ii) }\left[\frac{\text { output }}{\text { output }+ \text { losses }}\right) \geq \text { effi }_{\min } \\
& \text { (iii) } \mathrm{I}_{6} \leq \lim _{6} \\
& \text { (iv) } \mathrm{I}_{2} \leq \lim _{2}
\end{aligned}
$$

where $\alpha, \beta, \gamma$ weights for the various resistive losses,

$I_{6 i} \quad$ imaginary part of $d-q$ steady state six-pole current,

$I_{6 r} \quad$ real part of $d-q$ steady state six-pole current,

$\mathrm{pf}_{\min } \quad$ minimum six-pole power factor,

eff $_{\min }$ minimum overall efficiency,

$\lim _{6} \quad$ maximum current carrying capability on the six-pole side set by the wire gauge 
in use and

$\lim _{2} \quad$ maximum current carrying capability on the two-pole side set by the wire gauge in use.

The currents are calculated iteratively using the BDFM steady state model [6.5] as shown below and the equivalent circuit in Fig. 6.7.1:

$$
\begin{gathered}
\dot{V}_{q 6}=\left(r_{6}+j X_{c 6}\right) \dot{I}_{q \sigma}+j X_{q 6} \dot{I}_{q r} \\
\frac{\dot{V}_{q 2}}{s}=\left(\frac{r_{2}}{s}+j X_{s 3}\right) \dot{I}_{q 2}-j X_{m 2} \dot{I}_{q r}, \text { for } s \neq 0 \\
\frac{\dot{V}_{q r}}{s_{1}}=j X_{m 6} \dot{I}_{q 6}-j X_{m 2} \dot{I}_{q 2}+\left(\frac{r_{r}}{s_{1}}+j X_{r}\right) \dot{I}_{q r}
\end{gathered}
$$

In equations (6-6) through (6-8)

$$
\begin{gathered}
s=\frac{\omega_{2}}{\omega_{6}}, s_{1}=\left(\frac{\omega_{6}-3 \omega_{r}}{\omega_{6}}\right)=\left(\frac{\omega_{2}+\omega_{r}}{\omega_{6}}\right), \\
X_{s 6}=\omega_{6} L_{s 6}, X_{s 2}=\omega_{6} L_{s 2}, X_{r}=\omega_{6} L_{r}, \\
X_{m 6}=\omega_{6} M_{6}, X_{m 2}=\omega_{6} M_{2}, \omega_{6}=2 \pi f_{6}, \omega_{2}=2 \pi f_{2},
\end{gathered}
$$

with " $\mathrm{L}$ " and "M" representing the self and the mutual inductances in the model, respectively.

The diagrammatic representation of the optimization program flowchart is shown in Fig. 6.7.2. The optimization model is a 6-dimensional problem with the rotor parameters held constant. The parameters that need to be determined are the winding resistance and inductance for the six- and two-pole and the two stator to rotor mutual inductances. All these parameters are proportional to either the number of turns or the square of number of turns as shown below :

$$
\begin{aligned}
r_{p} & =r_{p, \text { base }} N_{p} \\
L_{s p} & =L_{s p, b a s e} N_{p}^{2} \\
M_{p} & =M_{p, \text { base }} N_{p}
\end{aligned}
$$


where $p=6$ or $2, r_{p}$ is the resistance, $L_{4 p}$ the stator inductance, $M_{p}$ the stator to rotor mutual inductance and $N_{p}$ the number of turns in the p-pole winding. The base values of the resistance and the inductances are calculated with a single turn on the six and the two-pole windings. These base values are calculated by new computer programs or ones derived from the detailed BDFM model [6.15].

The search algorithm sweeps over all possible resistances that can be generated using standard wire sizes from a wire-gauge table. The self and mutual inductances will be calculated based on the winding structure specified. The rotor resistance and inductance can be determined depending on the rotor structure to be used and is maintained constant throughout the program execution. Thus the algorithm searches for parameters by varying the number of turns, the range being specified by the user, on both the two-pole and the six-pole windings. The wire-gauge size is varied with the help of a wire-gauge look-up table on both windings. This changes the diameter and thus the resistance associated with the windings. To simulate realistic stator slot usage, machine parameters and eventual steady state calculations are carried out only for those number of turns and wire-gauge size combinations that satisfy the following slot-fill condition:

$$
0.6 \mathrm{~A}<\left(\mathrm{N}_{6} \mathrm{a}_{6}+\mathrm{N}_{2} \mathrm{a}_{2}\right)<0.7 \mathrm{~A}
$$

$N_{6}, N_{2}$ are the number of turns and $a_{6}, a_{2}$ are the cross-sectional area of the wires used for the sixpole and the two-pole respectively. " $A$ " is the cross-sectional area of the stator slot which needs to be distributed between the two windings.

Once condition (6-10) is satisfied, the steady state currents in the six-pole, two-pole and the rotor are calculated iteratively by the Newton-Raphson method. The six-pole excitation for the model on the six-pole side is held constant and that on the two-pole voltage is swept over a range of voltage around the corresponding constant $\mathrm{V} / \mathrm{Hz}$ operating point.

In motoring operation, the load torque is usually specified and it can be shown that, although the six and two-pole input voltages are given, the angle, $\beta$, between the reference voltage $V_{q 6}$ and $\mathrm{V}_{\mathrm{q} 2}$ is an unknown function of both load torque and two-pole excitation voltage. The solution of the steady state equations characterized by (6-6) through (6-8) thus requires that they be solved simultaneously with the torque equation. Before these equations can be solved, the complex equations are changed into real algebraic equations by the following relations :

$$
\dot{v}_{\phi 6}=v_{\phi 6 r}+j v_{q 6 i}=v_{\phi 6 r}+j 0
$$




$$
\dot{\mathrm{V}}_{\mathrm{q} 2}=\mathrm{V}_{\mathrm{q} 2 \mathrm{r}}+j \mathrm{~V}_{\mathrm{q} 2 \mathrm{i}}=\mathrm{V}_{\mathrm{q} 2} \cos \beta-j \mathrm{~V}_{\mathrm{q} 2} \sin \beta
$$

where $V_{92}$ is assumed to be lagging $V_{q 0}$ by the angle $\beta$ and

$$
\mathrm{i}=\mathrm{I}_{\mathrm{r}}+\mathrm{j} \mathrm{I}_{\mathrm{i}}
$$

where subscripts $r$ and $i$ represent real and imaginary parts of the phasor quantities, respectively.

By substitution of (6-11) through (6-13) into the steady state equations of (6-6) through (6-8) along with the torque equation, and separating the real and the imaginary parts, the following set of non-linear algebraic equations are obtained [6.5] :

$$
\begin{aligned}
& r_{6} I_{q \sigma r}-X_{66} I_{\phi 6 i}-X_{m o 6} I_{q r i}-V_{\phi b r}=0 \\
& r_{0} I_{q 6 i}+X_{66} I_{\phi b r}+X_{m 6} I_{q r}=0 \\
& \frac{\mathrm{r}_{2}}{\mathrm{~s}} \mathrm{I}_{\mathrm{q} 2 \mathrm{r}}-\mathrm{X}_{\mathrm{s} 2} \mathrm{I}_{\mathrm{q} 2 \mathrm{i}}+\mathrm{X}_{\mathrm{m} 2 \mathrm{qri}} \mathrm{I}_{\mathrm{qr}}-\frac{1}{\mathrm{~s}} \mathrm{~V}_{\mathrm{q} 2} \cos \beta=0 \\
& \frac{r_{2}}{s} I_{q 2 i}+X_{s 2} I_{q 2 r}-X_{m 2} I_{q r}+\frac{1}{s} V_{q 2} \sin \beta=0 \\
& -X_{m 60} I_{q 6 i}+X_{m 2} I_{q 2 i}+\frac{r_{r}}{s_{1}} I_{q \pi}-X_{r} I_{q i}=0 \\
& X_{m 66} I_{q b r}-X_{m 2} I_{q 2 r}+\frac{r}{s_{1}} I_{q r i}+X_{r} I_{q r}=0 \\
& 6 M_{6}\left(I_{q 6 i} I_{q \pi}-I_{q 6 r} I_{q \pi}\right) \\
& +2 M_{2}\left(I_{q 2 i} I_{q \pi}-I_{q 2 r} I_{q r i}\right)-T_{L}=0
\end{aligned}
$$

The iterative Newton-Raphson procedure for solving these equations has been presented in the Phase 2 report as well as in [6.2] and [6.5]. Suitable configurations of the BDFM which satisfy user specified six-pole power factor and overall machine efficiency requirements are written to an output file. The output file also contains information regarding the allocation of the $\mathrm{I}^{2} \mathrm{r}$ losses within the different parts of the machine. A sample output file is shown in Table 6.3. This design process has successfully been used to supply initial design values for the construction of the $5 \mathrm{hp}$ laboratory BDFM as discussed in chapter 4. 
TABLE 6.3. Sample Output File.

\begin{tabular}{|c|c|c|c|c|c|c|c|c|c|c|}
\hline $\begin{array}{l}\text { Totel } \\
\text { bones }\end{array}$ & $\begin{array}{l}\text { two-pole } \\
\text { volinge }\end{array}$ & $\begin{array}{l}\text { ix-pole no. } \\
\text { of terms }\end{array}$ & $\begin{array}{l}\text { six-pole } \\
A W G \text { size }\end{array}$ & $\begin{array}{l}\text { wo-pole } \\
\text { no. of wrm }\end{array}$ & $\begin{array}{l}\text { no-pole } \\
\text { AWG size }\end{array}$ & $\begin{array}{l}\text { ix-pole lose } \\
\text { (in waw) }\end{array}$ & $\begin{array}{l}\text { nwo-pole low } \\
\text { (in wans) }\end{array}$ & $\begin{array}{l}\text { rolor lowa } \\
\text { (is wana) }\end{array}$ & $\begin{array}{l}\text { officienc } \\
y \text { in } x\end{array}$ & $\begin{array}{l}\text { six.pole } \\
\text { p.f. }\end{array}$ \\
\hline 148.5 & 158 & 29 & 13 & 24 & 13 & 30.4 & 23.006 & 95.153 & 76.0311 & 0.780 \\
\hline 148.0 & 153 & 30 & 13 & 23 & 13 & 31.195 & 22.588 & 94.287 & 76.0911 & 0.783 \\
\hline 148.2 & 187 & 30 & 13 & 28 & 14 & 31.426 & 23.208 & 93.652 & 76.0645 & 0.780 \\
\hline 148.7 & 192 & 30 & 13 & 29 & 14 & 30.929 & 22.795 & 95.035 & 76.0065 & 0.787 \\
\hline 148.0 & 193 & 30 & 13 & 29 & 14 & 31.195 & 22.587 & 94.287 & 76.0913 & 0.783 \\
\hline 147.3 & 194 & 30 & 13 & 29 & 14 & 31.463 & 22.38 & 93.553 & 76.1741 & 0.780 \\
\hline 148.1 & 149 & 31 & 13 & 22 & 13 & 32.342 & 22.161 & 93.648 & 76.0811 & 0.782 \\
\hline 148.6 & 183 & 31 & 13 & 27 & 14 & 32.397 & 22.725 & 93.518 & 76.0212 & 0.782 \\
\hline 148.4 & 189 & 31 & 13 & 28 & 14 & 32.126 & 22.114 & 94.172 & 76.0492 & 0.785 \\
\hline 147.8 & 190 & 31 & 13 & 28 & 14 & 32.406 & 21.906 & 93.496 & 76.1233 & 0.782 \\
\hline
\end{tabular}

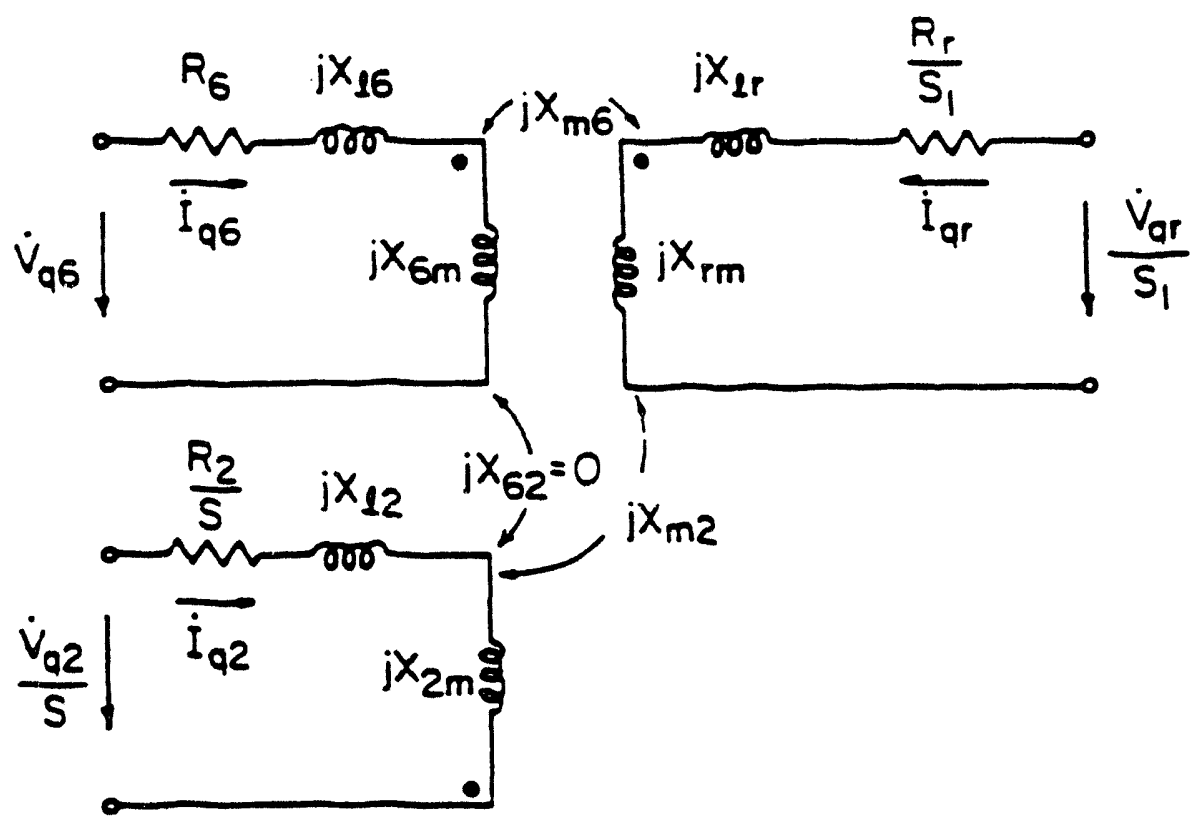

Fig. 6.7.1. BDFM Steady State Circuit. 


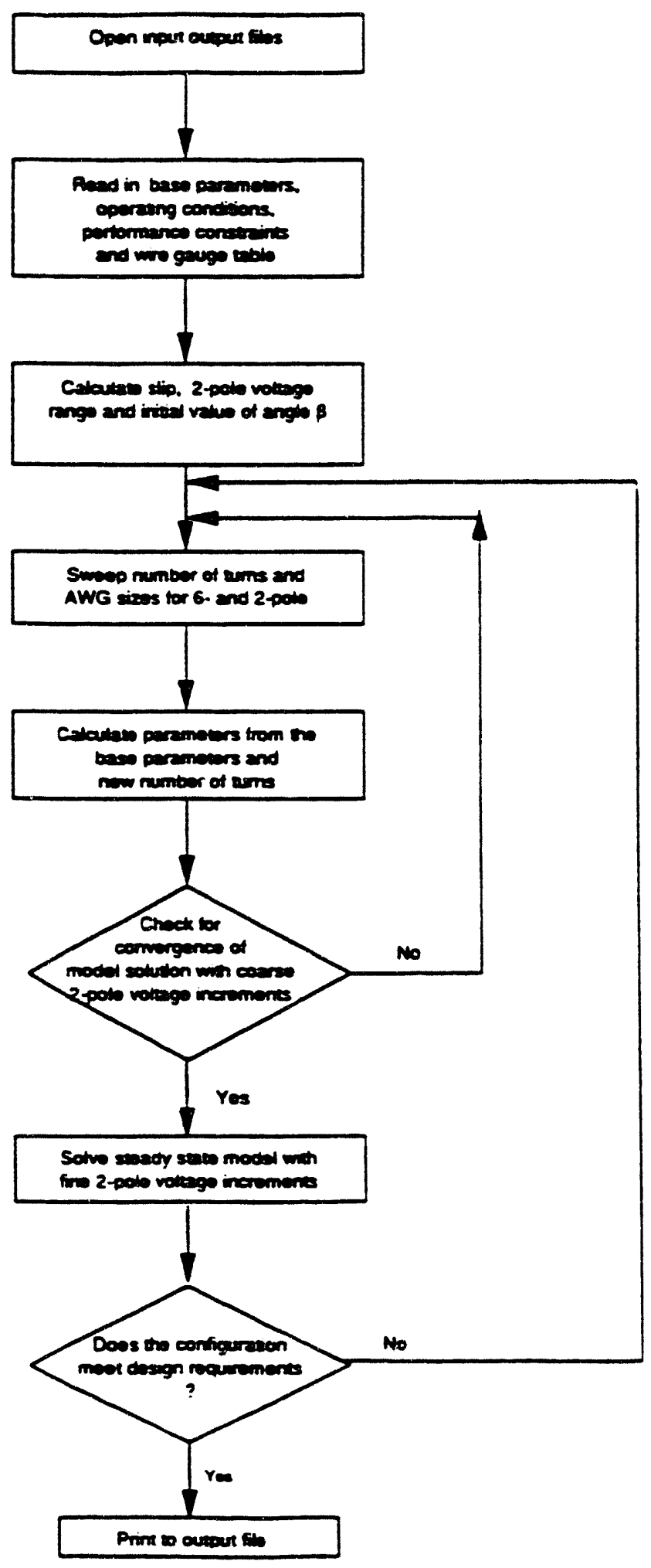

Fig. 6.7.2. Simplified Flowchart for Stator Optimization Routine. 


\subsection{References}

[6.1] A.K. Wallace, R. Spée and H.K. Lauw, "Dynamic Modeling of Brushless Doubly-Fed Machines," IEEE LAS Annual Meeting Conference Rec., pp 329-334, 1989.

[6.2] R. Li, "Dynamic Modeling, Simulation, and Stability Analysis of Brushless Doubly-Fed Machines," Ph.D. Dissenation, Oregon State University, May 1991.

[6.3] R. Li, A.K. Wallace, R. Spée and Y. Wang, "Two-axis Model Development of CageRotor Brushless Doubly-Fed Machines," IEEE Trans. on Energy Conversion, Vol. 6, No. 3, pp 453-460, 1991.

[6.4] R. Li, A.K. Wallace, R. Spée, "Dynamic Simulation of Brushless Doubly-Fed Machines," IEEE Trans. on Energy Conversion, Vol. 6, No. 3, pp 445-452, 1991.

[6.5] R. Li, R. Spée, A.K. Wallace and G.C. Alexander, "Synchronous Drive Performance of Brushiess Doubly-Fed Motors," IEEE LAS Annual Meeting Conference Record, pp 631-638, 1992.

[6.6] W.R. Brassfield, "Direct Torque Control for Brushless Doubly-Fed Machines," M.S. Thesis, Oregon State University, 1993.

[6.7] M. Salim and R. Spée, "High Frequency Cage Rotor Designs," IEEE LAS Annual Meeting Conference Record, pp 18-24, 1992.

[6.8] M. Salim, "Finite Element Based Rotor Design Optimization for the Brushless DoublyFed Machine," M.S. Thesis, Oregon State University, 1993.

[6.9] Ansoft Corporation, "Maxwell Field Simulator," 1991.

[6.10] S. Williamson and M. J. Robinson, "Calculation of Bar Leakage Reactance of Cage Rotors, " IEE 3rd International Conference on Elect. Machines and Drives, pp 122-126, 1987.

[6.11] S. Williamson and M.C. Begg, "Calculation of the Bar Resistance and Leakage Reactance of Cage Rotors with Closed Slots," Proceedings IEE, Vol. 132, No. 3, pp 125-132, 1985.

[6.12] J. Langheim, "Modelling of Rotorbars with Skin Effect for Dynamic Simulation of Induction Machines, “ IEEE LAS Annual Mecting Conference Record, pp 38-44, 1989.

[6.13] R. Belmans, D. Verdyck, T.B. Johansson, W. Geysen and R.D. Findlay, "Calculation of the No-Load and Torque Speed Characteristic of Induction Motors Using Finite Elements," International Conference on Elect. Machines, pp 724-729, 1990.

[6.14] S. Williamson and M.J. Robinson, "Calculation of Cage Induction Motor Equivalent Circuit Parameters Using Finite Elements," Proceedings IEE, Vol. 138, No. 3, pp 264-284, 1991.

[6.15] P. Rochelle, "Analysis and Design of the Brushless Doubly-Fed Machine, "M.S. Thesis, Oregon State University, 1990.

[6.16] P. Rochelle, "Program BDFM-User's Manual," Oregon State University, 1991.

[6.17] D.G. Holmes, "A New Modulation Algorithm for Voltage and Current Source Inverters, based on AC-AC Matrix Converter Theory," IEEE LAS Conference Record, pp 1190$1195,1990$.

[6.18] P.N. Enjeti, P.D. Ziogas and J.F. Lindsay, "A Current Source PWM Inverter With Instantaneous Current Control Capability, "IEEE LAS Conference Record, pp 927-933, 1988.

[6.19] D.M. Divan, "The Resonant DC Link Converter - A New Concept in Static Power Conversion," IEEE Trans. on Industry Applications, Vol. 25, No. 2, March/April, 1989. 
[6.20] Y. Murai and T.A. Lipo, "High Frequency Series Resonant DC Link Power Conversion," IEEE LAS Conference Record, pp 772-779, 1988.

[6.21] D.M. Brod and D. Novotny, "Current Control of VSI-PWM Inverters," IEEE Trans. on Industry Applications, Vol. 21, No. 4, May/June, 1985.

[6.22] H.K. Lauw, J.B. Klaassens, N.B. Butler and D.B. Seely, "Variable-Speed Generation with the Series-Resonant Converter," IEEE Trans. on Energy Conversion, December, 1988.

[6.23] S. Bhowmik, "System Optimization Studies Related to Stator Design and AC/AC Converter Selection for Brushless Doubly-Fed Machines," M.S. Thesis, Oregon State University, 1992.

[6.24] R. Fletcher, "Practical Methods of Optimization," Second Edition, John Wiley and Sons pp 140-149, 1987. 


\section{BDFM AUTOMOTIVE ALTERNATOR}

The potential of the BDFM as an automotive alternator has been described in the Phase 2 report as well as in Refs. [7.1-7.3]. Development activities during Phase 3 addressed the conversion of the control system to a simplified digital controller as well as construction of a high power, high voltage version to meet future automotive demand. Moreover, to support the higher power alternator version and to provide an attractive demonstration system, the alternator test bed was upgraded.

\subsection{Digital Control}

The analog alternator control system described in the Phase 2 report, while illustrating the potential of the brushless doubly-fed system, was found to be insufficient for high performance operation. Due to the analog nature, the component count was perceived as too high for successful commercialization, drift problems occurred and response/settling times were not sufficiently fast. Also, the analog nature of the system precluded rapid design changes for successive prototypes. Digital control is very versatile and new control strategies may easily and quickly be implemented in software.

The digital controller implemented uses an Intel $80 \mathrm{C} 196 \mathrm{KC}$ microprocessor. As illustrated in Fig. 7.1.1, the controller uses only three integrated circuits (ICs). In production, a maskprogrammed microprocessor could be used so that only one IC would be necessary. The cost of a commercial grade $80 \mathrm{C} 196$ in single unit quantities is approximately U.S. \$20. In larger quantities, this price would be lower, but the advantage may be offset by the required, automotive grade, quality.

The digital control scheme is based on a simplified version of the analog controller implemented previously. The switching algorithm for the control winding inverter is a simple square wave scheme. In order to maximize the efficiency, the frequency of the square wave is made as high as possible while maintaining the required battery charging voltage at the rectifier output. This control philosophy only requires the feedback of battery voltage and eliminates the speed or dc link current feedback used previously [7.3]. On start-up, the control frequency is set at the highest possible value. An integrating feedback loop then drives the frequency to the proper operating point. A lower limit on the frequency is necessary for low speed operation, since the input power may be insufficient to maintain the desired output voltage. Once the high 


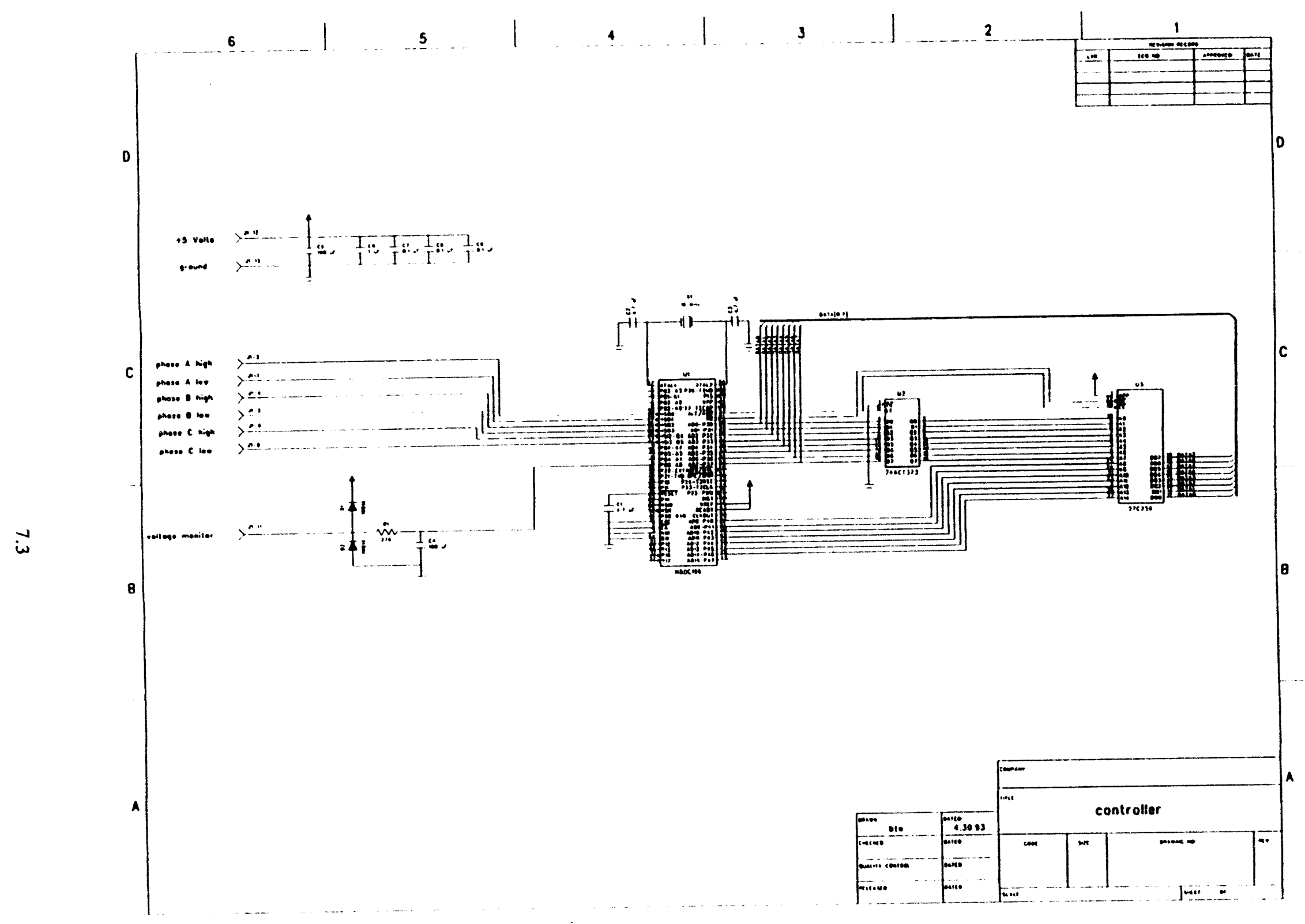

Fig. 7.1.1. Digital Controller for BDFM Automotive Alternator. 


\subsection{V System Design}

The $12 \mathrm{~V}$ autogenerator model is severely limited by the differences between its physical form (based on the frame and lamination of a small, four-pole induction motor) and what should be used to optimize the BDFM. However, as the $12 \mathrm{~V}$ automotive alternator has shown significant promise there is a possibility that it could be employed in automotive platforms, currently in the planning stage, for 1998 or later models. By this time projections are for an alternator rating of between $2 \mathrm{~kW}$ and $2.5 \mathrm{~kW}$. In order to meet these load levels an increase in the system voltage level, from today's $12 \mathrm{~V}$, to $24 \mathrm{~V}$ or $36 \mathrm{~V}$, or even $48 \mathrm{~V}$ are being considered by the major manufacturers.

Interest in the BDFM principle has been expressed by two major alternator manufacturers (Ford and Bosch). Contact with these has produced a performance requirement specification shown in Fig. 7.2.1, for a high-speed 48V (nominal) system.

In order to investigate the potential of the BDFM in meeting these requirements a design exercise has been undertaken to produce a machine of lower loss and wider speed range than previous models. This will be the first BDFM of this project to be designed and constructed completed with custom parts. In addition to the $48 \mathrm{~V}$ requirement, the machine is also required to be contained in a $162 \mathrm{~mm}$ outside diameter package. This limitation and the high speed requirement are more easily met with a higher pole number combination. In particular, a smaller stator core depth and a better rotor aspect ratio are obtained for a $12 / 4$ pole combination design which utilizes an 8 nest rotor. The laminations designed for this system are shown in Figs. 7.2.2 and 7.2.3. The stator laminations contain four $6 \mathrm{~mm}$ holes for stack alignment and four $8 \mathrm{~mm}$ holes for attachment of the end frames. As is evident from comparison with previous BDFM rotors, a much higher ratio of copper to steel in the rotor section is being used in this design to reduce rotor circuit losses. The completed rotor is shown in the photograph of Fig. 7.2.4.

The combination of constraints of a high pole number machine in a small diameter frame severely restricts the design of the stator windings. The four-pole control winding is close to the minimum ( 3 slots per pole per phase) recommended for good sinusoidal mmf distribution. As shown in Fig. 7.2.5 a 7/9 pitch coil is used; each coil is 15 turns of $\$ 20$ AWG wire. The power winding, which is less critical, can have only 1 slot/pole/phase. Hence, it must be concluded that there is no advantage to a two-layer configuration. Consequently, a single layer, consequent pole system, has been used for the 12-pole winding. Each coil is constructed of 3 turns/coil; each turn 
is 3 parallel conductors of \#20 AWG wire. This machine was explained and presented to the EPRI sponsored meeting and exhibition, "Power Electronics for the Automobile Industry," on June 18, 1993, in Dearborn, Michigan.

In addition to machine development, considerable effort has been put into upgrading the control converter from $12 \mathrm{~V} \mathrm{dc}$ to $48 \mathrm{~V} \mathrm{dc}$ (nominal) operation. Both rectifier and inverter are laid out using printed circuit boards rather than the previous "bread board" setups. Power device ratings and characteristics are summarized in Tables 7.1 and 7.2. Note that the MOSFETs were not chosen for their current rating, but for the low on-state resistance.

TABLE 7.1. Power Diode Specifications.

\begin{tabular}{||l|l||}
\hline Type & Schottky Rectifier \\
\hline Manufacturer & International Rectifier \\
\hline Model Number & $63 \mathrm{CNQ} 100$ \\
\hline Voltage Rating & $100 \mathrm{~V}$ \\
\hline Current Rating & $60 \mathrm{~A}$ \\
\hline Forward Drop & $0.64 \mathrm{~V}$ \\
\hline
\end{tabular}

TABLE 7.2. Power Transistor Specifications.

\begin{tabular}{||l|l||}
\hline Type & MOSFET \\
\hline Manufacturer & IXYS \\
\hline Model Number & IXTH75N10 \\
\hline Voltage Rating & $100 \mathrm{~V}$ \\
\hline Current Rating & $75 \mathrm{~A}$ \\
\hline On-State Resistance & $0.020 \mathrm{R}$ \\
\hline
\end{tabular}




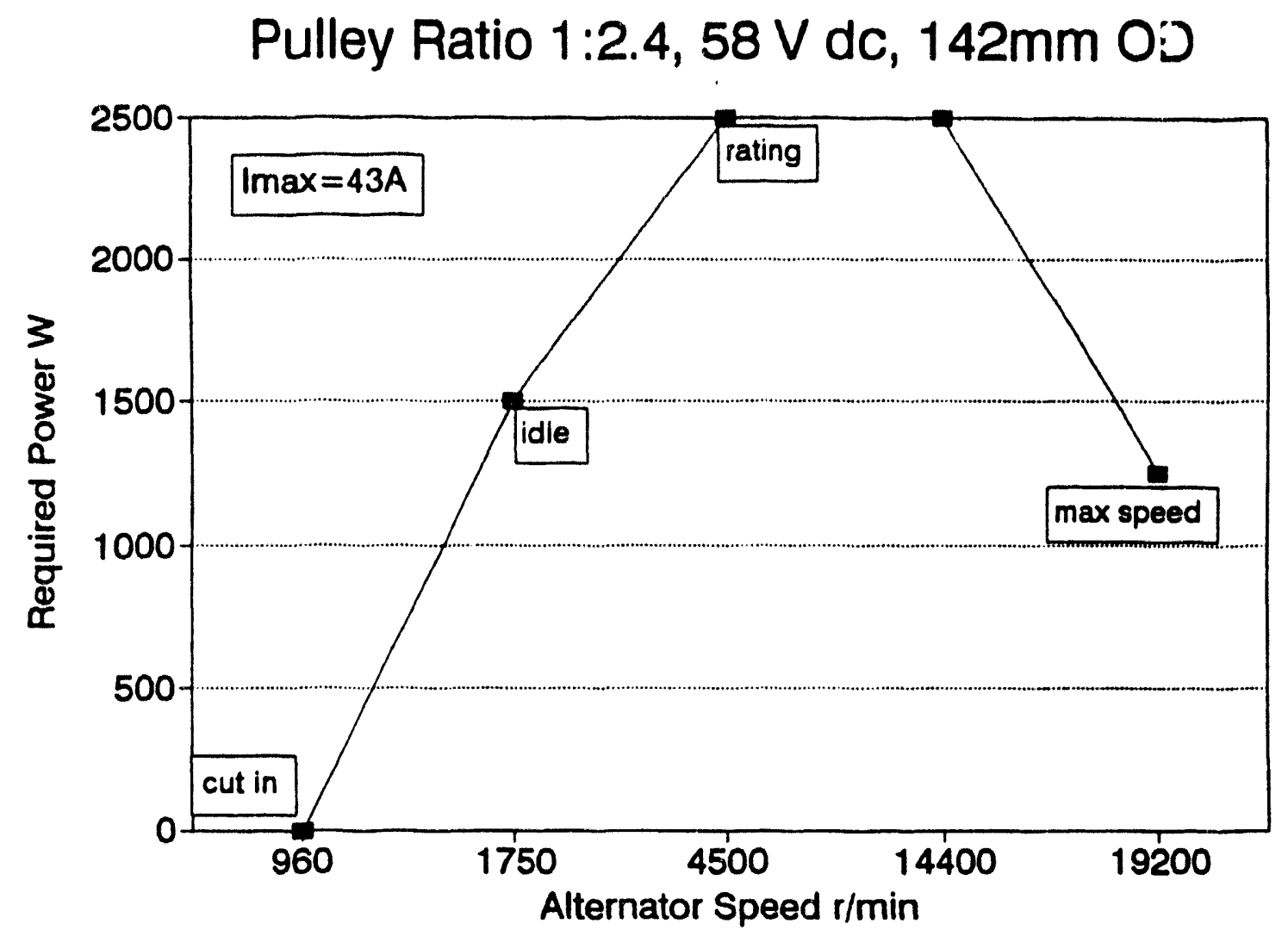

Fig. 7.2.1. Advanced 48V dc Automobile Alternator Output Performance Requirement. 


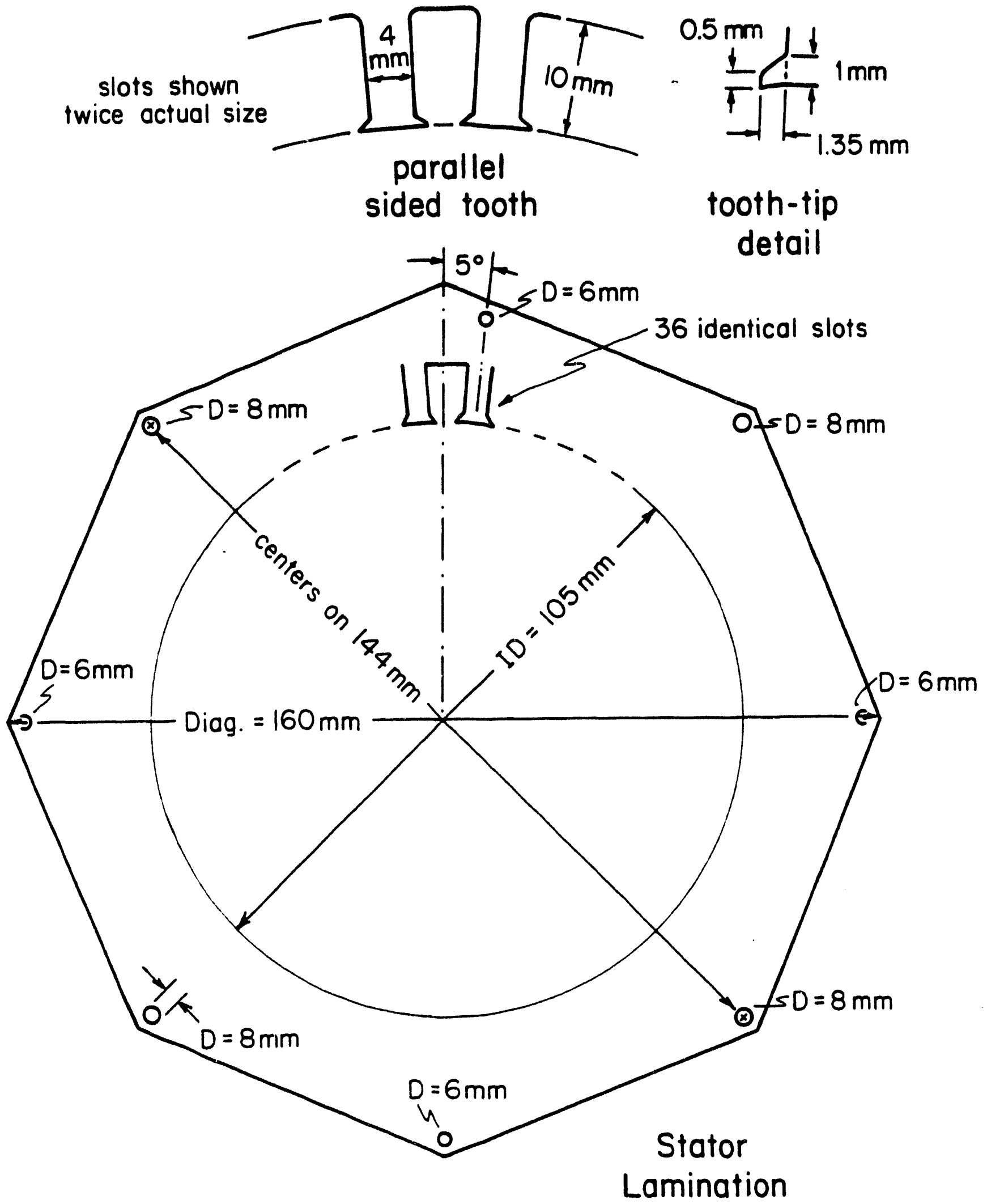

Fig. 7.2.2. Stator Lamination $48 \mathrm{~V}$ dc Alternator. 

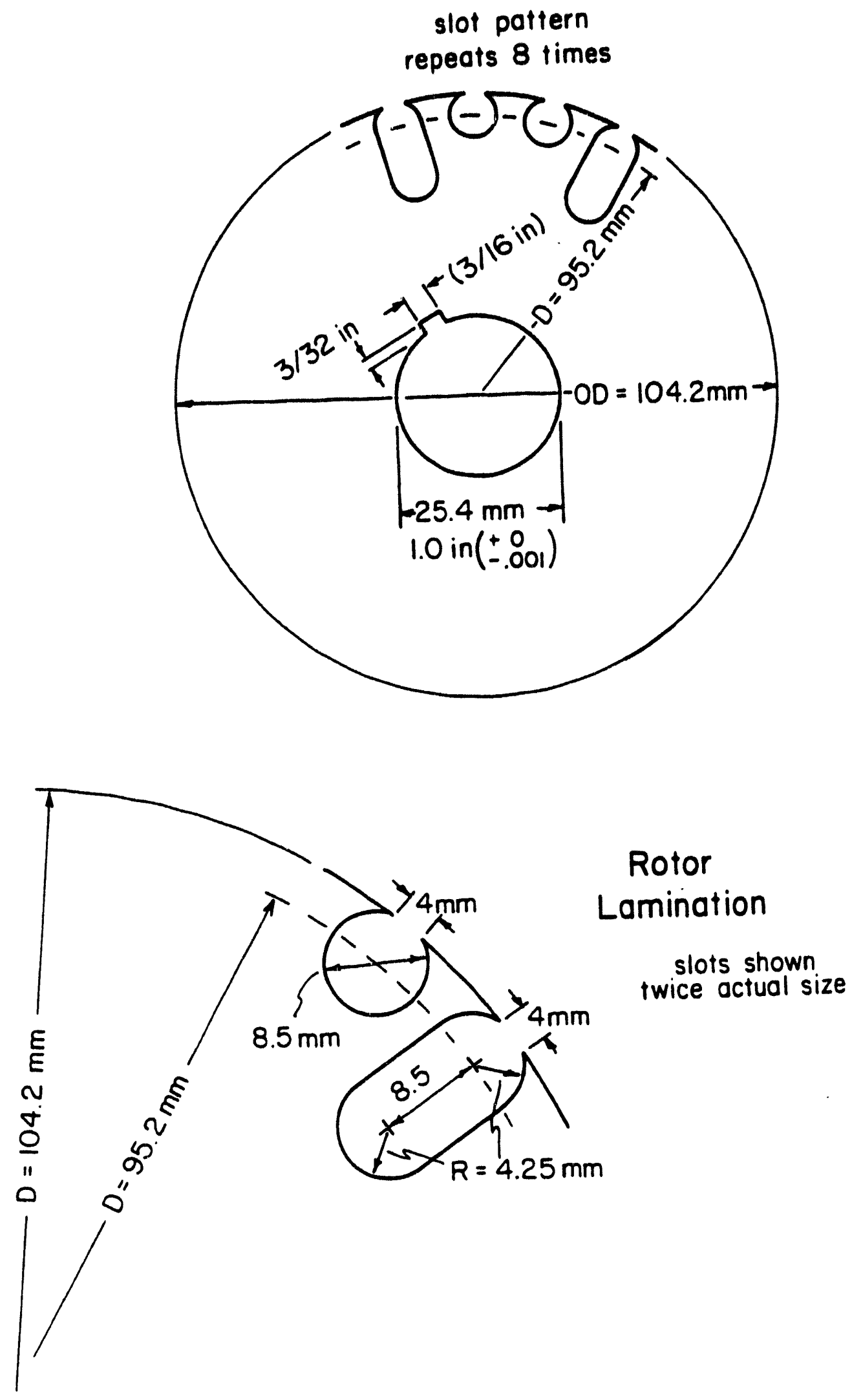

Fig. 7.2.3. Rotor Lamination for $48 \mathrm{~V}$ dc Alternator. 


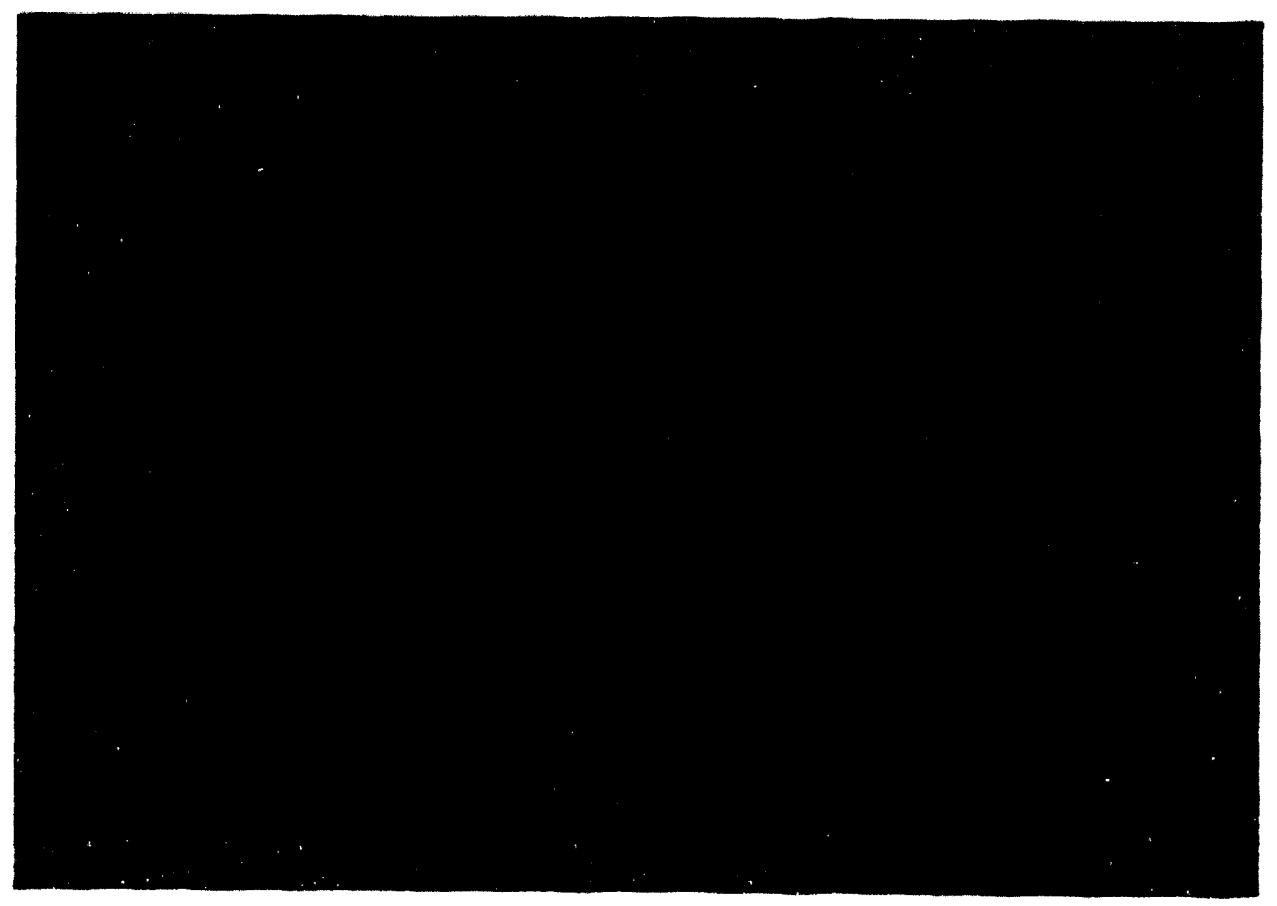

Fig. 7.2.4. Completed 48V dc Alternator Rotor. 

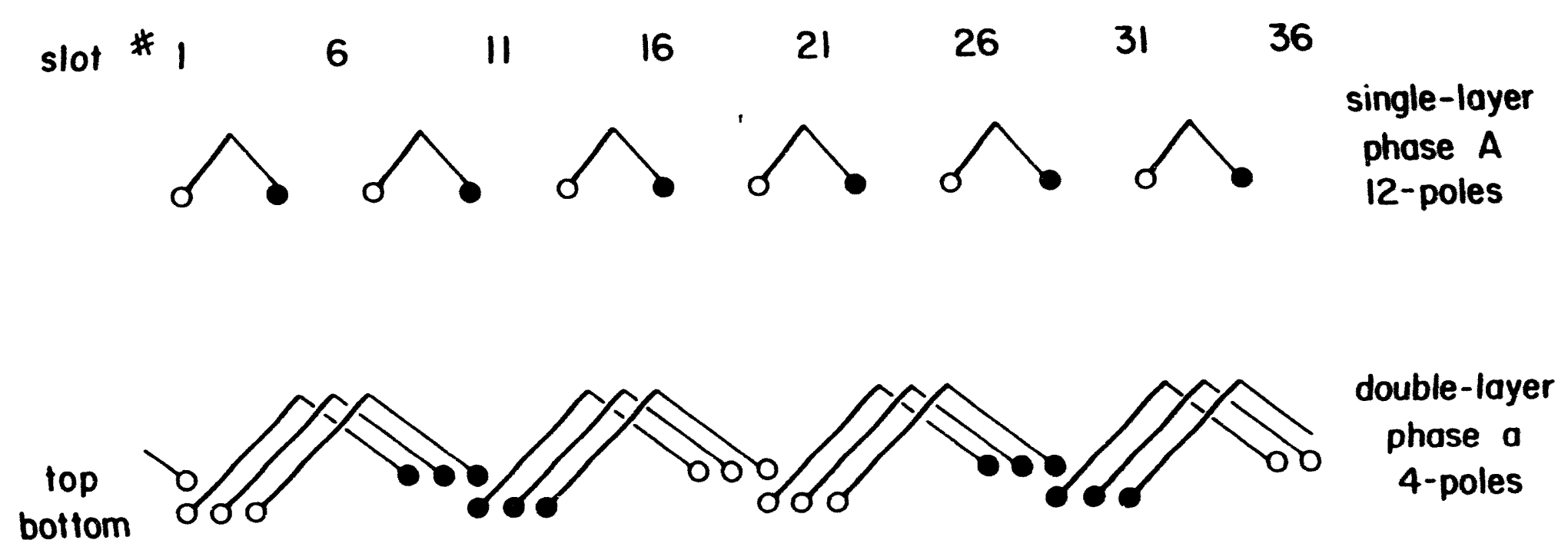

Fig. 7.2.5. Connection Diagram for $48 \mathrm{~V}$ dc Alternator. 


\subsection{Test Stand Upgrade}

In order to accommodate the increases in both power and speed necessary to evaluate the performance of the $48 \mathrm{~V}$ dc alternator system as specified in Fig. 7.2.1, compared to its $12 \mathrm{~V} \mathrm{dc}$ predecessor, the alternator test stand has been upgraded as follows:

(i) The belts and pulleys have been replaced so that ratio has been increased to approximately 4.8:1 thus enabling higher alternator speeds for a given range of drive motor speeds. This has necessitated the balancing of the alternator rotor system, including fan and driven pulley. In addition, the large (driver) pulley has been accurately balanced, as is customary in the automotive industry for high speed components.

(ii) The increase in belt speed and transmitted power has made it advisable to add a guard over the pulley/belt area of the test stand.

(iii) The $5 \mathrm{hp}$ induction motor has been replaced with a $15 \mathrm{hp}$ model and the adjustable frequency inverter, used to provide speed control has been similarly upgraded.

In addition to these purely practical developments, the alternator test stand has been modified to represent, with a little more authenticity, the intended application. Automotive style panel meters have been added to display level of battery charging and the voltage. Also the adjustable load resistor has been complimented by the parallel connection of two car headlights, either or both of which can be switched on to demonstrate changing load conditions on the system. Evaluation of the new unit is underway at time of writing.

\subsection{References}

[7.1] A.K. Wallace and R. Spée, "Brushless Doubly-Fed Generation System for Vehicles," U.S. Patent no. 5,083,077, Jan. 21, 1992.

[7.2] V. Javadekar, "Design and Development of a Controller for a Brushless Doubly-Fed Automotive Alternator System, " M.S. Thesis, Oregon State University, Jan. 1992.

[7.3] V. Javadekar and R. Spée, "Efficiency Maximizing Control of Brushless Automotive Alternators," IEEE Workshop on Power Electronics in Transportation, pp 163-167, Dearborn, MI, 1992. 


\section{ELECTRIC VEHICLE APPLICATIONS}

\subsection{Background}

In addition to the application of the BDFM as an automotive alternator, as discussed in Section 2, the BDFM has recently been considered for use in electric vehicles, hybrid vehicles and extended range electric vehicles. All of these vehicle types are currently being subjected to considerable scrutiny in the electric drive community because of the Califomia State legislation designed to promote the introduction of low emission and zero emission standards. Several configurations are being proposed and studied by the major automobile manufacturers.

Pure electric vehicles, for which the only on-board energy source is a bank of rechargeable batteries, have been used for urban delivery vehicles in Europe for many years. The high gasoline fuel costs and compact nature of cities in Europe give these battery-powered vehicles good long-term economic viability. Recent EPRI projects have addressed the problems of adjusting these technologies to North American conditions: the greatest technical problem being the larger range requirements between recharge cycles. Conversion kits for passenger cars are available from small manufacturers such as AC Propulsion Inc. [8.1]. These typically employ a four-pole induction motor as the drive machine with a transaxle (mechanical reduction gear and differential), typically providing torque to the front wheels as shown in the schematic of Fig. 8.1.1(a). An alternative configuration using two motors to provide independent power to both the front wheels was developed by G.M. for its "impact" concept sports car or alternatively to the rear wheels in an electric transit shuttle bus: the configuration schematic for both these is shown in Fig. 8.1.1(b) and some basic information is given in Refs. [8.2 and 8.3]. The configuration for a hybrid or extended-range electric vehicle is shown in Fig. 8.1.2: this is similar to that of the diesel-electric locomotive except that the battery rating needs to be larger for hybrids and extended-range vehicles.

For all electric vehicles, and in particular passenger cars, efficiency, power/weight ratio and initial capital cost are important considerations. For induction motors these three features are shown graphically in Fig. 8.1.3. The continuous power rating of both a delivery vehicle and a typical passenger car is expected to be about $40 \mathrm{hp}$. Hence there appears to be small, but definite, efficiency and weight advantages for the single motor drive system shown in Fig. 8.1.1(a) compared to the dual motor system of Fig. 8.1.1(b). The cost differential of two $20 \mathrm{hp}$ motors compared to a single $40 \mathrm{hp}$ motor is less well defined and is probably swamped by other costs: 
notably the power electronic converters. However, the rating efficiency requirement and topology of the most appropriate systems will probably dictate the use of power MOSFETs as the principal switching device. The ratings of these switches, as available commercially, continues to increase and in consequence there should be a considerable cost saving from the use of one $40 \mathrm{kVA}$ converter compared to two $20 \mathrm{kVA}$ converters. 


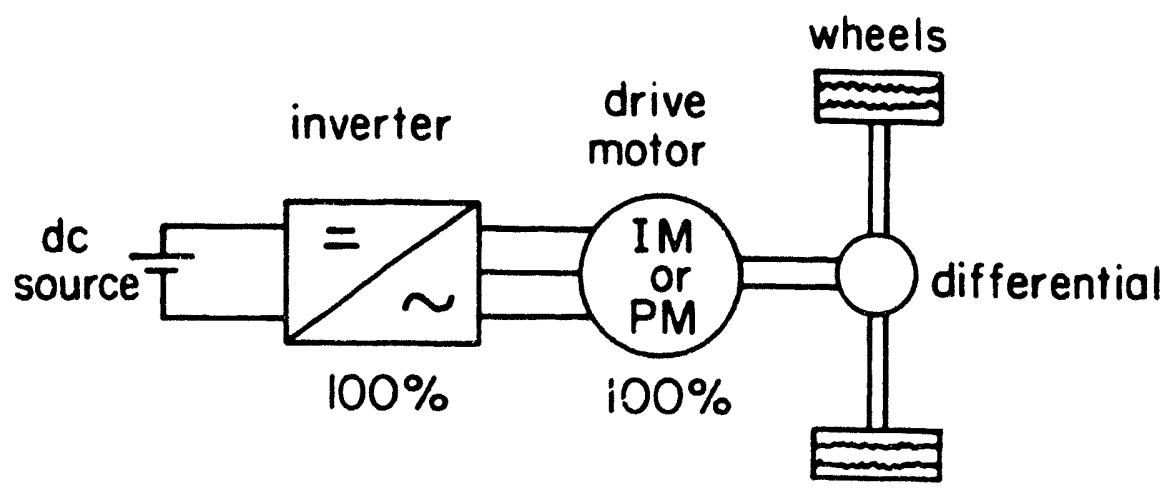

(a)

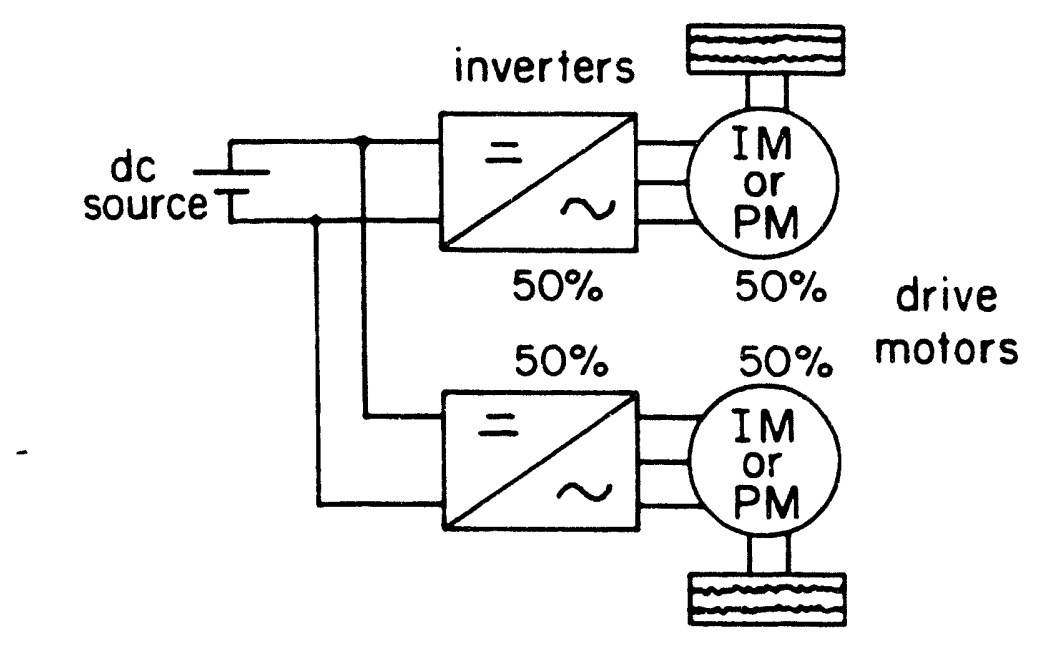

(b)

Fig. 8.1.1. Single (a) and Double (b) Motor Drive Systems for Pure Electric Vehicles. 


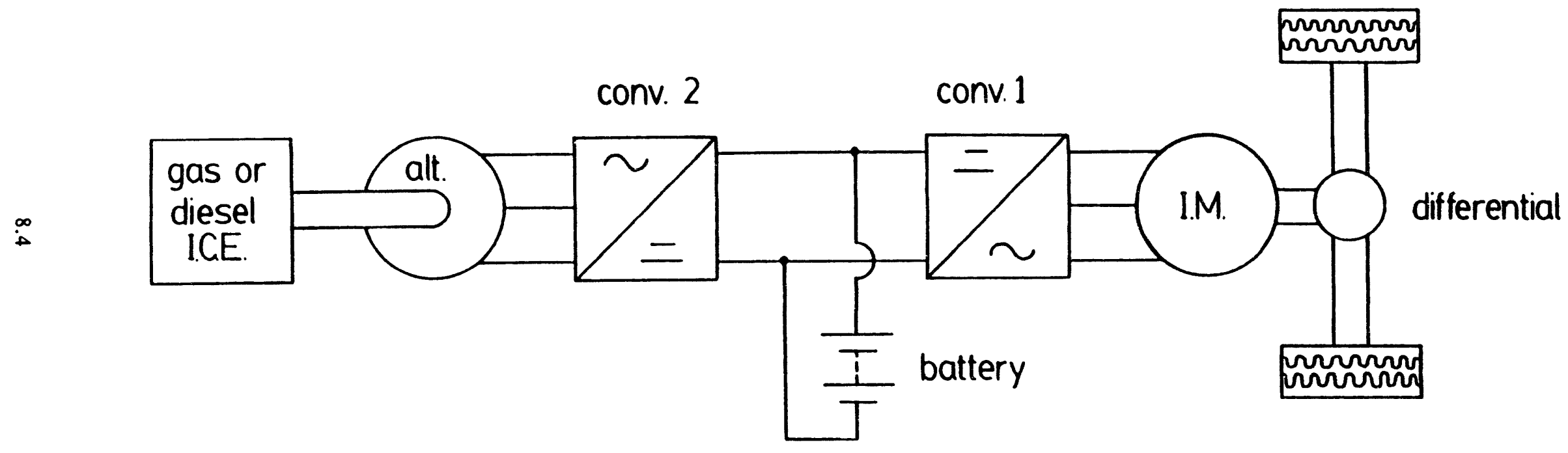

Fig. 8.1.2. Drive System for Hybrid or Extended-Range Electric Vehicles. 

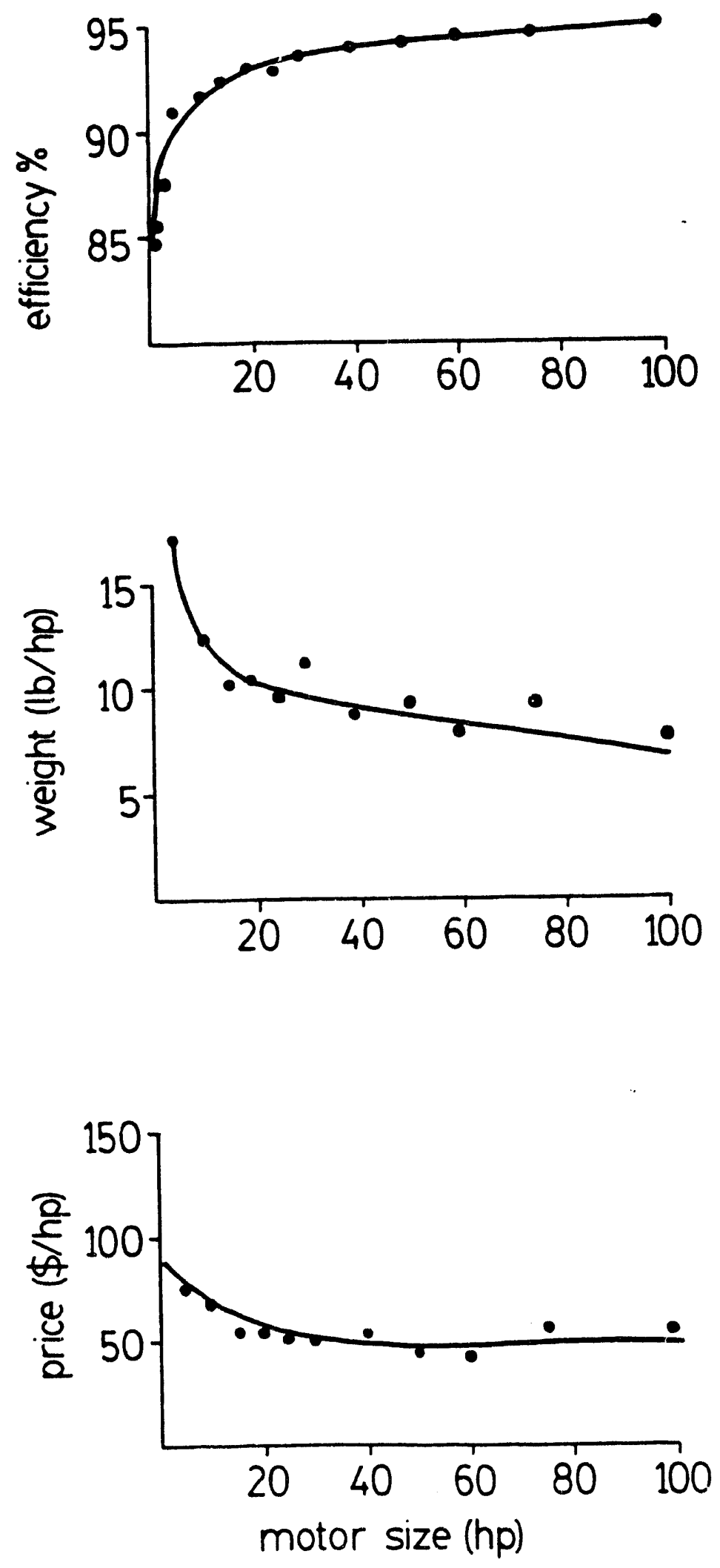

Fig. 8.1.3. Rated Efficiency; Power-to-Weight Ratio; Capital Cost of Induction Motors. 


\subsection{Potential BDFM Applications}

\subsubsection{Single-Motor; Pure Electric Vehicle}

The BDFM could be adapted as the drive for this configuration; as shown schematically in Fig. 8.2.1(a). The disadvantages over an induction machine or permanent magnet machine are obvious. Because the energy source is dc, the BDFM system requires two power converters. The power winding converter must be rated at $100 \%$ of motor rating. The control converter, according to the approximate relationship

$$
S_{c} \approx S_{m} \times \frac{f_{p}+\left|f_{c}\right|}{\left|f_{c}\right|}
$$

must be rated at about $50 \%$ of the motor rating. Clearly the BDFM is not appropriate for this drive configuration.

\subsubsection{Dual-Motor; Pure Electric Vehicle}

The BDFM system could be used in this configuration, as shown in schematic of Fig. 8.2.1(b). In this system the control inverters are very low rated, independently controlled units which enable the two motors to operate at different speeds when necessary. Thus the BDFM system should be more cost effective than the induction motor system of Fig. 8.1.1(b). Also inherent in the BDFM configuration is independent wheel control akin to an "electric limited slip differential" or "electric anti-lock braking system" (electric ABS).

\subsubsection{Hybrid or Extended-Range Vehicle}

The BDFM could be considered as a replacement for the induction motor in the hybrid layout of Fig. 8.1.2. However, all the disadvantages outlined in Section 8.2.1 above are equally appropriate here.

A more interesting potential BDFM application is shown in Fig. 8.2.2. In this, the capability of the BDFM to produce controlled adjustable voltage and frequency as a replacement for the fixed frequency alternator may have advantages. When operating in the electric mode Converter 1 must have $100 \%$ rating, but full frequency control can be obtained in the hybrid mode by Converter 2 of 50\% rating. In addition the BDFM is a good high speed generator so that a high speed internal combustion engine (ICE) can be used to reduce system weights for a given rating. 


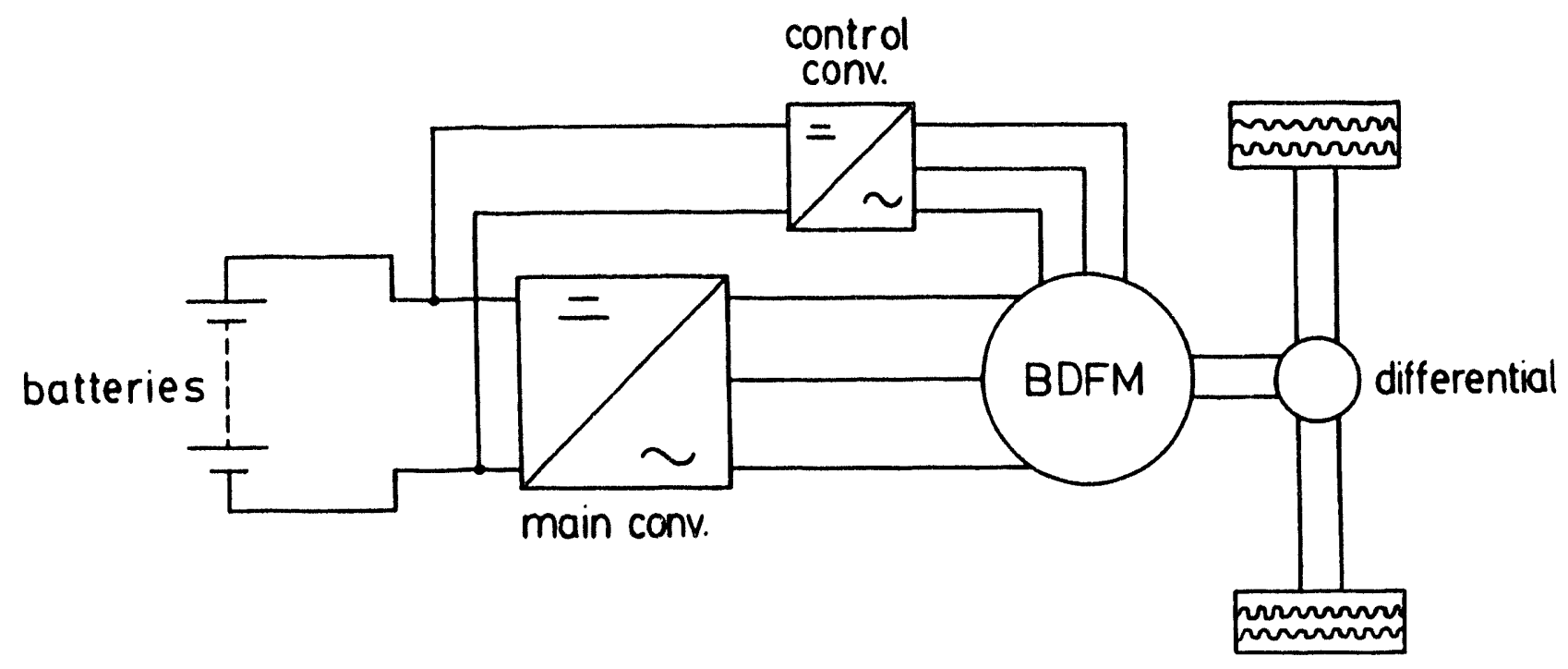

(a)

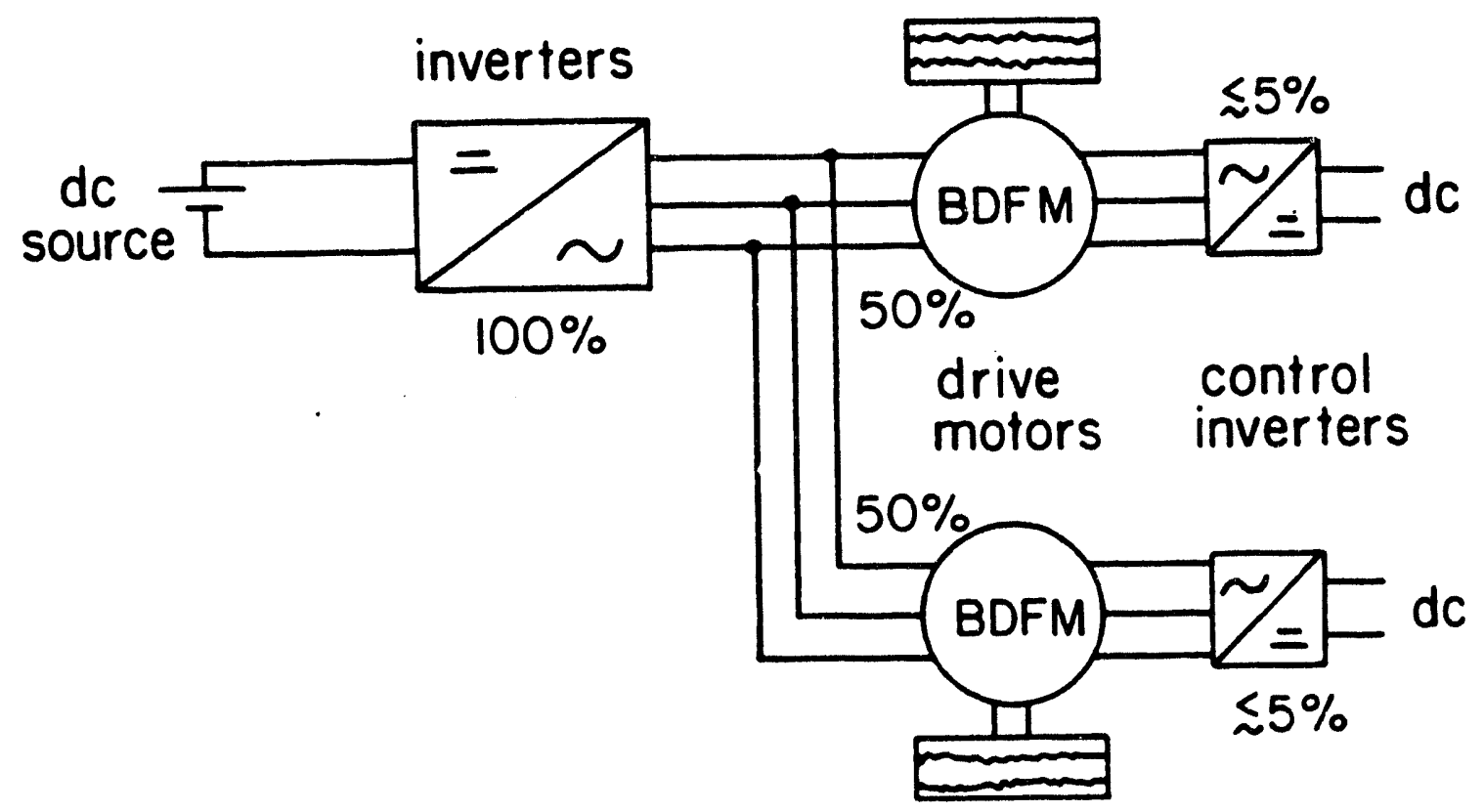

(b)

Fig. 8.2.1. BDFM as a Drive

(a) for Single-Motor Electric Vehicle with Mechanical Differential; and (b) for a Dual-Motor Electric Vehicle "Electric Differential" Configuration. 


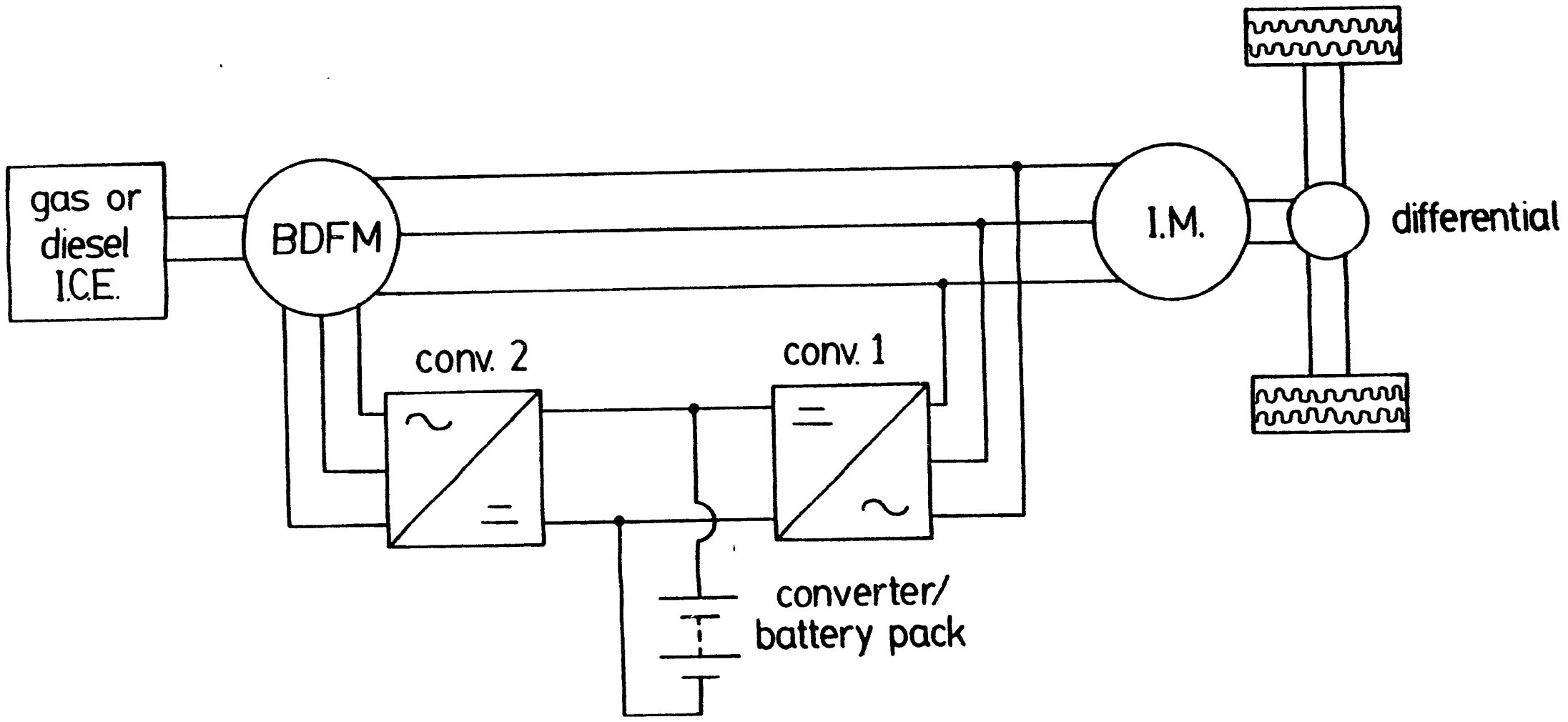

Fig. 8.2.2. BDFM as an Adjustable Frequency Generator for Hybrid Electric Vehicles. 


\subsection{Conclusions}

For the following reasons it is concluded that the possibility of the application of BDFM to electric vehicles is not strong. Consequently, because of limited resources of manpower, OSU efforts are more reasonably applied elsewhere at this time.

(i) The use of BDFM is not an appropriate drive for single-motor electric vehicles of either pure, hybrid or extended-range format, as converters are always required for both power and control windings.

(ii) The BDFM may have some system advantages for dual-motor electric vehicles, in which both motors operate from a single "power" converter with two "differential" converters supplying the control windings.

(iii) The BDFM may have some advantages for the generator of hybrid vehicles. to provide an adjustable frequency from either a constant or adjustable speed prime mover. More details of electric hybrid vehicles and requirements are needed from the manufacturers to clarify these issues.

(iv) The major electric vehicle manufacturers currently appear to be preferring the single-motor drive configuration for cars, which makes adoption of BDFM unlikely. However, for buses the dual-motor configuration may be preferred giving BDFM a possible "niche" application.

\subsection{References}

[8.1] K. Reynolds, "AC Propulsion CRX," Road and Track, pp 126-128, October, 1992.

[8.2] General Motors Co., "Impact Specifications," Data Sheet, 1993.

[8.3] F.L. Hitchcock, "Don't Miss the Bus," Public Power, pp 51-52, July/August, 1993. 

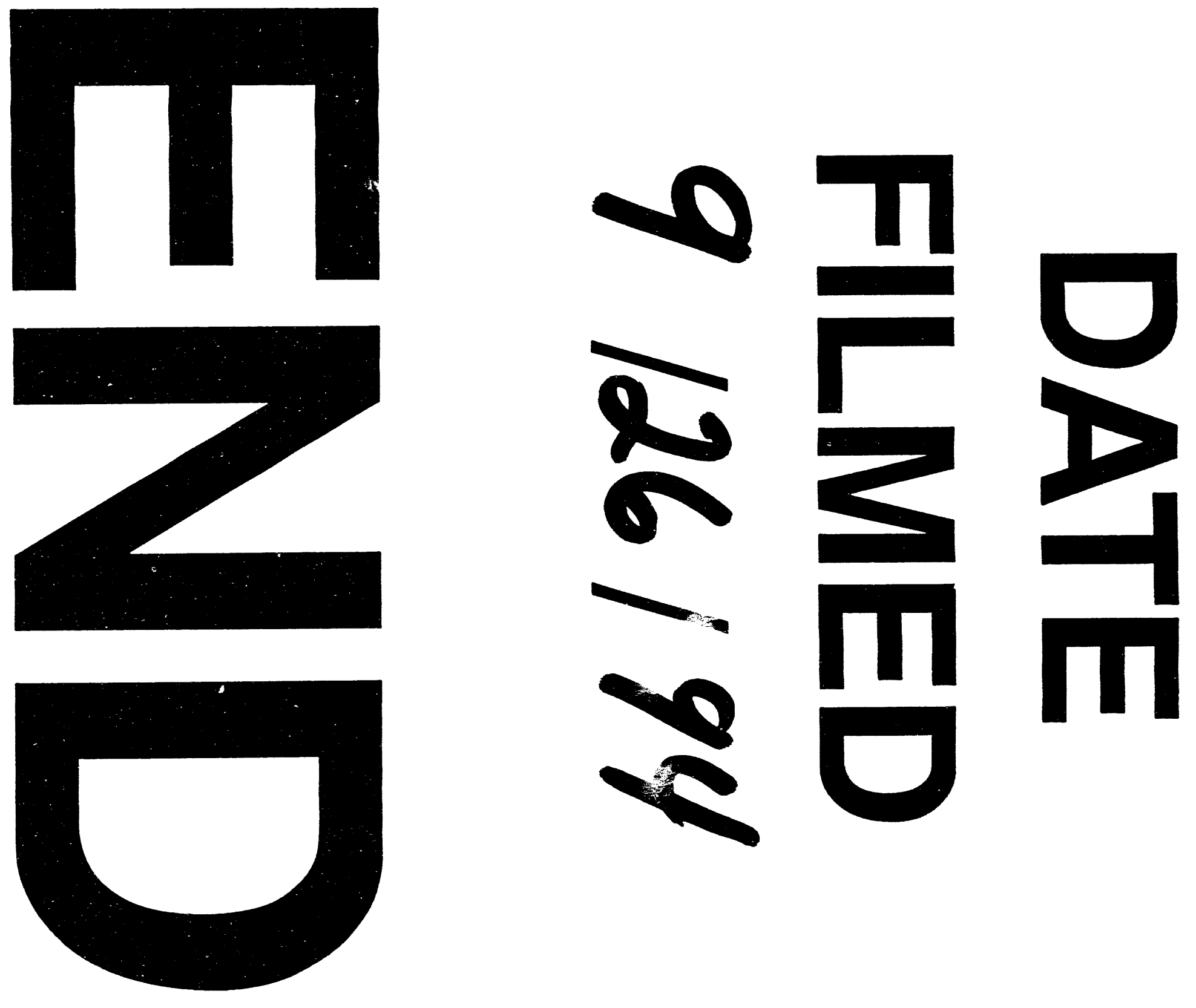
